\title{
Recent Advances in the Synthesis of Hydantoins: The State of the Art of a Valuable Scaffold
}

\author{
Laure Konnert,* Frédéric Lamaty, Jean Martinez, ${ }^{(\infty}$ and Evelina Colacino*(-) \\ Université de Montpellier, Institut des Biomolécules Max Mousseron UMR 5247 CNRS - Universités Montpellier - ENSCM, Place \\ E. Bataillon, Campus Triolet, cc 1703, 34095 Montpellier, France
}

ABSTRACT: The review highlights the hydantoin syntheses presented from the point of view of the preparation methods. Novel synthetic routes to various hydantoin structures, the advances brought to the classical methods in the aim of producing more sustainable and environmentally friendly procedures for the preparation of these biomolecules, and a critical comparison of the different synthetic approaches developed in the last twelve years are also described. The review is composed of 95 schemes, 8 figures and 528 references for the last 12 years and includes the description of the hydantoin-based marketed drugs and clinical candidates.

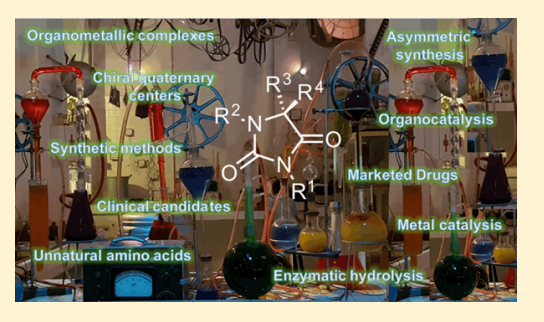

\section{CONTENTS}

1. Introduction

2. Hydantoins as Clinical Candidates and Marketed Drugs

2.1. Clinical Candidates
2.1.1. BMS-587101
2.1.2. GLGP-0492
2.2. Marketed Drugs
2.2.1. Phenytoin and Fosphenytoin
2.2.2. Ethotoin
2.2.3. Nilutamide
2.2.4. Nitrofurantoin
2.2.5. Dantrolene

3. 5- and 5,5-Disubstituted Hydantoins

3.1. Bucherer-Bergs Reaction

3.2. Use of Isocyanates and Formation of Urea Derivatives

3.3. Biltz-Type Synthesis, Preparation of Phenytoin Derivatives

3.4. Substitution at Position C-5

3.5. Metal-Catalyzed Procedures

4. 1- and 1,5-Disubstituted Hydantoins

4.1. Use of Isocyanates and Ureas

4.2. Biltz Synthesis

4.3. Alkylation/Acylation at $N-1$ Position

4.4. Miscellaneous

4.5. Hydantoins Derived from Guanosine and Analogues

5. 3- and 3,5-Disubstituted Hydantoins

5.1. Alkylation/Acylation at the $N-3$ Position

5.2. Use of Isocyanates

5.3. Miscellaneous

5.4. 3-Substituted Hydantoins from Amino Acids

5.4.1. Use of Isocyanates

5.4.2. Use of 1,1-Carbonyldiimidazole (CDI)

5.4.3. Use of (Tri)phosgene
13758

13758

13758

13758

13760

13760

13760

13760

13760

13760

13760

13760

13761

13761

13762

13762

13762

13763

13763

13763

13764

13765

13765

13766

13766

13766

13767

13767

13767

13768

13769
5.4.4. Use of Benzotriazole Carbonyl Derivatives

13769

5.4.5. Activation by Formation of Carbamates

5.4.6. From Urea and Other Activation Methods

13769

13769

$\begin{array}{ll}\text { 6. 1,3,5- and 1,3,5,5-Substituted Hydantoins } & 13769 \\ \text { 6.1. Substitution of the Hydantoin Core } & 13769\end{array}$

6.2. Use of Isocyanates 13770

6.3. Use of Urea Derivatives 13771

6.4. Activation with Carbonyl Donors 13771

6.5. Miscellaneous 13772

7. Alkylidene Hydantoins 13773

7.1. Non-substituted 5-Alkyl/Arylidene Hydantoins

7.2. 1-Substituted 5-Alkyl/Arylidene Hydantoins

7.3. 3-Substituted 5-Alkyl/Arylidene Hydantoins

7.4. 1,3,5-Alkyl/Arylidene Hydantoins

13773

13773

13774

13774

13775

$\begin{array}{ll}\text { 8.1. 5,5-Spirohydantoins } & 13775 \\ \text { 8.1.1. The Bucherer-Bergs Reaction } & 13775\end{array}$

8.1.2. Reaction with (Iso)cyanates and Urea Derivatives

13775

8.2. 1-Substituted or 3-Substituted 5-Spirohydantoins

13775

13776

13776

13776

13778

13778

9. Fused Hydantoins

9.1. 1,5-Bicyclic Hydantoins

9.2. Polycyclic Fused 1,3,5-Trisubstituted Hydantoins

13779

9.2.1. Tetrahydroisoquinoline Hydantoins 13779

9.2.2. Tetrahydro- $\beta$-carboline Hydantoins $\quad 13780$

9.2.3. Miscellaneous $\quad 13780$

10. Aminohydantoins 13780 
10.1. 1-Aminohydantoins

13780

10.2. 3-Aminohydantoins

13782

10.3. 5-Aminohydantoins

11. Hydantoins as Ligands in Organometallic Complexes

12. Asymmetric Synthesis of Hydantoins

12.1. 5,5-Disubstituted Hydantoins

12.1.1. Bucherer-Bergs Synthesis

12.1.2. Other Procedures

12.2. 1,5-Disubstituted Hydantoins

12.3. 3,5-Substituted Hydantoins

12.3.1. Alkylation of Position C-5

12.3.2. Miscellaneous

12.4. 1,3,5-Trisubstituted Hydantoins

12.4.1. Use of Isocyanates

12.4.2. Synthesis of BIRT-377, Generation of a Chiral Quaternary Center

12.4.3. Use of Urea Derivatives

12.5. 5,5-Spirohydantoins

12.5.1. Bucherer-Bergs Reaction

12.5.2. Reaction with Isocyanates and Urea Derivatives

12.6. 1,3-Disubstituted Spirohydantoins

12.6.1. From Methylene Hydantoins

12.6.2. From Other Substrates

12.7. Fused Hydantoins

12.7.1. 1,5-Bicyclic Hydantoins

12.7.2. Polycyclic Fused 1,3,5-Trisubstituted Hydantoins

13. Preparation of Amino Acids from Hydantoins

13.1. Chemical Hydrolysis

13.2. Enzymatic Hydrolysis of Hydantoins

14. Conclusions

Author Information

Corresponding Authors

ORCID

Notes

Biographies

References

Note Added after ASAP Publication

13783

13784

13785

13785

13785

13785

13785

13785

13785

13785

13786

13786

13787

13788

13789

13789

13789

13789

13789

13789

13791

13791

13792

13792

13792

13793

13794

13794

13794

13794

13794

13794

13794

13809

\section{INTRODUCTION}

Over the past decade, the synthetic and pharmaceutical interest for imidazolidine-2,4-diones, or hydantoins, has not faded and has given rise to more than 3000 publications and patents in methodological and medicinal chemistry. Several reviews have focused on the synthesis of these five-membered heterocycles, ${ }^{1-3}$ referencing their preparation methods from the main, historical ones such as the Read, ${ }^{4}$ Bucherer-Bergs, ${ }^{5}$ or Biltz ${ }^{6}$ syntheses to more modern ones, such as multicomponent reactions (MCRs), which enabled libraries of hydantoinic compounds to be obtained through simple routes. ${ }^{7,8}$ Since Meusel and Gütschow's last review in $2004,{ }^{3}$ novel synthetic routes to various hydantoin structures have been explored, as well as advances brought to the classical methods in the aim of producing more sustainable and environmental-friendly procedures for the preparation of these biomolecules. This paper is updating the progress in the chemistry of hydantoins and references the publications from 2004 to May 2016. It is organized in a different perspective than the previous report from 2004: hydantoins are grouped according to the substitution pattern on the principal backbone and the synthetic strategies for the preparation of each family of compounds are highlighted (mono-, di-, or trisubstituted hydantoins on the $\mathrm{C}-5, \mathrm{~N}-1 / \mathrm{N}-3$ positions, fused and polycyclic systems, spiro-, alkylidene or amino- hydantoins), including their use as organometallic ligands (Figure 1). One of the advantages

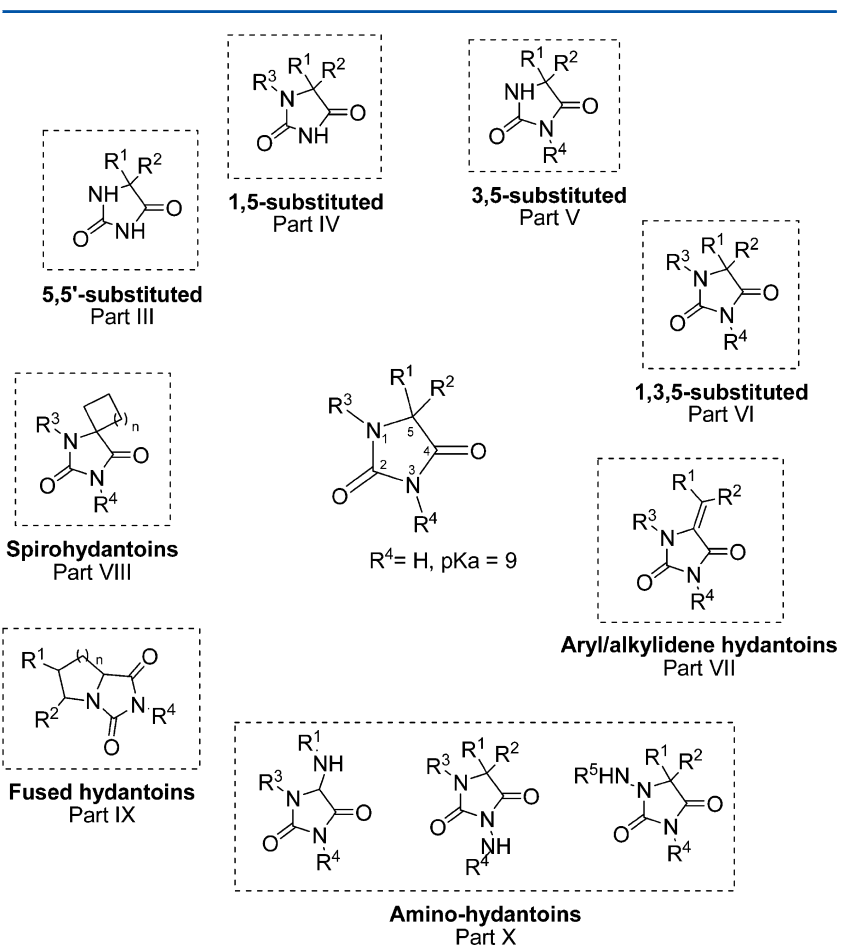

Figure 1. Hydantoin core and the classes of hydantoins.

of organizing the review from the point of view of the scaffold (and not considering the general method to access it) is the possibility to overview at a glance all of the available procedures to access a specific family of compounds.

This approach is very valuable not only for synthetic chemists but also for a broader readership in the field of medicinal chemistry, where target oriented syntheses is a must. The preparation of thiohydantoins will not be treated, being usually obtained similarly to hydantoins, but in the presence of thiobased reactants, or by transformation of the hydantoin scaffold by common thionation reactions (e.g., Lawesson's method). Reviews on their preparation were already reported. ${ }^{9,10}$ Moreover, the detailed description of the diverse biological activities displayed by hydantoin scaffolds is out of the scope of the review, and it would deserve a separate submission.

\section{HYDANTOINS AS CLINICAL CANDIDATES AND MARKETED DRUGS}

Many biological properties have been attributed to compounds containing a hydantoin moiety, as illustrated throughout the following sections of this review. Several of them have demonstrated strong bioactivity and thus have been led through clinical trials, ${ }^{11,12}$ and some of them have been commercialized as pharmaceuticals. ${ }^{13}$ In this section a short overview of hydantoincontaining clinical candidates (from 2004 to 2016) and marketed drugs is given, the structures of which are depicted in Figures 3 and 4 .

\subsection{Clinical Candidates}

2.1.1. BMS-587101. BMS587101 is a spirocyclic hydantoin which was developed by Bristol-Myers Squibb and showed 

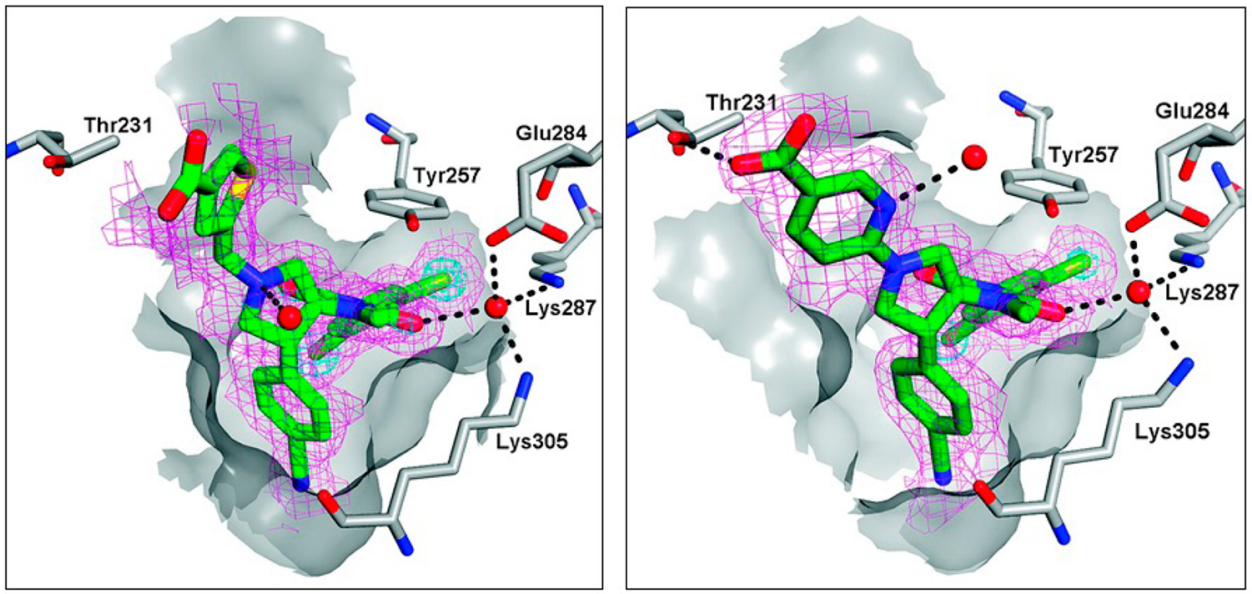

Figure 2. X-ray crystal structures of BMS-587101 (left) and BMS-688521 (right) bound to the I-Domain of LFA-1 (image reproduced with permission from ref 15 . Copyright 2014 American Chemical Society).<smiles>CN1C(=O)N(c2cc(Cl)cc(Cl)c2)C(=O)C1CN(CCc1ccc(C#N)cc1)Cc1cc(C(=O)O)cs1</smiles>

BMS-587101

Bristol-Myers Squibb LFA-1 antagonist Clinical phase II

Treatment of psoriasis<smiles>N#Cc1ccc(C2CN(Cc3ccc(C(=O)O)cn3)CC(=O)N2c2cc(Cl)cc(Cl)c2)c(=O)n1-c1ccccc1</smiles>

BMS-688621 Bristol-Myers Squibb Second-generation LFA-1 antagonist<smiles>CN1C(=O)N(c2ccc(C#N)c(C(F)(F)F)c2)C(=O)C1(O)c1ccccc1</smiles>

GLGP-0492 Galapagos
SARM Clinical phase I Cachexia

Figure 3. Hydantoin clinical candidates.<smiles>O=C1NC(=O)C(c2ccccc2)(c2ccccc2)N1</smiles>

Phenytoin Dilantin(C) Pfizer, 1951 anticonvulsant<smiles>CC1(C)NC(=O)N(c2ccc([N+](=O)[O-])c(C(F)(F)F)c2)C1=O</smiles>

\section{Nilutamide} Anandron $(9)$ Sanofi-Aventis, 1996 anti-androgen<smiles>O=C1NC(c2ccccc2)(c2ccccc2)C(=O)N1CP(=O)(O)O</smiles>

Fosphenytoin Cerebyx(C) Pfizer, 2013 anticonvulsant<smiles>O=C1CN(/N=C/c2ccc([N+](=O)[O-])o2)C(=O)N1</smiles>

Nitrofurantoin Furadantin( Shionogi, 1953 anti-bacterial<smiles>CCN1C(=O)NC(c2ccccc2)C1=O</smiles>

Ethotoin
Peganone Recordati, 1957 anticonvulsant

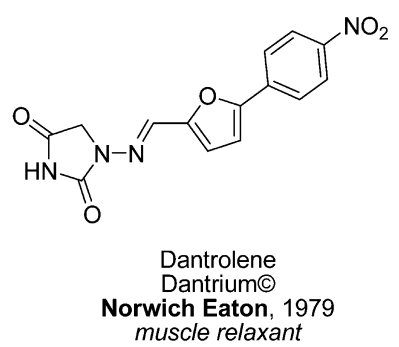

Figure 4. Hydantoin marketed drugs.

biological activity as a leukocyte function-associated antigen-1 (LFA-1) antagonist. The method for its preparation is described in section 12.6. ${ }^{14}$ This candidate reached clinical phase II in the treatment of moderate to severe psoriasis. The clinical trial was however discontinued for unspecified reasons. A secondgeneration LFA-1 antagonist spirocyclic hydantoin, BMS-
$688521,{ }^{15}$ showing a 4 - to 8 -fold improvement in human in vitro potency compared to BMS-587101 due to additional binding interactions with the receptor of interest (Figure 2), was then found as a potent clinical candidate, but to our knowledge no clinical trial was conducted on this molecule. 
Scheme 1. Three Main Routes to 5- and 5,5-Substituted Hydantoins ${ }^{a}$

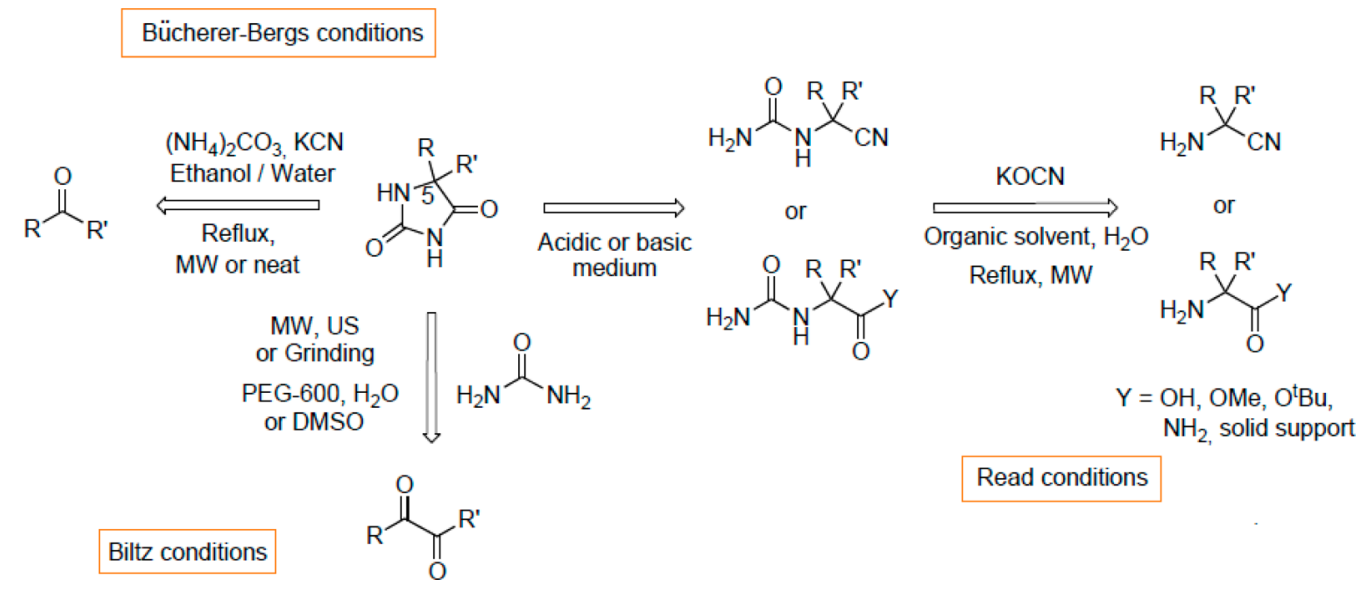

${ }^{a}$ Image reproduced with permission from ref 17 . Copyright 2014 American Chemical Society.

2.1.2. GLGP-0492. This 3-(3-cyano-2-trifluoromethyl-phenyl)-5-(hydroxymethyl)-1-methyl-5'-phenyl-hydantoin was developed by Galapagos. The compound was synthesized according to the Bucherer-Bergs reaction followed by the double substitution of its nitrogen atoms (see section 6.1). ${ }^{16}$ GLGP-0492 (Figure 3) went through clinical phase I in 2012. It was tested as a selective androgen receptor modulator (SARM) that should help increase the protein synthesis in muscle in the case of cachexia, i.e., muscle and weight loss, happening for instance along with cancer, chronic obstructive pulmonary disease (COPD), or AIDS, after immobilization or due to aging. The safety, tolerability, and pharmacokinetics of the candidate drug were also evaluated. Due to insufficient results, the clinical trial for cachexia was discontinued. However, GLGP-0492 showed interesting preclinical results toward Duchenne muscular dystrophy (DMD) and should be further developed in clinical trials in this frame.

\subsection{Marketed Drugs}

2.2.1. Phenytoin and Fosphenytoin. Phenytoin, or 5,5diphenylhydantoin (Figure 4), was first synthesized by Biltz in the early 1900s from the reaction of benzil with urea (see section 3.3). ${ }^{6}$ Alternatively, the Read synthesis was also successful by mechanochemistry ${ }^{17}$ (see section 3.2). The anticonvulsant and antiarrhythmic properties of this compound led Pfizer to commercialize it in 1951 as a sodium salt under the name of Dilantin. Apart from the already cited activities of this drug, it is also used as a muscle relaxant. Although the mechanism of action of phenytoin is unclear, it probably acts on the voltagedependent sodium channels of neurons and calcium efflux from neurons that leads to the raise of normal seizure threshold and the inhibition of seizure activity. Its use as an antiepileptic drug is however limited because of its numerous adverse effects and drug interactions. Its water-soluble prodrug, fosphenytoin, was marketed under its sodic form by Erfa in 2000 and then by Pfizer in 2013 under the name of Cerebyx.

2.2.2. Ethotoin. 3-Ethyl-5-phenylhydantoin or ethotoin is also an antiepileptic drug which was commercialized as Peganone by Recordati in 1957 and then by Abbott Laboratories. Its major metabolite is 5-phenylhydantoin, which mechanism of action may be analogous to that of phenytoin. However, unlike the latter, ethotoin does not raise the normal seizure threshold but rather stabilizes it and prevents the spread of seizure activity. Two recent examples for the preparation of ethotoin, by mechanochemistry ${ }^{13}$ or in solution, ${ }^{14}$ are described in section 5.4.

2.2.3. Nilutamide. Nilutamide was marketed as Anandron by Sanofi-Aventis in 1996. Its original synthesis relies on the $N$ alkylation of 5,5-dimethylhydantoin with 4-nitro-3-trifluoromethyl-phenyl chloride in the presence of cuprous oxide. ${ }^{18}$ Unlike the previous hydantoins presented, nilutamide does not exhibit antiepileptic activity but is a nonsteroidal antiandrogenic drug used in the treatment of prostate cancer. Its affinity for androgen receptors leads to the blocking of adrenal and prostatic androgens and thus to the inhibition of cellular growth of the prostatic tissue.

2.2.4. Nitrofurantoin. Nitrofurantoin is an $\mathrm{N}$-1-aminohydantoin (see section 10.1) which was first commercialized by Shionogi Inc. under the name of Furadantin in 1953. It is an antibacterial drug prescribed in the case of specific urinary tract infections. Its mechanism of action relies on its reduction by enzymes such as bacterial flavoproteins to produce reactive intermediates that damage DNA and proteins. It is efficient against both Gram-positive and Gram-negative organisms.

2.2.5. Dantrolene. This 1-aminohydantoin is a structural analogue of nitrofurantoin, and its synthesis, as well as its derivatives, has been reported several times in the past decade (see section 10.1). It was marketed as Dantrium by Norwich Eaton in 1979 and is used as a muscle relaxant and to prevent malignant hyperthermia.

\section{5- AND 5,5-DISUBSTITUTED HYDANTOINS}

The first methods developed for the synthesis of hydantoins were devoted to the preparation of 5- and 5,5-disubstituted hydantoins. Mainly, three different synthetic pathways are known: (i) the Urech or the Read synthesis, ${ }^{4}$ consisting in the reaction between amino acid derivatives and isocyanates; (ii) the Bucherer-Bergs reaction, ${ }^{5}$ starting from carbonyl compounds, potassium or sodium cyanide and ammonium carbonate; or (iii) the Biltz reaction, ${ }^{6}$ the historical procedure for the synthesis of the antiepileptic drug phenytoin from benzil and urea. They are still widely used nowadays, following the initial conditions or improving the methods by the use of modern technologies and ways of thinking synthetic chemistry (Scheme 1). Since 2004, the range of application of these methods, particularly the BuchererBergs reaction that affords the widest diversity of hydantoin structures, is very broad, especially in the field of medicinal 
Scheme 2. Bucherer-Bergs Reaction

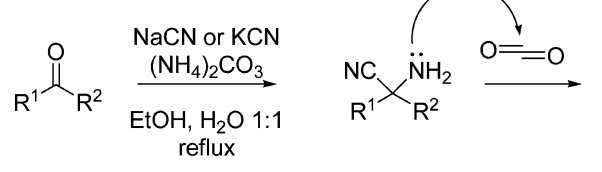

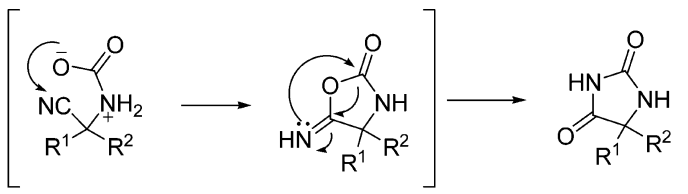

chemistry, in which the synthesis of hydantoins enables the access to numerous potent biological compounds.

Considering the large number of references concerning the preparation of hydantoins as bioactive compounds, we will focus in this section on the improvements or variations of the synthetic conditions, as well as on interesting or specific applications of the prepared compounds.

\subsection{Bucherer-Bergs Reaction}

Usually, the Bucherer-Bergs reaction was carried out in classical thermal conditions in a 1:1 mixture of $\mathrm{EtOH}$ and water at reflux for several hours, in a sealed tube to prevent the escape of volatile ammonium carbonate. In the presence of the latter, the carbonyl compound formed an imine intermediate on which cyanide reacted to obtain an amino nitrile. Subsequent carbamoylation with carbon dioxide issued from $\left(\mathrm{NH}_{4}\right)_{2} \mathrm{CO}_{3}$ and cyclization followed by rearrangement of the five-membered ring afforded the targeted hydantoin (Scheme 2).

This reaction is a valuable method to obtain various 5- and 5,5disubstituted hydantoins and was applied, as just mentioned, in many works (not referenced herein) focusing on the preparation of bioactive molecules ${ }^{19-23}$ and antibacterial polymers. ${ }^{24,25}$ Notably, an interesting and well-known application of obtaining such hydantoins is the access to quaternary non-natural amino acids or analogues of natural ones. ${ }^{26,27}$ The quaternary amino acids could then be used in bioactive peptide analogues ${ }^{28}$ to induce a specific secondary structure. ${ }^{29}$ Moreover, resolution of the mixture of hydantoins can afford the enantiopure amino acids (see also section 13). ${ }^{30}$

Variations of the Bucherer-Bergs method were explored and broadened the array of reactants that enter in the reaction procedure. Montagne et al. proposed to generate the imine intermediate from the nucleophilic addition of organolithium or Grignard reagents on either methyleneaziridines ${ }^{31}$ or nitriles. $^{32}$ This procedure would permit the variety of 5,5-disubstituted hydantoins to be extended. Another variant of the reaction was developed by Murray et al., in which the amino nitriles were generated from the $\mathrm{Ga}(\mathrm{OTf})_{3}$-catalyzed reaction, at $-78{ }^{\circ} \mathrm{C}$ in $\mathrm{CH}_{2} \mathrm{Cl}_{2}$, of liquid ammonia on ketones followed by the addition of hydrogen cyanide. The introduction of gaseous carbon dioxide in the presence of $N, N^{\prime}$-diisopropylethylamine afforded the hydantoins. ${ }^{33}$ As put forward by the authors, the use of organic solvent instead of a mixture of ethanol and water may advantageously offer better solubility of the reactants; however, this procedure required the use of a gallium-based Lewis acid and hazardous gaseous $\mathrm{CO}_{2}$ in strictly anhydrous conditions that may represent some drawbacks to the method. Kondo et al. recently developed an enantioselective synthesis of $\alpha, \beta$-diaminoacetonitriles, which they used in the Bucherer-Bergs reaction without loss of enantiopurity. ${ }^{34}$

Improvements in terms of reaction times, yields, and environmentally friendly conditions were also described. A catalyzed Bucherer-Bergs reaction was reported, in which $\mathrm{Fe}_{3} \mathrm{O}_{4}$ nanoparticles were employed as a reusable (up to four times) Lewis acid to promote both the amino nitrile formation and the carbon dioxide addition steps. ${ }^{35}$ Neat conditions, easy removal and recyclability of the catalyst, and short reaction times are obvious advantages to this method. The microwave technology enabled the reaction times to be reduced as well, as shown by Faghihi et al. ${ }^{36}$ The authors compared thermal heating and microwave irradiation for the synthesis of several 5,5disubstituted hydantoins, the microwave procedure providing the desired compounds within minutes of reaction in twice as high yields compared to thermal conditions. Very recently an intensified procedure of the Bucherer-Bergs reaction was reported using continuous-flow technology that shortened the reaction times to less than an hour. ${ }^{37}$

\subsection{Use of Isocyanates and Formation of Urea Derivatives}

Compared to the numerous examples of the Bucherer-Bergs reactions presented in the literature since 2004, few papers report the formation of hydantoins from isocyanates. The Urech or the Read synthesis, i.e., the reaction between amino acid derivatives and potassium or sodium cyanate to form an ureido derivative that is then cyclized in acidic conditions (Scheme 1), was applied to the synthesis of a variety of 5- and 5,5-disubstituted hydantoins that served for screening as potent bioactive compounds ${ }^{38}$ or as intermediates in the preparation of biomolecules containing enantiopure amino acid moieties. ${ }^{39,40}\left[{ }^{14} \mathrm{C}\right]$-labeled hydantoin SCH900567, a potential tumor necrosis factor-alpha converting enzyme (TACE) inhibitor, was synthesized from the hydrolysis of its unlabeled analogue and the reaction of the resulting amino acid with $\mathrm{KO}^{14} \mathrm{CN}$ after esterification of the acid moiety (Figure 5).

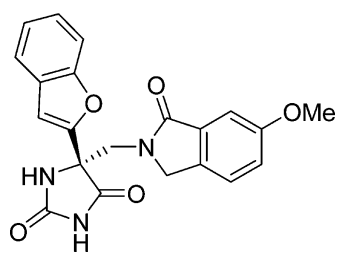

Figure 5. Hydantoin SCH900567.

The $\left[{ }^{13} \mathrm{C},{ }^{15} \mathrm{~N}\right]$ analog was prepared from labeled starting materials, leading to a methoxycarbonyl-protected amino methyl ester derivative that was cyclized in the presence of a $7 \mathrm{M}$ ammonia solution. ${ }^{41}$ Recently, Konnert et al. developed a mechanochemical solvent-free procedure for the preparation of various structures from natural amino methyl esters. ${ }^{17}$ These conditions enabled the general reaction in terms of yields and reaction time to be improved and afforded an alternative synthesis of phenytoin (see next section).

Apart from the Read synthesis, an interesting method for the formation of quaternary 5-allyl-5'-substituted hydantoins was reported by Hupp et al. in the course of the synthesis of a marine indole alkaloid. ${ }^{42,43}$ The procedure involved an oxazole rearrangement from thiourea derivatives and 1-ethyl-3-[3(dimethylamino)propyl]carbodiimide (EDC). The thiourea derivatives were prepared by the reaction of amino allyl esters and ethyl isothiocyanatoformate (Scheme 3). Desulfurization of the thiourea derivative in the presence of EDC led to the 
Scheme 3. Hydantoin Formation from Claisen Rearrangement of Oxazolones

$$
\text { (IEA, DCM, rt }
$$

Scheme 4. Biltz Synthesis

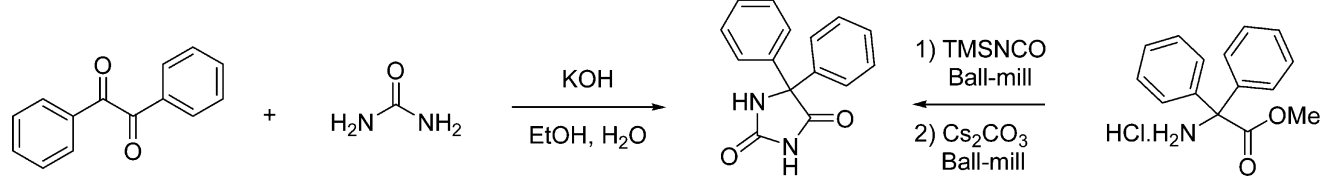

Scheme 5. Preparation of Phenylene-1,4-oxy-bis-hydantoins

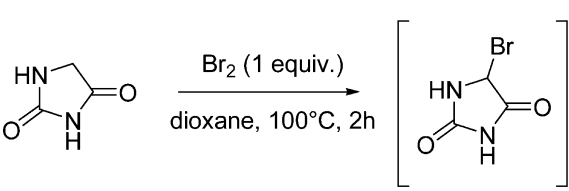

$\underset{\mathrm{H}}{\mathrm{H}}>=\mathrm{O}$

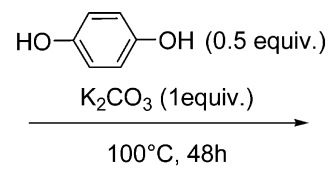

$100^{\circ} \mathrm{C}, 48 \mathrm{~h}$<smiles>O=C1NC(=O)C(Oc2ccc(OC3NC(=O)NC3=O)cc2)N1</smiles>

7 examples, $60-71 \%$ yield formation of a carbodiimide intermediate. The carbodiimide was attacked intramolecularly by the carbonyl of its allyl ester moiety to afford an oxazole intermediate that underwent a Claisen rearrangement into a quaternary oxazolone.

Treatment of the oxazolone with an excess of sodium methoxide led, after several transformations, to the 5-allyl-5' substituted hydantoin. This reaction afforded 5-allyl-5'-arylhydantoins in good yields, but limited reaction was observed with methyl and benzyl substituents, i.e., alanine and phenylalanine substrates.

Urea derivatives could be also obtained by other strategies. Agrawal et al. synthesized them by treatment of $\mathrm{N}$-cyano amino esters with dibutylphosphate for $30 \mathrm{~min}$ at reflux of toluene. Extending the reaction time led to the formation of the corresponding hydantoins. ${ }^{44}$ The method was efficient and versatile as it gave access to various heterocycles. Starting from methyl (aminocarbonyl)carbamate, Shaddy et al. obtained an ureido derivative of diphosphonate that cyclized to afford the corresponding 5,5-bis(diethylphosphonate)-hydantoin with potential therapeutic applications. ${ }^{45}$

\subsection{Biltz-Type Synthesis, Preparation of Phenytoin Derivatives}

Apart from few papers reporting the preparation of phenytoin and its derivatives from alternative methods ${ }^{46}$ like the BuchererBergs reaction ${ }^{20,47}$ or carbonylation of $\alpha, \alpha$-diphenyl-amino amide, ${ }^{48}$ the major pathway to access the antiepileptic drug remains the Biltz synthesis, consisting in the double condensation of urea on benzil in strong acid or basic conditions (Scheme 4).

Recently, many advances were brought to the original procedure. Indeed, novel conditions were reported, using heterogeneous catalysts $^{49,50}$ or modern technologies such as microwave irradiation $^{51,52}$ or ultrasonication. ${ }^{53-55}$ Solvent-free procedures were also developed and notably one solvent-free route in which a mixture of benzil, urea, and $\mathrm{NaOH}$ were ground with a mortar and a pestle. ${ }^{56}$ However, this method was found to be not applicable to ball-milling technology, ${ }^{17}$ and phenytoin was obtained by the Read procedure using activated trimethylsylilisocyanate (Scheme 4). All of these alternative procedures have the advantages of affording phenytoin derivatives in excellent yields and to be much faster and greener than the original version of the reaction. The access to benzil derivatives was moreover widened by the development of a DMSO-PdI 2 -promoted oxidation of diaryl alkynes into the corresponding benzils. ${ }^{57}$ More generally, the condensation of glyoxal derivatives with urea served for the synthesis of diverse 5- and 5,5-disubstituted hydantoins. ${ }^{58-60}$

\subsection{Substitution at Position C-5}

Substitution at the C-5 position of 5-bromohydantoin was the main strategy in the few examples reported since 2004. Arylation could take place through Friedel-Crafts reaction, involving recoverable and recyclable heterogeneous Lewis acids such as $\mathrm{Mg}$ and $\mathrm{Yb}$ on solid supports ${ }^{61}$ or phosphates. ${ }^{62}$ The reactions generally afforded excellent selectivities, except in the case of phenol for which para- and ortho-hydroxyphenylhydantoin were obtained. Phenylene-1,4-oxy-bis-hydantoins with antimicrobial properties were synthesized from the reaction of substituted quinols on 5-bromohydantoin in the presence of $\mathrm{K}_{2} \mathrm{CO}_{3}$ (Scheme 5). ${ }^{63}$

\subsection{Metal-Catalyzed Procedures}

Various 5-aryl-hydantoins were prepared from methyl arylacetates or $\beta, \gamma$-unsaturated methyl ester, via their copper-catalyzed $\alpha$-amination with di-tert-butyldiaziridinone. ${ }^{64}$ The obtained 
Scheme 6. Copper-Catalyzed Synthesis of $N, N$-Di(tert-butyl)-hydantoins

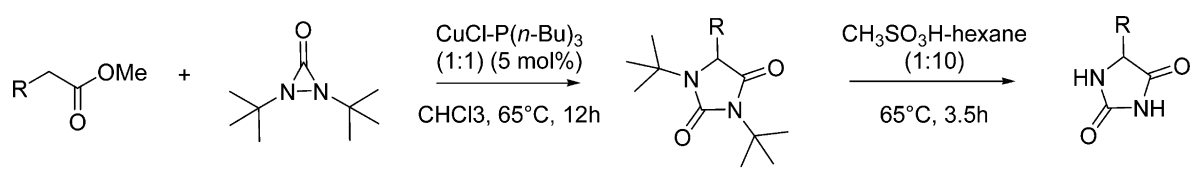

9 examples, $49-79 \%$ yield

Scheme 7. Formation of $\mathrm{N}$-Substituted Amino Acid Derivatives and Their Reaction with Isocyanates

$\mathrm{R}^{2}-\mathrm{NH}_{2} \quad \mathrm{X}=\frac{\mathrm{Br}, \mathrm{Cl}, \mathrm{R}^{1}=\mathrm{Me}, \mathrm{Et}, \mathrm{R}^{3}=\mathrm{H}, \mathrm{Ar}}{\mathrm{R}^{3}}$

$\mathrm{R}^{3}$

$\mathrm{H}_{2} \mathrm{~N}_{\mathrm{O}}^{\mathrm{R}^{3}} \mathrm{OR}^{1} \stackrel{\mathrm{R}^{2}-\mathrm{Br}}{\mathrm{N}}$

$\mathrm{R}^{1}=\mathrm{H}, \mathrm{Bn}$

$R^{3}=H$

hydantoins could be easily and selectively deprotected with methanesulfonic acid, with possible further substitution to give various 1,3,5-trisubstituted structures (Scheme 6).

\section{1- AND 1,5-DISUBSTITUTED HYDANTOINS}

\subsection{Use of Isocyanates and Ureas}

Reactions involving isocyanates are some of the oldest pathways to prepare hydantoins. ${ }^{65}$ More specifically, N-1-substituted hydantoins were obtained by the reaction between $N$-substituted amino acid derivatives and alkali cyanates or analogues such as chlorosulfonyl or trimethylsilyl isocyanate.

Two strategies were adopted to synthesize the $N$-substituted amino acid derivatives (Scheme 7). The first one is the substitution of the free $N$-terminal moiety of amino acids (usually glycine) by alkylation or reductive amination of aldehydes. This procedure enabled diarylether-derived 1substituted hydantoins to be prepared that were found to be potent non-nucleoside reverse transcriptase inhibitors (NNRTIs) for HIV treatment, ${ }^{66}$ as well as 1-[(1-benzyl indol3-yl)-carbomethyl]hydantoin which was evaluated as antimicrobial and anticancer agent. ${ }^{67}$

The second strategy, equally effective, consisted in the $\mathrm{N}$ alkylation of amines, including free $\mathrm{N}$-terminal moiety of amino acids, with ethyl bromo or chloroacetate. ${ }^{68}$ The corresponding $\mathrm{N}$-substituted glycine ethyl esters were thus obtained and then reacted with isocyanate to afford the 1-substituted hydantoins. $^{69-71}$

To synthesize 1,5-diaryl-hydantoins, Kwon et al. esterified and brominated commercially available phenylacetic acids which served for the $N$-alkylation of aniline. ${ }^{72}$

A variant to this reaction has been described by Pevarello et al. They prepared in a one-pot manner an $\mathrm{N}$-1-arylhydantoin by reacting methyl 4-aminophenylpropionate as the amine with chloroacetyl isocyanate in the presence of DBU (Scheme 8). ${ }^{73}$

The reaction between amino acid derivatives and isocyanates consists in the formation of the ureido derivatives as intermediates that are then cyclized to afford the hydantoin. In their work on the preparation of human $\beta 2$ adrenoceptor
Scheme 8. Use of Chloroacetyl Isocyanate for the Construction of the Hydantoin Ring

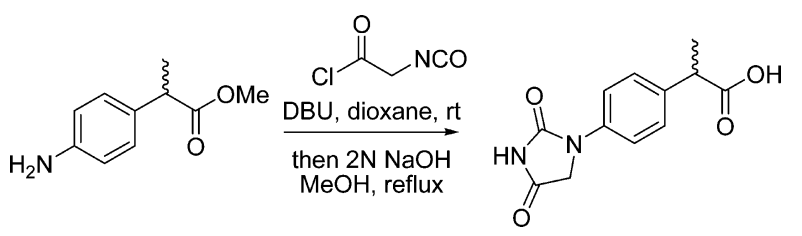

agonists, ${ }^{71}$ and in parallel of the synthesis already described above, Procopiou et al. prepared this intermediate starting not from an isocyanate but directly from the urea of 3-iodo-aniline and ethyl chloroacetate, the cyclization occurring in the presence of $\mathrm{NaH}$ (Scheme 9).

This alternative to the reaction with isocyanates using urea was also reported by Babaeva et al. ${ }^{74}$ They described the synthesis of oxa- and thiazolidine-1,3-diones in which they prepared in onepot the $\mathrm{N}$-substituted glycine from 4-chloro or bromo-aniline and chloro acetic acid, which reacted in situ with urea at 120-130 ${ }^{\circ} \mathrm{C}$ to afford the corresponding 1-(4-halogenophenyl)-hydantoin (Scheme 9). The advantage of this method was the neat conditions employed; however, compared to Procopiou's method they needed the amine as an extra reactant and gaseous ammonia was released.

\subsection{Biltz Synthesis}

Urea is besides one of the components of the Biltz synthesis. Modified procedures of the original reaction using substituted ureas and/or glyoxal derivatives enabled the access to 1- and 1,5disubstituted hydantoins.

Baccolini et al. ${ }^{60}$ recently reported the use of phosphorus pentoxide as a catalyst for the reaction between unsubstituted urea (or thiourea) or methylurea and glyoxal or its simple derivatives. The reactions were carried out at room temperature in aqueous media, offering mild and green conditions for the obtaining of methyl-substituted hydantoins (Scheme 10).

Aryl-substituted hydantoins were also synthesized following a modified Biltz reaction, starting from aryl methyl ketones, 
Scheme 9. Hydantoins from Ureas and Ethyl Chloroacetate

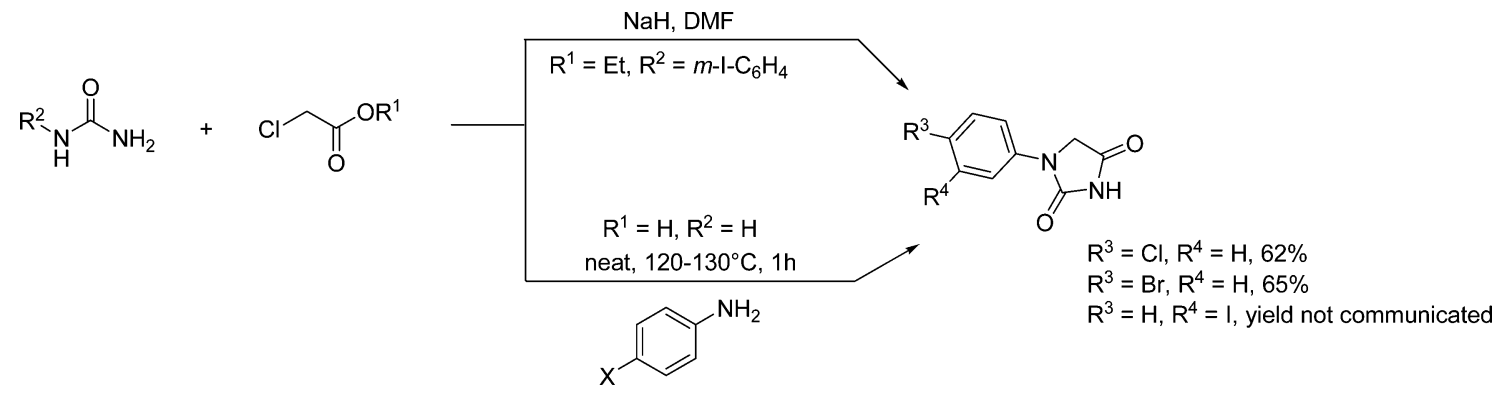

Scheme 10. Biltz-Type Reaction with Glyoxals

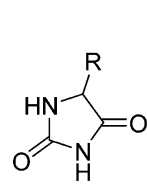

$\mathrm{R}=\mathrm{H}, 63 \%$ $\mathrm{R}=\mathrm{Me}, 60 \%$

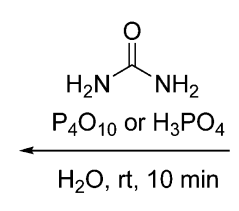

$\mathrm{PO}_{4}$

$$
\mathrm{R}=\mathrm{H}, \mathrm{Me}
$$
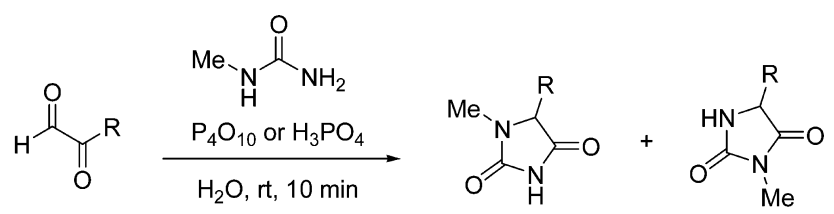

ratio $70: 30$

Scheme 11. Catalyzed Pathways to 1-Arylhydantoins<smiles>CC(=O)c1cc[R7]cc1</smiles><smiles>[R17][R17]1ccc(NC(N)=O)cc1</smiles>

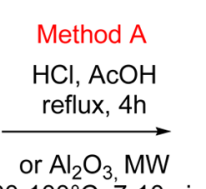

$80-100^{\circ} \mathrm{C}, 7-10 \mathrm{~min}$

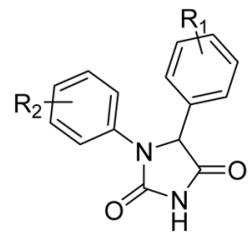

A : $58-70 \%$

B : $89-95 \%, 9 \%$ if $\mathrm{R}_{2}=4-\mathrm{NO}_{2}$

Scheme 12. Illustration of the Different Acidity of Positions N-1 and N-3

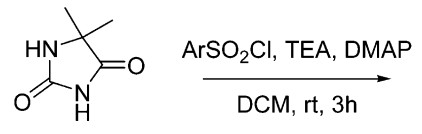

$>=\mathrm{O}$ $\underset{\text { dry benzene, Ar, reflux, } 2 \mathrm{~h}}{\mathrm{NaH}}$<smiles>CC1(C)C(=O)NC(=O)N1OS(=O)(=O)O</smiles>

oxidized with selenium oxide into their corresponding glyoxal and arylureas. The reactions were catalyzed either by $\mathrm{HCl}$ in acetic acid under reflux for $4 \mathrm{~h}$ (Scheme 11 , method $\mathrm{A})^{75,76}$ or by acidic alumina in short reaction times under MW irradiation (Scheme 11, method B), ${ }^{77}$ the latter procedure offering a greener synthetic route to 1,5-arylhydantoins.

\subsection{Alkylation/Acylation at $\mathrm{N}-1$ Position}

Derivatization of the $N-1$ position of unsubstituted hydantoins could be performed by alkylation methods ${ }^{78,79}$ or Mitsunobu reaction. ${ }^{80}$ The different acidity of both nitrogens of the hydantoin ring was highlighted by Kashif et al. in their synthesis of 1-arylsulfonylhydantoins by alkylation of 5,5-dimethylhydantoin. ${ }^{81}$ When reacting with aryl sulfonyl chlorides in the presence of triethylamine and DMAP, the 1,3-unsubstituted hydantoin was substituted in its more acidic position $\mathrm{N}$-3. In the presence of sodium hydride, the 3-arylsulfonyl-5,5-dimethylhydantoin underwent a rearrangement into 1-arylsulfonyl-5,5-dimethylhy- dantoin (Scheme 12). The obtained compounds were successfully tested for their in vitro hypoglycemic activity.

The selective $N-1$ or $N-3$ substitution of hydantoins not only relies on the difference in acidity but also on the bulkiness of the C-5 substituent of the hydantoin ring. The Boc-protection of $\mathrm{N}-1$ and $\mathrm{N}-3$ positions of the hydantoin core was described by Kruger. ${ }^{82,83}$ Mono or bis- $N$-acylation reactions were studied and compared for 5-methylhydantoin, 5,5-dimethylhydantoin, and the cage-like molecule trishomocubane hydantoin (Figure 6), highlighting the essential role of steric hindrance of C-5 position in the regioselectivity of the Boc-protection and the competitive

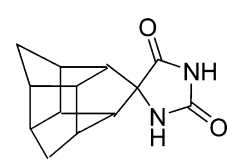

Figure 6. Trishomocubane Hydantoin. 
Scheme 13. Methods for the Synthesis of Hydantoins from $\mathrm{N}$-Cyano- $\mathrm{N}$-alkyl/Arylaminoacetate

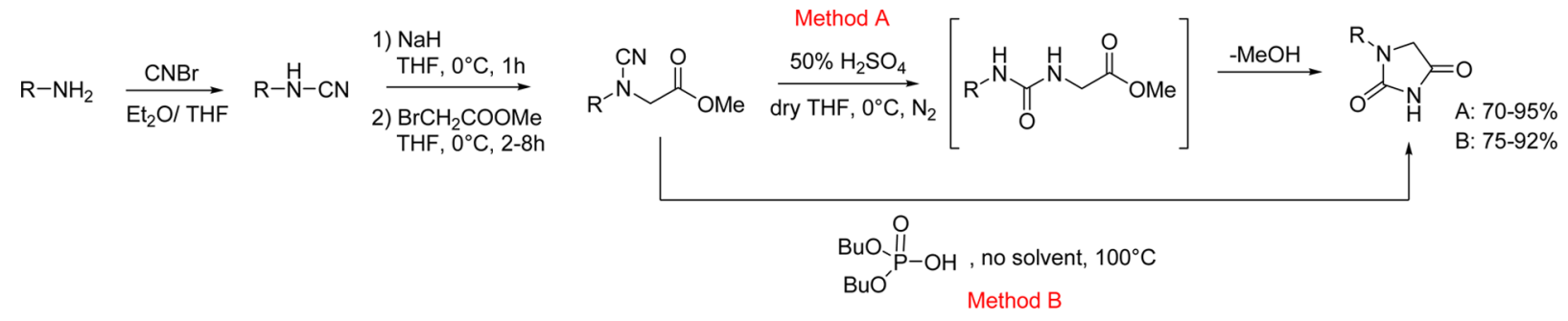

Scheme 14. Regioselective Reaction of Carbodiimides and $\alpha, \beta$-Unsaturated Carboxylic Acids or $\alpha$-Bromoaryl Acetic Acids

$$
\text { or }
$$

Scheme 15. Decomposition of Guanosine by Singlet Oxygen Oxidation
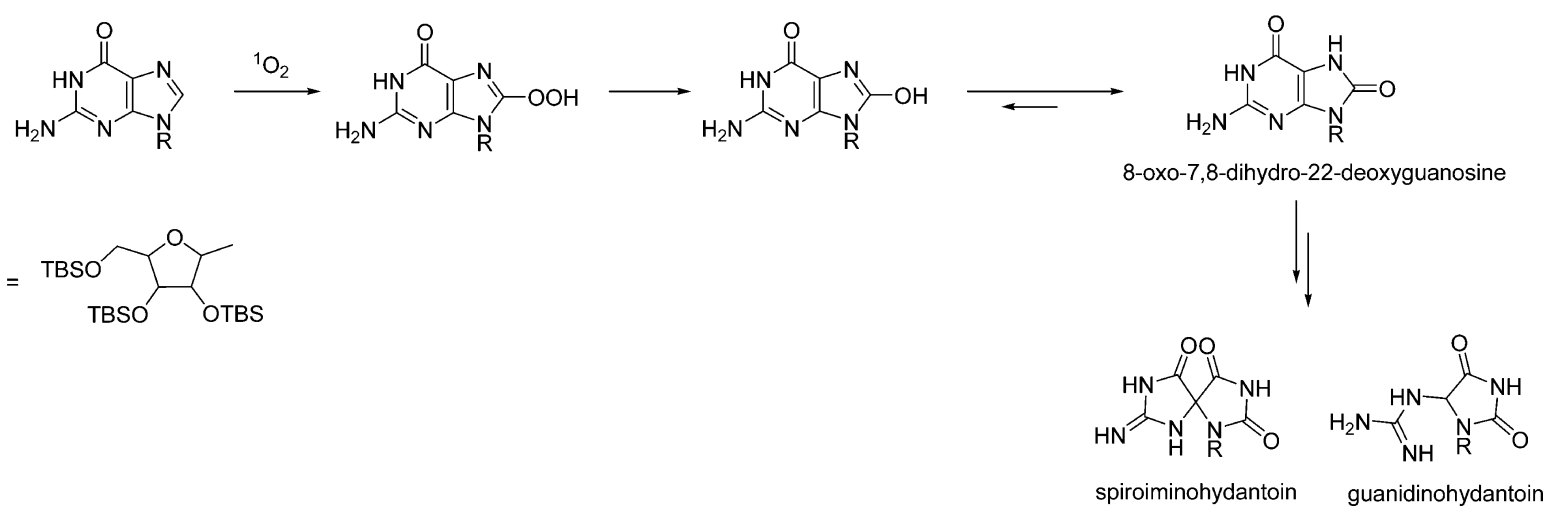

reaction between $\mathrm{N}-1$ (more hindered but stronger nucleophile) and $\mathrm{N}-3$ (less hindered but weaker nucleophile) positions.

Boc-deprotection with $\mathrm{K}_{3} \mathrm{PO}_{4} \cdot \mathrm{H}_{2} \mathrm{O}$ in methanol of position $\mathrm{N}$ 1 has been performed by Dandepally et al. ${ }^{84}$ Although substitution at the $N-3$ position can enhance the pharmaceutical activity of hydantoins, this same position can as well be deprotected. The ruthenium-catalyzed deprotection of $\mathrm{N}-3$ allylic hydantoin was reported, ${ }^{85}$ along with other examples of amide-like moieties that are lactams, imides, or oxazolidinones. This procedure has the advantage to promote the allylic function as a convenient protecting group, as its orthogonal deprotection is tolerant toward many functionalities.

\subsection{Miscellaneous}

A convenient route for the synthesis of 1-substituted hydantoins was described by Kumar et al. ${ }^{86}$ Using an amine as a cheap and versatile starting material, the corresponding cyanamide was formed by reaction with cyanogen bromide. The $N$-alkylation of this cyanamide was then performed with methyl bromoacetate in the presence of $\mathrm{NaH}$ to afford the methyl $\mathrm{N}$-cyano- $\mathrm{N}$-alkyl/ arylaminoacetate, which was then cyclized into the $N$-1substituted hydantoin in the presence of 50\% sulfuric acid (Scheme 13, method A). Later, they used DBP (dibutylphosphate) to perform the cyclization of these $N$-cyano- $N$-alkyl/ arylaminoacetates (Scheme 13, method B). ${ }^{87}$ The authors extended the two described procedures to a bis(hydantoin) compound, enhancing the possibility to include hydantoin moieties in bigger structures.

Olimpieri et al. prepared 1-alkyl/aryl-5-substituted hydantoins through an innovative two-step protocol involving $\mathrm{N}$-tert-butylor $N$-trityl-carbodiimides and $\alpha, \beta$-unsaturated carboxylic acids or $\alpha$-bromoaryl acetic acids. ${ }^{88}$

The described domino condensation/nucleophilic substitution/O $\rightarrow \mathrm{N}$ acyl migration afforded 1-alkyl/aryl-3-tert-butyl/ trityl-hydantoins with high regioselectivity. The occasional byproduct $\mathrm{N}$-acylurea could be easily cyclized into the desired hydantoins with $2 \mathrm{M} \mathrm{NaOH}$. The 3-substituent was then removed to access the 1,5-disubstituted compounds (Scheme 14). The proton transfer during the reaction of phenyl urea and ethyl chloroacetate to form 1-phenylimidazolidine-2,4-dione was studied through DFT calculations. ${ }^{89}$ The authors found that intermolecular proton transfer was the main transfer at $300 \mathrm{~K}$, and thus that both negative $N-1$ and $N-3$ coexisted, the phenomenon being very fast in concentrated solutions.

\subsection{Hydantoins Derived from Guanosine and Analogues}

DNA oxidation, also called oxidative stress, is mainly due to the easily oxidized nucleobase guanosine. To understand this 
Scheme 16. Oxidation Process of Cytosine

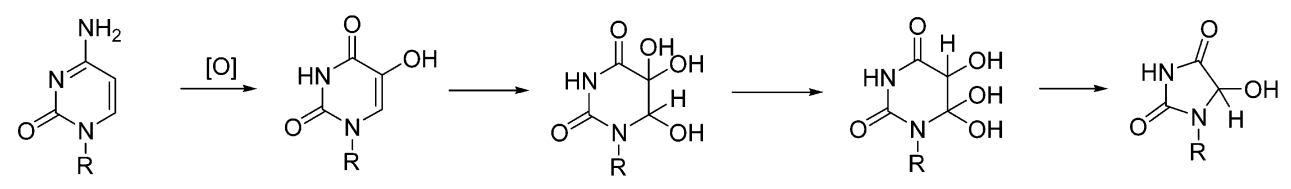

Scheme 17. Substitution at the N-3 Position of Hydantoins

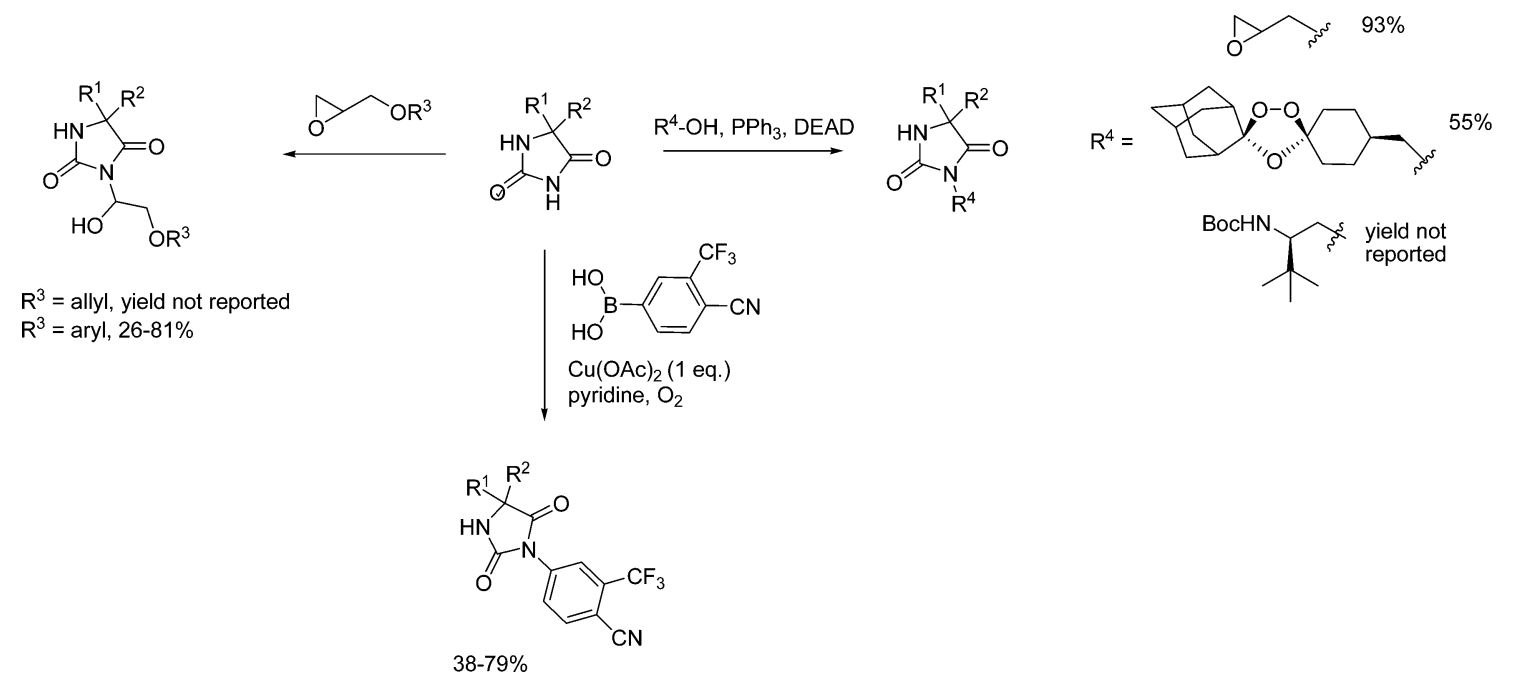

Scheme 18. Ureido Derivatives from Ethyl Isocyanatoacetate

$$
\text { EtO } \stackrel{\mathrm{O}}{\mathrm{NCO}}+\mathrm{R}_{-\mathrm{NH}_{2}} \longrightarrow \text { EtO }
$$

phenomenon, many studies on the singlet oxygen oxidation of guanosine enlightened the many products derived from the oxidation of the main metabolite of guanosine, 8-oxo-7,8dihydro-22-deoxyguanosine. Among the structures found in the products of decomposition there are hydantoins, namely spiroiminohydantoin (found at neutral or basic $\mathrm{pH}$ ) and guanidinohydantoin (found at acidic $\mathrm{pH}$ ) (Scheme 15), and their characterization and mechanism of formation were largely studied. ${ }^{90-96}$

The synthesis of derivatives of spiroiminodihydantoin was also described, ${ }^{97,98}$ as well as the oxidation mechanisms of two oxo analogues of guanosine, 5-hydroxyisourate,,$^{99-101}$ and caffeine. ${ }^{102}$ The oxidation process of cytosine was demonstrated toward the formation of 5-hydroxyhydantoin nucleosides (Scheme 16)..$^{103-105}$

Oxidative sources leading to hydantoins, other than singlet oxygen, were also reported, including chromium(V) complexes, ${ }^{106}$ azo-compound derived radicals, ${ }^{107}$ hydrobromous acid, ${ }^{108}$ or Fenton-like systems with $\mathrm{Cu}(\mathrm{II})^{109}$ or $\mathrm{Fe}(\mathrm{II}) .^{110}$

\section{3- AND 3,5-DISUBSTITUTED HYDANTOINS}

\subsection{Alkylation/Acylation at the N-3 Position}

The most usual way to substitute the $N-3$ position of hydantoins is alkylation with halides in the presence of a base (usually potassium carbonate). This strategy was largely adopted for the preparation of 3-substituted hydantoin-containing compounds with potential biological activities. ${ }^{16,111-124}$ Notably, 5,5dimethylhydantoin derivatives were synthesized by this means for applications in antimicrobial polymer coatings, ${ }^{125-127}$ as well as phenytoin derivatives. ${ }^{128-131}$

Besides, 3-substituted phenytoin derivatives were also obtained by nucleophilic addition on formaldehyde ${ }^{132}$ and by a solvent-free procedure relying on the aza-Michael addition of phenytoin on $\alpha, \beta$-unsaturated esters under ultrasonication. ${ }^{133} \mathrm{In}$ the latter case the presence of the ionic salt tetrabutylammonium bromide (TBAB) had an effect on the efficiency of the reaction as it acted as a solvent for both organic compounds and inorganic base.

Other pathways to substitute nitrogen $N-3$ are nucleophilic substitution of oxirane derivatives that led to 3 - $\beta$-hydroxyhydantoins $^{134,135}$ and Mitsunobu reaction. ${ }^{136-138}$ Hügel et al. circumvented the classical alkylation methods and developed, for the $N$-arylation of hydantoins, a copper-promoted coupling reaction with triarylbismuthanes and aryl boronic acids, ${ }^{139}$ the latter being better agents of arylation in the procedure (Scheme 17). Shinde et al. prepared a 3-(2-oxo-phenylethyl)-hydantoin from 5,5-dimethyl-1,3-dibromo-hydantoin to illustrate their $\mathrm{N}$ bromosuccinimide promoted synthesis of $\alpha$-imido ketones from styrenes. $^{140}$

\subsection{Use of Isocyanates}

3-Substituted hydantoins can be obtained by cyclization of the corresponding ureido derivatives. To synthesize these derivatives from amines, several reported procedures of these recent years involved the use of ethyl isocyanatoacetate with benzylamine ${ }^{71}$ or aniline derivatives. ${ }^{73,141}$ The cyclization of these intermediates in acidic conditions afforded the 3-substituted hydantoins (Scheme 18). 
Scheme 19. Hydantoins Formed by the Reaction between E-Phosphazidoesters and Isocyanates

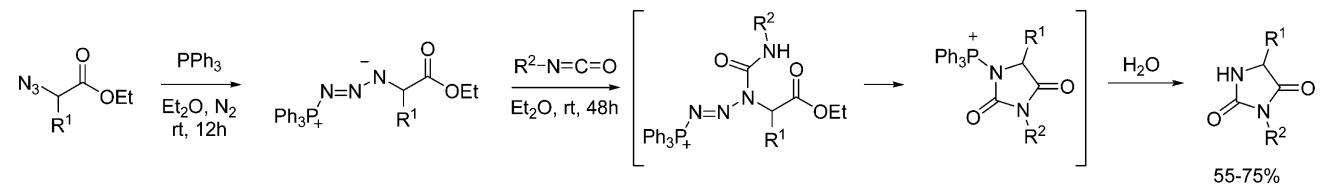

Scheme 20. Rearrangement from N-Benzyloxycarbonylamino Malonic Acid

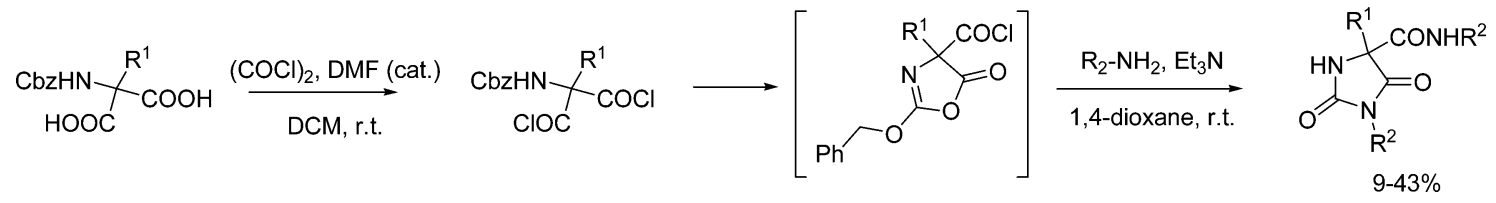

Scheme 21. Bis-hydantoin Structures

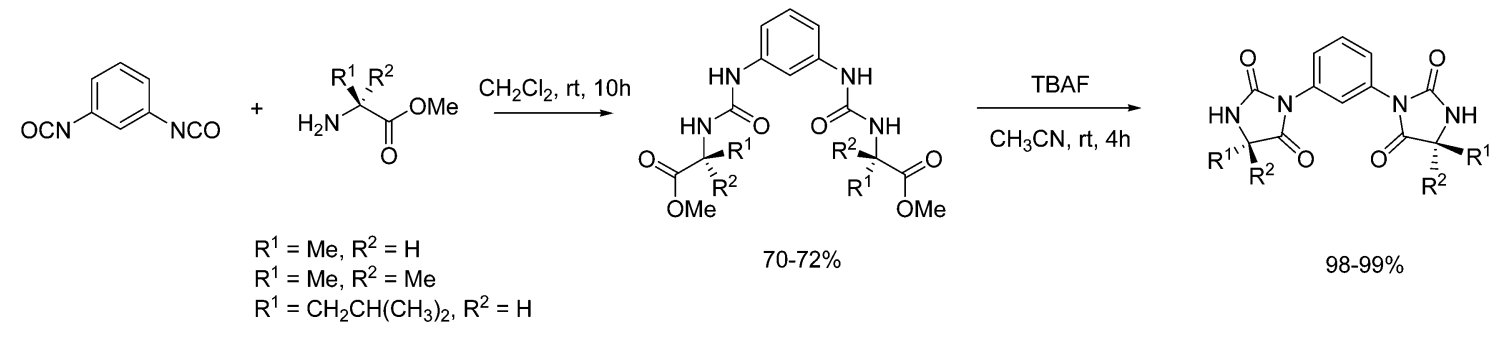

Apart from amines, other compounds were found to be starting materials for the synthesis of 3-substituted hydantoins using isocyanates. Fresneda et al. found that the reaction between E-phosphazidoester derivatives, obtained by the Staudinger reaction, and isocyanates could lead to 3-substituted hydantoins (Scheme 19). ${ }^{142}$

The use of aminonitriles was described as well, the cyclization occurring in the presence of $\mathrm{H}_{3} \mathrm{PO}_{4}$, hydrolyzing at the same time the iminohydantoin intermediate. ${ }^{143}$

\subsection{Miscellaneous}

The Biltz synthesis was employed by Muccioli et al. for the preparation of 3 -substituted phenytoin derivatives. ${ }^{144}$ The compounds were synthesized in DMSO in the presence of aqueous $\mathrm{KOH}$, under microwave irradiation (nine pulses at 750 $\mathrm{W}$ in a domestic microwave equipment). As a variant of the Biltz reaction, $N$-hydroxy and $N$-alkoxyureas were reacted with arylglyoxal hydrates to access 3-hydroxy or 3-alkoxy-5arylhydantoins. ${ }^{145}$ Acidic catalysis with $\mathrm{AcOH}$ helped the reaction to proceed at room temperature to afford the desired products after rather long reaction times but in good to excellent yields.

Hroch et al. started from benzyloxycarbonyl (Cbz)-amino malonic acids to prepare 3,5,5-trisubstituted hydantoins. ${ }^{146}$ After forming the corresponding acyl chlorides, the carbonyl oxygen on the $N$-carboxybenzyl $(\mathrm{Cbz})$ protection attacked one of the acyl chlorides, forming by cyclization an isoxazolidinone. A rearrangement took place with the addition of an amine on the same acyl chloride, affording the hydantoin by subsequent reopening and cyclization of the heterocyclic ring (Scheme 20). Similarly, hydantoins can be obtained from the rearrangement of $\mathrm{N}$-Boc-protected heterocycles. The reaction between Boc-imines and isonitriles led to the formation of oxazolidinones that rearranged into hydantoins. ${ }^{147}$ Chaubet et al. described the ring contraction of bis-Boc diketopiperazines into the corresponding hydantoins through a $\mathrm{KOH}$ or $\mathrm{NaOMe}$-mediated rearrangement. $^{148}$

\subsection{3-Substituted Hydantoins from Amino Acids}

5.4.1. Use of Isocyanates. As already mentioned, the use of substituted isocyanates enabled the preparation of the 3substituted hydantoins from amines and other reactants. However, the main pathway to hydantoins from isocyanates is their reaction with amino acids or their derivatives. Indeed, this reaction resulted in the formation of the corresponding ureido derivative of the amino acids, which cyclized intramolecularly by the attack of the nitrogen provided by the isocyanate on the $C$ terminal moiety of the amino acid derivative. Konnert et al. recently reported the first mechanochemical reaction of substituted isocyanates with amino methyl esters, to provide a range of 3-substituted hydantoins, including ethotoin (Figure 2), using poly(ethylene glycol)s (PEGs) as grinding additives. ${ }^{149}$

Since 2004, some examples have been reported in which analogues of natural amino acids, such as para-substituted phenylglycine $\mathrm{e}^{76,150}$ or $\beta$-amino-alanine derivatives ${ }^{151}$ were reacted with various isocyanates to generate the 3 -substituted hydantoins. ${ }^{152-154} \mathrm{~A}$ variant to this procedure was described by Park et al., ${ }^{155}$ who first formed the hydantoin scaffold from an $\mathrm{O}$ substituted tyrosine with potassium cyanate and then alkylated the $N-3$ position with the desired methyl sulfonate derivative. Haridas et al. prepared bis-hydantoin structures from a phenyl bis-isocyanate and alanine, aminoisobutyric acid, and leucine methyl esters. ${ }^{156}$ In their study of the anion binding of the corresponding ureido derivatives, they provoked the cyclization into hydantoins in the presence of tetrabutyl ammonium fluoride (TBAF) because of the high basicity of the fluoride anion (Scheme 21). Moreover, the crystal structure of these bishydantoins showed interesting self-assembly behavior thanks to unusual hydrogen bonding.

Pyroglutamate, the cyclic analogue of glutamic acid, underwent a rearrangement into hydantoin when reacted with isocyanates. ${ }^{157}$ In presence of $\mathrm{NaH}$, the ureido intermediate reacted intramolecularly on the ester moiety of pyroglutamate to form a fused bicyclic hydantoin intermediate. The released alkoxide ion opened the bicyclic intermediate to a 3,5- 
Scheme 22. Pyroglutamate Rearrangement

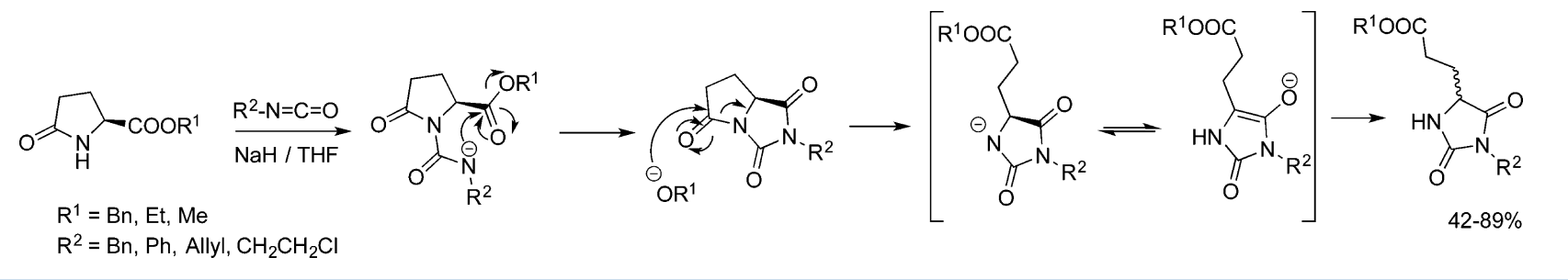

Scheme 23. Solid-Phase Synthesis of 3,5-Disubstituted Hydantoins

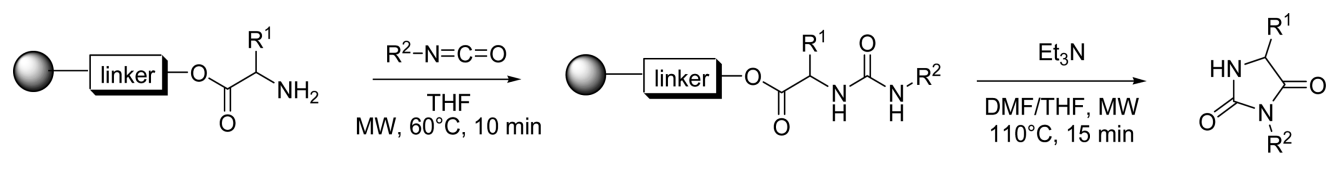

$70-100 \%$

Scheme 24. Formation of Isocyanates of Amino Acid Derivatives
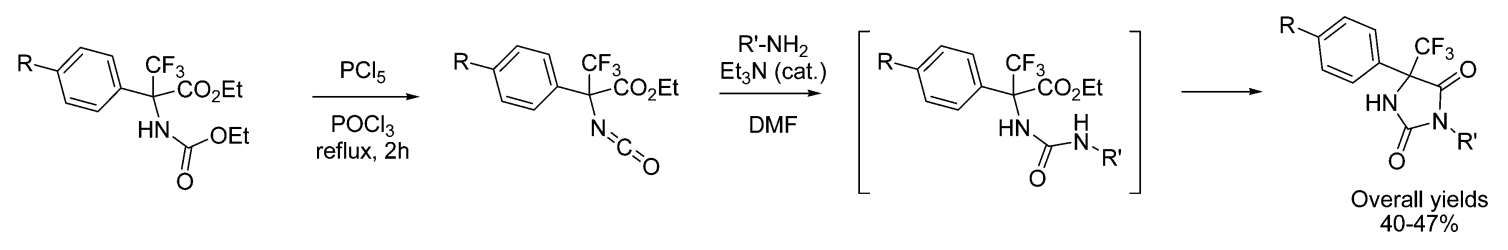

disubstituted hydantoin, after proton transfer and subsequent racemisation of the chiral center (Scheme 22). Preliminary alkylation of pyroglutamate led to 3,5,5-trisubstituted hydantoins.

Solid-phase synthesis is besides a useful technique for the synthesis of 3-substituted hydantoins from amino acids. Colacino et al. reported a microwave-assisted procedure ${ }^{158}$ in which resinbound amino acids with free $\mathrm{N}$-terminal moiety reacted with phenyl isocyanate. The generated ureido derivatives were then simultaneously cyclized and released from the resin in the presence of a base to afford the corresponding hydantoins, the unreacted material remaining bound to the resin (Scheme 23).

In a similar manner, El bakkari et al. developed a bismonopyridyl benzyl alcohol tag for the easy purification by hydrocarbon/perfluorocarbon phase-switching of products and substrates. They synthesized a hydantoin in four steps, by first anchoring by acylation $\mathrm{N}$-Boc-glycine on the hydroxyl group of the tag. ${ }^{159}$ After deprotection of the $\mathrm{N}$-terminal moiety, 4isopropyl-phenyl isocyanate was added, leading to the ureido derivative. Treatment with triethylamine led to the hydantoin while releasing it of the tag. For each step, the intermediates were purified by extraction with an aqueous solution containing a fluorous copper(II) carboxylate complex to which the pyridyl moiety could coordinate, easily removing the non-reacted and byproduct material in the organic phase. Washings of the perfluorodecalin solution with THF enabled the products to be released from the tag and to recover them in the organic phase.

The "reverse" pathway of the reaction of amino acids with isocyanates was to generate the isocyanate function from the carbamoylated $N$-terminal moiety of the amino acid. This transformation could be achieved by treatment of the carbamate function with $\mathrm{PCl}_{5} \cdot{ }^{160,161}$ The addition of an amine followed by cyclization of the obtained ureido derivative afforded the corresponding 3,5,5-trisubstituted hydantoins (Scheme 24).

The formation of an isocyanate intermediate was proposed in the mechanism of the rearrangement of Boc-protected amino amides into hydantoins in the presence of triflate anhydride
$\left(\mathrm{Tf}_{2} \mathrm{O}\right)$ and pyridine. ${ }^{162} \mathrm{Tf}_{2} \mathrm{O}$ would act as a Lewis acid and activate the carbonyl group of the amide bond, leading to the generation of an isocyanate moiety by liberation of the tert-butyl group of the Boc-protection. This intermediate would then cyclize into an oxazolidinone that would undergo a Mumm rearrangement into the corresponding hydantoin. Among the prepared compounds, the antiepileptic drug ethotoin was obtained in $60 \%$ yield (Scheme 25 ).

Scheme 25. $\mathrm{Tf}_{2} \mathrm{O}$-Mediated Formation of 3,5-Substituted Hydantoins from Amino Amides

$$
\text { BocHN } \prod_{\mathrm{O}}^{\mathrm{Tf}_{2} \mathrm{O} \text {, pyridine }}
$$

23 examples, $58-90 \%$ yield

Thus, hydantoins can be obtained from the intramolecular cyclization of ureido derivatives of amino acids or peptides obtained from isocyanates in solution, on solid phase or by mechanochemistry. These urea derivatives can besides be synthesized by the activation of the $N$-terminal moiety of amino acids or peptides by acylating agents such as 1,1carbonyldiimidazole (CDI), phosgene or triphosgene, benzotriazole carbonyl derivatives, or disuccinimidyl carbonate, as well as chloroformates, followed by the addition of an amine. The urea derivatives can then be cyclized to afford the hydantoins, usually in basic medium. The following paragraphs focus on the different kinds of $\mathrm{N}$-activation of amino acid derivatives allowing to access to 3-substituted hydantoins.

5.4.2. Use of 1,1-Carbonyldiimidazole (CDI). In peptidelike structures, the mechanism of formation of the hydantoin described with isocyanates may happen right after the activation step with CDI, the resulting activated $\mathrm{N}$-1-imidazole-carboxamido intermediate acting like an isocyanate. This intramolecular 
formation of hydantoin has been reported as a side reaction in the synthesis of aza-peptides ${ }^{163}$ or in the preparation of macrocycles containing an ureido function. ${ }^{164}$

However, this reaction can be taken advantage of for the solidphase synthesis of hydantoins from peptides. ${ }^{165}$ Vasquez et al. showed that CDI was a useful reagent for the formation of hydantoins from dipeptides without epimerization. ${ }^{166}$ They extended their work to the solid-phase synthesis of hydantoinbased peptidomimetics that were evaluated as inhibitors of caspase- 3 . $^{167}$

The mechanochemical formation of ureido derivatives from amino esters was also described, using CDI to form an acyl imidazole intermediate that underwent the nucleophilic attack of various amines. ${ }^{149}$ The ureido derivatives were then cyclized in the presence of potassium carbonate to afford the corresponding hydantoins. The use of poly(ethylene)glycol (PEG) as a reaction auxiliary during the ball-milled reaction ${ }^{168-170}$ proved to be beneficial both to the yields and the retention of the optical purity of the compounds. The drug ethotoin was notably synthesized in $65 \%$ yield following this procedure.

The synthesis of analogues of nilutamide was described by Varchi et al., who prepared amino amide-like structures from sulfinylimino propanamides. ${ }^{171}$ These structures were transformed into hydantoins by reaction with CDI which furnished the missing carbonyl function of the heterocycle, with no racemisation of the stereogenic center.

Total synthesis of the marine alkaloid Parazoanthine F was reported, which was based on the copper-assisted $\mathrm{C}-\mathrm{N}$ coupling of vinyl bromides and Boc-protected amino amides (namely alanine and arginine). The resulting enamides were then cyclized into hydantoins by reaction with CDI, after removal of the Bocgroup and without any epimerization of the chiral center. ${ }^{172}$

5.4.3. Use of (Tri)phosgene. Although phosgene and triphosgene were extensively used for the $N$-activation of amino acid derivatives to form ureido derivatives with the addition of amines, ${ }^{173-175}$ some reported procedures of the recent years employ triphosgene as a source of carbonyl group in the preparation of 3-substituted hydantoins starting from dipeptides $^{176}$ or amino amides. ${ }^{177}$ Notably, Zhang et al. prepared a library of amino acid-derived hydantoins and found out that, unlike CDI, triphosgene prevented epimerization of chiral amino acid derivatives. ${ }^{178}$

5.4.4. Use of Benzotriazole Carbonyl Derivatives. The group of Opacic worked on the preparation of amino amides by aminolysis of $N$-benzotriazolecarbonyl-amino acids. In presence of sodium carbonate, the cyclization occurred by the nucleophilic substitution of the amide nitrogen on the activated carbonyl function. ${ }^{179}$ By this method, the authors prepared a library of 3substituted hydantoins, evaluated for their antiviral activities. ${ }^{180}$

5.4.5. Activation by Formation of Carbamates. Fischer et al. generated succinimidyl carbamates by addition of hydroxysuccinimide on isocyanates prepared from amino acids by Curtius rearrangement. ${ }^{181}$ The reaction of $N$-free amino esters on the activated carbonyl group afforded the amino acid ureido derivatives, which cyclized in the presence of triethylamine into the corresponding hydantoins.

Zaccaro et al. used disuccinimidyl carbonate (DSC) for the activation of the $\mathrm{N}$-terminal moiety of resin-bound dipeptides, ${ }^{182}$ so as to provoke the nucleophilic attack of the peptide-bond nitrogen on the carbamate carbonyl function and cyclization into hydantoin. They could generate a combinatorial library of LysTrp based, hydantoin-containing dipeptides that could be tested as TRPV1 ion channel modulators.
Ureido derivatives from valine methyl amide were obtained by the addition of amines on the corresponding activated $p$ nitrophenyl-carbamate precursor. Cyclization of these ureido derivatives by acidic hydrolysis afforded the corresponding valine-derived hydantoins as reference compounds for the detection of valine adducts from dihydrohemoglobin after potential exposure to isocyanates. ${ }^{183}$

5.4.6. From Urea and Other Activation Methods. Dumbris et al. employed carbon monoxide itself as a source of carbonyl group in the transformation of amino amides into hydantoins in the presence of $\mathrm{W}(\mathrm{CO})_{6} \cdot{ }^{184}$ The amino amides were prepared from the corresponding amino esters, either by direct amidation of the ester moiety or by a mixed anhydride coupling reaction.

As CDI and the above reagents can activate the $N$-terminal moiety of amino acids and peptides to form, with the addition of an amine, an ureido derivative, other reactants enabled the access to these intermediates.

In their work on the preparation of $N$-hydroxyureas, Paz et al. coupled, among others, activated amino acid derivatives of carbamoyl azides and hydroxyl amines. ${ }^{185}$ They took advantage of the side reaction of hydantoin formation to generate a library of 3-hydroxyhydantoins by performing the intramolecular cyclization of $\mathrm{N}$-hydroxyureas in the presence of potassium or cesium carbonate. They also prepared a pyroglutamic-hydantoin derivative starting from glutamic acid.

Anhydride bonds also represent activated scaffolds for amine substitution reactions and so formation of ureas. Malcor et al. prepared 3-(2-pyrrolyl)-5-methylhydantoin by the opening of an oxazine with the $N$-terminal moiety of alanine methyl ester. ${ }^{186}$ This led to an ureido intermediate which cyclized in acidic medium into the hydantoin. The same group extended this procedure to the synthesis of thienylhydantoins from various amino acids. ${ }^{187,188}$

In their work on the preparation of 3,5-substituted 5 trifluoromethyl-hydantoins, Sokolov et al. synthesized analogues of the amino acid-like ureido derivatives described in the previous paragraph, by reacting the free amino moiety of $N$ benzylurea in $\alpha$-position of an $\alpha, \beta$-unsaturated ester derivative. Cyclization in the presence of triethylamine afforded the corresponding 3-benzyl-5-pyrazoline-5' -trifluoromethyl-hydantoin. ${ }^{189}$

Hillier et al. studied the thermal cyclization of ureidoacetamides into hydantoins and dihydrouracils. ${ }^{190}$ The ureidoacetamide substrates were prepared from the reaction of carbamoyl chlorides on amino acids (glycine, aminoisobutyric acid, and valine), followed by the amidation of their acid moiety. The effects of the solvent and the substitution of the ureidoacetamide on the reaction kinetics and the racemization rate (in the case of valine) were studied. It appeared that diols were solvents of choice and ureido acetamides containing $N$-methyl- $N$-phenyl ureas provided products with minimal racemization. This method afforded a potent cytochrome P-450 inhibitor in a very good yield of $95 \%$ with minimized racemization.

\section{1,3,5- AND 1,3,5,5-SUBSTITUTED HYDANTOINS}

\subsection{Substitution of the Hydantoin Core}

Usually, 1,3,5- and 1,3,5,5-substituted hydantoins are obtained from the substitution by alkylation, acylation, or Mitsunobu reaction of $N-1$ and/or N-3 positions of hydantoins. ${ }^{83,119,154,191-196}$ The hydantoin core could be prepared from the Bucherer-Bergs reaction and then undergo a double 
Scheme 26. Reductive Amination of Amino Acids for the N-1 Substitution of Hydantoins

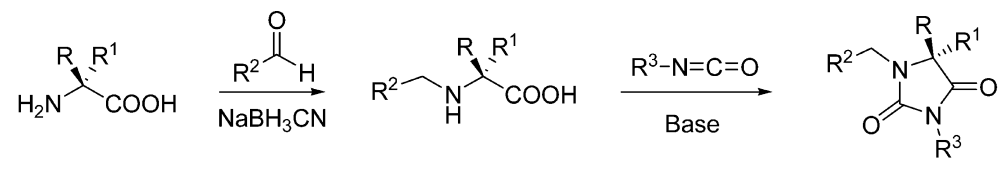

Scheme 27. Preparation of 5-Aza-Substituted Hydantoins

$$
\underset{\mathrm{EtOH}, \mathrm{rt}}{\stackrel{\mathrm{R}^{4}-\mathrm{NH}_{2}}{\longrightarrow}}\left[\mathrm{R}_{\mathrm{N}^{3} \mathrm{O}^{3} \mathrm{~N}_{\mathrm{R}^{1}}}^{\stackrel{\mathrm{O}}{\mathrm{R}^{4} \cdot \mathrm{NH}}}\right.
$$

17 examples, $47-76 \%$ yield

substitution. ${ }^{16,197-199}$ Analogues of phenytoin were notably prepared with this procedure. ${ }^{138,200-203}$ Acylation methods gave $N$-acylated-N-chloro-hydantoins ${ }^{204}$ that were then used as chlorine source and a polymer-linked chiral hydantoin used as an auxiliary in asymmetric aldol reactions. ${ }^{205}$ Chlorohydantoins were besides obtained from the treatment of the nonsubstituted hydantoins with trichloroisocyanuric acid (TCCA) 206,207 or hypochlorites. ${ }^{208-214}$ The preparation of the textile antimicrobial additive 1-chloro-3-ethyl-5,5-dimethylhydantoin (CEDMH) with calcium hypochlorite by mechanochemistry was recently reported by Konnert et al., providing a clean procedure with high yields and easy workup. ${ }^{149}$

Copper-catalyzed coupling reactions of allenyl ${ }^{215}$ or aryl ${ }^{216}$ iodides and hydantoins were reported, as well as rutheniumcatalyzed hydroamidation of alkynes. ${ }^{217,218}$ Demmer et al. recently reported the synthesis of $\mathrm{N}$-1-allenyl-hydantoins by a copper-catalyzed coupling reaction involving propargylic bromides. ${ }^{219}$ Hydantoin-containing macrocycles such as crown ethers ${ }^{220}$ could be synthesized by double alkylation of phenytoin with oligo(ethylene glycol) diiodide. Macrocyclic bis-hydantoin structures could as well be obtained by metathesis of the allyl $\mathrm{N}-1$ substituents of both hydantoin cores.

Double substitution of hydantoins can as well be obtained with the use of carbodiimides. Their reaction with $\alpha, \beta$-unsaturated carboxylic acids or $\alpha$-bromoaryl acetic acids (Scheme 14) enabled Volonterio et al. to prepare a large variety of 1,3,5trisubstituted hydantoins. ${ }^{221-223}$ The preparation of unsymmetrical carbodiimides widened the scope of possible structures, $^{224}$ incorporating carbohydrates ${ }^{225-227}$ or glycosylamines $^{228}$ as substituents of the hydantoins. However, when $\alpha$ azido esters were used as starting material with various isocyanates, the authors observed that the main product of the reaction was not the expected carbodiimide but the $N$ carbamoyl-hydantoin obtained by the reaction of two equivalents of isocyanate on the $\alpha$-azido esters. ${ }^{229}$ Although the hydantoins showed a loss of enantioselectivity compared to the enantiopure $\alpha$-azido esters, this method was more straightforward than the already existing procedure for the synthesis of $\mathrm{N}$-carbamoylhydantoins. The same strategy was employed for the synthesis of spirohydantoins formed from the carbohydrate derivative sialic acid and various carbodiimides, ${ }^{230}$ as well as for the preparation of benzofuran-3(2H)-one-hydantoin dyads. ${ }^{231,232}$

The $C-5$ position of hydantoins can as well be substituted to obtain 5,5-disubstituted rings, as described by Fernández-Nieto et al., who reported the palladium-catalyzed $C$-arylation of $\alpha$ amino acid-derived 1,3,5-trisubstituted hydantoins. ${ }^{233}$ The reaction afforded the compounds in good to very good yields, using electron-rich and electron-poor aryl iodides, and enabled, after deprotection of the $\mathrm{N}$-positions of the hydantoin ring, to access pharmaceutically relevant molecules, such as phenytoin, or quaternary $\alpha$-amino acids after cleavage in basic medium. Some drawbacks of this reaction would be the need of multiple additives, long reaction times under refluxing toluene, and no enantioselectivity.

\subsection{Use of Isocyanates}

1,3,5-Trisubstituted hydantoins can be synthesized from $\mathrm{N}$ substituted amino acids and alkyl, aryl, ${ }^{234}$ or sulfonyl $l^{235}$ isocyanates. One of the developed methods consists of first the reductive alkylation of the $\mathrm{N}$-terminal moiety of amino acids with an aldehyde in the presence of sodium cyanoborohydride. The obtained $\mathrm{N}$-substituted amino acids then react with substituted isocyanates in the presence of a base to afford the corresponding 1,3,5-trisubstituted hydantoins (Scheme 26). This procedure could be performed on solid phase, ${ }^{236-238}$ as well as with fluorous tagged reactants, that allowed easy purification via FSPE (fluorous solid-phase extraction). ${ }^{239,240}$

Similar methods were described, preparing the $N$-substituted amino acid or nitrile from amination of $\alpha$-bromocarboxylic acids $^{241,242}$ or Strecker reaction, ${ }^{243}$ respectively. $N$-substituted glycine derivatives were also prepared via a PEG-supported solution-phase method performed under microwave irradiation. ${ }^{244}$ A polymer immobilized chloroacetyl ester, resulting from the reaction of chloroacetyl chloride on PEG-6000, was substituted with various primary amines, leading to a polymeric bis- $\mathrm{N}$-substituted glycine ester structure. The amino moiety of each glycine was then reacted with aryl or alkyl isocyanates, and the obtained ureido derivatives were simultaneously cyclized and released from the polymer support to yield the corresponding 1,3-disubstituted hydantoins.

A similar strategy was applied to synthesize a $N, N^{\prime}$ disubstituted urea from an amine and an isocyanate and to react this urea derivative with chloroacetyl chloride to obtain the hydantoin ring. ${ }^{245}$ This procedure was employed by Rmedi et al. to prepare $N$-sulfonylhydantoins. ${ }^{246}$ However, the yields remaining poor, they developed another method to access the desired hydantoins, using $\alpha$-bromoacetamides instead of bromoacetyl bromide. This second method would enable variously substituted hydantoins to be prepared thanks to the versatility of the starting materials.

A method to obtain various 1,3-disubstituted, 5-azasubstituted hydantoins was developed by Attanasi et al. starting from 1,2diaza-1,3-diene esters, primary amines, and isocyanates. ${ }^{247,248} \mathrm{An}$ aza-Michael addition occurred between the 1,2-diaza-1,3-diene 
Scheme 28. Retro Diels-Alder Reaction Leading to 1,3-Dibenzyl-5-ethoxy-hydantoin

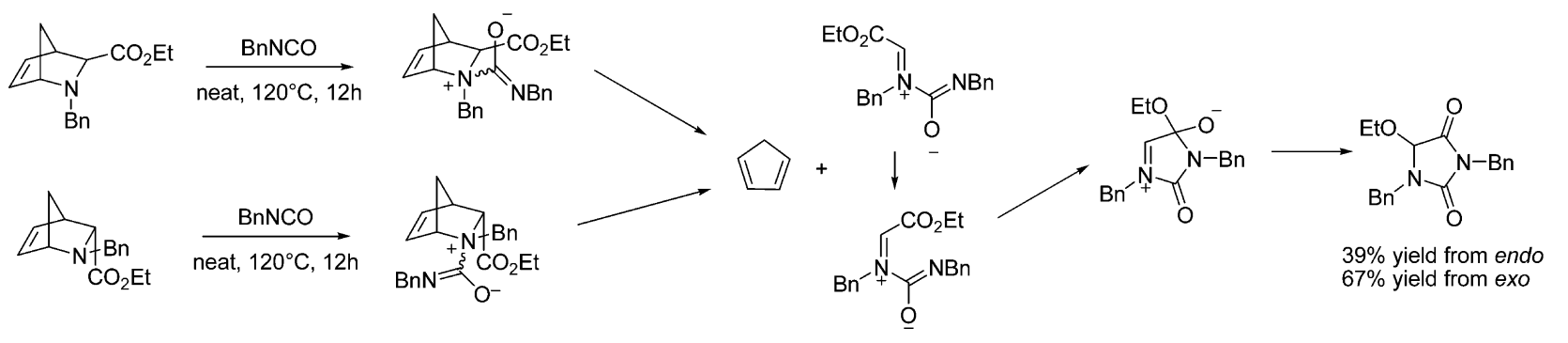

Scheme 29. Trifluoromethylhydantoin from Perfluorodiacetyl and Alkyl Urea

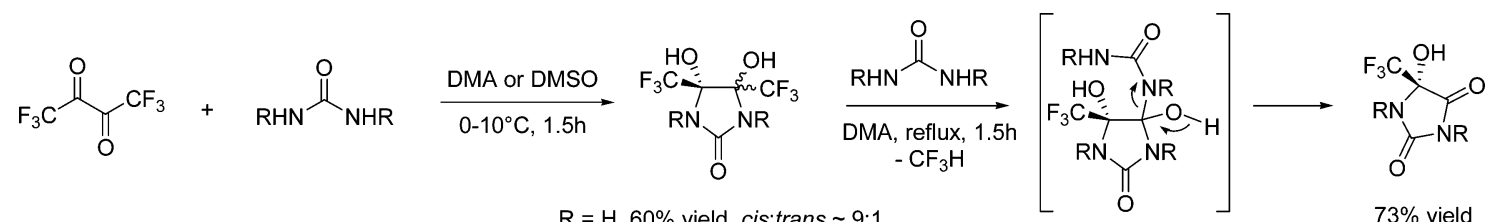

$$
\begin{aligned}
& \mathrm{R}=\mathrm{H}, 60 \% \text { yield, cis:trans } \sim 9: 1 \\
& \begin{array}{l}
\mathrm{R}=\mathrm{Me}, 75 \% \text { yield, cis:trans } \sim 1: 6.5 \\
\mathrm{R}=\mathrm{Et}, 64 \% \text { yield, cis:trans } \sim 36: 64
\end{array}
\end{aligned}
$$

Scheme 30. 1,3,5-Trisubstituted Helix Forming Pseudopeptidic Hydantoins from Ugi Reaction

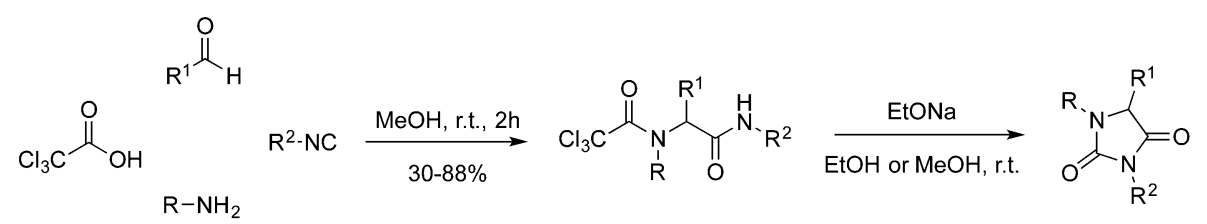

10 examples, $31-89 \%$

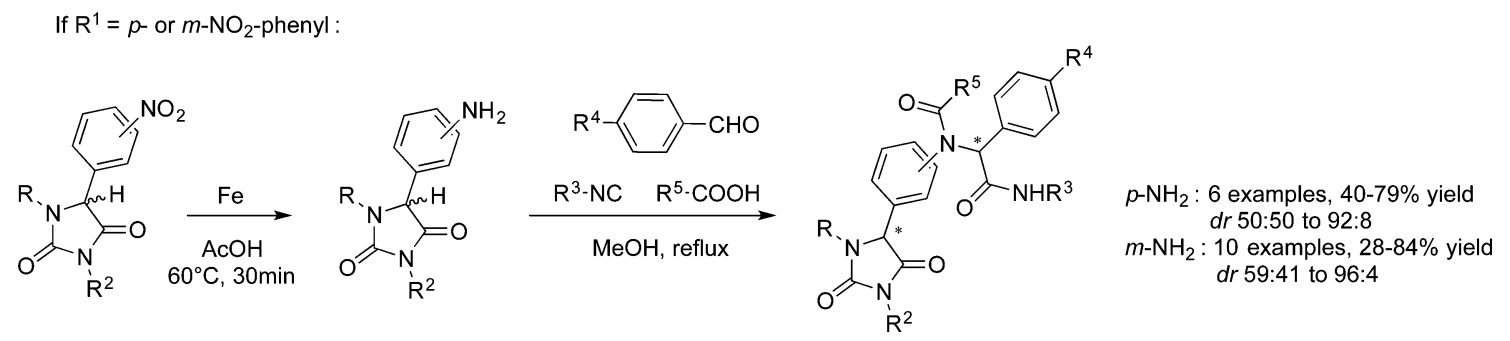

esters and the amines, and the Michael adduct was reacted with isocyanates to yield the desired aza-heterocycles (Scheme 27).

Aranha Potter et al. observed the formation of 1,3-dibenzyl-5ethoxy-hydantoin in the reaction between $\mathrm{N}$-benzyl-2-ethoxycarbonyl-endo- or exo-azanorbornene and benzylisocyanate. ${ }^{249}$ Instead of the expected Claisen rearrangement, a retro DielsAlder reaction took place upon the addition of the isocyanate on the norbornene, leading to the formation of the hydantoin along with liberation of cyclopentadiene (Scheme 28).

Rigby et al. demonstrated that although the formation of 1,3diaryl-5,5-dimethoxyhydantoin occurred from the reaction between dimethoxycarbene and aryl isocyanates, ${ }^{250}$ in the presence of a metal, especially copper catalysts, the reactivity could be switched to the formation of $[4+1]$ cycloadducts. To prepare enantiopure quaternary amino esters, Nique et al. prepared a 5,5-disubstituted hydantoin from para-methoxyphenylethanone following the Bucherer-Bergs reaction. Hydrolysis of the hydantoin and enantiomeric resolution with $(R)-(+)$ or $(S)-(-)-\alpha$-methylbenzylamine afforded the optically pure amino acid derivatives. ${ }^{251}$ Their reaction with aryl isocyanates enabled to access diaryl hydantoins as potent androgen receptor modulators.

\subsection{Use of Urea Derivatives}

$N, N^{\prime}$-Dimethylurea and other dialkyl ureas were used in the formation of 1,3,5,5-tetrasubstituted hydantoins from their reaction with 1,4-enediones. ${ }^{252}$ The originality of the reaction consisted of two consecutive iodine-catalyzed domino processes, the first one being the synthesis of the 1,4-enediones and the second one, in which iodine was regenerated by oxidation, the addition of $N, N^{\prime}$-disubstituted ureas to afford the hydantoins. Ventosa-Andrès et al. studied the cyclization of $\mathrm{N}$ (cyanomethyl)urea derivatives in basic, neutral or acidic conditions. The authors observed that only strong acidic conditions led to the formation of hydantoins, whereas basic, neutral, or even mild acidic treatment afforded the 4-iminoimidazolidin-2-ones. ${ }^{253}$

\subsection{Activation with Carbonyl Donors}

The activation of the amino moiety of amino acid derivatives was also employed for the synthesis of 1,3,5-trisubstituted hydantoins. The reaction of $N$-substituted amino amides with triphosgene, ${ }^{254} \mathrm{CDI},{ }^{255} \mathrm{Boc}_{2} \mathrm{O},{ }^{256}$ or $p$-nitrophenol chloroformate, ${ }^{257}$ which provided the missing carbonyl function of the heterocycle, offered methods of preparation of 1,3,5-trisubstituted hydantoins. This strategy allowed the preparation of a large 
Scheme 31. Synthesis of Tetrazole-hydantoins

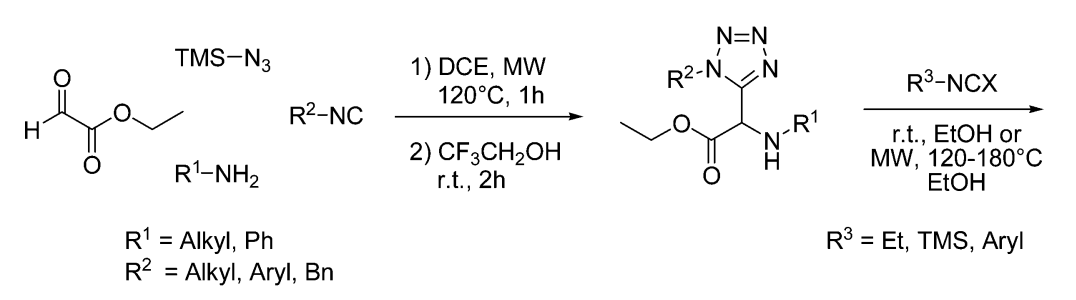<smiles>[X]C1N([R])C(=O)C(c2nnnn2[R])N1[R]</smiles>
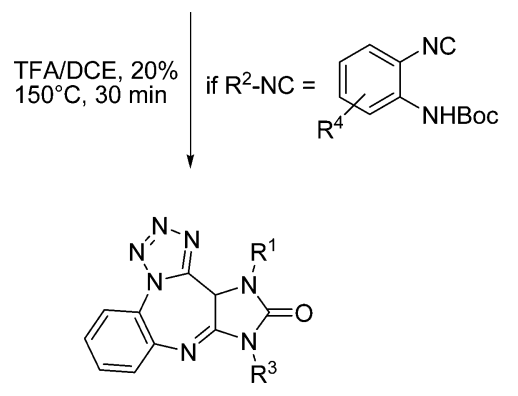

Scheme 32. Preparation of Polyhydantoins by Ugi Condensation
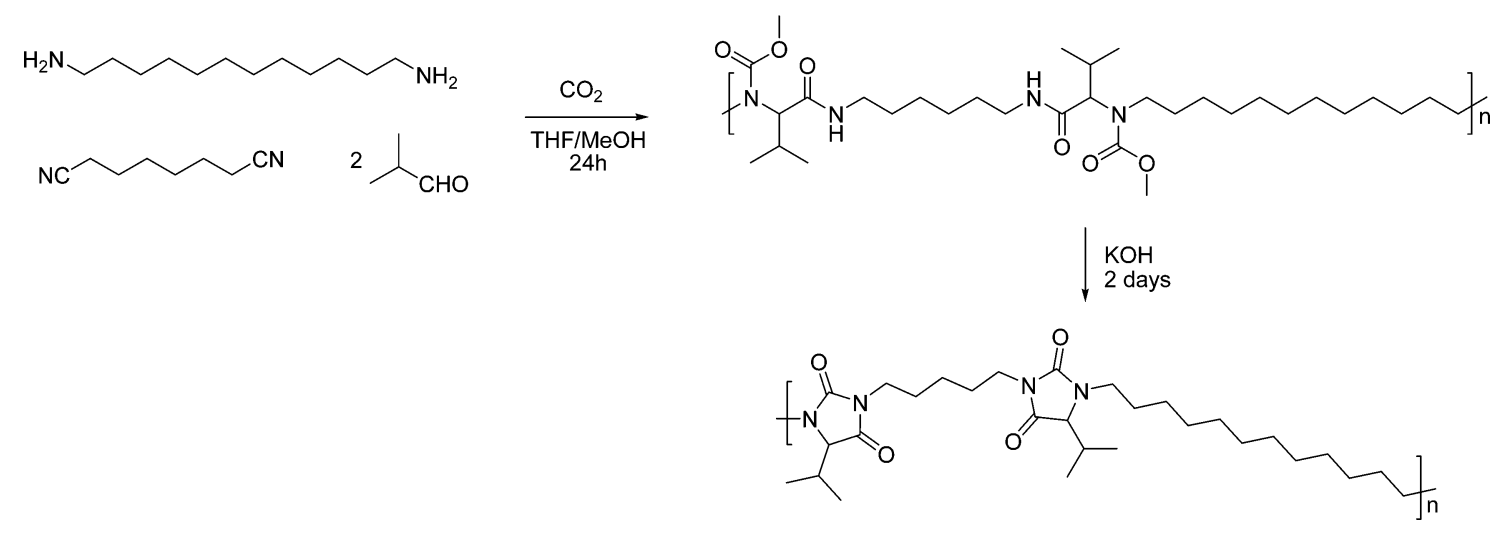

variety of substrates including hydantoin analogues for biological evaluation or as intermediates in the synthesis of heterocycles. Notably, a phenyl-linked hydantoin oligomer was prepared by concomitant cyclization of a triamino amide structure with triphosgene. ${ }^{258}$ This scaffold presented an antiparallel $\beta$-strand conformation for application as a nonpeptido mimetic of protein secondary structures.

Triphosgene was used for the formation of $N, N^{\prime}$-disubstituted ureido derivatives of amino acids in solid-phase synthesis, ${ }^{238}$ while $N$-hydroxyurea derivatives of amino acids were prepared with CDI and spontaneously cyclized into $N$-hydroxyhydantoins. $^{259}$

\subsection{Miscellaneous}

The Biltz reaction between diterpene ureido esters and glyoxal afforded the corresponding hydantoins with high regio- and stereoselectivity. The starting ureido esters were derived from the Lossen rearrangement of $N$-hydroxymaleopimaric acid amide p-toluenesulfonate. ${ }^{260}$ The condensation of urea and dimethyl or diethylurea with perfluorodiacetyl led to the formation of imidazolidines-2-ones which rearranged into trifluoromethylhydantoins upon further reaction with urea (Scheme 29). ${ }^{261}$

A convenient synthesis of 1,3,5-trisubstituted hydantoins via a multicomponent Ugi condensation was described by Ignacio et al. $^{262}$ The Ugi reaction between primary amines, aldehydes, isocyanides, and trichloroacetic acid afforded the corresponding adducts. The enhanced electrophilicity of the trichloroacetamide moiety enabled the cyclization of the adducts into hydantoins in the presence of sodium ethoxide (Scheme 30). The advantages of the method are the possibility of preparing various structures from easily obtainable starting materials, a simple procedure and easy recovery of the products by precipitation off the reaction medium. The same group reported later a Ugi/cyclization/Ugi sequence for the preparation of helix-forming pseudopeptidic hydantoins (Scheme 30). ${ }^{263}$

A modified Ugi reaction, using ethyl glyoxalate as the aldehyde and trimethylsilyl azide as the fourth component of the reaction along with amines and isocyanides, enabled tetrazole Ugi adducts to be accessed with an amino ester structure. The subsequent reaction of these compounds with various isocyanates afforded a versatile library of 1,3-disubstituted 5-tetrazole-hydantoin derivatives, ${ }^{264}$ further leading to the access to imidazotetrazolodiazepinones (Scheme 31). ${ }^{265}$

In their method for the synthesis of benzofuran-2-carboxamides consisting on a Ugi reaction followed by a Rap-Stoermer reaction of salicylaldehydes with the Ugi-adducts, Han et al. obtained 1,3,5-trisubstituted hydantoins as byproducts from the cyclization of these adducts under the reaction conditions. ${ }^{266}$

Sehlinger et al. performed a Ugi five-component condensation from carbon dioxide, methanol, isobutyraldehyde, 1,12-diaminododecane, and hexyl-1,6-diisocyanide to synthesize polymers containing $\mathrm{N}$-alkoxycarbonyl-amino amide units which were 
cyclized into hydantoins in the presence of $\mathrm{KOH}$ so as to obtain polyhydantoins (Scheme 32). ${ }^{267}$

In their attempts to obtain macrocyclic 5-bromouracil derivatives, Nikolaev et al. observed the ring contraction of 5bromouracil into hydantoin or hydroxyhydantoin (Scheme 33). ${ }^{268}$ This rearrangement occurred during the reaction of the

Scheme 33. Formation of Hydantoin and Hydroxyhydantoin from 5-Bromouracil Derivatives<smiles>[R]n1cc(Br)c(=O)n([R])c1=O</smiles>
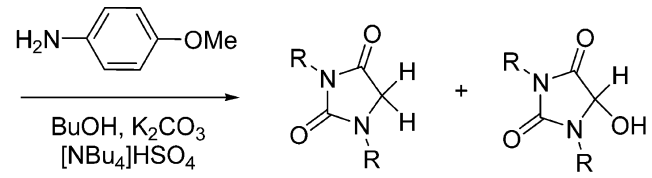

$\mathrm{R}=\mathrm{C}_{5} \mathrm{H}_{11}, \mathrm{Bn}$

5-bromouracil derivatives with para-methoxybenzylamine, leading to hydantoin or hydroxyhydantoin depending on the subsequent oxidation with $\mathrm{O}_{2}$ after the ring contraction.

1-Aryl-3-alkyl-hydantoins were obtained in the tandem $\mathrm{N}$ arylation/cyclization reaction of Boc-glycinamide derivatives. ${ }^{269}$ The palladium-catalyzed reaction afforded the hydantoins in moderate yields, the scope of the reaction being limited to $\mathrm{N}$ alkyl amides (Scheme 34).

The formation of 1,5-bicyclic hydantoins from the cyclization of amino-amide-like structures was observed by Kaschani et al. in their studies on the preparation of syringolins (Scheme 35). They took advantage of this side reaction to prepare hydantoinic compounds that were tested as activity-based probes for glyceraldehyde 3-phosphate dehydrogenases (GAPDH). ${ }^{270}$

\section{ALKYLIDENE HYDANTOINS}

To date, the preparation of 5-alkylidene hydantoins was described by mainly two procedures. Most of the reported protocols rely on a Knoevenagel condensation between the C-5 position of a hydantoin and a carbonyl compound. Procedures in which Wittig-type reactions take place, using 5-phosphorylatedhydantoins, were also described. These two strategies were n

$\mathrm{n}$

$\mathrm{N}-1$ and $\mathrm{N}-3^{. \prime \prime}$ 'Their reactivity toward Diels-Alder, epoxidation, and nucleophilic addition reactions was explored. However, apart from these very used procedures, other methods were reported for the formation of 5-alkyl/arylidene hydantoins, which are referenced in the following sections.

\subsection{Non-substituted 5-Alkyl/Arylidene Hydantoins}

A number of procedures for the synthesis of N-1 and N-3 nonsubstituted 5-alkyl/arylidene hydantoins employed a Knoevenagel-type reaction, starting from hydantoin and a wide range of substituted-aryl aldehydes. This method indeed enabled libraries of analogues to be accessed for the screening of potent bioactive compounds (Scheme 36). ${ }^{272-275}$
Microwave-induced reactions were also reported, ${ }^{38,276}$ and Thirupathi Reddy et al. showed the tremendous advantage of this technology on the condensation reaction, comparing classical heating and microwave conditions that reduced the reaction times from hours to seconds while improving the yields. ${ }^{277}$ The solvent-free, microwave-assisted, boric acid-catalyzed condensation of 4-methoxybenzaldehyde with (thio)hydantoin was also reported, leading to the corresponding benzilidene (thio)hydantoin in moderate to good yields. ${ }^{278}$ A Horner-WadsworthEmmons reaction was described as well using an aryl trifluoromethyl ketone, obtaining the corresponding 5-methylene hydantoin in a $E / Z$ ratio of $2: 1$. $^{279}$

Other original procedures were described for the preparation of such hydantoins. Keiko et al. developed a variant of the Bucherer-Bergs reaction, using cyano-enols, properly 2-alkoxy1-cyanoprop-1-en-1-ols, instead of ketones, which were reacted with ammonium carbonate to afford the 5-(1-alkoxyethylidene)hydantoins. This procedure however yielded byproducts of the reaction and thus implied careful respect of the temperature conditions.

A 2-oxo-furanylidene hydantoin was prepared from the reaction of urea with dimethyl dihydronaphtofuran-2,3-dicarboxylate (Scheme 37). In the presence of sodium ethoxide, the cyclization of the ureido derivative provoked the rearrangement of the dihydrofuran ring into a lactone, keeping the enantioselectivity of the structure unmodified. ${ }^{280}$

\subsection{1-Substituted 5-Alkyl/Arylidene Hydantoins}

As previously described in section 4.1, Carmi et al. prepared 5benzylidene hydantoins by a Knoevenagel condensation performed under MW irradiation (Scheme 38). ${ }^{69,70}$

Pardasani et al. largely studied the Knoevenagel type condensation of hydantoin and 1-methylhydantoin with dicarbonyl compounds such as cyclohexan-1,4-dione ${ }^{281}$ or 9,10-phenanthrenequinone ${ }^{282}$ and notably $\alpha$-dicarbonyl compounds like benzo[ $b]$ thiophene-2,3-dione, acenaphtylene-1,2dione, ${ }^{283}$ or 1,2-naphthoquinone ${ }^{284}$ (Scheme 39). Semiempirical calculations determined that, in all cases, the product of the condensation adopted an anti conformation, because of steric

nitrogen of the hydantoin moiety. Some of the products of these studies were evaluated for their potential bioactivity. ${ }^{282,284}$

Gwynne et al. described an efficient synthesis of boroncontaining arylidene hydantoins. ${ }^{285}$ When the aldehyde function was in ortho position, they observed after the Knoevenagel condensation the formation of a fused azaborine, containing the hydantoin core, deriving from the arylidene hydantoin cyclization by dehydration of the boronic acid moiety (Scheme 40).

A number of other arylidene hydantoin structures via a Knoevenagel condensation were prepared to be tested for their potential bioactivity as inhibitors of zinc metalloprotease

Scheme 34. Palladium-Catalyzed N-Arylation/Cyclization of Glycinamide Derivatives into Hydantoins

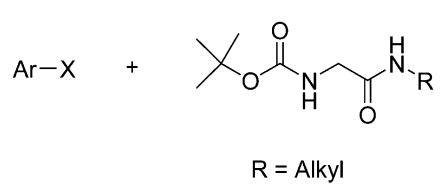

$\mathrm{R}=\mathrm{Alkyl}$

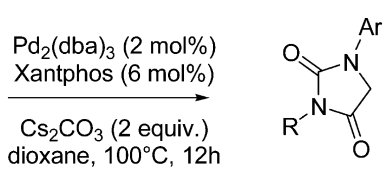

3 examples, $19-40 \%$ yield 
Scheme 35. Formation of a Bicyclic Hydantoin from an Amino-Amide-Like Macrocycle
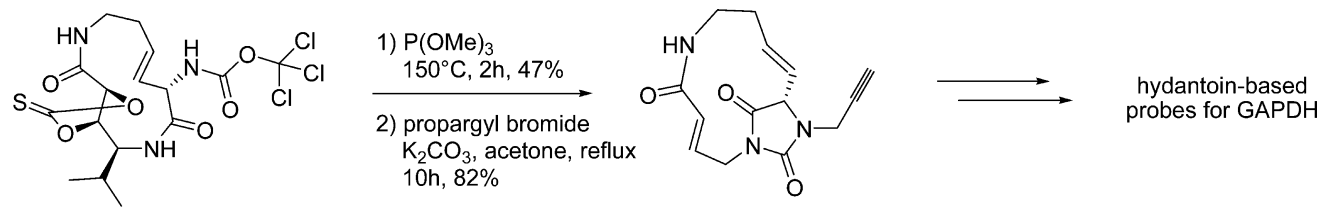

Scheme 36. Knoevenagel Reaction for the Synthesis of 5Arylidene-hydantoins<smiles>O=C1CNC(=O)N1</smiles>

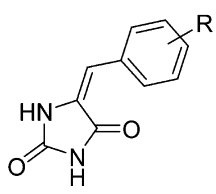

ADAMTS-5, ${ }^{286}$ inhibitors of Pim-1 and Pim-2 protein kinases, ${ }^{287}$ PPAR modulators, ${ }^{288}$ or $\alpha 1$ selective GlyR antagonists. ${ }^{289}$

Chezal et al. prepared imidazo[1,5- $a]$ pyridin-1,3-diones by a Horner-Wadsworth-Emmons reaction between 5(diethylphosphonate)hydantoin and aromatic acetal aldehydes (Scheme 41). ${ }^{290}$ Once the arylidene hydantoin was obtained, the addition of a few drops of aqueous $\mathrm{HCl}$ enabled the intramolecular condensation between the ortho-diethyl acetal function and nitrogen $N-1$ of the hydantoin core, in the case of pyrimidinic compounds. Otherwise, the authors observed the formation of carbamoylpyridine derivatives due to a decarboxylation side reaction. 5-(Diethylphosphonate)hydantoin was also used for the synthesis of potent tubulin inhibitors, ${ }^{291}$ by coupling with a tripeptide aldehyde (Scheme 41) that shows antitumor effects.

\subsection{3-Substituted 5-Alkyl/Arylidene Hydantoins}

Most procedures for the preparation of 3-substituted 5-alkyl/ arylidene hydantoins involve a Knoevenagel-type condensation (as already described above) preceded or followed by a substitution reaction at the N-3 nitrogen of the hydantoin by alkylation with a halogeno derivative or by Mitsunobu reaction with an alcohol (Scheme 42). ${ }^{292-295}$ This protocol enabled notably pyren-1-ylidene hydantoins, ${ }^{296}$ 5-arylidene-3-(4-substituted benzyl)sulfonylhydantoins, ${ }^{297}$ 3-phenethyl-5-furfurylmethylidene hydantoin, ${ }^{298}$ chromophore-containing arylidene hydantoins, ${ }^{299}$ 3-methoxyphenyl-5-(3-bromo-4-hydroxy)-benzylidene hydantoin, ${ }^{300}$ and other 3-acetamide-5-arylidene hydantoin derivatives to be prepared (Figure 7). ${ }^{292,301-303}$

The Wittig reaction was also used instead of the Knoevenagel condensation (Scheme 42). ${ }^{304}$ Horner-Wadsworth-Emmons reaction was used to prepare the marine alkaloid parazoanthine $\mathrm{B}$ and its analogues. ${ }^{305}$ Another strategy consisted in synthesizing the 3-substituted hydantoin via the cyclization of an ureido intermediate and then to perform Knoevenagel condensation to afford the desired hydantoins. The intermediate was prepared from an isocyanate, ${ }^{306}$ commercially available ${ }^{307}$ or generated from the corresponding amine with triphosgene ${ }^{308}$ or oxalyl chloride. $^{309}$

Interestingly, when Hidayat et al. performed the condensation reaction of 3-substituted hydantoins and different benzaldehydes under microwave irradiation, the major products obtained were not the expected benzylhydantoins but the corresponding benzylhydantoin alcohols, underlining the fact that microwave conditions favored the formation of the $\mathrm{C}-\mathrm{C}$ bond but did not accelerated the dehydration step of the reaction. ${ }^{310}$

A Biltz-type reaction was performed for the preparation of 3substituted 5-diethoxymethylidene-hydantoins starting from methyl, phenyl, or benzylureas and diethyl 2-ethoxy-3oxosuccinate (Scheme 43). The hydantoins were then used as intermediates in the synthesis of highly functionalized pyrimidones.

Other procedures allowed the access to various structures. The $[2+2]$ cycloaddition of alkynes and 5-methylidene hydantoins was performed under MW irradiation, affording 5-(substituted)diene hydantoins (Scheme 44). ${ }^{311,312}$

Finally, the oxidation of a 2-ethyl-imidazole derivative afforded the corresponding hydantoin. ${ }^{313}$ Oxidation of thio-derivatives led to the corresponding hydantoins ${ }^{314}$ and served for the preparation of brominated benzylidene hydantoins (Scheme $45) .{ }^{315}$

\subsection{1,3,5-Alkyl/Arylidene Hydantoins}

An interesting procedure consisting of a Wittig reaction was described by Ungören et al. In their method, $N, N^{\prime}$-disubstituted parabanic acids acted as ketones and were condensed with various aryliminophosphoranes to afford 5-iminohydantoins (Scheme 46). ${ }^{316}$ The procedure was both regio- and stereoselective, the $Z$-stereoisomers of the hydantoins being obtained from the reaction.

Again, Knoevenagel-type reaction on 1,3-disubstituted hydantoins were largely described. ${ }^{317,318}$ Among those, $N, N^{\prime}$ disubstituted ureido derivatives, after cyclization into hydantoins in acidic conditions, underwent Knoevenagel-type condensation with Vilsmeier-Haack reagent (dimethylformamide-dimethyl acetal) to obtain a series of aminomethylene hydantoins. ${ }^{319}$ The compounds were synthesized with easily available starting materials such as sarcosine and aniline derivatives and were then coupled to quinolone pharmacophores to afford a series of potential antitumor agents (Scheme 47).

The hydantoin core can as well be synthesized from a Biltztype reaction. Martinez-Lopez et al. designed 1,3-dimethyl-5arylmethylidene-hydantoins from the condensation of dimethyl

Scheme 37. Preparation of a 5-(2-Oxo-furanylidene)-hydantoin

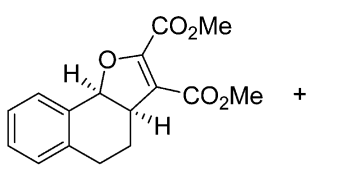<smiles>NC(N)=O</smiles>

$\frac{\mathrm{NaOEt}}{\mathrm{EtOH}, 60^{\circ} \mathrm{C}, 20 \mathrm{~h}}$<smiles>O=C1NC(=O)C(=C2C(=O)OC3c4ccccc4CCC23)N1</smiles> 
Scheme 38. Knoevenagel Condensation at Position C-5

$$
\underset{\text { anh. } \mathrm{CHCl}_{3}, \mathrm{rt}, 2 \mathrm{~h}}{\stackrel{\mathrm{BrCH}_{2} \mathrm{CO}_{2} \mathrm{Et}}{\longrightarrow}} \stackrel{\mathrm{N}}{\mathrm{R}}
$$

Scheme 39. Arylidene Hydantoins from $\alpha$-Dicarbonyl Compounds
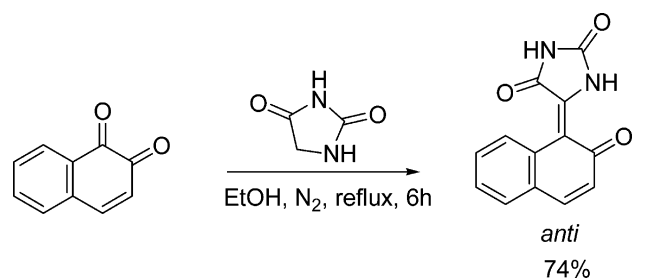

urea and glyoxal and Knoevenagel reaction with several aryl aldehydes. ${ }^{20}$ In all cases, the $E$ isomer was obtained, and the authors studied the photoisomerization into the $Z$ isomers in different conditions, revealing these hydantoin-based compounds as new photoswitches with potent biological and optical applications. The $E / Z$ photoisomerization of 5-arylidenehydantoins was also studied in the case of the formation of hydantoin dyads described by Tahli et al. (cf. section 6.1). ${ }^{232}$ The study showed the existence of an equilibrium between the $E$ and $Z$ stereoisomers in which the $E / Z$ ratio, although always in favor of the most thermodynamically $Z$ isomer, depended on the experimental conditions.

Several other methods implied catalyzed-reactions between alkynes and isocyanates. Alizadeh et al. described a threecomponent reaction, employing substituted benzylamines, arylsulfonylisocyanates, and diverse dialkyl acetylenedicarboxylates that led to 1-arylsulfonyl-3-benzyl-5-methylidene hydantoin derivatives in the presence of isoquinoline in neutral conditions. $^{321}$ Metal-catalyzed reactions were also reported between alkynes and 2 equivalents of isocyanates, with either $\mathrm{Fe}(\mathrm{CO})_{5}^{322}$ or $\mathrm{BrMn}(\mathrm{CO})_{5}^{323}$ as catalysts (Scheme 48).

\section{SPIROHYDANTOINS}

\subsection{5,5-Spirohydantoins}

8.1.1. The Bucherer-Bergs Reaction. In the same manner as the preparation of 5- and 5,5-disubstituted hydantoins, the synthesis of 5,5-spirohydantoins mainly relies on the use of the Bucherer-Bergs reaction, in classical conditions or using microwave technology. ${ }^{36,324-327}$ This method enabled unusual and constrained hydantoin structures to be accessed such as camphor, anthracene, and naphthalene-derived hydantoins. ${ }^{328}$ In turn, these hydantoins can be hydrolyzed into the corresponding amino acids with resolution of the enantiomers, notably by lipase catalysis. $^{329}$ This strategy afforded potent group II mGluR agonists, $^{330,331}$ phosphotyrosyl mimetics to induce a specific conformation in peptides, ${ }^{332}$ or cage-like amino acids that, once incorporated into drugs, would improve its transport through lipophilic membranes. ${ }^{333}$

8.1.2. Reaction with (Iso)cyanates and Urea Derivatives. Pesquet et al. performed the reaction of $\mathrm{N}$-carbamoylisatin and 2-ethyl-2-isothiourea in the presence of triethylamine that led, after heating at $80^{\circ} \mathrm{C}$ with $10 \%$ hydrochloric acid, to the rearrangement of the substrate structure to a spiro(imidazolidinoquinazolinones), a spirohydantoin further derived toward the formation of hydroxyspirolactams (Scheme 49). ${ }^{334}$

\subsection{1-Substituted or 3-Substituted 5-Spirohydantoins}

The reaction between amino nitriles and potassium cyanate was recently reported for the preparation of 1-substituted 5spirohydantoins. The amino nitriles were obtained by Strecker reaction on cyclic ketones. By this protocol, melaninconcentrating hormone receptor-1 (MCH-R1) ${ }^{335}$ and CGRP receptor antagonists ${ }^{336-338}$ were prepared, as well as bioactive compounds in the treatment of tropical diseases (Scheme 50). ${ }^{339}$

Further N-3 alkylation of 1-substituted 5-spirohydantoins obtained following this route enabled structures with antimalarial activity to be accessed. ${ }^{340}$ 3-Substituted 5,5-spiro(pyrrolidinyl)hydantoins were prepared by reaction of methyl 3-amino-1methyl-4-arylpyrrolidine-3-carboxylates with isocyanates. ${ }^{341}$

The quaternary amino ester structure was first synthesized from methyl nitroacetate which underwent a Knoevenagel condensation with aryl phenylimines. 1,3-dipolar cycloaddition with in situ generated azomethine ylide and subsequent reduction with Raney nickel afforded the pyrrolidinyl ring bearing the amino and methyl ester functions. Reaction of this amino ester with diverse isocyanates generated a library of (pyrrolidinyl)hydantoins (Scheme 51).

5,5-Cyclopropanespirohydantoins were synthesized from ethyl $\alpha, \alpha^{\prime}$-cyclopropane-isocyanatoacetate obtained from a Curtius rearrangement of the corresponding acids (Scheme 52). Similarly to the reactions between ethyl isocyanatoacetate and primary amines (see section 5.2), the 3-substituted 5,5-

\section{Scheme 40. Boron-Containing Arylidene Hydantoins}

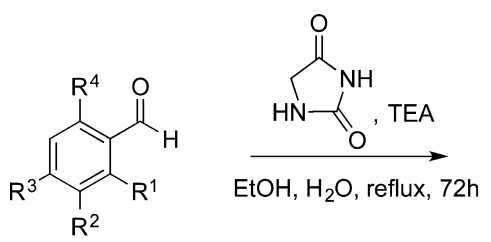

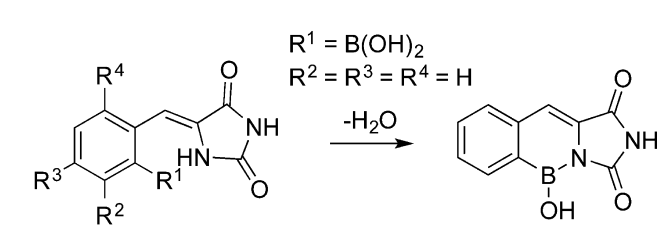

$R^{1}=R^{3}=R^{4}=H, R^{2}=B(O H)_{2}, 85 \%$ 
Scheme 41. Horner-Wadsworth-Emmons Reaction with a Phosphonate-hydantoin

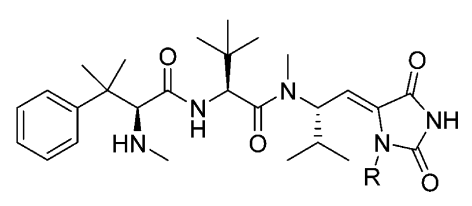<smiles>CNC(C(=O)NC(C(=O)N(C)C(C=O)C(C)C)C(C)(C)C)C(C)(C)c1ccccc1</smiles>

LiOH, EtOH, $\mathrm{H}_{2} \mathrm{O}$

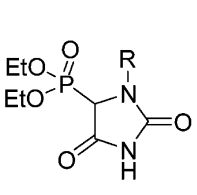

$\mathrm{R}=\mathrm{H}, \mathrm{Me}$
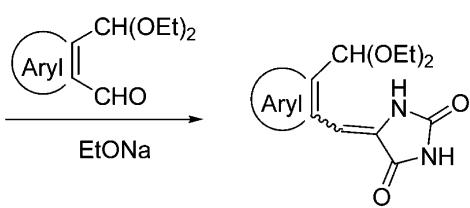

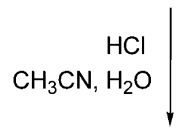

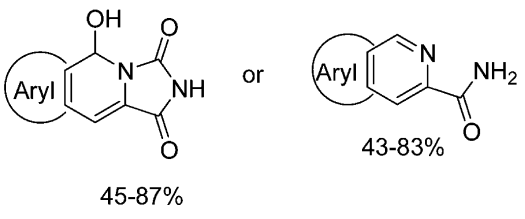

Scheme 42. Strategies to Access 3-Substituted 5-Arylidene Hydantoins

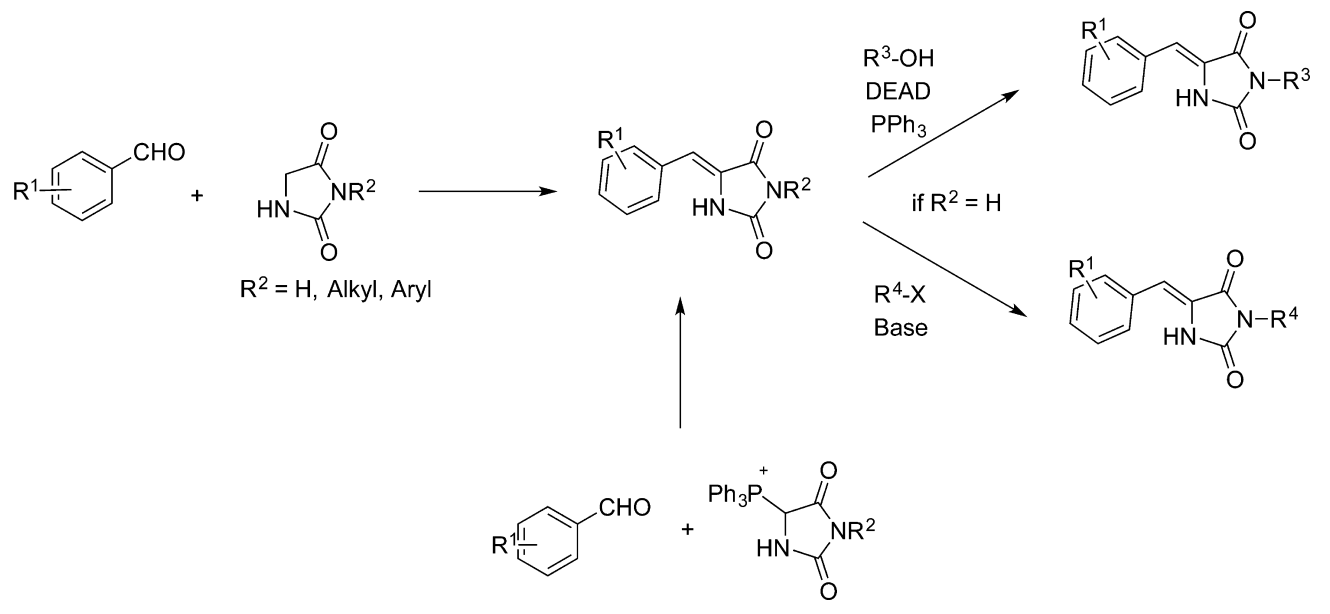

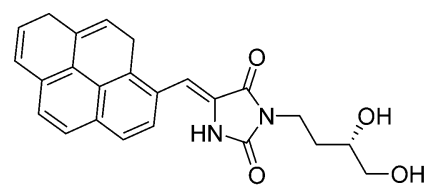

pyren-1-ylidene hydantoin

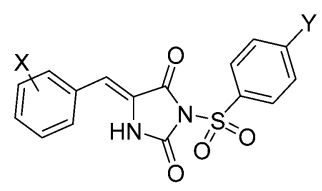

5-arylidene-3-(4-substituted-benzyl)sulfonylhydantoins

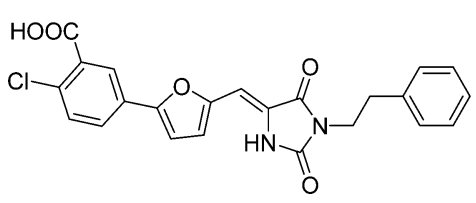

3-phenethyl-5-furfurylmethylidene hydantoin

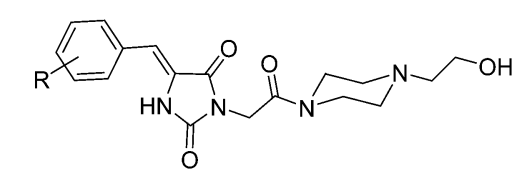

3-acetamide-5-arylidene hydantoins

(3) 3-substituted-5-(6-methylchromen-3-yl)methylene hydantoins

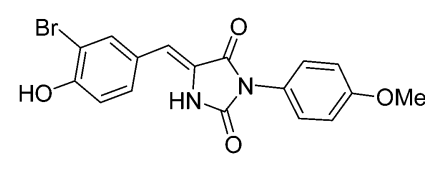

3-methoxyphenyl-5-(3-bromo-4-hydroxy)benzylidene hydantoin

Figure 7. 5-Alkyl/arylidene-hydantoin derivatives prepared by Knoevenagel condensation.

cyclopropanespirohydantoin derivatives were obtained and tested as potent anticonvulsant agents. ${ }^{342}$

\subsection{1,3-Disubstituted 5-Spirohydantoins}

8.3.1. From Methylene Hydantoins. Procedures for the preparation of 1,3-disubstituted 5-spirohydantoins from methylene hydantoins reported since 2004 present a high stereoselectivity and are described in section 12.6 of this review.
8.3.2. From Diverse Substrates. An alternative to the use of methylene hydantoins was to build an $\alpha, \alpha^{\prime}$-cyclic amino acid prior to the formation of the hydantoin ring. Kuster et al. prepared spirohydantoins with substituted cyclohexene as the 5,5-substituent of the hydantoins. ${ }^{343}$ The authors performed a solid-phase synthesis, by anchoring nitroacetic acid on a hydroxymethylene resin. The cyclohexene structure was 
Scheme 43. Biltz-Type Reaction Leading to 3-Substituted 5-Diethoxymethylidene-Hydantoins<smiles>[R]NC(N)=O</smiles><smiles></smiles><smiles>[C-]=C</smiles>

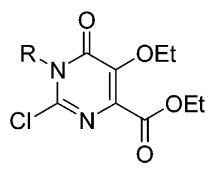

Scheme 44. Microwave-Promoted [2+2] Cycloaddition of Alkynes and 5-Methylidene Hydantoins

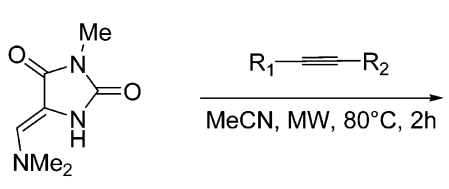<smiles>[R2]C(=CNC)C([R])=C1NC(=O)N(C)C1=O</smiles><smiles>[R]C(=CNC)C([R])=C1NC(=O)N(C)C1=O</smiles>

Scheme 45. Formation of Brominated Benzylidene Hydantoins

$$
\text { Ph }
$$

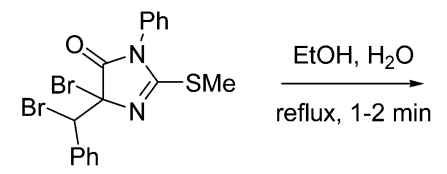<smiles>O=C1N/C(=C(/Br)c2ccccc2)C(=O)N1c1ccccc1</smiles>

Scheme 46. Wittig Reaction of Parabanic Acids and Aryliminophosphoranes

$$
\begin{aligned}
& \mathrm{R}^{1}=\mathrm{Ph}, \mathrm{Me} \\
& \mathrm{R}^{2}=\mathrm{Me}, \mathrm{CH}_{2} \text { COOMe } \\
& \mathrm{Y}=\mathrm{Me}, \mathrm{Br}
\end{aligned}
$$

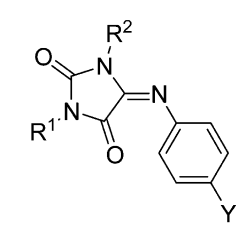

4 examples, $56-75 \%$ yield obtained by a Knoevenagel condensation/Diels-Alder reaction pathway and the nitro group was reduced into the free amino moiety, which reacted with isocyanates to afford after cyclization the corresponding spirohydantoins (Scheme 53).

The preparation of the $N$-substituted $\alpha, \alpha^{\prime}$-cyclic amino acids was achieved by reductive amination of the corresponding $\alpha, \alpha^{\prime}$ cyclic amino acid with aryl aldehydes. The hydantoins were then obtained from their reaction with isocyanates. This method was applied by Schafmeister's group to prepare proline-derived spirohydantoins used as ligands in spiroligomers complexes ${ }^{344}$ or organocatalysts $^{345}$ in the proline-catalyzed asymmetric aldol reaction, showing excellent diastereo- and enantioselectivities.

The reaction between 4-cyanophenyl isocyanate and an amino nitrile (described in section 8.2) was employed by Mehrotra et al., enabling the substitution of $N-3$ position of the desired spiro[4.5] hydantoin that was part of a number of analogous scaffolds evaluated as potent GPIIb-IIIa antagonists. ${ }^{346}$

A 1-isocyanato-2,2'-dimethyl-cyclopropane ethyl ester was reacted with various amines to afford the corresponding urea derivatives and spirohydantoins upon cyclization. The cyclopropanehydantoins were then tested for their anticonvulsant activity. $^{347}$

Patel et al. performed the condensation of unsymmetrical ureas, prepared from amines and isocyanates, with ninhydrin to obtain indeno-[1,2,d]-imidazole intermediates that were then oxidized with $\mathrm{NaIO}_{4}$ to form spiro-(2-benzofuran-5-one)-

\section{Scheme 47. Knoevenagel-Type Condensation of Hydantoins with Vismeier-Haack Reagent}

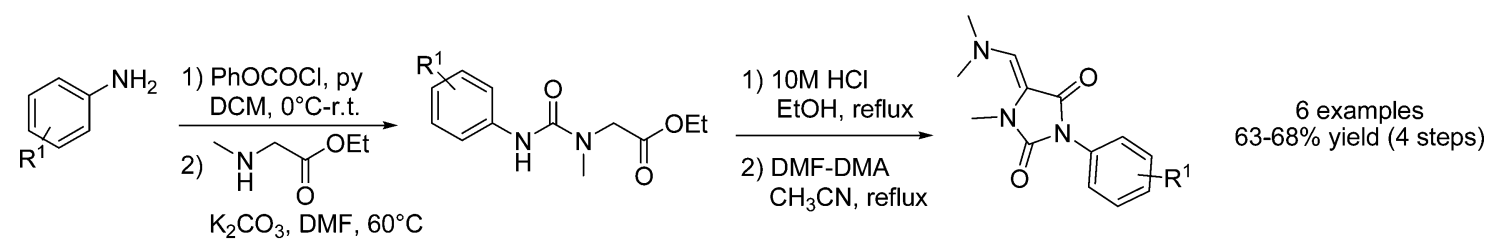

$\mathrm{K}_{2} \mathrm{CO}_{3}, \mathrm{DMF}, 60^{\circ} \mathrm{C}$<smiles>[R]CCCOc1cc2ncc(Oc3ccc(N/C=C4\C(=O)N(c5ccc([R])cc5)C(=O)N4C)cc3F)cc2cc1OC</smiles> 
Scheme 48. Access to 1,3-Disubstituted 5-Alkyl/Arylidene Hydantoins

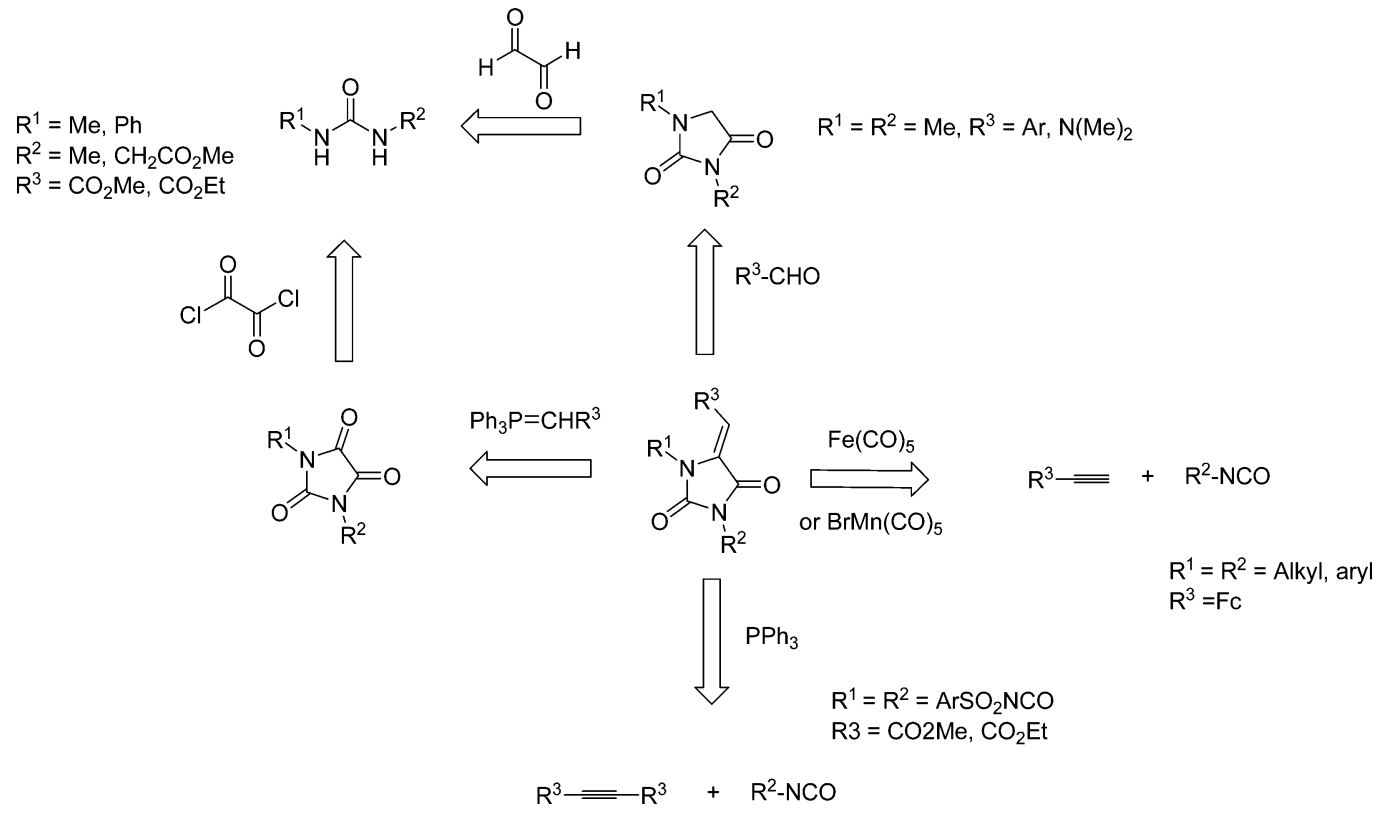

Scheme 49. Preparation of Spiro(imidazolidinoquinazolinones)
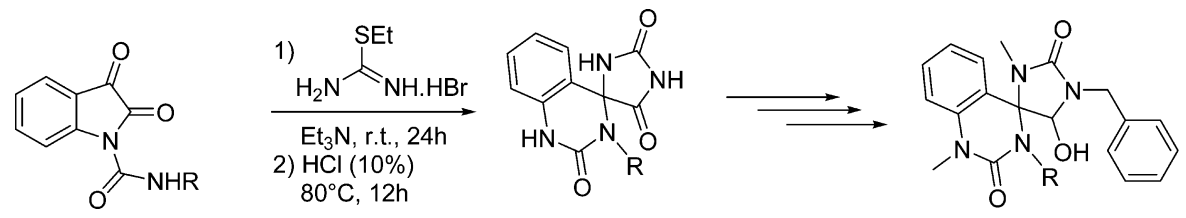

Scheme 50. Spirohydantoins from the Reaction of Amino Nitriles and Isocyanates

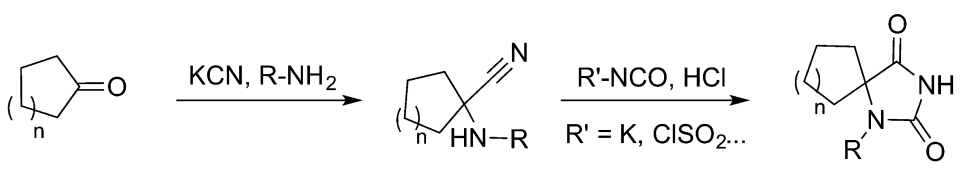<smiles>N#Cc1cccc(-c2ccc(CN3CCC4(CC3)C(=O)NC4=O)cc2)c1</smiles>

$\mathrm{MCH}-\mathrm{R} 1$ antagonist

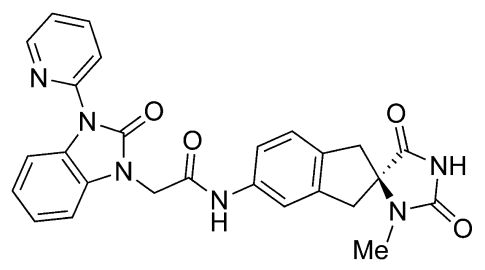

CGRP receptor antagonist hydantoin derivatives (Scheme 54). ${ }^{348}$ The compounds were then tested for their potent anticonvulsant activity.

\section{FUSED HYDANTOINS}

\subsection{1,5-Bicyclic Hydantoins}

In the recent literature, 1,5-bicyclic hydantoins have been prepared following two main pathways. The first one consisted of using proline and its derivatives as starting material. Some methods have already been mentioned in section 5.4 and simply applied to proline. ${ }^{158,181,187}$ Its reaction with isocyanates and eventual further alkylation was one of the synthetic routes of choice for the formation of the corresponding hydantoins. ${ }^{349-353}$
Konnert et al. performed the solventless mechanochemical reaction between proline methyl ester and potassium cyanate. ${ }^{17}$ The corresponding ureido derivative was then cyclized in the presence of potassium carbonate and triethylamine to afford the hydantoin tetrahydro-pyrrol-[1,2,c]-imidazole-1,3-dione in $91 \%$ yield (Scheme 55 ). This route, although in acidic solution, was also used by Delgado et al. to study the X-ray structure of the molecule. $^{354}$

Apart from cyanates, urea is also a reagent of choice for the obtention of bicyclohydantoins from proline. The simple condensation reaction of proline with urea in the presence of sulfuric acid led to tetrahydro-pyrrol-[1,2,c]-imidazole-1,3dione. $^{355}$ The reaction between proline diester derivative and phenyl urea in the presence of an excess of sodium ethoxide 
Scheme 51. Multistep Synthesis of 3-Substituted 5,5-Spiro(pyrrolidinyl)hydantoins

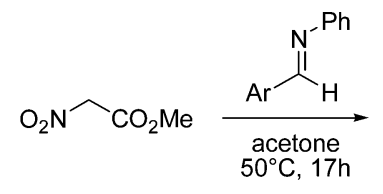<smiles>COC(=O)C(=CBr)[N+](=O)[O-]</smiles><smiles>COC(=O)C1([N+](=O)[O-])CN(C)C[C@H]1[Te]</smiles>

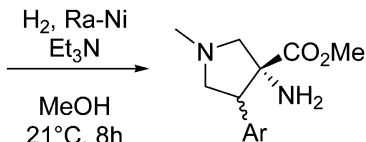

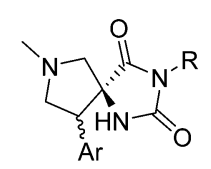

Scheme 52. 3-Substituted 5,5-Cyclopropanespirohydantoin from the Corresponding Cyclopropane-Isocyanatoacetate
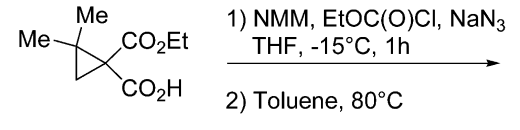

$\mathrm{Me} \downarrow_{\mathrm{NCO}}^{\mathrm{Me}}$

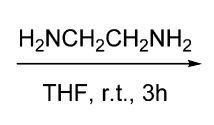<smiles>CC1(C)CC12NC(=O)N(CCN)C2=O</smiles>

Scheme 53. Preparation of a Library of 3-Substituted 5,5-Cyclohexen-spirohydantoins

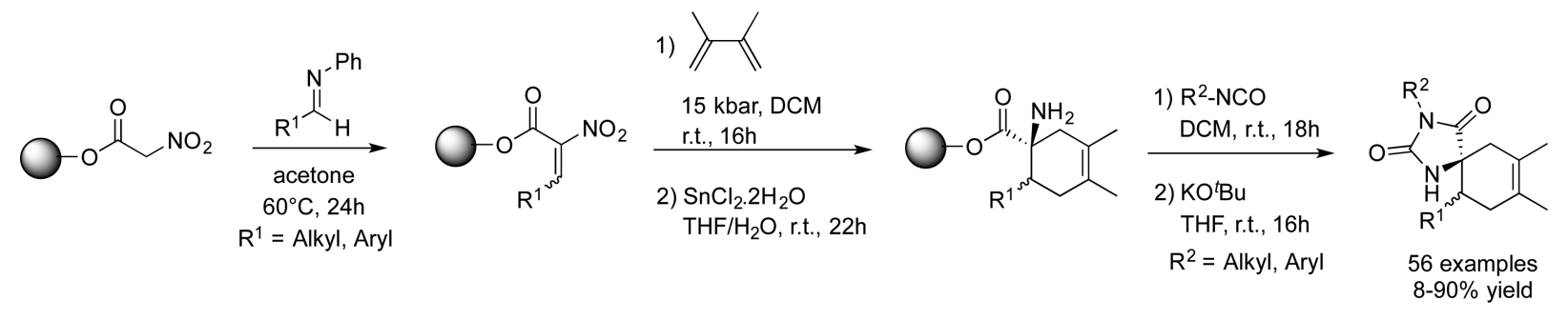

Scheme 54. Synthesis of Spiro-(2-benzofuran-5-one) Hydantoins

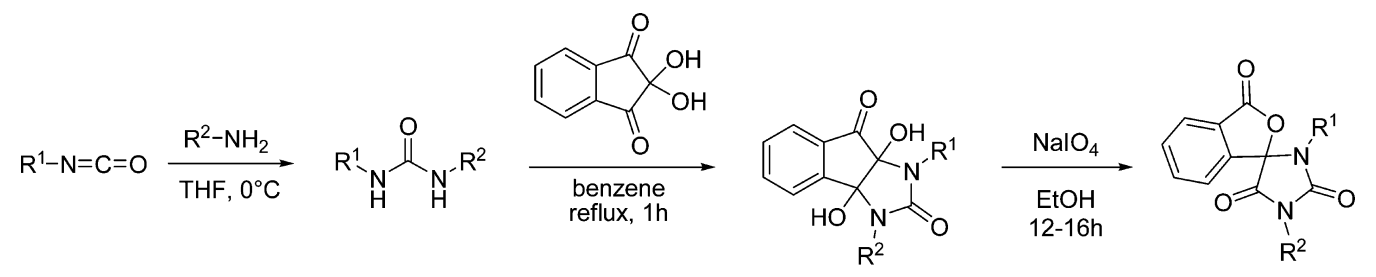

Scheme 55. Mechanochemical Reaction of Proline Methyl Ester and Potassium Cyanate

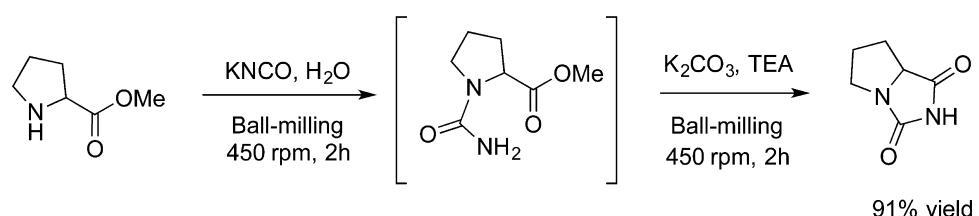

conducted to an aminobarbituric acid-hydantoin rearrangement ${ }^{356}$ to afford the 5-carbamoyl-bicyclohydantoin (Scheme 56). The procedure of Kumar et al. with dibutyl phosphate applied to proline methyl ester also enabled to access the bicyclic hydantoin. ${ }^{87}$

\subsection{Polycyclic Fused 1,3,5-Trisubstituted Hydantoins}

A number of fused polycyclic hydantoins present an interest as biologically active scaffolds and a number of methods were reported for the synthesis of these polycyclic hydantoins. Notably, bioactive structures derive from tetrahydroisoquinoline and tetrahydro- $\beta$-carboline derivatives (Scheme 57).
9.2.1. Tetrahydroisoquinoline Hydantoins. Tricyclic compounds containing a hydantoin moiety were obtained starting from tetrahydroisoquinoline and analogs. The reaction of tetrahydroisoquinoline-3-carboxylic acid ${ }^{357-360}$ or its carboxylate derivatives, ${ }^{357,361}$ which indeed act as an amino acid analogues, and potassium cyanate has been reported. The indole analog was also prepared in the same way. ${ }^{357,359}$ Otherwise, the ureido derivatives could be prepared by $\mathrm{N}$-activation of the tetrahydroisoquinoline ring with CDI or triphosgene and subsequent addition of an amine before their cyclization into hydantoins (Scheme 57). ${ }^{362-364}$ 
Scheme 56. Aminobarbituric Rearrangement Leading to 5-Carbamoyl-bicyclohydantoin

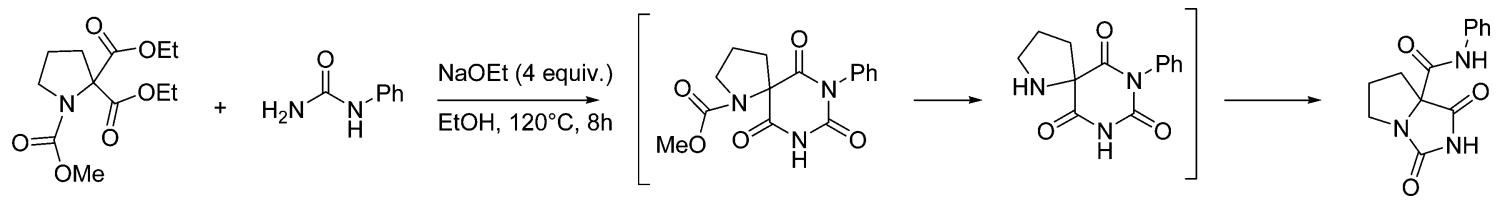

Scheme 57. Retrosynthetic Pathways to Tetrahydro-isoquinoline and $\beta$-Carboline Hydantoins<smiles>[R]NC(=O)C1([R])Cc2ccccc2CN1</smiles>
$\mathrm{R}^{3}-\mathrm{NH}_{2} \Uparrow \begin{gathered}\mathrm{CDI} \\ \text { or } \\ \text { triphosgene }\end{gathered}$

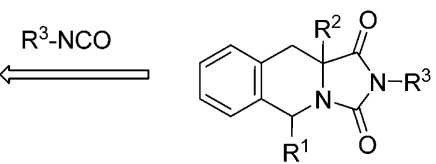

Tetrahydroisoquinoline hydantoins

$$
\begin{aligned}
\mathrm{R}^{2}= & \mathrm{R}=\mathrm{H}, \mathrm{R}^{3}=\mathrm{K} \\
\mathrm{R}^{2}= & \mathrm{NMe} \\
\mathrm{R}^{3}= & \mathrm{Et}, \mathrm{PhCH}_{2} \mathrm{CH}_{2}, \mathrm{EtO}_{2} \mathrm{CCH}_{2} \mathrm{CH}_{2}, \\
& \mathrm{Ph}, 4-\mathrm{EtOC}_{6} \mathrm{H}_{4}, 4-\mathrm{CF}_{3} \mathrm{C}_{6} \mathrm{H}_{4}, \\
& 3-\mathrm{CNC}_{6} \mathrm{H}_{4}, 2 \text {-thienyl, 3-Py }
\end{aligned}
$$<smiles>NC(Cc1c[nH]c2ccccc12)C(=O)O</smiles>
$\mathrm{R}^{3}=\mathrm{H}, \mathrm{Bn}$ Pictet-Spengler $\Uparrow \mathrm{R}^{1}-\mathrm{CHO}$<smiles>[R10]C1c2c(c3ccccc3n2[R])CC2C(=O)N([R])C(=O)N21</smiles><smiles>[R]C1NC(C(=O)O)Cc2c1[nH]c1ccccc21</smiles>

Tetrahydro- $\beta$-carboline hydantoins<smiles>COc1ccccc1</smiles><smiles>[R]n1c2c(c3ccccc31)CCN(C(=O)Oc1ccccc1)C2([R])C</smiles>

$\mathrm{R}^{1}=\mathrm{Ph}$

9.2.2. Tetrahydro- $\beta$-carboline Hydantoins. Like tetrahydroisoquinoline-hydantoins, tetrahydro- $\beta$-carboline hydantoins were mainly prepared from isocyanates and carboxylic derivatives of tetrahydro- $\beta$-carbolines. These precursors were synthesized by a Pictet-Spengler reaction from tryptophane, that enabled to access a large variety of structures due to the use of various aldehydes and ketones (Scheme 57). ${ }^{361,365-367}$ Besides, alternatives to the classical solution-phase synthesis were developed, such as microwave-induced procedures, ${ }^{368-370}$ PEG-supported synthesis, ${ }^{370,371}$ and the use of ionic liquids as a reaction medium. ${ }^{372}$ Hydrolysis of tetrahydroisoquinoline and tetrahydro- $\beta$-carboline cyano-derivatives in the presence of $\mathrm{LiOH}$ and $\mathrm{H}_{2} \mathrm{O}_{2}$ afforded tricyclic structures containing a hydantoin moiety (Scheme 57). ${ }^{373,374}$

9.2.3. Miscellaneous. Diverse fused compounds were obtained by cyclization of ureido or amino amide derivative structures, such as thiazolidine, morpholine, triazoline-, pyrrole-, or indole-containing hydantoins (Figure 8). The reaction of ethyl isocyanate on a proline-like substrate was also reported. ${ }^{375}$ Indole-hydantoins were also obtained by $\mathrm{Cu}$-catalyzed intramolecular cyclization of haloarylidene hydantoins, obtained from Knoevenagel condensation of hydantoin and aryl aldehydes. ${ }^{293}$<smiles>[R]C1SCC2C(=O)N([R])C(=O)N12</smiles><smiles>[R]C1=CC2(C)C(=O)C([R])=C1C2n1c(=O)n([R])n(C)c1=O</smiles><smiles>[R]N1C(=O)N2C[C@H]([2H])O[C@H](CO)[C@]2([R])C1=O</smiles>

Figure 8. Examples of fused hydantoins.
Firth et al. prepared a large library of bicyclic hydantoins via a three-component Ugi-Joullie reaction, followed by the cyclization of the obtained amino amide structures (Scheme 58). ${ }^{376}$

\section{AMINOHYDANTOINS}

\subsection{1-Aminohydantoins}

An important class of hydantoins consists of the derivatives of 1aminohydantoin. The compounds are usually prepared from 1aminohydantoin hydrochloride, which synthesis on solidsupport has been described recently (Scheme 59), ${ }^{377}$ and the aldehyde or ketone corresponding to the desired substitution on the hydrazide moiety. ${ }^{378-381}$

By this procedure, Leban et al. prepared proteasome inhibitors from peptide aldehydes and 1-aminohydantoin. ${ }^{382}$ They synthesized a number of compounds by coupling dipeptides with a Weinreb amide of phenylalanine, the resulting tripeptide amide being hydrolyzed to aldehyde by treatment with lithium aluminum hydride (LAH) and reacted with 1-aminohydantoin hydrochloride to afford the desired compounds (Scheme 60).

Dantrolene is a hydantoin-based compound used as a skeletal muscle relaxant for malignant hyperthermia (see section 2). Various derivatives and analogues of this active biomolecule have been synthesized in recent years. ${ }^{383}$ A diazido-functionalized analogue was prepared by Hosoya et al. following the procedure described above to synthesize a photolabeling probe for the inhibition of physiological $\mathrm{Ca}^{2+}$ release. ${ }^{384}$ An analogue containing a fluorescein moiety was prepared and used as a PET probe for imaging the hERG potassium channel. ${ }^{385}$ Kumata et al. designed $\left[{ }^{13} \mathrm{~N}\right]$ dantrolene as a PET probe for imaging the 
Scheme 58. Three-Component Ugi-Joullié Reaction

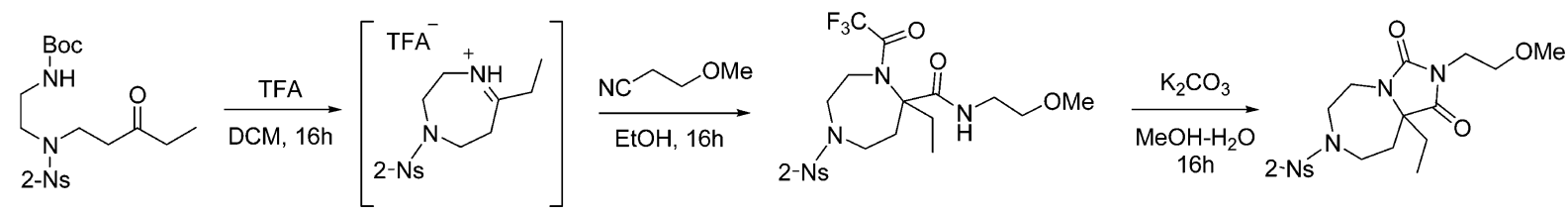

Scheme 59. Solid-Phase Synthesis of 1-Aminohydantoin and Its Subsequent Condensation with Carbonyl Compounds
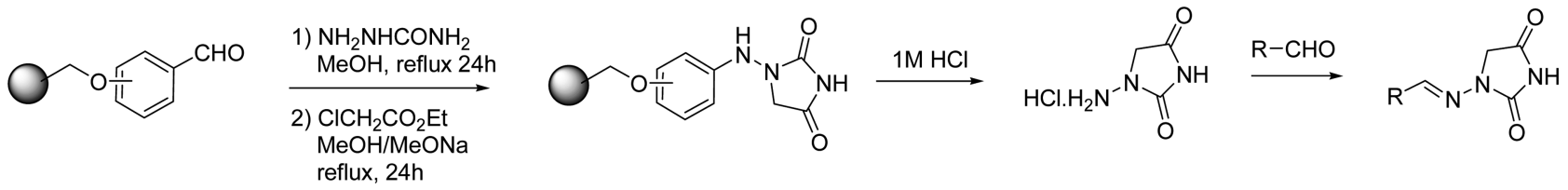

Scheme 60. Hydantoin-Based Proteasome Inhibitors

$$
\text { (2) }
$$

Scheme 61. Synthetic Methods for the Preparation of Dantrolene

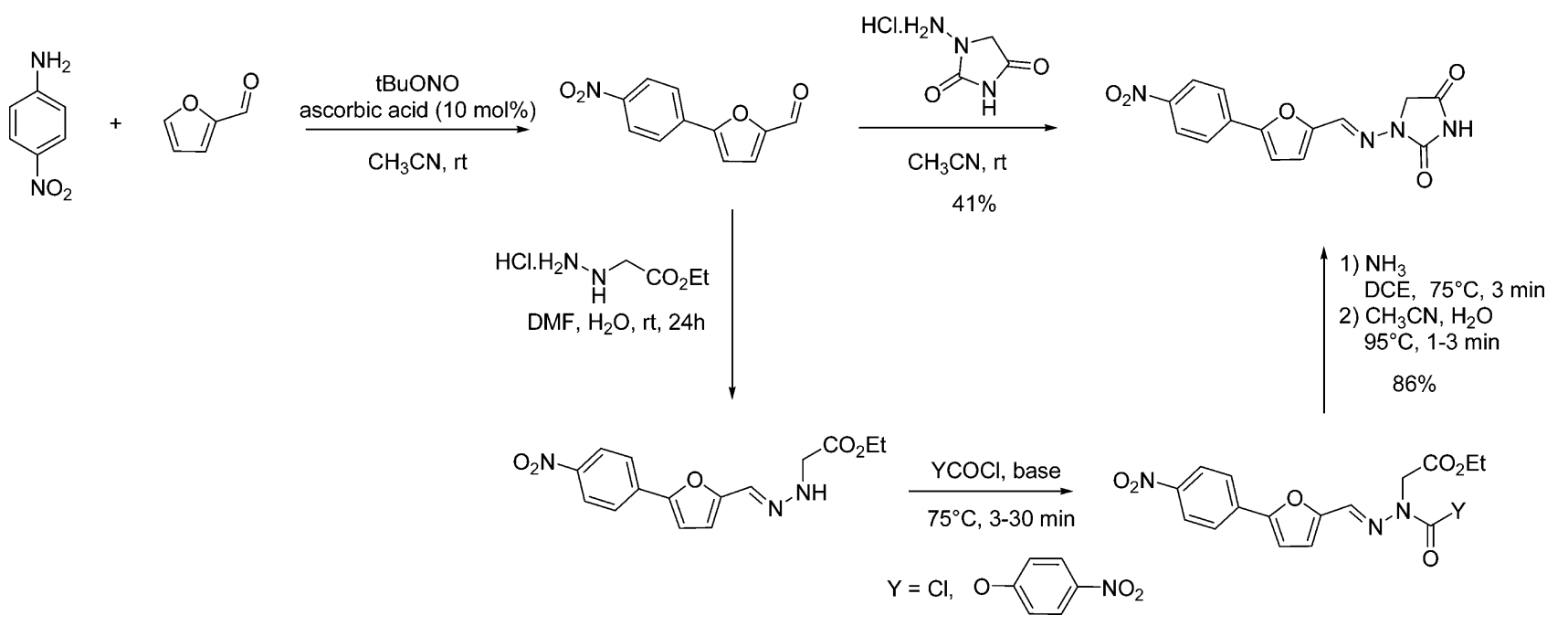

Scheme 62. Tetrakis(N-hydantoinylamido) cavitand $^{a}$

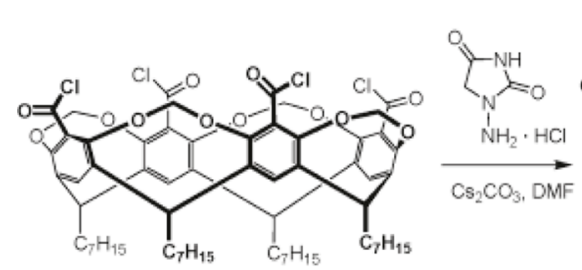

Tetrakis (chlorocarbonyl)cavitand

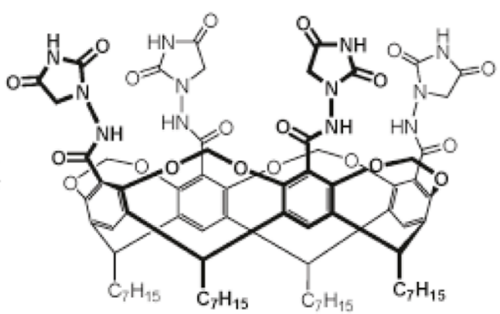

Tetrakis(N-hydantoinylamido)cavitand

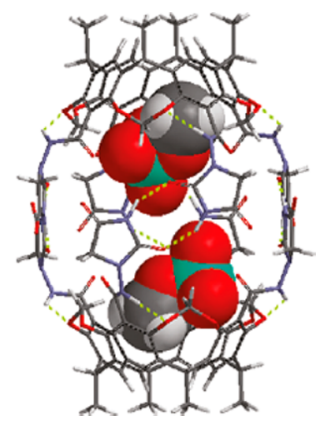

${ }^{a}$ Image reproduced with permission from ref 388. Copyright 2011 American Chemical Society. 
Scheme 63. Preparation of Potent Kv1.5 Potassium Channel Inhibitors<smiles>Cc1ccccc1C=O</smiles>

1) $\mathrm{KOH}$
$\stackrel{\mathrm{EtOH}, \mathrm{H}_{2} \mathrm{O} \text {, reflux }}{\underset{\mathrm{B}}{\mathrm{Br}}}$
2) $\mathrm{Br}\left(\mathrm{CH}_{2}\right)_{\mathrm{n}} \mathrm{Br}, \mathrm{DMF}$
3) $\mathrm{R}_{1}-\mathrm{H}, \mathrm{K}_{2} \mathrm{CO}_{3}, \mathrm{CH}_{3} \mathrm{CN}$

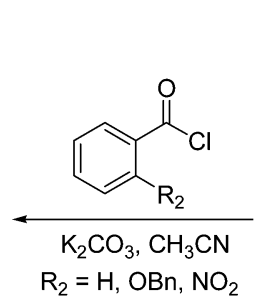

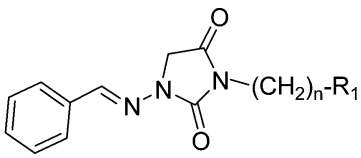

$\downarrow \begin{aligned} & \mathrm{HCl} \\ & \mathrm{H}_{2} \mathrm{O}\end{aligned}$<smiles>[R]CCN1C(=O)CN(NC(=O)c2ccccc2[R2])C1=O</smiles>

$16-67 \%$

Scheme 64. Preparation of 3-Aminohydantoin Analogues of Azumolene
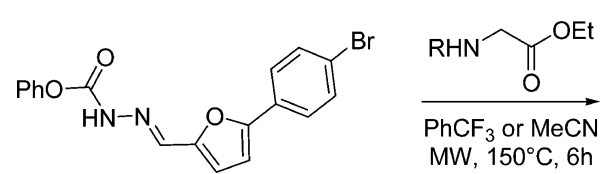

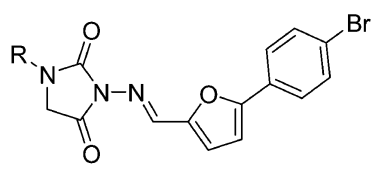

5 examples, $72-97 \%$ yield

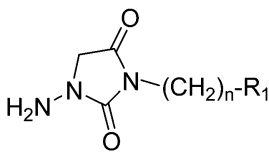

Scheme 65. 1-Substituted 3-Aminohydantoins
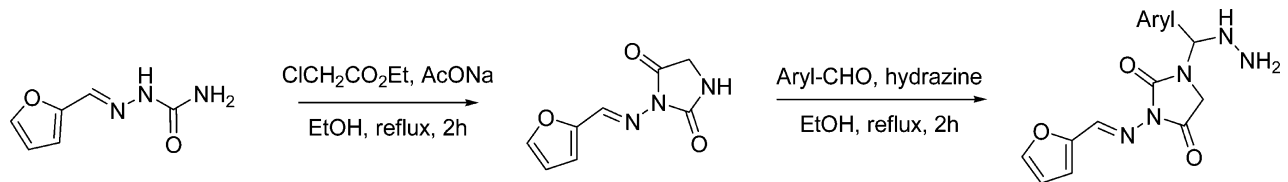

breast cancer resistance protein (BCRP) in the blood-brain barrier. ${ }^{386}$ Instead of starting from 1-aminohydantoin, they used ethyl hydrazinoacetate in the condensation with 5-(4-nitrophenyl)-2-furaldehyde, and the resulting amine was reacted with 4-nitrophenylcarbamoyl chloride or triphosgene to form the corresponding carbamoyl derivative. Ammonolysis with $\left[{ }^{13} \mathrm{~N}\right]$ ammonia afforded the corresponding ureido derivative that then underwent thermal cyclization into hydantoin (Scheme 61).

The synthesis of dantrolene was performed by Crisostomo et al. to illustrate the reaction of $\mathrm{C}-\mathrm{H}$ arylation promoted by ascorbic acid as a radical initiator. Furfural was arylated with 4nitroaniline in the presence of tert-butyl nitrite and ascorbic acid and then coupled to 1-aminohydantoin to afford dantrolene (Scheme 61). 1-Aminohydantoin is the main metabolite of the antibiotic nitrofurantoin. To detect this metabolite, an ELISA method was developed, and an immunogen, CPAHD-JeffamineBSA, was prepared from the condensation reaction of 1-aminohydantoin and 4-carboxybenzaldehyde. ${ }^{387}$

1-Aminohydantoin was recently used for the synthesis of a macromolecular cage for anionic guests like $\mathrm{CH}_{3} \mathrm{OSO}_{3}{ }^{-}$or $\mathrm{BF}_{4}{ }^{-}$. Molecules of 1-aminohydantoins were coupled to the structure tetrakis (chloro-carbonyl)cavitand to form a tetrakis $(\mathrm{N}$ hydantoinylamido)cavitand. ${ }^{388}$ Depending on the solvent and on the anionic guest, this cavitand can form a dimeric complex via hydrogen bonding to form a molecular capsule (Scheme 62).

Potent Kv1.5 potassium channel inhibitors for the atrium fibrillation treatment have been prepared from 1-aminohydantoin. $^{389}$ The structures being 1,3,5-trisubstituted hydantoins, the synthetic route consisted in protecting the amino group with benzaldehyde before alkylating the $N-3$ position of the hydantoin core. After its deprotection, the free amino moiety could be coupled to various acyl chlorides to afford the targeted structures (Scheme 63).

\subsection{3-Aminohydantoins}

An amino substituent on the hydantoin core can also be present on nitrogen N-3. Since 2004, some examples of formation of 3aminohydantoins have been described, following procedures that do not involve the use of amino acid derivatives, as already described in the past. ${ }^{390-392}$ A procedure involving amino esters and in situ generated $\mathrm{N}$-substituted isocyanates has been recently described by Vincent-Rocan et al. The reaction between different amino ester derivatives and several hydrazones and hydrazides, the $\mathrm{N}$-isocyanate precursors, under microwave activation afforded a series of 3-aminohydantoins in good to excellent yields, among those compounds related to the vetenary drug azumolene (Scheme 64), which is itself a more soluble analogue of dantrolene (see sections 2 and 10.1). ${ }^{393}$

Abdul Nasser et al. performed the synthesis of 3-[(2furylmethylene)-amino] hydantoin ${ }^{394}$ and 3-[(1-pyridin-2ylmethylene)amino]hydantoin ${ }^{395}$ by reacting the corresponding aminourea derivatives with ethyl chloroacetate in the presence of fused sodium acetate. The resulting aminohydantoins then underwent a Mannich type condensation on the $\mathrm{N}-1$ nitrogen of the hydantoin moiety (Scheme 65). The obtained compounds were tested for their antimicrobial and antifungal activity. This strategy has also been used by Amin et al. for the synthesis of hydantoin derivatives of spiro $[(2 \mathrm{H}, 3 \mathrm{H})$ quinazoline-2,10cyclohexan]-4(1H)-one with potential anti-inflammatory and analgesic activities. ${ }^{396}$ 
Scheme 66. Rearrangement of Catalytic Hydrogenation of 4-Aminopyrazolidin-3-ones into 3-Aminohydantoins

$$
\text { EtOH, rt }
$$

Scheme 67. Synthesis of Naamidines and Analogues
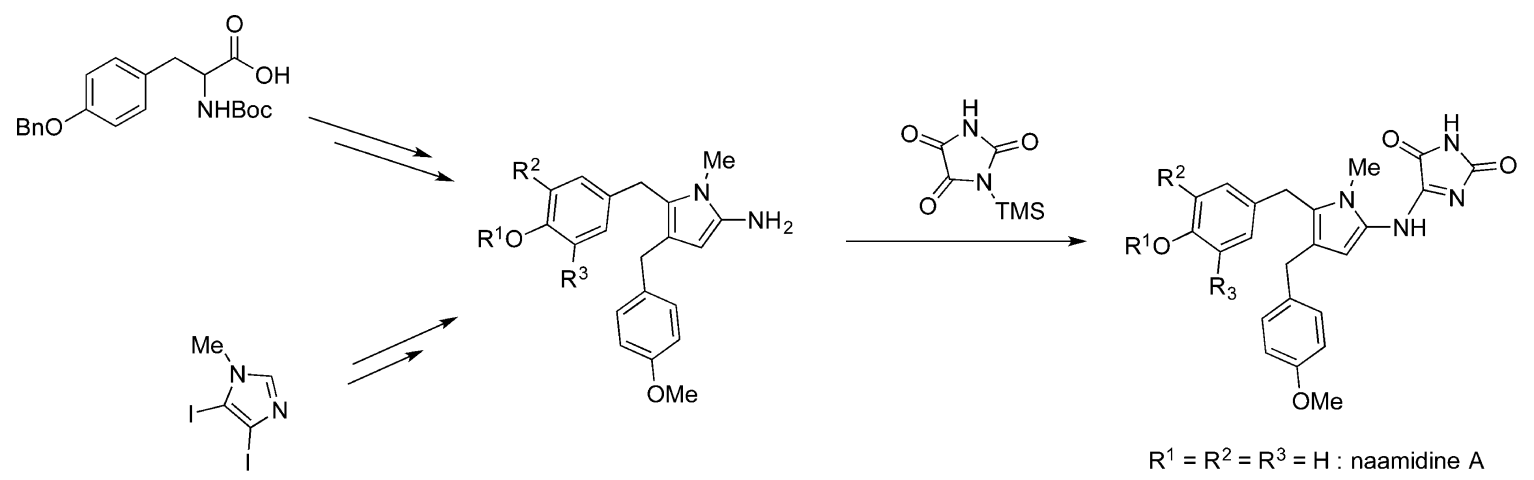

$R^{1}=R^{2}=R^{3}=H$ : naamidine $A$

$R^{1}=M e, R^{2}=R^{3}=H:$ naamidine $G$

$\mathrm{R}^{1}=\mathrm{H}, \mathrm{R}^{2}=\mathrm{R}^{3}=\mathrm{OMe}$ : naamidine $\mathrm{H}$

$\mathrm{R}^{1}=\mathrm{R}^{2}=\mathrm{OMe}, \mathrm{R}^{3}=\mathrm{H}$ : isonaamidine $\mathrm{E}$

Scheme 68. 1,3,5-Triazine Analogues of the Naamidine Core<smiles>CN1C(=O)NC(=O)C1=O</smiles><smiles>O=C1NC(NCc2ccccc2)C(=O)N1[N+](=O)[O-]</smiles>

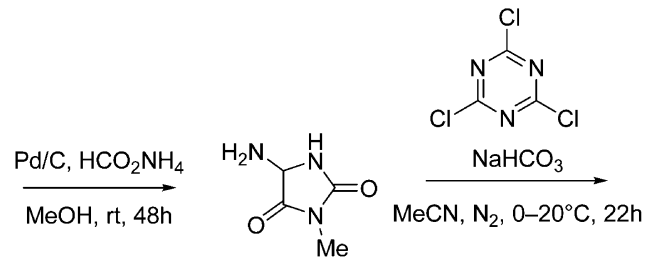<smiles>CN1C(=O)NC(Nc2nc(Cl)nc(Cl)n2)C1=O</smiles><smiles>COc1ccc(Oc2nc(NC3NC(=O)N(C)C3=O)nc(Oc3ccc(OC)cc3)n2)cc1</smiles>

The total synthesis and the biological activity of naamidine A was explored by Aberle et al. The authors described a six-step synthesis starting from Boc- $\mathrm{Tyr}(\mathrm{Bzl})-\mathrm{OH}$ as a cheap and easily available precursor of the 2 -aminoimidazole moiety. ${ }^{399}$ The antitumor activity as well as the structure-activity relationship of naamidine A was studied, notably by the synthesis of thiazole analogues. ${ }^{400}$ The syntheses of clathridine $A^{401}$ as well as other analogs of naamidine $A$ such as naamidine $G$ and 14methoxynaamidine $\mathrm{G},{ }^{402}$ naamidine $\mathrm{H}^{403}$ and isonaamidine $\mathrm{E}^{404}$ were reported by Lovely's group. Their strategy relied on the synthesis of the 2-aminoimidazole moiety by substitution of 1 methyl-4,5-diiodoimidazole, the difference between the analogues being mainly the nature of the substituents on the benzyl ring(s). Another strategy for the preparation of naamidine analogues has been to synthesize 3-methyl-5-aminohydantoin from 3-methylparabanic acid and then to alkylate the free amino function to afford 1,3,5-triazine derivatives of the aminohydantoin (Scheme 68). ${ }^{405}$ 
Scheme 69. Platinum(II) Complexes of Spiro Hydantoins

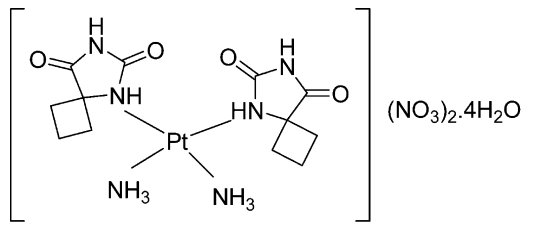

$\mathrm{PtCBH}$

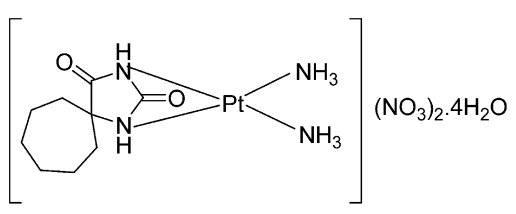

$\mathrm{PtCHTH}$

Scheme 70. Diverse Metallo Complexes of 5-Pyridinyl-Hydantoins<smiles></smiles><smiles>CC1(n2c(=O)[nH]c(=O)n2-c2ccccn2)C(=O)NC(=O)N1c1ccccn1</smiles>

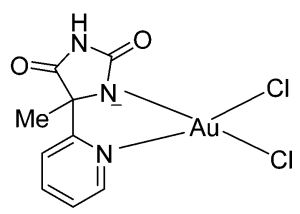

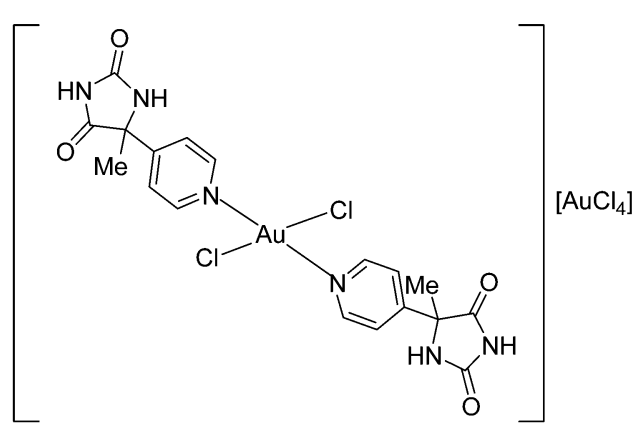

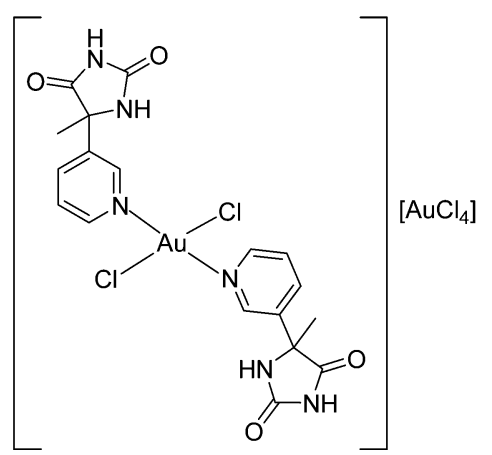

Scheme 71. Stereoselective Bucherer-Bergs Reaction

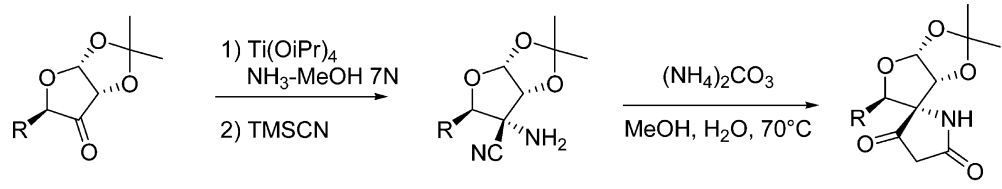

$$
\begin{aligned}
& \mathrm{R}=\mathrm{CH} 2 \mathrm{OBn}, 95 \% \text { yield } \\
& \mathrm{R}=\underbrace{\mathrm{O}}_{0} \xi_{97 \% \text { yield }}
\end{aligned}
$$

\section{HYDANTOINS AS LIGANDS IN ORGANOMETALLIC COMPLEXES}

Hydantoins can complex to various metals to form complexes that present cytotoxic activity. In these complexes, the hydantoins can coordinate to the metal with the nitrogen atoms, and so can adopt mono or bidentate behavior.

As an example, Bakalova et al. synthesized platinum(II) complexes, PtCBH and PtCHTH (Scheme 69), each adopting one or the other coordination pattern. ${ }^{406}$ The same group recently prepared $\mathrm{Pt}(\mathrm{II})$ and $\mathrm{Pt}(\mathrm{IV})$ complexes with 3thiolanespiro-5'-hydantoin and 4-thio- $1 \mathrm{H}$-tetrahydropyranespiro- 5 '-hydantoin as ligands. In this case, the metal ion was coordinated to the sulfur contained in the spiro-compounds, as proved by DFT calculations. ${ }^{407}$

5-Methyl-5'-pyridinyl-hydantoin and its derivatives are widely used ligands for the preparation of platinum(II), palladium(II), ${ }^{408-413}$ gold(III), ${ }^{414}$ and mercury(II) complexes. ${ }^{415,416}$ Depending on the position of the hydantoin core on the pyridinyl ring, 5-methyl-5-pyridylhydantoin could adopt either monodentate or bidentate coordination behavior (Scheme 70).

Silver complexes were also synthesized with hydantoin, 1methylhydantoin, 5,5-dimethylhydantoin, and allantoin. ${ }^{417}$ With the three first hydantoins, the X-ray structure of the complex revealed a coordination of $N-3$ nitrogen of one ring and the oxygens $\mathrm{O}-4$ of two other rings. These complexes were tested and found to be strong cytotoxic agents. In the case of allantoin, the subsequent coordination of the nitrogen of the lateral chain decreased dramatically the activity. 1-Methylhydantoin was also used as a ligand in nickel(III) complexes. ${ }^{418} \mathrm{Hu}$ et al. reported the preparation and X-ray structure analysis of bis(diphenylhydantoin) (ethylenediamine) zinc(II) complex, in which the $\mathrm{Zn}$ atom is coordinated to nitrogens $\mathrm{N}-3$ of both diphenylhydantoins. ${ }^{419} \mathrm{~N}$ - and $\mathrm{C}$-ferrocenyl derivatives of nilutamide were prepared for the evaluation of their antiproliferative and cytotoxic properties. Their syntheses involved the reaction of $\mathrm{N}$-ferrocenyl-amino nitriles with 4-cyano-3-trifluoromethyl-phenylisocyanate and double $N-1$ and C-5 alkylation of 5-ferrocenylhydantoin, respectively. ${ }^{420}$ Other $\mathrm{N}$-ferrocenyl hydantoins were prepared by substituting the $N-3$ position of proline-hydantoin with iodoferrocene. ${ }^{421}$ The synthesis was then efficiently extended to ferrocene bearing electrophilic groups.

Recently, Ahmedova et al. studied the complexation of $\left(9^{\prime}\right.$ fluorene)-spiro-5-hydantoin prepared by the Bucherer-Bergs reaction, with $\mathrm{Cu}(\mathrm{II})$. They showed that in the presence of a strong base, the hydantoin formed complexes with copper as monodentate ligands, coordinating nitrogen $N-3$ to the metal. ${ }^{422}$ 


\section{ASYMMETRIC SYNTHESIS OF HYDANTOINS}

\subsection{5,5-Disubstituted Hydantoins}

12.1.1. Bucherer-Bergs Synthesis. While usual conditions of the Bucherer-Bergs reaction lead to racemic forms of the desired hydantoins, modified reaction conditions were elaborated by Wynands et al. for the synthesis of glycosylhydantoins as precursors of glyco-amino acids (GAAs), used as catalysts for enantioselective aldol reactions. A first step consisting in the Strecker reaction using $\mathrm{Ti}(\mathrm{O} i \mathrm{Pr})_{4}$ stereoselectively afforded the glycosyl $\alpha$-amino nitrile, which was then reacted with ammonium carbonate to yield almost quantitatively the corresponding hydantoins (Scheme 71). ${ }^{27}$

Diastereospecific formation of a camphor-derived 5,5disubstituted hydantoin was observed by Knizhnikov et al. in their study of the Bucherer-Bergs reaction involving $(R)$ (+)-bornane-2,3-dione, or camphorquinone, ${ }^{423}$ implying the regioselective cleavage of its $\mathrm{C}_{2}-\mathrm{C}_{3}$ bond due to the presence of ammonia in the reaction medium (Scheme 72).

Scheme 72. Camphor-Derived Hydantoin from the Bucherer-Bergs Synthesis
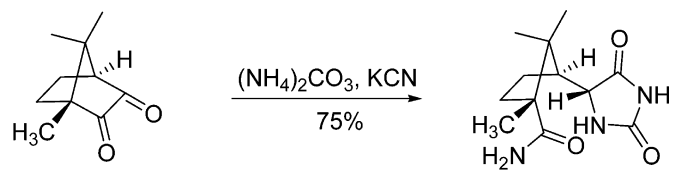

12.1.2. Other Procedures. Miscellaneous procedures for the preparation of 5,5-disubstituted hydantoins relied on the cyclization of an intermediate with a $N$-carbamoyl- $\alpha, \alpha^{\prime}$ disubstituted amino amide structure. This intermediate could be obtained from several starting materials (Scheme 73). Mashiko et al. obtained the amino amide derivative from the La-catalyzed asymmetric $\alpha$-amination of $\alpha$-alkoxycarbonyl amides and subsequent carbamoylation with $p$-nitrophenyl chloroformate. ${ }^{424}$ Girijavallabhan et al. performed the multistep construction of the amino amide intermediate, resulting from the reaction of glyoxylic acid and methyl carbamate and double substitution in the $\alpha$-position of the obtained amino methyl ester that underwent amidification with ammonia. ${ }^{425}$ Finally, Barnwell et al. prepared a phenylglycinol-derived amino nitrile by asymmetric Strecker reaction that underwent a sequence consisting of intramolecular lactonisation, carbamoylation with methyl chloroformate, and amidification with ammonia. ${ }^{426}$ Once the intermediate was formed, it cyclized simultaneously to afford in each case a 5,5-disubstituted hydantoin with a stereogenic center at its $C-5$ position.

\subsection{1,5-Disubstituted Hydantoins}

An enantioselective pathway for the synthesis of 1,5disubstituted hydantoins was proposed by Saravanan et al. The starting imine is subjected to asymmetric Strecker reaction in the presence of a chiral organocatalyst, ${ }^{427}$ and the subsequent nitrile is transformed after hydrolysis to the corresponding hydantoin by the use of triphosgene (Scheme 74).

Etxabe et al. designed an organocatalyzed, enantioselective route to quaternary $\alpha$-amino acid derivatives by the addition reaction of 2-thio- $1 \mathrm{H}$-imidazol-4 $(5 \mathrm{H})$-ones to nitro olefins. The corresponding quaternary adducts were the key intermediates to access the targeted compounds and in particular 1,5disubstituted hydantoins that were easily obtained by hydrolysis of these adducts (Scheme 75).

\subsection{3,5-Substituted Hydantoins}

12.3.1. Alkylation of Position C-5. Fang et al. reported a procedure for the enantioselective hydroamination of allenyl esters. ${ }^{428}$ The reactions were catalyzed with chiral disubstituted thioureas and afforded ethyl 4-(2,5-dioxoimidazolidin-1-yl)pent2-enoate when hydantoin was used as the amine component of the reaction (Scheme 76).

12.3.2. Miscellaneous. Mehra et al. prepared ureido derivatives of cis-3-amino-2-azetidinones by activation of the amino function with phenyl chloroformate and substitution with several amines. ${ }^{429}$ The intramolecular ring opening of the $\beta$ -

\section{Scheme 73. 5,5-Disubstituted Hydantoins from $N$-Carbamoyl- $\alpha, \alpha^{\prime}$-Disubstituted Amino Amide Derivatives}

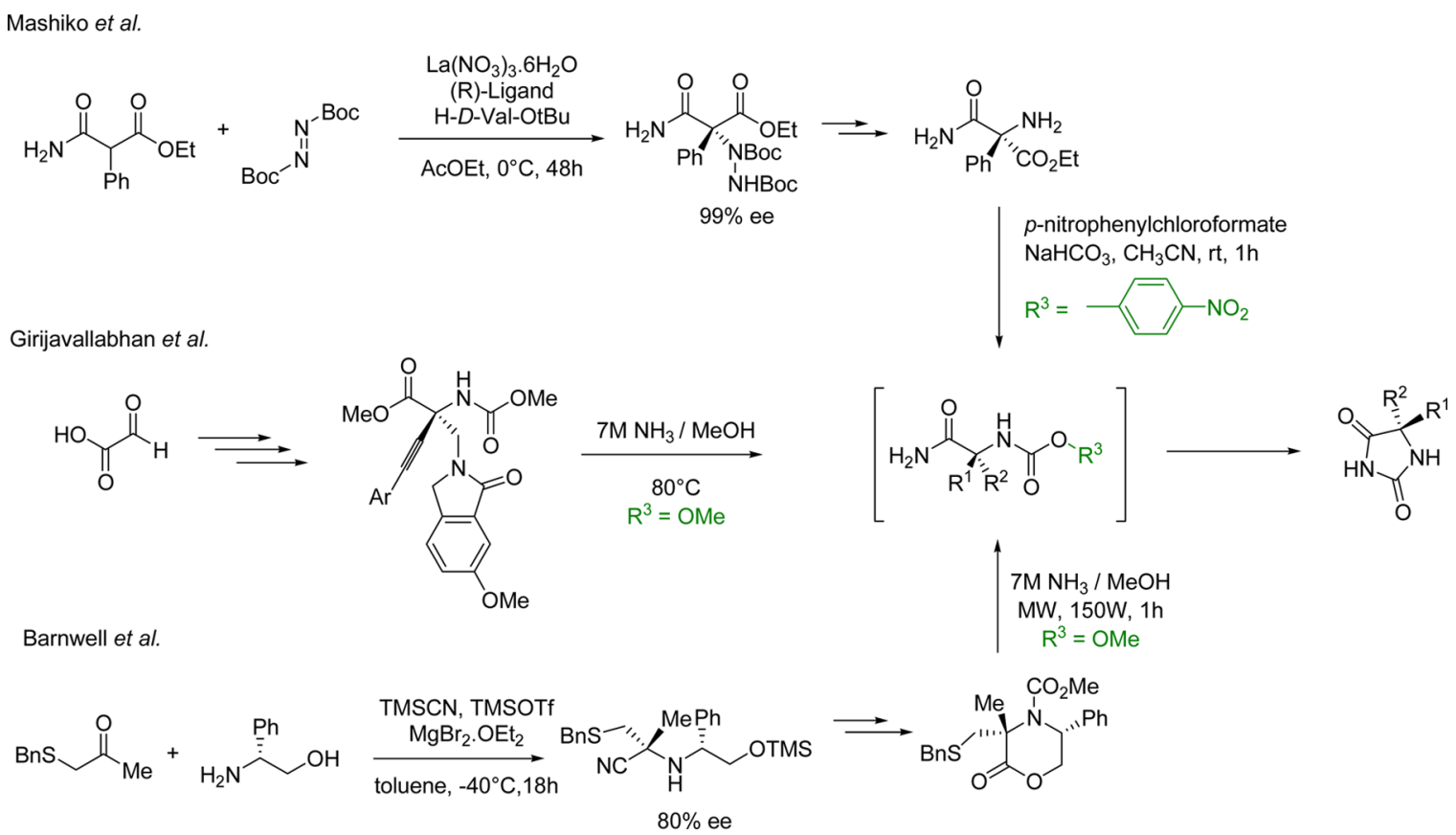


Scheme 74. Asymmetric Strecker Reaction and Subsequent Cyclization into Hydantoin<smiles>C(=N/C(c1ccccc1)c1ccccc1)\c1cccnc1</smiles>

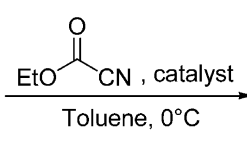<smiles>CC(NC(c1ccccc1)c1ccccc1)c1cccnc1</smiles><smiles>CC(C)(C)[Mg]O[Na]</smiles><smiles>NC(=O)[C@H](NC(c1ccccc1)c1ccccc1)c1cccnc1</smiles><smiles>O=C1NC(=O)N(C(c2ccccc2)c2ccccc2)C1c1ccccc1</smiles><smiles>C[C@H](NC(=O)CNS(=O)C(C)(C)C)c1ccccc1</smiles>

Scheme 75. Enantioselective Synthesis of Hydantoins from 2-Thio-1 $\mathrm{H}$-imidazol-4(5H)-ones<smiles>[R]C=C[N+](=O)[O-]</smiles>

Scheme 76. Substitution of Hydantoins by Hydroamination of Allenyl Esters<smiles>CC=CC(=O)OCC</smiles><smiles>CC(C)[C@H](C)OP</smiles><smiles>CCOC(=CC(C)N1C(=O)NC(C)(C)C1=O)OCC</smiles><smiles>CC(C)(C)[C@H](NC(=S)N[C@H]1CCCC[C@H]1Pc1ccccc1)C(=O)N(Cc1ccccc1)Cc1ccc(-c2ccccc2)cc1</smiles>

lactam by nucleophilic attack of the external nitrogen of the urea moiety afforded the 3,5-disubstituted hydantoins, along with a non-negligible proportion of dimers (Scheme 77).

In their work on the iodine-mediated formation of azetidines from amidomalonate derivatives and enones, Miao et al. performed the addition reaction of 2-(3-phenylureido)malonate and chalcone that led, after optimization of the conditions, to the diastereoselective formation of a 3,5,5-trisubstituted hydantoin (Scheme 78). ${ }^{430}$

\subsection{1,3,5-Trisubstituted Hydantoins}

12.4.1. Use of Isocyanates. A number of published works reported the synthesis of 1,3,5- and 1,3,5,5-substituted hydantoins involving the reaction of various compounds with
Scheme 78. Diastereoselective Synthesis of 3,5,5-

Trisubstituted Hydantoins

$$
\mathrm{Hin}_{\mathrm{Ph}}^{+}
$$

two equivalents of isocyanates to form the hydantoin ring. Alizadeh et al. developed a simple procedure for the synthesis of phosphorus ylides of 1,3-diarylsulfonyl-5,5-disubstituted hydantoins, ${ }^{431,432}$ consisting of the reaction of dialkyl acetylenedicarboxylates with two equivalents of arylsulfonyl isocyanates in the presence of trialkyl phosphites (Scheme 79). This procedure was advantageously easy-to-handle as performed in mild conditions with no need of activation of the reactants.

Gololobov et al. described the formation of 1,3-ditosyl-5,5diethoxycarbonyl-hydantoin from $\beta$-carbonyl sulfonium ylides and tosyl isocyanate. ${ }^{43}$ The specific nucleophilicity of the sulfonium ylide led to the hydantoin, whereas the reaction between iodonium ylides and isocyanates led to the formation of substituted oxazolin-2-ones.

Varying the reaction conditions was also determining for the obtention of hydantoin derivatives, as shown by Boultwood et al. $^{434}$ On the one hand, when aziridinyllithium species were reacted with isocyanates in the presence of $n$-Buli at $-100^{\circ} \mathrm{C}$,

Scheme 77. Intramolecular Ring Opening of $\beta$-Lactam Leading to the Hydantoin Ring
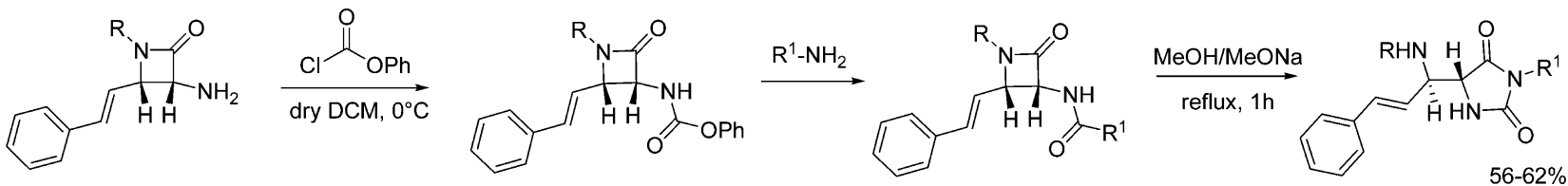
Scheme 79. Diastereoselective Synthesis of Phosphorus Ylides of 1,3,5-Trisubstituted Hydantoins

$$
\begin{array}{ll}
\mathrm{CO}_{2} \mathrm{R}^{\prime} \\
\mathrm{R}=\mathrm{Me}, \mathrm{Et}, \mathrm{R}^{\prime}=\mathrm{Me}, \mathrm{Et} \\
\mathrm{Ar}=\mathrm{C}_{6} \mathrm{H}_{5}, 4-\mathrm{Me}_{6} \mathrm{C}_{6} \mathrm{H}_{4}
\end{array}
$$

Scheme 80. 1,3,5-Trisubstituted Hydantoins from Acylated Aziridines

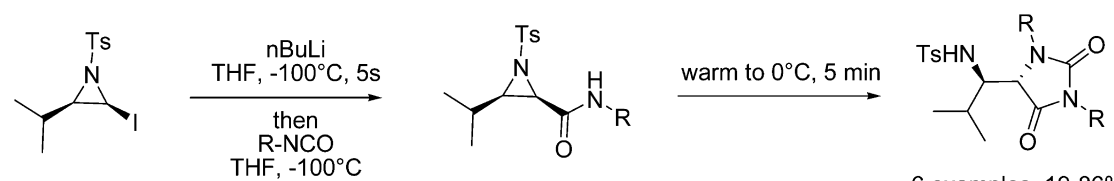

6 examples, $19-86 \%$ yield
single diastereoisomer

Scheme 81. Synthetic Routes to BIRT-377

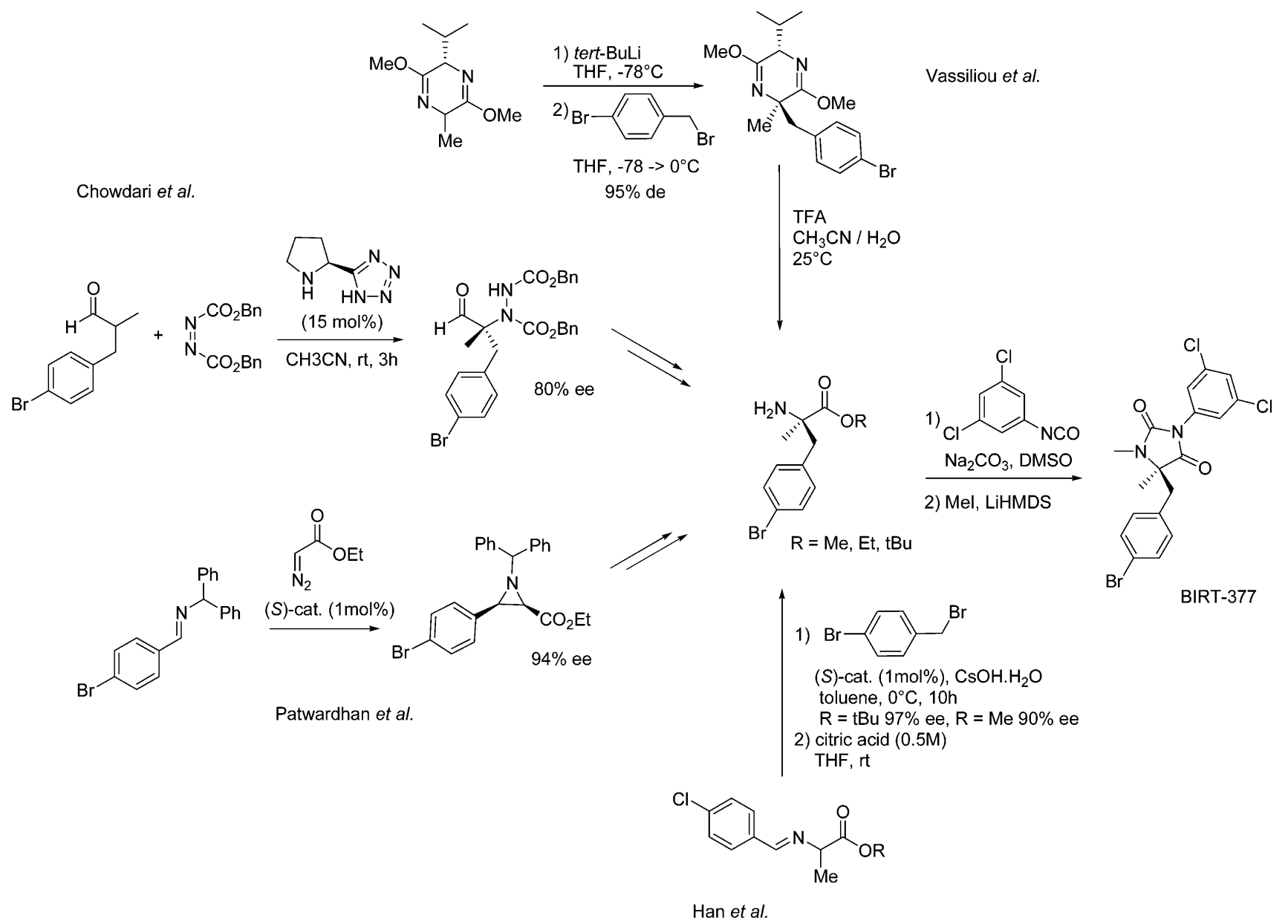

only the acylated aziridine was obtained, whereas warming up the reaction led to the progressive formation of 1,3,5-trisubstituted hydantoins, as the amide anion of the acylated aziridine would react on a second equivalent of isocyanate (Scheme 80).

Metal-catalyzed syntheses of hydantoins from isocyanates were besides described. The Ni-catalyzed formation of 1,3,5trisubstituted hydantoins from acrylates in the presence of two equivalents of aryl isocyanates was reported. ${ }^{435}$ Although tolerating a variety of acrylates, including cyclic 5,6-dihydro-
$2 H$-pyran-2-one, the method was not efficient with alkyl isocyanates. Hill et al. reported the diastereoselective, $\mathrm{Mg}$ catalyzed cascade reaction of four equivalents of isocyanates on phenylacetylene, which yielded to bis(hydantoin) structures. ${ }^{436}$

12.4.2. Synthesis of BIRT-377, Generation of a Chiral Quaternary Center. 1,3,5,5-Tetrasubstituted hydantoins that possess a stereocenter may not be synthesized from the chiral pool and usual amino acids. Much attention has been focused on the synthesis of the LFA-1 antagonist BIRT-377, which can 
Scheme 82. Synthesis of BIRT-377 from Malonic Diester

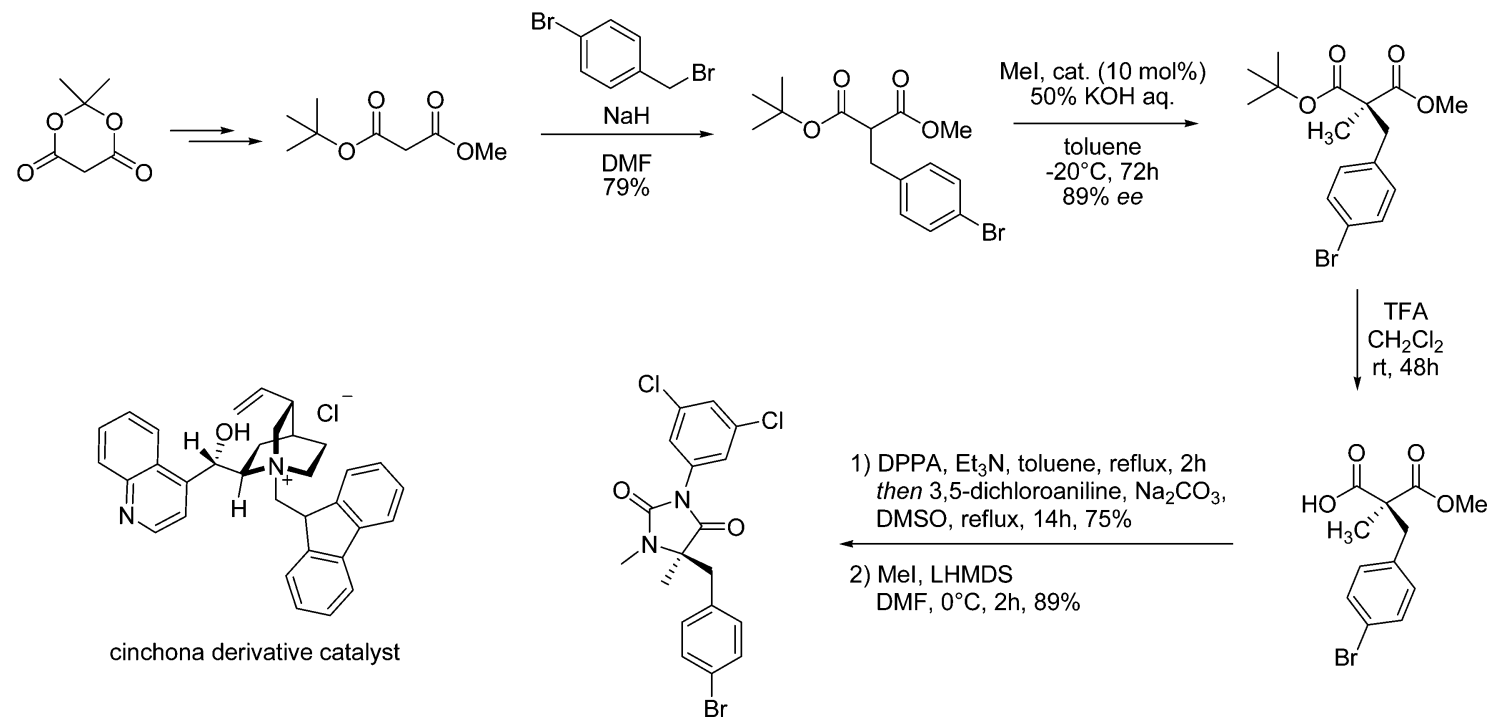

Scheme 83. Intramolecular C-Arylation of Urea Derivatives of Amino Acid Enolates

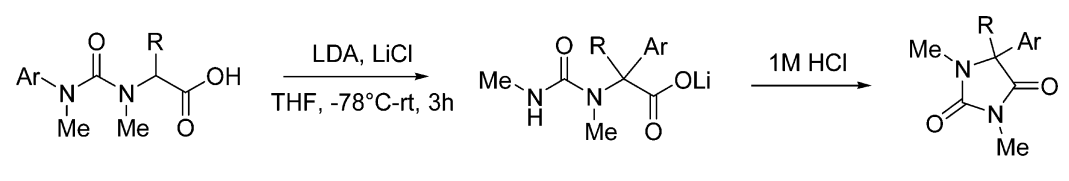

$52-99 \%$

potentially treat several inflammatory and immune diseases, and the synthesis of which needs the generation of a quaternary stereocenter. In recent years, innovative pathways for the synthesis of BIRT-377 have been described, circumventing the usual Seebach's method of self-regeneration of stereocenters ${ }^{437}$ mainly employed until then. In these procedures, the key step is the formation of the quaternary chiral $\alpha$-amino acid derivative, prepared from various starting materials (Scheme 81). Once obtained, the latter was reacted with 3,5-dichlorophenyl isocyanate to afford the hydantoin ring, that was then methylated in position $N-1$ to give BIRT-377.

Starting from 3-(4-bromophenyl)-2-methylpropanal, Chowdari et al. proposed the total synthesis of BIRT-377 in eight steps involving the enantioselective proline-derived tetrazole-catalyzed $\alpha$-amination of the aldehyde that led upon oxidation to the chiral quaternary amino acid ${ }^{438}$ (Scheme 81). Patwardhan et al. applied their method for the diastereoselective alkylation of aziridine-2carboxylate esters to the synthesis of BIRT-377. Methylation and ring opening of (2R,3R)-ethyl 1-benzhydryl-3-(4bromophenyl)aziridine-2-carboxylate enabled the corresponding quaternary enantiopure (>99\%) amino acid to be accessed ${ }^{439}$ (Scheme 81). Han et al. described an efficient synthesis of BIRT377 by generating the chiral quaternary amino acid from $\mathrm{N}$ (para-chloromethylene)-alanine tert-butyl or ethyl ester. ${ }^{440}$ The authors developed a chiral phase-transfer catalyst to perform the asymmetric para-bromobenzoylation of the amino acid derivative and accessed the desired hydantoin in fewer steps than the above procedures (Scheme 81).

Vassiliou et al. proposed to synthesize BIRT-377 by a Schöllkopf-type reaction of construction of enantiopure quaternary amino acids. Alkylation of a bis-lactim ether with para-bromobenzyl bromide after deprotonation with tert-BuLi and subsequent hydrolysis with TFA afforded the enantiopure amino methyl ester. ${ }^{441}$
Recently, Kanemitsu et al. proposed to access BIRT-377 from malonic diesters. ${ }^{442}$ Instead of preparing enantioselectively a quaternary amino acid, they performed the asymmetric methylation of 1-tert-butyl-3-methyl-2-(4-bromobenzyl)-malonate using a cinchona alkaloid derivative as catalyst to obtain the corresponding chiral $\alpha, \alpha$-disubstituted malonic diester (Scheme 82). After selective cleavage of the tert-butyl ester with TFA, the resulting acid moiety was turned into an azide and underwent a Curtius rearrangement to generate the isocyanate. The latter was reacted in one-pot with 3,5-dichloroaniline to form the corresponding urea derivative that cyclized into the hydantoin. Subsequent $N$-1 methylation afforded BIRT-377.

BIRT-377 was also synthesized from the diastereoselective asymmetric desymmetrization of 2-(4-bromobenzyl)-serinol derivative. $^{443}$ The desymmetrization method relied on the diastereoselective formation of a 2-oxazolidinone from serinol followed by reduction to afford the corresponding quaternary chiral amino alcohol. The disadvantage compared to the other methods is that, in this case, a Ru-catalyzed oxidation step must be performed to provoke the cyclization after the addition of the isocyanate.

From a critical point of view, Han's method seems the most interesting for the synthesis of BIRT-377. The starting material and the catalyst are synthezised from commercially available chemicals, i.e., alanine and gallic acid, respectively. The organocatalyzed reaction did not require the highly inflammable $t$-BuLi and the workup was performed with relatively innocuous aqueous citric acid. Moreover, the few steps of the procedure represent an additional advantage compared to the other methods.

12.4.3. Use of Urea Derivatives. Innovative pathways have been reported for the preparation of 1,3,5-trisubstituted hydantoins from urea derivatives. 
Atkinson et al. developed a method relying on the intramolecular $C$-arylation of urea derivatives of amino acid enolates. ${ }^{444}$ The aryl migration was followed by the cyclization of the ureido derivative into hydantoin (Scheme 83). This strategy enabled, from the 1,3,5-substituted 5-aryl hydantoins, to quaternary amino acids to be accessed. Although various quaternary structures can be obtained through this method, the enantioselectivity of the reaction was still to be improved. The authors eventually provided an enantioselective version of their work by using pseudoephedrine as a chiral auxiliary. ${ }^{445} \mathrm{~A}$ similar asymmetric $\alpha$-arylation of urea derivatives of amino acids was besides brought by Tomohara et al., who obtained the chiral hydantoins via a memory of chirality strategy in 55-98\% ee, by generation of axially chiral enolates of the urea derivatives. ${ }^{446}$

The development by Gore et al. of a low-melting mixture of (+)-tartaric acid and $N, N^{\prime}$-dimethylurea (DMU) as a solvent, a catalyst, and a reactant offered environmentally friendly conditions to the diastereoselective formation of $1,3,5$ trisubstituted hydantoins from $\beta, \gamma$-unsaturated ketocarboxylic acids (Scheme 84). ${ }^{447}$

Scheme 84. DMU as Solvent, Catalyst, and Reactant for the Synthesis of Hydantoins
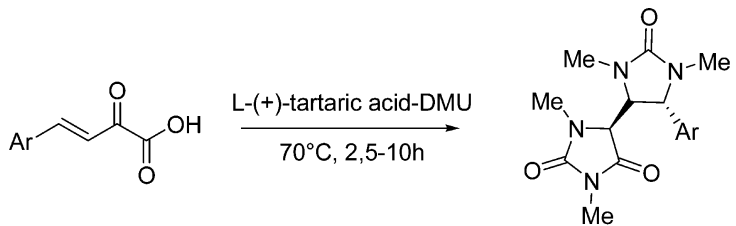

$84-92 \%$

\subsection{5,5-Spirohydantoins}

12.5.1. Bucherer-Bergs Reaction. On their work on the synthesis of functionalized cyclobutanones derivatives, Lumbroso et al. applied the Bucherer-Bergs conditions to (S)-3(benzyloxy)-2,2-dimethylcyclobutanone (Scheme 85) and obtained the corresponding spirohydantoin in a good yield of $77 \%$. The reaction was diastereoselective and afforded the major isomer in a 92:8 d.r. ratio. ${ }^{448}$

Scheme 85. Diastereoselective Bucherer-Bergs Reaction for the Formation of Spirohydantoins
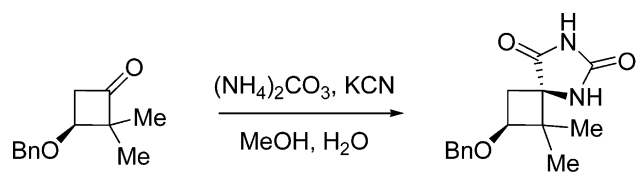

$77 \%$ yield, d.r. $92: 8$

12.5.2. Reaction with Isocyanates and Urea Derivatives. Kato and Liu employed the same strategy to prepare spirohydantoins from amino nitriles and potassium cyanate or chlorosulfonyl isocyanate (see also section 8.2). The two groups described the enantioselective Strecker synthesis of the amino nitriles by asymmetric cyanation of ketoimines. Kato et al. developed a gadolinium-catalyzed system with a D-glucosederived ligand and applied their method to the synthesis of the drug sorbinil, a spirohydantoin with therapeutic effects on chronic complications of diabetes mellitus (Scheme 86). ${ }^{449}$ Liu et al. preferred organocatalysis, using a cinchonidine-derived thiourea catalyst, to perform the same reaction from isatinderived ketoimines ${ }^{450}$ and prepare by this way a spiro- [imidazolidine-4,3'-indole $] 2,2^{\prime}, 5^{\prime}$ - $(1 \mathrm{H})$-trione (Scheme 86 ) which is an inhibitor at the vanilloid receptor 1 (VR1) developed by Astra Zeneca for the treatment of pain. A similar diastereoselective reaction pathway had already been described by Sacchetti et al. ${ }^{451}$ More classically, Blériot et al. used potassium cyanate for the formation of a 6-deoxy-L-lyxofuranose-derived spirohydantoin from the corresponding $\alpha, \alpha^{\prime}$ cyclic amino ester that possessed potent herbicidal activity. ${ }^{452}$

\subsection{1,3-Disubstituted Spirohydantoins}

12.6.1. From Methylene Hydantoins. 1,3-Disubstituted 5spirohydantoins were prepared by Pham et al., who synthesized analogues of hydantocidin, a naturally occurring spironucleoside first isolated from Streptomyces hygroscopicus, via the $[3+2]$ cycloaddition of methylene hydantoins and several methyl butynoate-derived phosphonium ylides. ${ }^{192}$ The regio- and diastereoselectivity of the reaction could be reached by using chiral auxiliaries-derived butynoates (Scheme 87). Similar structures to those obtained by Pham et al. were prepared from the $[3+2]$ cycloaddition of methylene hydantoins and allenes. ${ }^{453}$ The reaction was enantioselective and regioselective, thanks to the use of a chiral phosphepine catalyst.

A number of recent papers focused on the synthesis of spiroisoxazolinohydantoins. These structures, found to have biological activities, were usually prepared from the cycloaddition between 1,3-disubstituted 5-methylene hydantoins and nitrile oxides ${ }^{454-457}$ or nitrones. ${ }^{458,459}$ The reactions were regio- and diastereoselective and allowed access to various structures thanks to the variety of substitution of the reactants (Scheme 87).

The synthesis of the LFA-1 antagonist BMS-587101 and its analogues (see section 2.1) have been largely described. The key step in the preparation of this spirohydantoin relied on the cycloaddition of $\mathrm{N}$-(methoxymethyl)- $\mathrm{N}$-(trimethylsilylmethyl)benzylamine on the suitable arylidene hydantoin, obtained from the reaction between 3,5-dichlorophenylisocyanate and sarcosine methyl ester followed by the Knoevenagel condensation of 4-cyanobenzaldehyde (Scheme 88). After the cycloaddition, further steps enable the desired spirohydantoins BMS-587101 and derivatives to be accessed. ${ }^{14,15,460,461}$

12.6.2. From Other Substrates. Kuster et al. prepared spirohydantoins with substituted cyclohexene as the 5,5substituent of the hydantoins. ${ }^{343}$ The authors performed a solid-phase synthesis, anchoring nitroacetic acid on a hydroxymethylene resin. The cyclohexene structure was obtained by a Knoevenagel condensation/Diels-Alder reaction pathway, and the nitro group was reduced into the free amino moiety, which reacted with isocyanates to afford after cyclization the corresponding spirohydantoins.

Oroidin-derived alkaloids, and particularly spirocyclic palau'amines, attracted interest for their numerous biological activities. The synthesis of the structural cores of these natural products was described following two procedures (since 2004) that are depicted in Scheme 89.

Romo et al. developed a Diels-Alder/olefin isomerization/ chlorination/ring contraction sequence starting from $N, N^{\prime}$ diprotected imidazolone as diene and $\alpha, \beta$-unsaturated lactam as dienophile. ${ }^{462,463}$ Tan et al. performed a comparatively more efficient manganese(III)-promoted radical cyclization cascade by the oxidation of a $\beta$-ketoester derivative of $N, N^{\prime}$-diprotected imidazolone that created the four stereocenters of the palau'amine core in one single step (Scheme 89). ${ }^{464}$ Besides, Cernak et al. described a Diels-Alder reaction between methylene hydantoins and cyclopentadiene that could be applicable to the 
Scheme 86. Preparation of Bioactive Spirohydantoins via Asymmetric Synthesis of Amino Nitriles

1) $\mathrm{Gd}(\mathrm{OPr})_{3}(1 \mathrm{~mol} \%)$ ligand $(2 \mathrm{~mol} \%)$ TMSCN (1.1 equiv.) DMP (1 equiv.) $\mathrm{EtCN},-40^{\circ} \mathrm{C}, 83 \mathrm{~h}$

2) Recryst. from $\mathrm{CHCl}_{3}$-hexane
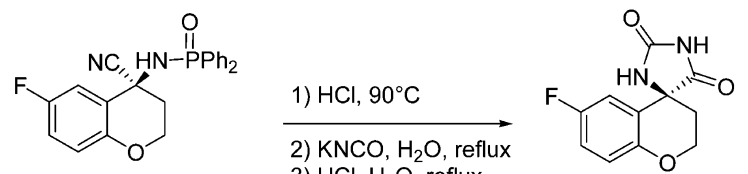

3) $\mathrm{HCl}, \mathrm{H}_{2} \mathrm{O}$, reflux

$93 \%$ yield, > $99 \%$ ce

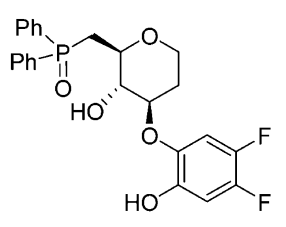

ligand

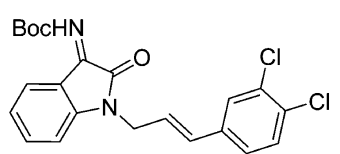

$$
\begin{aligned}
& \text { catalyst (5 mol\%) } \\
& \text { HFIP (1 equiv.) } \\
& \text { TMSCN ( } 2 \text { equiv.) } \\
& \underset{\mathrm{DCM},-70^{\circ} \mathrm{C}, 4 \mathrm{~d}}{\longrightarrow}
\end{aligned}
$$

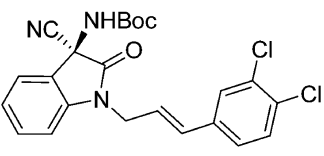

$82 \%$ yield, $94 \%$ ce

1) $\mathrm{HCl}(\mathrm{g})$, EtOAc, r.t.

2) $\mathrm{ClSO}_{2}-\mathrm{NCO}$ (1 equiv.), DCM

3) $2 \mathrm{~N} \mathrm{HCl}$, reflux

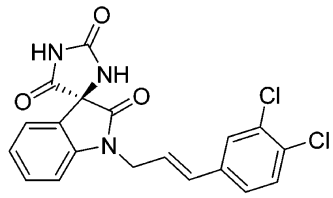

Sorbinil

$67 \%$ yield ( 3 steps)

Inhibitor at the vanilloid receptor 1 (VR1)

$34 \%$ yield ( 3 steps), $99 \%$ oe after recryst.

Scheme 87. Access to Spirohydantoins from Methylene Hydantoin<smiles>[R]N1C(=O)N([R1])C2(CCC=C2C(=O)OCC)C1=O</smiles>

minor

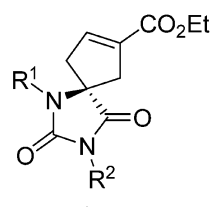

major
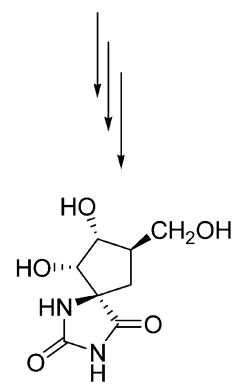

Hydantocidin
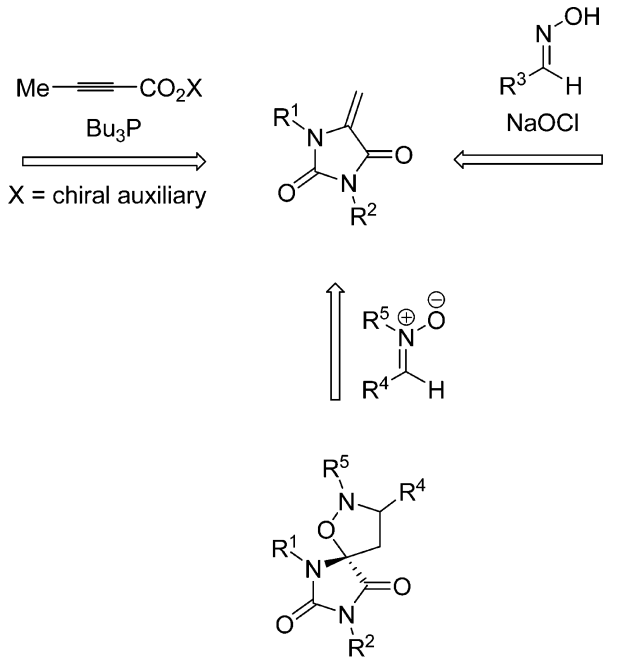
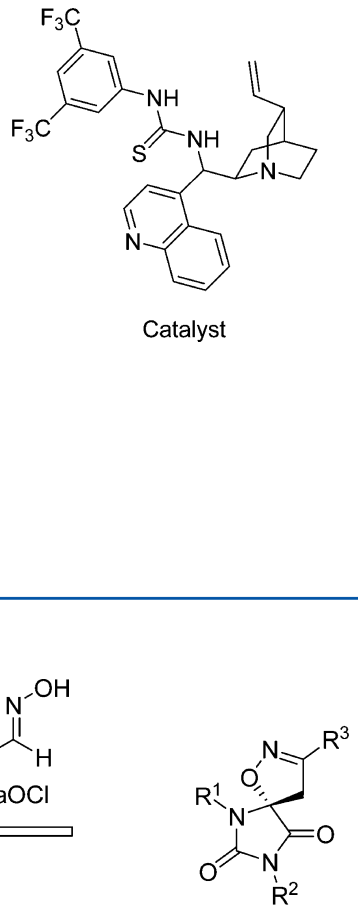

Catalyst

Scheme 88. Synthesis of LFA-1 Antagonist BMS-587101<smiles>CNCC(=O)OCC(=O)O[InH]</smiles>
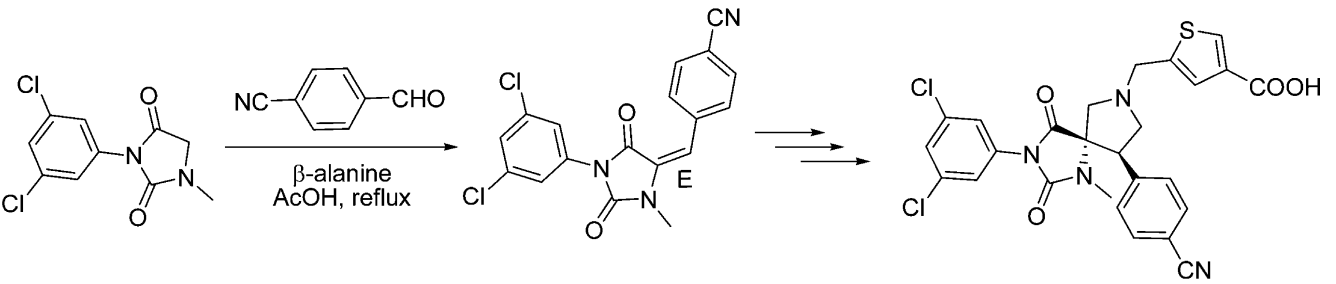

BMS-587101 
Scheme 89. Synthesis of Cores of Natural Alkaloids

Romo et al.
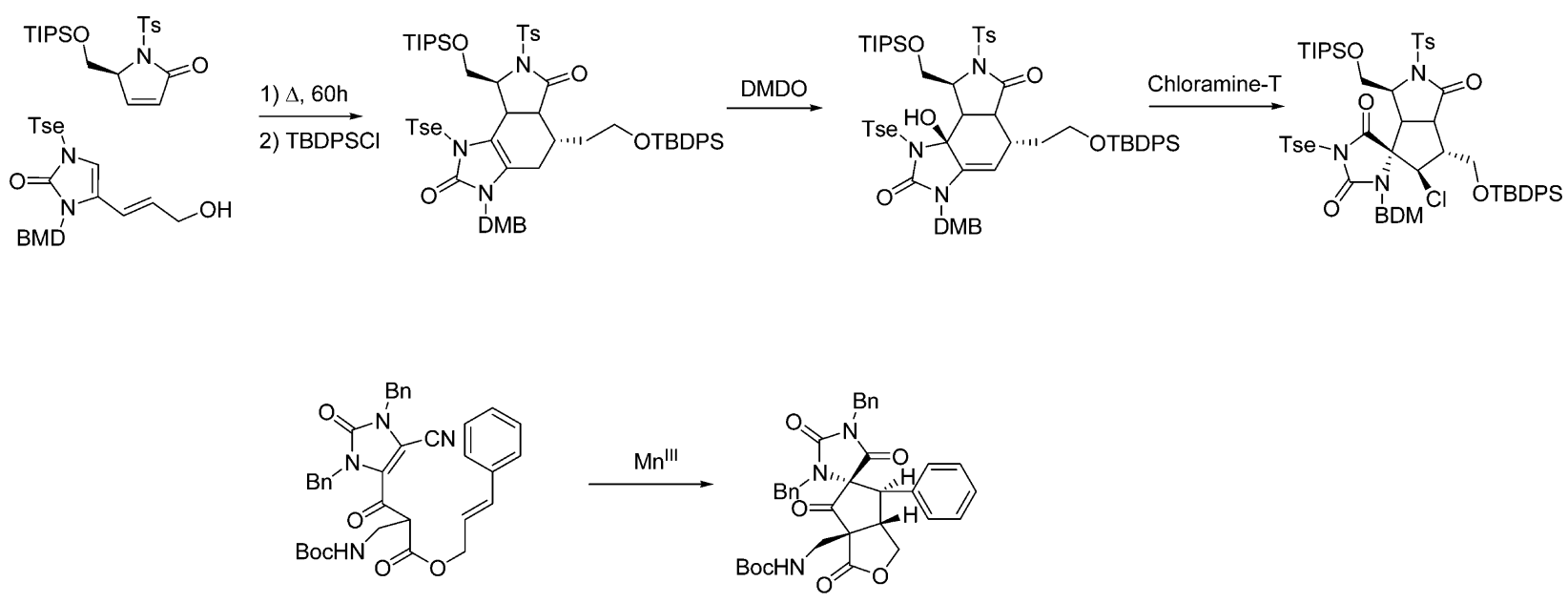

Tan et al.

Scheme 90. Selenium-Containing Fused Bicyclic Hydantoins

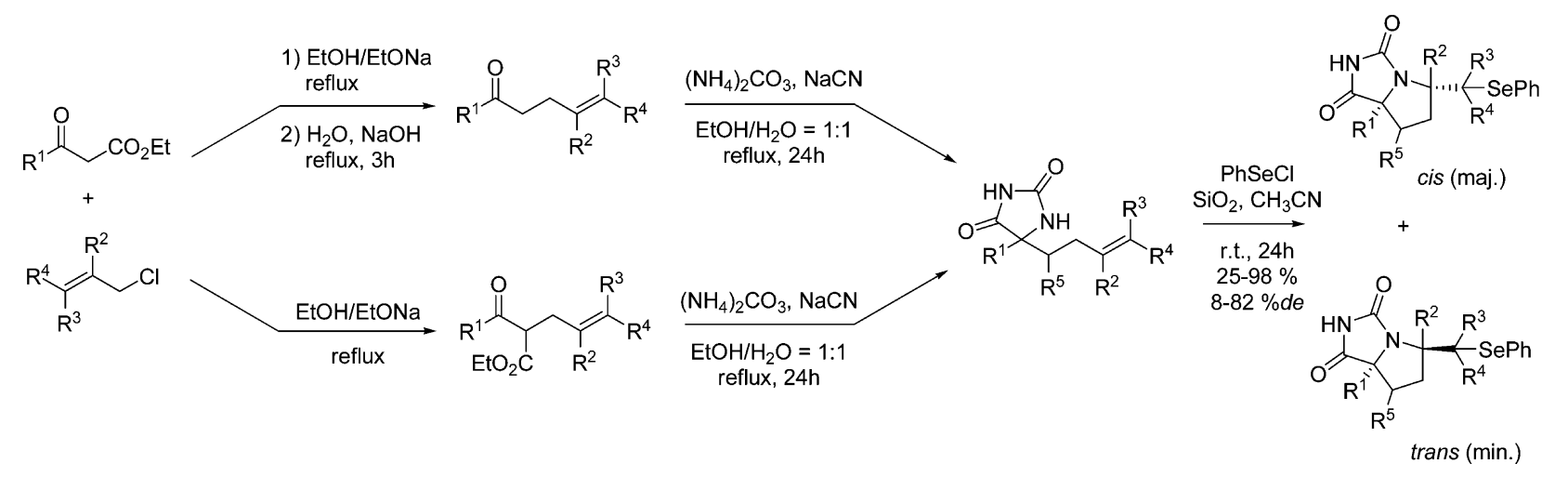

Scheme 91. Construction of a Bicyclic Hydantoin Through a Three-Component Reaction
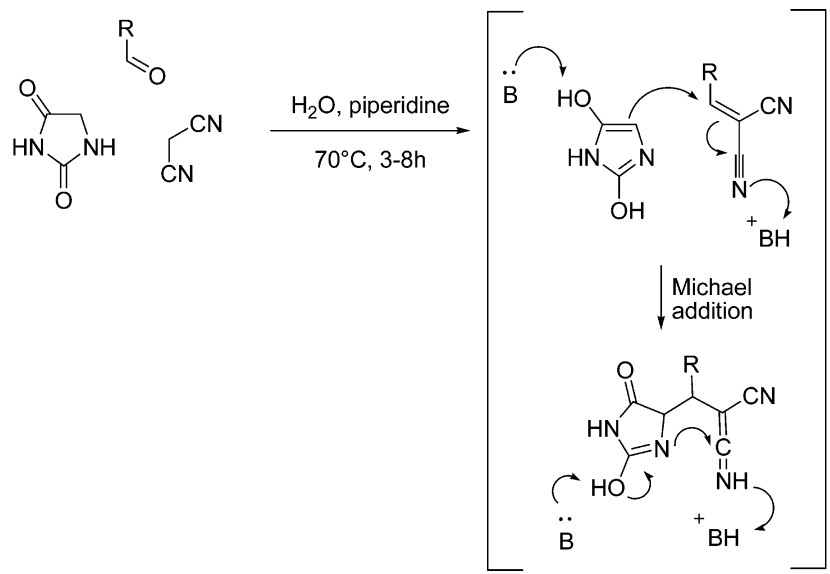

synthesis of palau'amine, as the adducts adopted a major exo conformation. ${ }^{465}$ Axinellamines, which are other oroidin-derived alkaloids, contain a fused hydantoin structure. The synthesis of their core as well as the preparation of diverse fused hydantoins are described in the following paragraph.

\subsection{Fused Hydantoins}

12.7.1. 1,5-Bicyclic Hydantoins. The diastereoselective preparation of fused bicyclic hydantoins has been described by Smit and Pavlovic. ${ }^{466}$ The three steps of the reaction consisted of first the reaction between $\beta$-ketoesters and alkenyl chlorides to provide the corresponding unsaturated ketones, which were subjected in the second step to the Bucherer-Bergs conditions, 
Scheme 92. From Palau'amine to Axinellamine
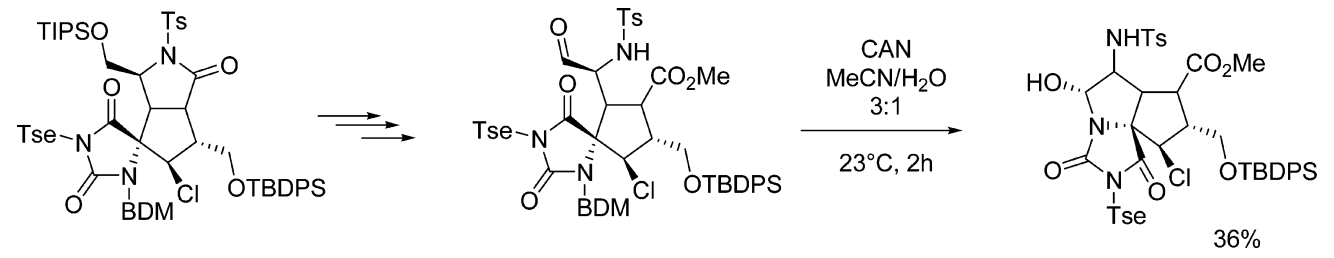

leading to the corresponding 5-alkenyl-hydantoins. Finally, an intramolecular electrophilic amidoselenylation of the hydantoin compounds afforded the fused bicyclic hydantoins (Scheme 90). The reaction proceeded in mild conditions, giving the desired hydantoins in moderate to excellent yields with, however, only moderate to good diastereomeric ratios between the cis and the trans configurations.

Other bicyclic hydantoin structures that are 2-azapyrrolizidine alkaloid analogues have been recently reported. ${ }^{467}$

The procedure consists $f$ a three-component reaction in water involving a 1-substituted hydantoin, malononitrile, and an aldehyde. The proposed mechanism suggests a Knoevenagel condensation between the aldehyde and malononitrile. The cyclization step follows either a concerted pathway or a two-step route consisting of a Michael addition of the C-5 carbon of the hydantoin on the Knoevenagel intermediate followed by a 5-exodig-cyclization (Scheme 91). A variety of substituted bicyclic structures were synthesized following this highly regio-, chemo-, and diastereoselective synthesis.

12.7.2. Polycyclic Fused 1,3,5-Trisubstituted Hydantoins. Romo et al. described the synthesis of the axinellamine core, ${ }^{468}$ starting from the palau'amine core previously described (see section 12.6). They first opened the lactam ring of the spiro structure and oxidized the resulting amino alcohol into the corresponding aldehyde, after removing the triisopropylsilyl(TIPS) protecting group. Then, $\mathrm{N}-1$ deprotection and intramolecular cyclization were provoked by treatment with cerium ammonium nitrate to afford the 1,5-fused hydantoin corresponding to the axinellamine core (Scheme 92).

The reaction between aziridine aldehydes and isocyanates, as well as a hetero Diels-Alder reaction with diazenes, afforded reduced hydantoin structures that could be then oxidized through classical protocols. ${ }^{469,470}$

Very recently, Umstead et al. described the synthesis of pentacyclic structures with a fused hydantoin core by photoinduced intramolecular cycloaddition reactions (Scheme 93). ${ }^{471}$

Scheme 93. Photoinduced Intramolecular Cycloaddition into Hydantoins
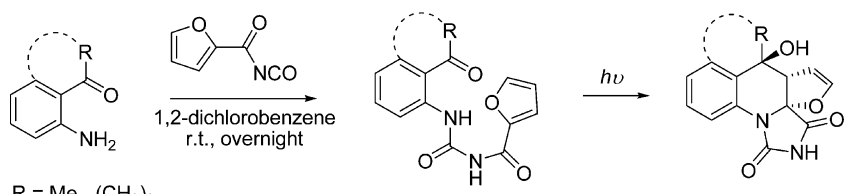

$\mathrm{R}=\mathrm{Me},-\left(\mathrm{CH}_{2}\right)_{3-}^{-}$

The synthesis of these structures was based on linking photoprecursors that were aromatic $o$-amino ketones to furan by a heteroatom-containing tether. The photochemical reaction enabled then to form the hydantoin core by intramolecular cycloaddition.

\section{PREPARATION OF AMINO ACIDS FROM HYDANTOINS}

The hydrolysis of hydantoins is a straightful pathway to the obtention of unnatural amino acids. Usually, the hydantoins are prepared from the corresponding ketone following the Bucherer-Bergs conditions and are then hydrolyzed chemically or enzymatically. This approach is generally used to prepare quaternary ${ }^{444,445}$ and constrained amino acids, ${ }^{197,330,333,472-476}$ such as spiro structures, ${ }^{477-480}$ which can then find applications as potent bioactive compounds, ${ }^{481-486}$ as peptidomimetics for peptide modification, ${ }^{29,332,487-490}$ or as intermediates in the synthesis of natural products. ${ }^{491}$ In this section, we will present the different methods to prepare amino acids from hydantoins (Scheme 94).

\subsection{Chemical Hydrolysis}

The chemical hydrolysis of hydantoins, as opposed to the enzymatic hydrolysis, which is described in the next paragraph, is mainly performed under basic conditions followed by strong acidification. One of the most used procedures consists of hydrolyzing the hydantoinic ring in aqueous concentrated solutions of sodium hydroxide ( $2 \mathrm{~N}$ to $5 \mathrm{~N} \mathrm{NaOH}$ solutions). Although this method is effective, it usually demands high temperatures and long reaction times, up to several days, to obtain the desired amino acids. ${ }^{233,472,475,478}$ Improved conditions were described by Chen et al., who employed an aqueous solution of $0.5 \mathrm{~N} \mathrm{NaOH}$ in 1,2-dimethoxyethane, for 10 min only at $150{ }^{\circ} \mathrm{C}$ under microwave irradiation. ${ }^{477}$ However, in the case of their compound of interest, the yield of the resulting amino acid was low (16\% yield). The use of $\mathrm{Ba}(\mathrm{OH})_{2},{ }^{26,27}$ although still demanding harsh conditions, ${ }^{29,492}$ was reported to be more efficient than $\mathrm{NaOH}^{493}$ Milder conditions can be found following procedures employing potassium ${ }^{41,494,495}$ or lithium $^{496-498}$ hydroxide for the hydrolysis of 1,3-di(tert-butyloxycarbonyl)-hydantoins. The hydrolysis of the unsubstituted hydantoins prepared from the Bucherer-Bergs reaction was then developed as a two-step procedure, in which the hydantoins are first $\mathrm{N}$-substituted by reaction with $\mathrm{Boc}_{2} \mathrm{O}$ and then cleaved at room temperature in solutions of THF and aq. $\mathrm{LiOH}$ or $\mathrm{KOH}$, the reaction times remaining consequently long. ${ }^{199,499,500}$

Apart from the hydrolysis of hydantoins in basic conditions, some procedures have been reported to be performed in acidic media, and particularly with halogenohydric acids $\mathrm{HCl}^{501-506}$ $\mathrm{HBr},{ }^{507,508}$ and $\mathrm{HI}^{509}$ Hydrobromic acid was notably reported to be more efficient in terms of rate of reaction and ease of workup than sodium hydroxide, hydrochloric acid, or sulfuric acid. ${ }^{508}$ As well as in basic media, the hydrolysis of hydantoins using these reagents required high temperatures, concentrated aqueous solutions, and long reaction times. Microwave irradiation proved again to improve these harsh conditions, as Pham et al. reported the cleavage of their hydantoinic compounds in $30 \mathrm{~min}$ at $100{ }^{\circ} \mathrm{C}$ in a $10 \% \mathrm{HCl}$ solution. ${ }^{192}$ Although these different methods demonstrated to be efficient for the preparation of unnatural amino acids, one inconvenient thing is that they do not enable to 
Scheme 94. Pathways to the Production of Amino Acids from Hydantoins

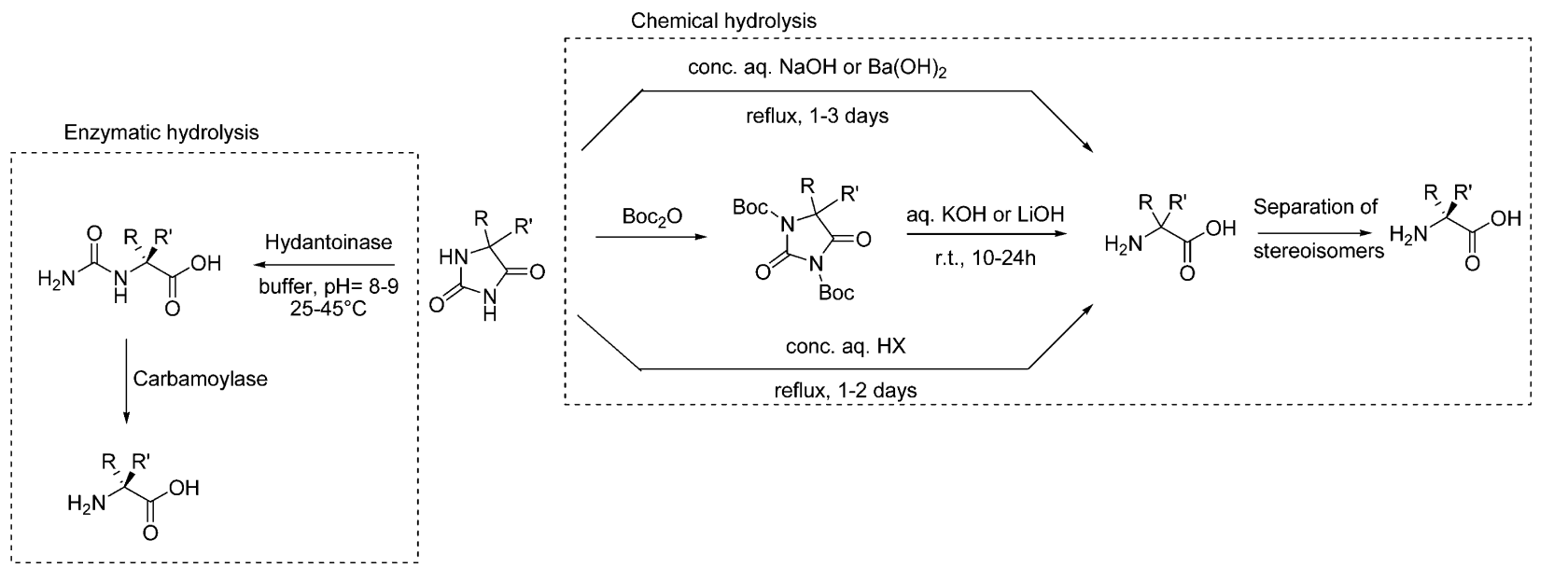

Scheme 95. Enzymatic Process for the Production of D-p-Hydroxyphenylglycine

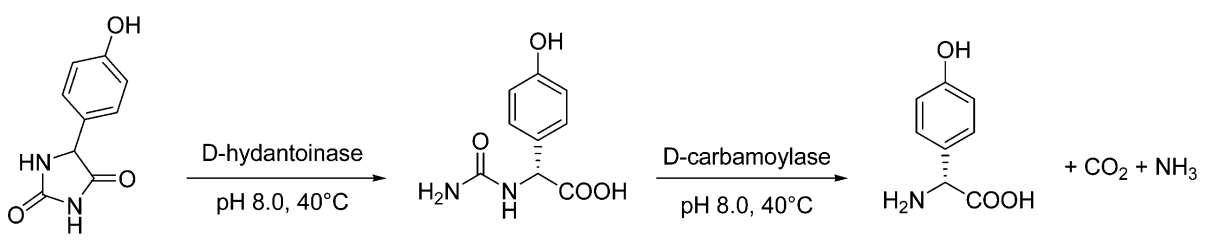

obtain them in an enantiopure form, as it would be advantageous for instance in the case of their insertion in modified peptides. In the case of constrained structures, the Bucherer-Bergs reaction afforded the corresponding hydantoins with a favored isomer that enabled then to recover one major isomer of the desired amino acid. ${ }^{487,510}$ In any case, the mixture of isomers needed to be separated. The resolution can be performed by column chromatography, ${ }^{487,511}$ selective recrystallization of diastereoisomeric derivatives, ${ }^{331,512}$ formation of complexes, ${ }^{251,513,514}$ or by an enzymatic pathway. ${ }^{329,515}$

\subsection{Enzymatic Hydrolysis of Hydantoins}

On the contrary to chemical methods, the enzymatic hydrolysis of hydantoins enables the corresponding amino acid to be obtained enantioselectivelys. D-Hydantoinase is the most common enzyme to produce D-amino acids from racemic hydantoins, L-hydantoinase is more rarely found in Nature and moreover needs ATP as well as $\mathrm{Mn}^{2+}, \mathrm{Mg}^{2+}$, or $\mathrm{K}^{+}$as cofactors to be selectively active toward L-substrates. ${ }^{516}$

The enzymatic process for the production of pure D-amino acids from racemic hydantoins relies on the activity of two enzymes, namely D-hydantoinase (E.C.3.5.2.2) and D-Ncarbamoylase, also called $\mathrm{N}$-carbamoyl-D-amino acid amidohydrolase (E.C.3.5.1.6). Dynamic kinetic resolution is performed with D-hydantoinase, which cleaves selectively D-hydantoins to afford $N$-carbamoyl-D-amino acids, while L-hydantoins racemize in the basic conditions of the enzymatic reaction medium. The activity of D-N-carbamoylase on the $\mathrm{N}$-carbamoyl-amino acids enables them to obtain the free D-amino acids (Scheme 95). This process was widely used for the production of $\mathrm{D}-p$-hydroxyphenylglycine, a valuable precursor of semisynthetic penicillins and cephalosporins. ${ }^{517}$ Enzymes in many isolated microorganisms were studied, either after being immobilized on a matrix $^{518,519}$ or used in the whole cells. ${ }^{520-522}$ Chiang et al. synthesized by genetic modification of Escherichia coli a bifunctional protein with both D-hydantoinase and D-N- carbamoylase activities, which showed a higher reaction rate than both enzymes used in the common process. ${ }^{523}$

Other D-amino acids than D-p-hydroxyphenylglycine could be produced enzymatically, ${ }^{28,39,524}$ but the corresponding 5substituted hydantoin precursors possessed a limiting rate of spontaneous racemization compared to 5-p-hydroxyphenylglycine. To overcome this problem, Nozaki et al. used whole cells of E. coli in which the three genes encoding respectively for Dhydantoinase, $\mathrm{D}-\mathrm{N}$-carbamoylase, and hydantoin racemase were coexpressed, ${ }^{525}$ which enabled them to efficiently catalyze the production of eight different pure $\mathrm{D}$-amino acids.

If, as previously mentioned, L-hydantoinase is less commonly available in Nature, the enantioselective production of L-amino acids was however reported. Lo et al. prepared variants of Brevibacillus agri dihydropyrimidinase (BaDHP), an enzyme that usually acts preferentially on D-homophenylalaninhydantoin (DHPAH), by site-directed mutagenesis of the residues important in the enzyme activity. These variants exhibited then an activity toward L-HPAH, which enabled to obtain the pure L-amino acid in a $90 \%$ conversion yield upon coupling one of the selected variants with $N$-carbamoylase and $N$-acylamino acid racemase. ${ }^{526}$ Ohishi et al. used D-hydantoinase to perform the enantioselective cyclization of $N$-carbamoyl-S-tert-butyl-D,L- $\alpha$ methylcysteine, which is the reverse reaction of the usual hydrolysis activity of this enzyme on hydantoins. This enzymatic resolution led them to get pure $N$-carbamoyl-S-tert-butyl-L- $\alpha$ methylcysteine, while D-5-methyl-5-tert-butylcysteinhydantoin was hardly hydrolyzed by D-hydantoinase. Easy separation of the $N$-carbamoyl-L-amino acid and further hydrolysis with $\mathrm{LiOH}$ and $\mathrm{HCl}$ afforded L-methylcysteine with $99.6 \% e e^{30}$

Overall, the enzymatic hydrolysis of racemic hydantoins represents an attractive process for the preparation of enantiopure amino acids. The enantioselectivity of the enzymatic reactions, the mild reaction conditions, and the stability of the enzymes, either immobilized or in cells, as efficient catalysts are 
advantages that enable this process to be scalable $e^{30,527}$ and then potentially applicable in the industry.

\section{CONCLUSIONS}

As illustrated by the literature presented in this review, the preparation of hydantoin structures has raised a great interest in the methodology, total synthesis, and medicinal chemistry areas. The hydantoin core has proven to be an important pharmacophore that provides a wide range of biological properties to the diverse hydantoin derivatives. This has led groups of synthetic and medicinal chemists to explore the synthetic methods to access these valuable molecules, as well as looking for more sustainable alternatives to the previously existing procedures. ${ }^{528}$ The different families of molecules, i.e., substituted hydantoins at positions $C-5, N-1$, and $N-3$, alkyl/ arylidene, spiro, polycyclic, and amino hydantoins, contribute to the extended variety of biomedical applications that have already been assessed or that will be with the future discovery or design of novel structures. The latter as well as further exploration of the potential medicinal and pharmaceutical relevance of hydantoinic compounds represent the future directions and challenges of the field.

\section{AUTHOR INFORMATION}

\section{Corresponding Authors}

*E-mail: laure.konnert@hotmail.fr.

*Tel. +33 (0)4 671442 85. Fax +33 (0)467 1448 66. E-mail: evelina.colacino@umontpellier.fr.

\section{ORCID $\odot$}

Jean Martinez: 0000-0002-4551-4254

Evelina Colacino: 0000-0002-1179-4913

Notes

The authors declare no competing financial interest.

\section{Biographies}

Evelina Colacino received her double Ph.D. (with European Label) in 2002 at the University of Montpellier II, France, and at the University of Calabria, Italy. She was appointed Research Fellow at the Catholic University of Louvain, Belgium, in 2003 (working on the preparation of new hydantoin scaffolds as antibacterial agents), Research Scientist at Sigma-Tau Pharmaceuticals, Italy, in 2004, Post-Doctoral Fellow and Research Assistant at the University of Montpellier II, France, until 2007. Since 2008, she is Assistant Professor of Organic and Green Chemistry at the University of Montpellier, France. She was Visiting Professor in Spain (Castellon University, 2012), Slovenia (Polymer Technology College, 2014), and Italy (Universities of Turin, Siena, and Cagliari, 2017) for her expertise in green chemistry. Her main research activities concern the development of ecofriendly methodologies for the preparation of biomolecules, small heterocyclic compounds and hybrid materials by mechanochemistry (dry or wet grinding), with a main focus on hydantoin scaffold. Sustainable approaches to homogeneous or heterogeneous metal-catalyzed processes are also investigated by combining green technologies (ultrasounds, microwaves, and flow systems) with nonconventional media [e.g., glycerol, water, poly(ethylene)glycols, and PEG-based ionic liquids] or in micellar conditions (in water and glycerol). (Text partially reproduced from Lupacchini et al. Tetrahedron 2017, 73, 609-653. Copyright 2017 Elservier.)

Laure Konnert graduated in Fine and Industrial Organic Chemistry from the Ecole Nationale Supérieure de Chimie de Clermont-Ferrand (now Sigma Clermont) in 2011. After a master degree in 2012 in
Organic Synthesis and Chemistry of Bioactive Molecules at the University Claude Bernard Lyon 1, she received her Ph.D. in biomolecular engineering from the University of Montpellier (Institute of Biomolecules Max Mousseron) in 2015, under the direction of Dr. Evelina Colacino and Dr. Frédéric Lamaty as co-director, on the mechanochemical synthesis of amino acid derivatives and hydantoins. She then joined the group of Prof. Carsten Bolm at the Institute of Organic Chemistry in RWTH Aachen University as a postdoctoral researcher in 2016, where she worked on functionalization of lignin by mechanochemistry.

Frédéric Lamaty graduated as a chemical engineer from the Ecole Supérieure de Chimie Industrielle de Lyon (ESCIL now ESCPE, France). In 1992, he received his Ph.D. from Purdue University (West Lafayette, IN, USA) under the supervision of Professor Ei-chi Negishi in the field of Pd-catalyzed cyclizations. He then joined, as a RhônePoulenc postdoctoral fellow, the group of Professor Marc Julia at the Ecole Normale Supérieure in Paris to work on the synthesis of Vitamin A. In 1994, he obtained a permanent position at the Centre National de la Recherche Scientifique (CNRS) in Montpellier and is currently working as Directeur de Recherche at the Institute of Biomolecules Max Mousseron (IBMM). Since 2011, he has been heading the Green Chemistry and Enabling Technologies team at IBMM in the Department of Amino Acids, Peptides and Proteins. His research topics in the area of catalysis, organic and green chemistry are devoted to the synthesis of amino acids, peptides, heterocycles, organometallics and MOFs, the use of alternative solvents (PEG, PEG-IL, glycerol, water), mechanochemistry and applications of enabling technologies (microwaves, ultra-sounds, ball-milling, continuous flow).

Jean Martinez received his Ph.D. in Organic Chemistry from the University of Montpellier at the Ecole Nationale Supérieure de Chimie de Montpellier under the direction of Prof. F. Winternitz. He completed his chemical education as a postdoctoral fellow with Dr. E. Bricas, Orsay, University of Paris Sud, and then with Prof. M. Bodanszky, Case Western Reserve University, Cleveland, OH. Back in France he was recruited as a CNRS Research Associate and then as a Research Director in Montpellier. Pursuing his investigation at the interface of chemistry and biology, he joined the University of Montpellier and was appointed as Full Professor in both Organic Chemistry and Medicinal Chemistry. He became successively the head of various research laboratories in Montpellier including the Laboratory of Chemistry and Pharmacology of Biologically Interesting Molecules, the Laboratory of Amino Acids, Peptides and Proteins. He founded the Institute of Biomolecules Max Mousseron in 2007, and acted as the Director until December 2014. In 2015, in the same institute he stayed as the Head of the Department of Amino Acids, Peptides and Proteins. His current research interests focus on peptide chemistry, stereoselective syntheses of biomolecules, design and production of original biomaterials, green chemistry, biology and pharmacology of neuropeptides of the gastrointestinal tract.

\section{REFERENCES}

(1) Ware, E. The Chemistry of the Hydantoins. Chem. Rev. 1950, 46, 403-470.

(2) López, C. A.; Trigo, G. G. The Chemistry of Hydantoins. Adv. Heterocycl. Chem. 1985, 38, 177-228.

(3) Meusel, M.; Gütschow, M. Recent Developments in Hydantoin Chemistry. A Review. Org. Prep. Proced. Int. 2004, 36, 391-443.

(4) Read, W. T. Researches on Hydantoins. Synthesis of the Soporific 4,4-Phenylethyl-hydantoin (Nirvanol). J. Am. Chem. Soc. 1922, 44, $1746-1755$.

(5) Bucherer, H. T.; Lieb, V. A. Syntheses of Hydantoins. II. Formation of Substituted Hydantoins from Aldehydes and Ketones. J. Prakt. Chem. 1934, 141, 5-43. 
(6) Biltz, H. Constitution of the Products of the Interaction of Substituted Carbamides on Benzil and Certain New Methods for the Preparation of 5,5-Diphenylhydantoin. Ber. Dtsch. Chem. Ges. 1908, 41, 1379-1393.

(7) Hulme, C.; Bienaymé, H.; Nixey, T.; Chenera, B.; Jones, W.; Tempest, P.; Smith, A. L. Library Generation Via Postcondensation Modifications of Isocyanide-Based Multicomponent Reactions. Methods Enzymol. 2003, 369, 469-496.

(8) Hulme, C.; Ma, L.; Romano, J.J.; Morton, G.; Tang, S.-Y.; Cherrier, M.-P.; Choi, S.; Salvino, J.; Labaudiniere, R. Novel Applications of Carbon Dioxide/MeOH for the Synthesis of Hydantoins and Cyclic Ureas Via the Ugi Reaction. Tetrahedron Lett. 2000, 41, 1889-1893.

(9) Savjani, J. K.; Gajjar, A. K. Pharmaceutical Importance and Synthetic Strategies for Imidazolidine-2-thione and Imidazole-2-thione Derivatives. Pak. J. Biol. Sci. 2011, 14, 1076-1089.

(10) Metwally, M. A.; Abdel-Latif, E. Thiohydantoins: Synthetic Strategies and Chemical Reactions. J. Sulfur Chem. 2012, 33, 229-257.

(11) Https://Clinicaltrials.gov/; accessed June 6, 2017.

(12) Https://www.clinicaltrialsregister.eu/; accessed June 6, 2017.

(13) U.S. Food and Drug Administration, www.accessdata.fda.gov/ scripts/cder/drugsatfda/; accessed June 6, 2017.

(14) Potin, D.; Launay, M.; Monatlik, F.; Malabre, P.; Fabreguettes, M.; Fouquet, A.; Maillet, M.; Nicolai, E.; Dorgeret, L.; Chevallier, F.; et al. Discovery and Development of 5-[(5S,9R)-9-(4-Cyanophenyl)-3(3,5-dichlorophenyl)-1-methyl-2,4-dioxo-1,3,7-triazaspiro[4.4] non-7yl-methyl]-3-thiophenecarboxylic Acid (BMS-587101)-a Small Molecule Antagonist Leukocyte Function Associated Antigen-1. J. Med. Chem. 2006, 49, 6946-6949.

(15) Watterson, S. H.; Xiao, Z.; Dodd, D. S.; Tortolani, D. R.; Vaccaro, W.; Potin, D.; Launay, M.; Stetsko, D. K.; Skala, S.; Davis, P. M.; et al. Small Molecule Antagonist of Leukocyte Function Associated Antigen-1 (LFA-1): Structure-Activity Relationships Leading to the Identification of 6-((5S,9R)-9-(4-Cyanophenyl)-3-(3,5-dichlorophenyl)-1-methyl2,4-dioxo-1,3,7-triazaspiro[4.4] nonan-7-yl)nicotinic Acid (BMS688521). J. Med. Chem. 2010, 53, 3814-3830.

(16) Nique, F.; Hebbe, S.; Triballeau, N.; Peixoto, C.; Lefrancois, J.-M.; Jary, H.; Alvey, L.; Manioc, M.; Housseman, C.; Klaassen, H.; et al. Identification of a 4-(Hydroxymethyl)diarylhydantoin as a Selective Androgen Receptor Modulator. J. Med. Chem. 2012, 55, 8236-8247.

(17) Konnert, L.; Reneaud, B.; de Figueiredo, R. M.; Campagne, J.-M.; Lamaty, F.; Martinez, J.; Colacino, E. Mechanochemical Preparation of Hydantoins from Amino Esters: Application to the Synthesis of the Antiepileptic Drug Phenytoin. J. Org. Chem. 2014, 79, 10132-10142.

(18) Seuron, P.; Varraillon, D. EP436426A1, 1991.

(19) Yu, W.; Guo, Z.; Orth, P.; Madison, V.; Chen, L.; Dai, C.; Feltz, R. J.; Girijavallabhan, V. M.; Kim, S. H.; Kozlowski, J. A.; et al. Discovery and SAR of Hydantoin Tace Inhibitors. Bioorg. Med. Chem. Lett. 2010, 20, 1877-1880.

(20) Yu, W.; Tong, L.; Kim, S. H.; Wong, M. K. C.; Chen, L.; Yang, D.Y.; Shankar, B. B.; Lavey, B. J.; Zhou, G.; Kosinski, A.; et al. Biaryl Substituted Hydantoin Compounds as TACE Inhibitors. Bioorg. Med. Chem. Lett. 2010, 20, 5286-5289.

(21) Byrtus, H.; Obniska, J.; Czopek, A.; Kaminski, K. Synthesis and Anticonvulsant Activity of New N-Mannich Bases Derived from 5Cyclopropyl-5-phenyl-hydantoins. Arch. Pharm. 2011, 344, 231-241.

(22) Walls, T. H.; Grindrod, S. C.; Beraud, D.; Zhang, L.; Baheti, A. R.; Dakshanamurthy, S.; Patel, M. K.; Brown, M. L.; MacArthur, L. H. Synthesis and Biological Evaluation of a Fluorescent Analog of Phenytoin as a Potential Inhibitor of Neuropathic Pain and Imaging Agent. Bioorg. Med. Chem. 2012, 20, 5269-5276.

(23) Koura, M.; Matsuda, T.; Okuda, A.; Watanabe, Y.; Yamaguchi, Y.; Kurobuchi, S.; Matsumoto, Y.; Shibuya, K. Design, Synthesis and Pharmacology of 1,1-Bistrifluoromethylcarbinol Derivatives as Liver X Receptor $\beta$-Selective Agonists. Bioorg. Med. Chem. Lett. 2015, 25, 26682674.

(24) Lin, X.; Pan, J.; Zhou, M.; Xu, Y.; Lin, J.; Shen, J.; Gao, C.; Van der Bruggen, B. Extraction of Amphoteric Amino Acid by Bipolar Membrane Electrodialysis: Methionine Acid as a Case Study. Ind. Eng. Chem. Res. 2016, 55, 2813-2820.
(25) Jiang, Z.; Liu, Y.; Li, R.; Ren, X.; Huang, T. S. Preparation of Antibacterial Cellulose with a Monochloro-s-triazine-based N-Halamine Biocide. Polym. Adv. Technol. 2016, 27, 460-465.

(26) Nenajdenko, V. G.; Zakurdaev, E. P.; Prusov, E. V.; Balenkova, E. S. A Novel Convenient Approach to the Synthesis of 2-Substituted Analogs of Ornithine and Homolysine. Russ. Chem. Bull. 2004, 53, 2866-2870.

(27) Wynands, L.; Delacroix, S.; Nguyen, A. V. N.; Soriano, E.; MarcoContelles, J.; Postel, D. New Glycosyl- $\alpha$-Aminotetrazole-Based Catalysts for Highly Enantioselective Aldol Reactions. Tetrahedron 2013, 69, 4899-4907.

(28) Weckenmann, N. M.; Nachtsheim, B. J. Enantioselective Synthesis of D- $\alpha$-(Uracil-5-yl)glycine Derivatives and Their Racemization-Free Incorporation into a Model Peptide. Eur. J. Org. Chem. 2015, 2015, 6624-6630.

(29) Arduin, M.; Spagnolo, B.; Calo, G.; Guerrini, R.; Carra, G.; Fischetti, C.; Trapella, C.; Marzola, E.; McDonald, J.; Lambert, D. G.; et al. Synthesis and Biological Activity of Nociceptin/Orphanin FQ Analogues Substituted in Position 7 or 11 with C $\alpha, \alpha$-Dialkylated Amino Acids. Bioorg. Med. Chem. 2007, 15, 4434-4443.

(30) Ohishi, T.; Nanba, H.; Sugawara, M.; Izumida, M.; Honda, T.; Mori, K.; Yanagisawa, S.; Ueda, M.; Nagashima, N.; Inoue, K. Enantioselective Synthesis of D- and L- $\alpha$-Methylcysteine with Hydantoinase. Tetrahedron Lett. 2007, 48, 3437-3440.

(31) Montagne, C.; Shiers, J. J.; Shipman, M. Rapid Generation of Molecular Complexity Using Sequenced Multi-Component Reactions. One-Pot Synthesis of 5,5'-Disubstituted Hydantoins from Methyleneaziridines. Tetrahedron Lett. 2006, 47, 9207-9209.

(32) Montagne, C.; Shipman, M. Modified Bucherer-Bergs Reaction for the One-Pot Synthesis of 5,5'-Disubstituted Hydantoins from Nitriles and Organometallic Reagents. Synlett 2006, 17, 2203-2206.

(33) Murray, R. G.; Whitehead, D. M.; Le Strat, F.; Conway, S. J. Facile One-Pot Synthesis of 5-Substituted Hydantoins. Org. Biomol. Chem. 2008, 6, 988-991.

(34) Kondo, M.; Nishi, T.; Hatanaka, T.; Funahashi, Y.; Nakamura, S. Catalytic Enantioselective Reaction of $\alpha$-Aminoacetonitriles Using Chiral Bis(imidazoline) Palladium Catalysts. Angew. Chem., Int. Ed. 2015, 54, 8198-8202.

(35) Safari, J.; Javadian, L. A One-Pot Synthesis of 5,5-Disubstituted Hydantoin Derivatives Using Magnetic $\mathrm{Fe}_{3} \mathrm{O}_{4}$ Nanoparticles as a Reusable Heterogeneous Catalyst. C. R. Chim. 2013, 16, 1165-1171.

(36) Faghihi, K.; Zamani, K.; Mobinikhaledi, A. Facile Synthesis of Hydantoin Derivatives under Microwave Irradiation. Turk. J. Chem. 2004, 28, 345-350.

(37) Monteiro, J. L.; Pieber, B.; Correa, A. G.; Kappe, C. O. Continuous Synthesis of Hydantoins: Intensifying the Bucherer-Bergs Reaction. Synlett 2015, 27, 83-87.

(38) Mendgen, T.; Steuer, C.; Klein, C. D. Privileged Scaffolds or Promiscuous Binders: A Comparative Study on Rhodanines and Related Heterocycles in Medicinal Chemistry. J. Med. Chem. 2012, 55, 743-753.

(39) Borthwick, A. D.; Davies, D. E.; Exall, A. M.; Livermore, D. G.; Sollis, S. L.; Nerozzi, F.; Allen, M. J.; Perren, M.; Shabbir, S. S.; Woollard, P. M.; et al. 2,5-Diketopiperazines as Potent, Selective, and Orally Bioavailable Oxytocin Antagonists. 2. Synthesis, Chirality, and Pharmacokinetics. J. Med. Chem. 2005, 48, 6956-6969.

(40) Liu, Y.; Zhang, W.; Sayre, L. M. An Alternative Total Synthesis of Pentosidine. J. Heterocycl. Chem. 2011, 48, 426-433.

(41) Ren, S.; Hesk, D.; McNamara, P.; Koharski, D.; Borges, S. Synthesis of $\left[{ }^{3} \mathrm{H}\right],\left[{ }^{13} \mathrm{C}_{3},{ }^{15} \mathrm{~N}\right]$, and $\left[{ }^{14} \mathrm{C}\right] \mathrm{SCH} 900567$ : An Inhibitor of TNF- $\alpha$ (Tumor Necrosis Factor Alpha) Converting Enzyme (TACE). J. Labelled Compd. Radiopharm. 2014, 57, 632-636.

(42) Hupp, C. D.; Tepe, J. J. Total Synthesis of a Marine Alkaloid from the Tunicate Dendrodoa Grossularia. Org. Lett. 2008, 10, 3737-3739.

(43) Hupp, C. D.; Tepe, J. J. 1-Ethyl-3-(3-dimethylaminopropyl)carbodiimide Hydrochloride-Mediated Oxazole Rearrangement: Gaining Access to a Unique Marine Alkaloid Scaffold. J. Org. Chem. 2009, 74, 3406-3413.

(44) Agrawal, S. K.; Sathe, M.; Halve, A. K.; Kaushik, M. P. Dibutylphosphate (DBP) Mediated Synthesis of Cyclic N,N'- 
Disubstituted Urea Derivatives from Amino Esters: A Comparative Study. Tetrahedron Lett. 2012, 53, 5996-5999.

(45) Shaddy, A. A.; Kamel, A. A.; Abdou, W. M. Synthesis, Quantitative Structure-Activity Relationship, and Anti-Inflammatory Profiles of Substituted 5- and 6-N-Heterocycle Bisphosphonate Esters. Synth. Commun. 2013, 43, 236-252.

(46) Elati, C. R.; Gangula, S.; Naredla, A.; Ashok, S.; Bhattacharya, A.; Bandichhor, R. Novel Synthesis of Fosphenytoin. Anti-Convulsant Prodrug. Synth. Commun. 2008, 38, 2950-2957.

(47) Gallienne, E.; Muccioli, G. G.; Lambert, D. M.; Shipman, M. Microwave-Assisted Four-Component Reaction for the Synthesis of a Monothiohydantoin Inhibitor of a Fatty Acid Amide Hydrolase. Tetrahedron Lett. 2008, 49, 6495-6497.

(48) Dumbris, S. M.; Diaz, D. J.; McElwee-White, L. Preparation of Hydantoins by Catalytic Oxidative Carbonylation of $\alpha$-Amino Amides. J. Org. Chem. 2009, 74, 8862-8865.

(49) Sachdev, D.; Dubey, A. One Step Liquid Phase Heterogeneous Synthesis of Phenytoin over MgAl Calcined Hydrotalcites. Catal. Commun. 2010, 11, 1063-1067.

(50) Tang, Y.; Cheng, Q.; Wang, S.; Zhang, J. One-Step Liquid-Phase Heterogeneous Synthesis of Phenytoin Using Modified Calcium Oxide as a Solid Basic Catalyst. Monatsh. Chem. 2014, 145, 1501-1506.

(51) Safari, J.; Naeimi, H.; Ghanbari, M. M.; Sabzi Fini, O. Preparation of Phenytoin Derivatives under Solvent-Free Conditions Using Microwave Irradiation. Russ. J. Org. Chem. 2009, 45, 477-479.

(52) Gbaguidi, F. A.; Kpoviessi, S. S. D.; Kapanda, C. N.; Muccioli, G. G.; Lambert, D. M.; Accrombessi, G. C.; Moudachirou, M.; Poupaert, J. H. A High Yield Synthesis of Phenytoin and Related Compounds Using Microwave Activation. Afr. J. Pure Appl. Chem. 2011, 5, 168-175.

(53) Arani, N. M.; Safari, J. A Rapid and Efficient Ultrasound-Assisted Synthesis of 5,5-Diphenylhydantoins and 5,5-Diphenyl-2-thiohydantoins. Ultrason. Sonochem. 2011, 18, 640-643.

(54) Safari, J.; Moshtael Arani, N.; Ramezan Isfahani, A. UltrasoundEnhanced Green Synthesis of 5,5-Diphenylhydantoin Derivatives Using Symmetrical or Unsymmetrical Benzils. Chin. J. Chem. 2010, 28, 255258.

(55) Du, T.; Li, J.; Min, L. Green Synthesis of Phenytoin Sodium. Adv. Mater. Res. 2012, 518-523, 3917-3920.

(56) Hashmi, I. A.; Aslam, A.; Ali, S. K.; Ahmed, V.-u.; Ali, F. I. Synthesis of Hydantoins, Thiohydantoins, and Glycocyamidines under Solvent-Free Conditions. Synth. Commun. 2010, 40, 2869-2874.

(57) Mousset, C.; Provot, O.; Hamze, A.; Bignon, J.; Brion, J.-D.; Alami, M. DMSO-PdI 2 as a Powerful Oxidizing Couple of Alkynes into Benzils: One-Pot Synthesis of Nitrogen-Containing Five- or SixMembered Heterocycles. Tetrahedron 2008, 64, 4287-4294.

(58) Cativiela, C.; Fraile, J. M.; García, J. I.; Lazaro, B.; Mayoral, J. a.; Pallares, A. The Replacement of Mineral Acids by Sulfonic Resins in the Synthesis of Rac-5-(4-hydroxyphenyl)hydantoin from $p$-Hydroxymandelic Acid and Urea. Appl. Catal., A 2004, 274, 9-14.

(59) Bhat, B. A.; Dhar, K. L.; Puri, S. C.; Spiteller, M. A Novel One-Pot Rearrangement Reaction of 2,3-Epoxydiaryl Ketones: Synthesis of ( \pm -5,5-Disubstituted Imidazolones and 5,5-Disubstituted Hydantoins. Synlett 2006, 17, 2723-2726.

(60) Baccolini, G.; Boga, C.; Delpivo, C.; Micheletti, G. Facile Synthesis of Hydantoins and Thiohydantoins in Aqueous Solution. Tetrahedron Lett. 2011, 52, 1713-1717.

(61) Cativiela, C.; Fraile, J. M.; Garcia, J. I.; Lafuente, G.; Mayoral, J. A.; Tahir, R.; Pallares, A. The Use of Lewis Acids in the Synthesis of 5Arylhydantoins. J. Catal. 2004, 226, 192-196.

(62) Tahir, R.; Banert, K.; Sebti, S. Natural and Synthetic Phosphates: New and Clean Heterogeneous Catalysts for the Synthesis of 5Arylhydantoins. Appl. Catal., A 2006, 298, 261-264.

(63) Surose, R. G.; Ingle, V. N.; Paliwal, L. J. Synthesis, Characterization and Antimicrobial Evaluation of Phenylene-1,4-Oxy-BisHydantoins. Am. J. PharmTech Res. 2014, 4, 297-304.

(64) Zhao, B.; Du, H.; Shi, Y. A Cu(I)-Catalyzed C-H $\alpha$-Amination of Esters. Direct Synthesis of Hydantoins. J. Am. Chem. Soc. 2008, 130, $7220-7221$.
(65) Ware, E. The Chemistry of the Hydantoins. Chem. Rev. 1950, 46, 403-470.

(66) Sweeney, Z. K.; Kennedy-Smith, J. J.; Wu, J.; Arora, N.; Billedeau, J. R.; Davidson, J. P.; Fretland, J.; Hang, J. Q.; Heilek, G. M.; Harris, S. F.; et al. Diphenyl Ether Non-Nucleoside Reverse Transcriptase Inhibitors with Excellent Potency against Resistant Mutant Viruses and Promising Pharmacokinetic Properties. ChemMedChem 2009, 4, 88-99.

(67) El-Sawy, E. R.; Bassyouni, F. A.; Abu-Bakr, S. H.; Rady, H. M.; Abdlla, M. M. Synthesis and Biological Activity of Some New 1-Benzyl and 1-Benzoyl-3-heterocyclic Indole Derivatives. Acta Pharm. 2010, 60, $55-71$.

(68) Randolph, J. T.; Huang, P. P.; Flosi, W. J.; DeGoey, D.; Klein, L. L.; Yeung, C. M.; Flentge, C.; Sun, M.; Zhao, C.; Dekhtyar, T.; et al. Synthesis, Antiviral Activity, and Pharmacokinetic Evaluation of P3 Pyridylmethyl Analogs of Oximinoarylsulfonyl HIV-1 Protease Inhibitors. Bioorg. Med. Chem. 2006, 14, 4035-4046.

(69) Carmi, C.; Cavazzoni, A.; Zuliani, V.; Lodola, A.; Bordi, F.; Plazzi, P. V.; Alfieri, R. R.; Petronini, P. G.; Mor, M. 5-Benzylidene-hydantoins as New EGFR Inhibitors with Antiproliferative Activity. Bioorg. Med. Chem. Lett. 2006, 16, 4021-4025.

(70) Zuliani, V.; Carmi, C.; Rivara, M.; Fantini, M.; Lodola, A.; Vacondio, F.; Bordi, F.; Plazzi, P. V.; Cavazzoni, A.; Galetti, M.; et al. 5Benzylidene-Hydantoins: Synthesis and Antiproliferative Activity on A549 Lung Cancer Cell Line. Eur. J. Med. Chem. 2009, 44, 3471-3479.

(71) Procopiou, P. A.; Barrett, V. J.; Bevan, N. J.; Butchers, P. R.; Conroy, R.; Emmons, A.; Ford, A. J.; Jeulin, S.; Looker, B. E.; Lunniss, G. E.; et al. The Discovery of Long-Acting Saligenin $\beta_{2}$ Adrenergic Receptor Agonists Incorporating Hydantoin or Uracil Rings. Bioorg. Med. Chem. 2011, 19, 4192-4201.

(72) Kwon, S.-K.; Park, H.-S. Synthesis of Potential COX-2 Inhibitory 1,5-Diarylhydantoin Derivatives. Yakhak Hoechi 2004, 48, 135-140.

(73) Pevarello, P.; Brasca, M. G.; Orsini, P.; Traquandi, G.; Longo, A.; Nesi, M.; Orzi, F.; Piutti, C.; Sansonna, P.; Varasi, M.; et al. 3Aminopyrazole Inhibitors of CDK2/Cyclin A as Antitumor Agents. 2. Lead Optimization. J. Med. Chem. 2005, 48, 2944-2956.

(74) Babaeva, G. V.; Shikhaliev, N. G.; Gasanov, V. S.; Kurbanov, K. B.; Allakhverdiev, M. A. Synthesis of Some Oxa- and Thiazolidine-1,3Diones and Their Oxiranyl and Thiiranyl Derivatives. Russ. J. Org. Chem. 2011, 47, 960-963.

(75) Muccioli, G. G.; Wouters, J.; Charlier, C.; Scriba, G. K. E.; Pizza, T.; Di Pace, P.; De Martino, P.; Poppitz, W.; Poupaert, J. H.; Lambert, D. M. Synthesis and Activity of 1,3,5-Triphenylimidazolidine-2,4-diones and 1,3,5-Triphenyl-2-thioxoimidazolidin-4-ones, Characterization of New CB1 Cannabinoid Receptor Inverse Agonists/Antagonists. J. Med. Chem. 2006, 49, 872-882.

(76) Muccioli, G. G.; Fazio, N.; Scriba, G. K. E.; Poppitz, W.; Cannata, F.; Poupaert, J. H.; Wouters, J.; Lambert, D. M. Substituted 2-Thioxo-4 imidazolidinones and Imidazolidine-2,4-diones as Fatty Acid Amide Hydrolase Inhibitors Templates. J. Med. Chem. 2006, 49, 417-425.

(77) Patel, V. M.; Desai, K. R. Microwave-Induced Synthesis of Fluorine Containing 1,5-Disubstituted Hydantoins and Thiohydantoins and Their Antibacterial Activity. Indian J. Chem., Sect. B: Org. Chem. Incl. Med. Chem. 2005, 44B, 1084-1087.

(78) Ali, O. M.; Amer, H. H.; Mosaad, A. A.; Abdel-Rahman, A. A. H. Synthesis and Antimicrobial Activity of New Phenytoin Derivatives and Their Acyclic Nucleoside Analogs. Chem. Heterocycl. Compd. 2012, 48, $1043-1049$

(79) Gazieva, G. A.; Lozhkin, P. V.; Kravchenko, A. N. $\alpha$ Ureidoalkylation of 1,3-Bis(hydroxymethyl)imidazolidin-2-one. Chem. Heterocycl. Compd. 2007, 43, 1406-1410.

(80) Bhandari, M. R.; Sivappa, R.; Lovely, C. J. Total Synthesis of the Putative Structure of Nagelamide D. Org. Lett. 2009, 11, 1535-1538.

(81) Kashif, M. K.; Ahmad, I.; Hameed, S. Synthesis and Hypoglycemic Activity of 5,5-Dimethylarylsulfonylimidazolidine-2,4-diones. ARKIVOC 2008, 311-317.

(82) Kruger, H. G.; Mdluli, P.; Power, T. D.; Raasch, T.; Singh, A. Experimental and Computational Studies of the Regioselective Protection of Hydantoins Using Anhydride. J. Mol. Struct.: THEOCHEM 2006, 771, 165-170. 
(83) Kruger, H. G.; Mdluli, P. S. Regioselective Protection of Hydantoins - Essential for Hydantoin Based Anti-Epileptic Drugs. Struct. Chem. 2006, 17, 121-125.

(84) Dandepally, S. R.; Williams, A. L. Microwave-Assisted N-Boc Deprotection under Mild Basic Conditions Using $\mathrm{K}_{3} \mathrm{PO}_{4} \cdot \mathrm{H}_{2} \mathrm{O}$ in MeOH. Tetrahedron Lett. 2009, 50, 1071-1074.

(85) Alcaide, B.; Almendros, P.; Alonso, J. M. A Practical RutheniumCatalyzed Cleavage of the Allyl Protecting Group in Amides, Lactams, Imides, and Congeners. Chem. - Eur. J. 2006, 12, 2874-2879.

(86) Kumar, L. V.; Kaushik, M. P.; Mazumdar, A. An Efficient Approach for the Synthesis of N-1 Substituted Hydantoins. Eur. J. Org. Chem. 2008, 11, 1910-1916.

(87) Kumar, V.; Rana, H.; Sankolli, R.; Kaushik, M. P. Highly Efficient Dialkylphosphate-Mediated Syntheses of Hydantoins and a Bicyclohydantoin under Solvent-Free Conditions. Tetrahedron Lett. 2011, 52, 6148-6151.

(88) Olimpieri, F.; Bellucci, M. C.; Volonterio, A.; Zanda, M. A Mild, Efficient Approach for the Synthesis of 1,5-Disubstituted Hydantoins. Eur. J. Org. Chem. 2009, 12, 6179-6188.

(89) Hu, X.; Xu, W.; Wang, R.; Cheng, X.; Tang, L. Computational Study of the Proton Transfer of Phenyl Urea. Drug Discoveries Ther. 2009, 3, 10-12.

(90) McCallum, J. E. B.; Kuniyoshi, C. Y.; Foote, C. S. Characterization of 5-Hydroxy-8-oxo-7,8-dihydroguanosine in the Photosensitized Oxidation of 8-Oxo-7,8-dihydroguanosine and its Rearrangement to Spiroiminodihydantoin. J. Am. Chem. Soc. 2004, 126, 16777-16782.

(91) Niles, J. C.; Wishnok, J. S.; Tannenbaum, S. R. Spiroiminodihydantoin and Guanidinohydantoin are the Dominant Products of 8Oxoguanosine Oxidation at Low Fluxes of Peroxynitrite: Mechanistic Studies with ${ }^{18} \mathrm{O}$. Chem. Res. Toxicol. 2004, 17, 1510-1519.

(92) Hah, S. S.; Kim, H. M.; Sumbad, R. A.; Henderson, P. T. Hydantoin Derivative Formation from Oxidation of 7,8-Dihydro-8-oxo$2^{\prime}$-deoxyguanosine (8-OxodG) and Incorporation of ${ }^{14} \mathrm{C}$-Labeled 8OxodG into the DNA of Human Breast Cancer Cells. Bioorg. Med. Chem. Lett. 2005, 15, 3627-3631.

(93) Ravanat, J.-L.; Martinez, G. R.; Medeiros, M. H. G.; Di Mascio, P.; Cadet, J. Singlet Oxygen Oxidation of $2^{\prime}$-Deoxyguanosine. Formation and Mechanistic Insights. Tetrahedron 2006, 62, 10709-10715.

(94) Fleming, A. M.; Orendt, A. M.; He, Y.; Zhu, J.; Dukor, R. K.; Burrows, C. J. Reconciliation of Chemical, Enzymatic, Spectroscopic and Computational Data to Assign the Absolute Configuration of the DNA Base Lesion Spiroiminodihydantoin. J. Am. Chem. Soc. 2013, 135, 18191-18204.

(95) Chen, X.; Fleming, A. M.; Muller, J. G.; Burrows, C. J. Endonuclease and Exonuclease Activities on Oligodeoxynucleotides Containing Spiroiminodihydantoin Depend on the Sequence Context and the Lesion Stereochemistry. New J. Chem. 2013, 37, 3440-3449.

(96) Karwowski, B.; Dupeyrat, F.; Bardet, M.; Ravanat, J.-L.; Krajewski, P.; Cadet, J. Nuclear Magnetic Resonance Studies of the $4 R$ and $4 S$ Diastereomers of Spiro-iminodihydantoin 2'-Deoxyribonucleosides: Absolute Configuration and Conformational Features. Chem. Res. Toxicol. 2006, 19, 1357-1365.

(97) Ye, Y.; Muller, J. G.; Burrows, C. J. Synthesis and Characterization of the Oxidized dGTP Lesions Spiroiminodihydantoin-2'-deoxynucleoside-5'-triphosphate and Guanidinohydantoin-2'-deoxynucleoside-5' triphosphate. J. Org. Chem. 2006, 71, 2181-2184.

(98) Mueller, H.; Carell, T. A Carbocyclic Analog of the Oxidatively Generated DNA Lesion Spiroiminodihydantoin. Eur. J. Org. Chem. 2007, 9, 1438-1445.

(99) Gourdain, S.; Martinez, A.; Petermann, C.; Harakat, D.; Clivio, P. Unraveling the Photochemistry of the 5-Azido-2'-deoxyuridine Photoaffinity Label. J. Org. Chem. 2009, 74, 6885-6887.

(100) Nguyen, K. V.; Muller, J. G.; Burrows, C. J. Oxidation of 9- $\beta$-DRibofuranosyl Uric Acid by One-Electron Oxidants Versus Singlet Oxygen and Its Implications for the Oxidation of 8-Oxo-7,8dihydroguanosine. Tetrahedron Lett. 2011, 52, 2176-2180.

(101) Yu, H.; Niles, J. C.; Wishnok, J. S.; Tannenbaum, S. R. Spirodihydantoin Is a Minor Product of 5-Hydroxyisourate in Urate Oxidation. Org. Lett. 2004, 6, 3417-3420.
(102) Neves, C. M. B.; Simoes, M. M. Q.; Santos, I. C. M. S.; Domingues, F. M. J.; Neves, M. G. P. M. S.; Almeida Paz, F. A.; Silva, A. M. S.; Cavaleiro, J. A. S. Oxidation of Caffeine with Hydrogen Peroxide Catalyzed by Metalloporphyrins. Tetrahedron Lett. 2011, 52, 28982902.

(103) Riviere, J.; Bergeron, F.; Tremblay, S.; Gasparutto, D.; Cadet, J.; Wagner, J. R. Oxidation of 5-Hydroxy-2'-deoxyuridine into Isodialuric Acid, Dialuric Acid, and Hydantoin Products. J. Am. Chem. Soc. 2004, 126, 6548-6549.

(104) Riviere, J.; Klarskov, K.; Wagner, J. R. Oxidation of 5Hydroxypyrimidine Nucleosides to 5-Hydroxyhydantoin and Its $\alpha$ Hydroxy-ketone Isomer. Chem. Res. Toxicol. 2005, 18, 1332-1338.

(105) Samson-Thibault, F.; Madugundu, G. S.; Gao, S.; Cadet, J.; Wagner, J. R. Profiling Cytosine Oxidation in DNA by LC-MS/Ms. Chem. Res. Toxicol. 2012, 25, 1902-1911.

(106) Slade, P. G.; Priestley, N. D.; Sugden, K. D. Spiroiminodihydantoin as an Oxo-atom Transfer Product of 8-Oxo-2'-deoxyguanosine Oxidation by Chromium(V). Org. Lett. 2007, 9, 4411-4414.

(107) Shao, J.; Geacintov, N. E.; Shafirovich, V. Oxidation of 8-Oxo7,8-dihydro-2'-deoxyguanosine by Oxyl Radicals Produced by Photolysis of Azo Compounds. Chem. Res. Toxicol. 2010, 23, 933-938.

(108) Suzuki, T.; Nakamura, A.; Inukai, M. Reaction of 3',5'-Di-Oacetyl-2'-deoxyguanosine with Hypobromous Acid. Bioorg. Med. Chem. 2013, 21, 3674-3679.

(109) Fleming, A. M.; Muller, J. G.; Ji, I.; Burrows, C. J. Characterization of 2 -Deoxyguanosine Oxidation Products Observed in the Fenton-like System $\mathrm{Cu}(\mathrm{II}) / \mathrm{H}_{2} \mathrm{O}_{2} /$ Reductant in Nucleoside and Oligodeoxynucleotide Contexts. Org. Biomol. Chem. 2011, 9, 33383348.

(110) Alshykhly, O. R.; Fleming, A. M.; Burrows, C. J. 5-Carboxamido5-formamido-2-iminohydantoin, in Addition to 8-Oxo-7,8-Dihydroguanine, is the Major Product of the Iron-Fenton or X-Ray RadiationInduced Oxidation of Guanine under Aerobic Reducing Conditions in Nucleoside and DNA Contexts. J. Org. Chem. 2015, 80, 6996-7007.

(111) Martinez, A.; Alonso, M.; Castro, A.; Dorronsoro, I.; Gelpi, J. L.; Luque, F. J.; Perez, C.; Moreno, F. J. SAR and 3D-QSAR Studies on Thiadiazolidinone Derivatives: Exploration of Structural Requirements for Glycogen Synthase Kinase 3 Inhibitors. J. Med. Chem. 2005, 48, $7103-7112$.

(112) Soltani Rad, M. N.; Khalafi-Nezhad, A.; Behrouz, S. Synthesis of Some Novel Hydrazono Acyclic Nucleoside Analogs. Beilstein J. Org. Chem. 2010, 6, 49 10.3762/bjoc.6.49.

(113) Yousefi, R.; Khalafi-Nezhad, A.; Soltani Rad, M. N.; Behrouz, S.; Panahi, F.; Esmaili, M.; Ghaffari, S. M.; Niazi, A.; Moosavi-Movahedi, A. A. Structure-Cytotoxicity Relationship of a Novel Series of Miconazolelike Compounds. Med. Chem. Res. 2012, 21, 1921-1928.

(114) Talamas, F. X.; Ao-Ieong, G.; Brameld, K. A.; Chin, E.; de Vicente, J.; Dunn, J. P.; Ghate, M.; Giannetti, A. M.; Harris, S. F.; Labadie, S. S.; et al. De Novo Fragment Design: A Medicinal Chemistry Approach to Fragment-based Lead Generation. J. Med. Chem. 2013, 56, 3115-3119.

(115) Theodore, C. E.; Naveen, S.; Benaka Prasad, S. B.; Madaiah, M.; Ananda Kumar, C. S.; Lokanath, N. K. Crystal Structure of 1'-(2Methylpropyl)-2,3-dihydrospiro[1-benzothiopyran-4,4'-imidazolidine]-2',5'-dione. Acta Crystallogr., Sect. E: Struct. Rep. Online 2014, 70, 1043-1044.

(116) Babkov, D. A.; Chizhov, A. O.; Khandazhinskaya, A. L.; Corona, A.; Esposito, F.; Tramontano, E.; Seley-Radtke, K. L.; Novikov, M. S. An Efficient Route to Novel Uracil-Based Drug-like Molecules. Synthesis 2015, 47, 1413-1422.

(117) Czopek, A.; Byrtus, H.; Kolaczkowski, M.; Pawlowski, M.; Dybala, M.; Nowak, G.; Tatarczynska, E.; Wesolowska, A.; ChojnackaWojcik, E. Synthesis and Pharmacological Evaluation of New 5(Cyclo)alkyl-5-phenyl- and 5-Spiroimidazolidine-2,4-dione Derivatives. Novel 5-HT1A Receptor Agonist with Potential Antidepressant and Anxiolytic Activity. Eur. J. Med. Chem. 2010, 45, 1295-1303.

(118) Trisovic, N.; Timic, T.; Divljakovic, J.; Rogan, J.; Poleti, D.; Savic, M. M.; Uscumlic, G. Synthesis, Structural and Biological 
Characterization of 5-Phenylhydantoin Derivatives as Potential Anticonvulsant Agents. Monatsh. Chem. 2012, 143, 1451-1457.

(119) Tzvetkov, N. T.; Euler, H.; Mueller, C. E. Regioselective Synthesis of 7,8-Dihydroimidazo[5,1-c] $[1,2,4]$ triazine-3,6 $(2 \mathrm{H}, 4 \mathrm{H})$ dione Derivatives: A New Drug-Like Heterocyclic Scaffold. Beilstein J. Org. Chem. 2012, 8, 1584-1593.

(120) Thomas, A. A.; Hunt, K. W.; Newhouse, B.; Watts, R. J.; Liu, X.; Vigers, G.; Smith, D.; Rhodes, S. P.; Brown, K. D.; Otten, J. N.; et al. 8Tetrahydropyran-2-yl Chromans: Highly Selective Beta-site Amyloid Precursor Protein Cleaving Enzyme 1 (BACE1) Inhibitors. J. Med. Chem. 2014, 57, 10112-10129.

(121) Matsuda, T.; Okuda, A.; Watanabe, Y.; Miura, T.; Ozawa, H.; Tosaka, A.; Yamazaki, K.; Yamaguchi, Y.; Kurobuchi, S.; Koura, M.; et al. Design and Discovery of 2-Oxochromene Derivatives as Liver $\mathrm{X}$ Receptor $\beta$-Selective Agonists. Bioorg. Med. Chem. Lett. 2015, 25, 12741278 .

(122) Czopek, A.; Kolaczkowski, M.; Bucki, A.; Byrtus, H.; Pawlowski, M.; Kazek, G.; Bojarski, A. J.; Piaskowska, A.; Kalinowska-Tluscik, J.; Partyka, A.; et al. Novel Spirohydantoin Derivative as a Potent Multireceptor-Active Antipsychotic and Antidepressant Agent. Bioorg. Med. Chem. 2015, 23, 3436-3447.

(123) Hussain, A.; Kashif, M. K.; Naseer, M. M.; Rana, U. A.; Hameed, S. Synthesis and in Vivo Hypoglycemic Activity of New Imidazolidine2,4-Dione Derivatives. Res. Chem. Intermed. 2015, 41, 7313-7326.

(124) Matys, A.; Podlewska, S.; Witek, K.; Witek, J.; Bojarski, A. J.; Schabikowski, J.; Otrebska-Machaj, E.; Latacz, G.; Szymanska, E.; KiecKononowicz, K.; et al. Imidazolidine-4-one Derivatives in the Search for Novel Chemosensitizers of Staphylococcus Aureus Mrsa: Synthesis, Biological Evaluation and Molecular Modeling Studies. Eur. J. Med. Chem. 2015, 101, 313-325.

(125) Cheng, X.; Li, R.; Du, J.; Sheng, J.; Ma, K.; Ren, X.; Huang, T.-S. Antimicrobial Activity of Hydrophobic Cotton Coated with NHalamine. Polym. Adv. Technol. 2015, 26, 99-103.

(126) Xi, G.; Xiu, Y.; Wang, L.; Liu, X. Antimicrobial N-Halamine Coatings Synthesized Via Vapor-Phase Assisted Polymerization. J. Appl. Polym. Sci. 2015, 132, 41821-41827.

(127) Chen, Z.; Sun, Y. N-Halamine-Based Antimicrobial Additives for Polymers: Preparation, Characterization, and Antimicrobial Activity. Ind. Eng. Chem. Res. 2006, 45, 2634-2640.

(128) Hmuda, S.; Trisovic, N.; Rogan, J.; Poleti, D.; Vitnik, Z.; Vitnik, V.; Valentic, N.; Bozic, B.; Uscumlic, G. New Derivatives of Hydantoin as Potential Antiproliferative Agents: Biological and Structural Characterization in Combination with Quantum Chemical Calculations. Monatsh. Chem. 2014, 145, 821-833.

(129) Sadek, B.; Schwed, J. S.; Subramanian, D.; Weizel, L.; Walter, M.; Adem, A.; Stark, H. Non-imidazole Histamine H3 Receptor Ligands Incorporating Antiepileptic Moieties. Eur. J. Med. Chem. 2014, 77, 269279.

(130) Abdulrahman, L. Q.; Mohammed, M. A.; Qasim, M. L. Synthesis and Evaluation of Iodinated Phenytoin for Antimicrobial Activity. Int. Res. J. Pharm. 2014, 5, 155-158.

(131) Liu, J.-K.; Gu, W.; Cheng, X.-R.; Cheng, J.-P.; Zhou, W.-X.; Nie, A.-H. Design and Synthesis of Cyclic Acylguanidines as BACE1 Inhibitors. Chin. Chem. Lett. 2015, 26, 1327-1330.

(132) Sun, T.; Morger, A.; Castagner, B.; Leroux, J.-C. An Oral Redoxsensitive Self-immolating Prodrug Strategy. Chem. Commun. 2015, 51, 5721-5724.

(133) Imanzadeh, G.; Rezaee-Gatar, S. Solvent-Free Highly Regioselective Michael Addition of Phenytoin to $\alpha, \beta$-Unsaturated Esters in the Presence of $\mathrm{TBAB}$ under Ultrasound Irradiation. ARKIVOC 2015, 121-133.

(134) Mesropyan, E. G.; Hambardzumyan, G. B.; Avetisyan, A. A.; Galstyan, A. S.; Khachatryan, A. G. Synthesis of 3-(3-Allyloxy-2hydroxypropyl)-5,5-dimethylhydantoin, 1-(3-Allyloxy-2-hydroxypropyl)-substituted Benzotriazole and Benzimidazole, and N-(3-Allyloxy-2hydroxypropyl)-substituted Pyrrolidone, Caprolactam, and Phthalimide. Chem. Heterocycl. Compd. 2005, 41, 962-966.

(135) Fullam, E.; Abuhammad, A.; Wilson, D. L.; Anderton, M. C.; Davies, S. G.; Russell, A. J.; Sim, E. Analysis of $\beta$-Amino Alcohols as
Inhibitors of the Potential Anti-Tubercular Target N-Acetyltransferase. Bioorg. Med. Chem. Lett. 2011, 21, 1185-1190.

(136) Tang, Y.; Dong, Y.; Karle, J. M.; DiTusa, C. A.; Vennerstrom, J. L. Synthesis of Tetrasubstituted Ozonides by the Griesbaum Coozonolysis Reaction: Diastereoselectivity and Functional Group Transformations by Post-Ozonolysis Reactions. J. Org. Chem. 2004, 69, 6470-6473.

(137) Chen, K. X.; Nair, L.; Vibulbhan, B.; Yang, W.; Arasappan, A.; Bogen, S. L.; Venkatraman, S.; Bennett, F.; Pan, W.; Blackman, M. L.; et al. Second-Generation Highly Potent and Selective Inhibitors of the Hepatitis C Virus NS3 Serine Protease. J. Med. Chem. 2009, 52, 13701379.

(138) Handzlik, J.; Bojarski, A. J.; Satala, G.; Kubacka, M.; Sadek, B.; Ashoor, A.; Siwek, A.; Wiecek, M.; Kucwaj, K.; Filipek, B.; et al. SARStudies on the Importance of Aromatic Ring Topologies in Search for Selective 5-HT7 Receptor Ligands among Phenylpiperazine Hydantoin Derivatives. Eur. J. Med. Chem. 2014, 78, 324-339.

(139) Hugel, H. M.; Rix, C. J.; Fleck, K. Comparison of Copper(II) Acetate Promoted N-Arylation of 5,5-Dimethylhydantoin and Other Imides with Triarylbismuthanes and Arylboronic Acids. Synlett 2006, 14, 2290-2292.

(140) Shinde, M. H.; Kshirsagar, U. A. N-Bromosuccinimide Promoted and Base Switchable One Pot Synthesis of $\alpha$-Imido and $\alpha$ Amino Ketones from Styrenes. Org. Biomol. Chem. 2016, 14, 858-861.

(141) Guo, C.; Hu, M.; DeOrazio, R. J.; Usyatinsky, A.; Fitzpatrick, K.; Zhang, Z.; Maeng, J.-H.; Kitchen, D. B.; Tom, S.; Luche, M.; et al. The Design and Synthesis of Novel SGLT2 Inhibitors: C-Glycosides with Benzyltriazolopyridinone and Phenylhydantoin as the Aglycone Moieties. Bioorg. Med. Chem. 2014, 22, 3414-3422.

(142) Fresneda, P. M.; Castaneda, M.; Sanz, M. A.; Molina, P. Trapping of a Phosphazide Intermediate in the Staudinger Reaction of Tertiary Phosphines with Azides and its Application to the Synthesis of Analogs of the Marine Alkaloid Midpacamide. Tetrahedron Lett. 2004, $45,1655-1657$.

(143) Sedlak, M.; Keder, R.; Hanusek, J.; Ruzicka, A. Synthesis of New Substituted 5-Methyl-3,5-diphenylimidazolidine-2,4-diones from Substituted 1-(1-Cyanoethyl-1-phenyl)-3-phenylureas. J. Heterocycl. Chem. 2005, 42, 899-906

(144) Muccioli, G. G.; Wouters, J.; Scriba, G. K. E.; Poppitz, W.; Poupaert, J. H.; Lambert, D. M. 1-Benzhydryl-3-phenylurea and 1Benzhydryl-3-phenylthiourea Derivatives: New Templates among the Cb1 Cannabinoid Receptor Inverse Agonists. J. Med. Chem. 2005, 48, $7486-7490$

(145) Shtamburg, V. G.; Shtamburg, V. V.; Anishchenko, A. A.; Zubatyuk, R. I.; Mazepa, A. V.; Klotz, E. A.; Kravchenko, S. V.; Kostyanovsky, R. G. Single-Stage Synthesis of 3-Hydroxy- and 3-Alkoxy5-arylimidazolidine-2,4-diones by Reaction of Arylglyoxal Hydrates with N-Hydroxy- and N-Alkoxyureas. Chem. Heterocycl. Compd. 2015, 51, 553-559.

(146) Hroch, L.; Hruskova, M.; Schmitz, J.; Schnakenburg, G.; Guetschow, M. 3,5,5-Trisubstituted Hydantoins from Activated (Benzyloxycarbonyl-amino)malonic Acids. Synthesis 2012, 44, 19071914.

(147) Wehner, V.; Stilz, H.-U.; Osipov, S. N.; Golubev, A. S.; Sieler, J.; Burger, K. Trifluoromethyl-substituted Hydantoins, Versatile Building Blocks for Rational Drug Design. Tetrahedron 2004, 60, 4295-4302.

(148) Chaubet, G.; Cazals, G.; Lebrun, A.; Martinez, J.; Parrot, I. From Diketopiperazines to Hydantoins: An Unprecedented Rearrangement. Synlett 2014, 25, 574-578.

(149) Konnert, L.; Dimassi, M.; Gonnet, L.; Lamaty, F.; Martinez, J.; Colacino, E. Poly(ethylene) Glycols and Mechanochemistry for the Preparation of Bioactive 3,5-Disubstituted Hydantoins. RSC Adv. 2016, 6, 36978-36986.

(150) Luis, J. A. d. S.; Barbosa Filho, J. M.; Lira, B. F.; Medeiros, I. A.; Lima de Morais, L. C. S.; Fernandes dos Santos, A. F.; Soares de Oliveira, C.; Filgueiras de Athayde-Filho, P. Synthesis of New Imidazolidin-2,4dione and 2-Thioxoimidazolidin-4-ones Via C-Phenylglycine Derivatives. Molecules 2010, 15, 128-137. 
(151) Fujisaki, F.; Toyofuku, K.; Egami, M.; Ishida, S.; Nakamoto, N.; Kashige, N.; Miake, F.; Sumoto, K. Antibacterial Activity of Some 5Dialkylaminomethylhydantoins and Related Derivatives. Chem. Pharm. Bull. 2013, 61, 1090-1093.

(152) Broeren, M. A. C.; de Waal, B. F. M.; van Genderen, M. H. P.; Sanders, H. M. H. F.; Fytas, G.; Meijer, E. W. Multicomponent HostGuest Chemistry of Carboxylic Acid and Phosphonic Acid Based Guests with Dendritic Hosts: An NMR Study. J. Am. Chem. Soc. 2005, 127, 10334-10343.

(153) Beckmann, H. S. G.; Nie, F.; Hagerman, C. E.; Johansson, H.; Tan, Y. S.; Wilcke, D.; Spring, D. R. A Strategy for the DiversityOriented Synthesis of Macrocyclic Scaffolds Using Multidimensional Coupling. Nat. Chem. 2013, 5, 861-867.

(154) Li, K.; Shi, D.-Q. Synthesis and Herbicidal Activity of 3-Aryl-1[2-(Aryloxy)propanoyl]imidazolidine-2,4-diones. J. Heterocycl. Chem. 2009, 46, 544-547.

(155) Park, J.-H.; Lee, G.-E.; Lee, S.-D.; Hien, T. T.; Kim, S.; Yang, J. W.; Cho, J.-H.; Ko, H.; Lim, S.-C.; Kim, Y.-G.; et al. Discovery of Novel 2,5-Dioxoimidazolidine-based P2 $\times 7$ Receptor Antagonists as Constrained Analogues of KN62. J. Med. Chem. 2015, 58, 2114-2134.

(156) Haridas, V.; Sadanandan, S.; Hundal, G.; Suresh, C. H. 1,3Phenyl Linked Urea-based Receptors for Anions and the Facile Cyclization to Imidazolidinedione. Tetrahedron Lett. 2012, 53, 55235527.

(157) Dieltiens, N.; Claeys, D. D.; Zhdankin, V. V.; Nemykin, V. N.; Allaert, B.; Verpoort, F.; Stevens, C. V. The Pyroglutamate Hydantoin Rearrangement. Eur. J. Org. Chem. 2006, 11, 2649-2660.

(158) Colacino, E.; Lamaty, F.; Martinez, J.; Parrot, I. MicrowaveAssisted Solid-Phase Synthesis of Hydantoin Derivatives. Tetrahedron Lett. 2007, 48, 5317-5320.

(159) El Bakkari, M.; Vincent, J.-M. Fluorous Phase-switching of Pyridyl-tagged Substrates/Products. Org. Lett. 2004, 6, 2765-2767.

(160) Sokolov, V. B.; Epishina, T. A.; Aksinenko, A. Y. Esters of 2-Aryl2-isocyanato-3,3,3-trifluoropropionic Acid in Cyclocondensation with Amines. Russ. J. Gen. Chem. 2012, 82, 672-675.

(161) Sokolov, V. B.; Goreva, T. V.; Epishina, T. A.; Aksinenko, A. Y. Cyclocondensation of 2-Alkoxy-2-isocyanato-3,3,3-trifluoropropionates with Primary Amines. Russ. Chem. Bull. 2012, 61, 670-673.

(162) Liu, H.; Yang, Z. M.; Pan, Z. Y. Synthesis of Highly Substituted Imidazolidine-2,4-dione (Hydantoin) through $\mathrm{Tf}_{2} \mathrm{O}$-mediated Dual Activation of Boc-protected Dipeptidyl Compounds. Org. Lett. 2014, 16, 5902-5905.

(163) Verhelst, S. H. L.; Witte, M. D.; Arastu-Kapur, S.; Fonovic, M.; Bogyo, M. Novel Aza Peptide Inhibitors and Active-site Probes of Papain-family Cysteine Proteases. ChemBioChem 2006, 7, 943-950.

(164) Arumugasamy, J.; Arunachalam, K.; Bauer, D.; Becker, A.; Caillet, C. A.; Glynn, R.; Latham, G. M.; Lim, J.; Liu, J.; Mayes, B. A.; et al. Development of Related HCV Protease Inhibitors: Macrocyclization of Two Highly Functionalized Dienyl-ureas Via RingClosing Metathesis. Org. Process Res. Dev. 2013, 17, 811-828.

(165) Dadiboyena, S.; Nefzi, A. Parallel Solid-Phase Synthesis of Disubstituted 3-(1H-Benzo[d]imidazol-2-yl)imidazolidine-2,4-diones and 3-(1H-Benzo[d]imidazol-2-yl)-2-thioxoimidazolidin-4-ones. Tetrahedron Lett. 2011, 52, 7030-7033.

(166) Vazquez, J.; Royo, M.; Albericio, F. Re-evaluation of a SolidPhase Hydantoin Synthesis. Lett. Org. Chem. 2004, 1, 224-226.

(167) Vazquez, J.; Garcia-Jareno, A.; Mondragon, L.; Rubio-Martinez, J.; Perez-Paya, E.; Albericio, F. Conformationally Restricted HydantoinBased Peptidomimetics as Inhibitors of Caspase-3 with Basic Groups Allowed at the S3 Enzyme Subsite. ChemMedChem 2008, 3, 979-985.

(168) Declerck, V.; Colacino, E.; Bantreil, X.; Martinez, J.; Lamaty, F. Poly(ethylene Glycol) as Reaction Medium for Mild Mizoroki-Heck Reaction in a Ball-Mill. Chem. Commun. 2012, 48, 11778-11780.

(169) Hasa, D.; Carlino, E.; Jones, W. Polymer-Assisted Grinding (POLAG), a Versatile Method for Polymorph Control of Cocrystallization. Cryst. Growth Des. 2016, 16, 1772-1779.

(170) Mascitti, A.; Lupacchini, M.; Guerra, R.; Taydakov, I.; Tonucci, L.; d'Alessandro, N.; Lamaty, F.; Martinez, J.; Colacino, E. Poly(ethylene Glycol)s as Grinding Additives in the Mechanochemical Preparation of
Highly Functionalized 3,5-Disubstituted Hydantoins. Beilstein J. Org. Chem. 2017, 13, 19-25.

(171) Varchi, G.; Guerrini, A.; Tesei, A.; Brigliadori, G.; Bertucci, C.; Di Donato, M.; Castoria, G. Nonsteroidal Androgen Receptor Ligands: Versatile Syntheses and Biological Data. ACS Med. Chem. Lett. 2012, 3, 454-458.

(172) Wefer, J.; Lindel, T. Total Synthesis of the Marine Natural Product Parazoanthine F by Copper-Mediated C-N Coupling. Eur. J. Org. Chem. 2015, 28, 6370-6381.

(173) Bolognese, A.; Correale, G.; Manfra, M.; Esposito, A.; Novellino, E.; Lavecchia, A. Antitumor Agents 6. Synthesis, Structure-Activity Relationships, and Biological Evaluation of Spiro[imidazolidine-4,3' thieno[2,3-g] quinoline]-tetraones and Spiro[thieno[2,3-g]quinoline$3,5^{\prime}-[1,2,4]$ triazinane $]$-tetraones with Potent Antiproliferative Activity. J. Med. Chem. 2008, 51, 8148-8157.

(174) Lee, J.; Park, T.; Jeong, S.; Kim, K.-H.; Hong, C. 3Hydroxychromones as Cyclin-Dependent Kinase Inhibitors: Synthesis and Biological Evaluation. Bioorg. Med. Chem. Lett. 2007, 17, 12841287.

(175) Jamali, H.; Khan, H. A.; Stringer, J. R.; Chowdhury, S.; Ellman, J. A. Identification of Multiple Structurally Distinct, Nonpeptidic Small Molecule Inhibitors of Protein Arginine Deiminase 3 Using a Substratebased Fragment Method. J. Am. Chem. Soc. 2015, 137, 3616-3621.

(176) Wang, G.; Wang, Y.; Wang, L.; Han, L.; Hou, X.; Fu, H.; Fang, H. Design, Synthesis and Preliminary Bioactivity Studies of Imidazolidine2,4-dione Derivatives as BCL-2 Inhibitors. Bioorg. Med. Chem. 2015, 23, $7359-7365$

(177) Teng, X.; Degterev, A.; Jagtap, P.; Xing, X.; Choi, S.; Denu, R.; Yuan, J.; Cuny, G. D. Structure-Activity Relationship Study of Novel Necroptosis Inhibitors. Bioorg. Med. Chem. Lett. 2005, 15, 5039-5044.

(178) Zhang, D.; Xing, X.; Cuny, G. D. Synthesis of Hydantoins from Enantiomerically Pure $\alpha$-Amino Amides without Epimerization. J. Org. Chem. 2006, 71, 1750-1753.

(179) Opacic, N.; Barbaric, M.; Zorc, B.; Cetina, M.; Nagl, A.; Frkovic, D.; Kralj, M.; Pavelic, K.; Balzarini, J.; Andrei, G.; et al. The Novel L- and D-Amino Acid Derivatives of Hydroxyurea and Hydantoins: Synthesis, X-Ray Crystal Structure Study, and Cytostatic and Antiviral Activity Evaluations. J. Med. Chem. 2005, 48, 475-482.

(180) Rajic, Z.; Zorc, B.; Raic-Malic, S.; Ester, K.; Kralj, M.; Pavelic, K.; Balzarini, J.; De Clercq, E.; Mintas, M. Hydantoin Derivatives of L- and D-Amino Acids: Synthesis and Evaluation of Their Antiviral and Antitumor Activity. Molecules 2006, 11, 837-848.

(181) Fischer, L.; Semetey, V.; Lozano, J.-M.; Schaffner, A.-P.; Briand, J.-P.; Didierjean, C.; Guichard, G. Succinimidyl Carbamate Derivatives from N-Protected $\alpha$-Amino Acids and Dipeptides-Synthesis of Ureidopeptides and Oligourea/Peptide Hybrids. Eur. J. Org. Chem. 2007, 15, 2511-2525.

(182) Zaccaro, L.; Garcia-Lopez, M. T.; Gonzalez-Muniz, R.; GarciaMartinez, C.; Ferrer-Montiel, A.; Albericio, F.; Royo, M. TRPV1Modulators: Structure-Activity Relationships Using a Rational Combinatorial Approach. Bioorg. Med. Chem. Lett. 2011, 21, 3541-3545.

(183) Davies, R.; Rydberg, P.; Westberg, E.; Motwani, H. V.; Johnstone, E.; Törnqvist, M. A New General Pathway for Synthesis of Reference Compounds of N-Terminal Valine-isocyanate Adducts. Chem. Res. Toxicol. 2010, 23, 540-546.

(184) Dumbris, S. M.; Diaz, D. J.; McElwee-White, L. Preparation of Hydantoins by Catalytic Oxidative Carbonylation of Alpha-Amino Amides. J. Org. Chem. 2009, 74, 8862-8865.

(185) Paz, J.; Perez-Balado, C.; Iglesias, B.; Munoz, L. Different Reactivity of Hydroxylamine with Carbamoyl Azides and Carbamoyl Cyanides: Synthesis of Hydroxyureas and Carbamoyl Amidoximes. J. Org. Chem. 2010, 75, 8039-8047.

(186) Malcor, J.-D.; Brouillette, Y.; Graffion, J.; Spielmann, K.; Masurier, N.; Maillard, L. T.; Martinez, J.; Lisowski, V. Synthesis and Reactivity of Pyrrolo[3,2-d][1,3] oxazine-2,4-dione. Access to New Pyrrolo[3,2-e][1,4]diazepine-2,5-diones. Tetrahedron 2014, 70, 46314639. 
(187) Brouillette, Y.; Lisowski, V.; Guillon, J.; Massip, S.; Martinez, J. Efficient One-Pot Microwave-Assisted Synthesis of 3-(Thien-3-yl)imidazolidine-2,4-dione Analogs. Tetrahedron 2007, 63, 7538-7544.

(188) Brouillette, Y.; Sujol, G.; Martinez, J.; Lisowski, V. RegioControlled Nucleophilic Attack of 3-Thiaisatoic Anhydride by $\alpha$-Amino Acids: One-Pot Synthesis of 3-(2-Thienyl)imidazolidine-2,4-dione and 3,4-Substituted Thieno[2,3-e][1,4] diazepine-2,5-dione Analogues. Synthesis 2009, 3, 389-394.

(189) Sokolov, V. B.; Aksinenko, A. Y. Modification of Biologically Active Amides and Amines with Fluorine-Containing Heterocycles. 6. Methyl 3,3,3-Trifluoro-2-(3-methyl-5-oxo-1-phenyl-1,5-dihydro-4Hpyrazol-4-ylidene)propionate in Cyclocondensation with 1,3-Binucleophiles. Russ. Chem. Bull. 2012, 61, 1965-1968.

(190) Hillier, M. C.; Gong, H.-H.; Clyne, D. S.; Babcock, M. J. Synthesis of Hydantoins and Dihydrouracils Via Thermally-Promoted Cyclization of Ureidoacetamides. Tetrahedron 2014, 70, 9413-9420.

(191) Pesquet, A.; Daich, A.; Decroix, B.; Van Hijfte, L. Acid-Catalysed Formation of Tricyclic N,S-Acetals in Imidazolinone Series Based on the Use of the Unprecedented N-Acyliminium Ion Cascade Reaction Involving Transposition, Heterocyclisation and Pi-Cyclisation. Org. Biomol. Chem. 2005, 3, 3937-3947.

(192) Pham, T. Q.; Pyne, S. G.; Skelton, B. W.; White, A. H. Synthesis of Carbocyclic Hydantocidins Via Regioselective and Diastereoselective Phosphine-Catalyzed [3 + 2]-Cycloadditions to 5-Methylenehydantoins. J. Org. Chem. 2005, 70, 6369-6377.

(193) Dandepally, S. R; Williams, A. L. Synthesis of Imidazoisoindol3-ones by a Palladium-catalyzed Intramolecular C-H Insertion Reaction. Tetrahedron Lett. 2009, 50, 1395-1398.

(194) Wang, R.-L.; Li, W.-M.; Liu, M.-Y.; Xu, W.-R. Synthesis and Biological Activity Evaluation of Novel Imidazolidinedione Derivatives as Potent Antidiabetic Agents. J. Chin. Chem. Soc. 2009, 56, 34-39.

(195) Lee, J.; Kim, J.; Koh, J. S.; Chung, H.-H.; Kim, K.-H. Hydantoin Derivatives as Non-Peptidic InOhibitors of RAS Farnesyl Transferase. Bioorg. Med. Chem. Lett. 2006, 16, 1954-1956.

(196) Wang, D.-W.; Syu, S.-E.; Hung, Y.-T.; Chen, P.-Y.; Lee, C.-J.; Chen, K.-W.; Chen, Y.-J.; Lin, W.-W. Organocatalytic Tandem ThreeComponent Reaction of Aldehyde, Alkyl Vinyl Ketone, and Amide: One-Pot Syntheses of Highly Functional Alkenes. Org. Biomol. Chem. 2011, 9, 363-366.

(197) Greenfield, A. A.; Butera, J. A. Convenient Synthesis and Isolation of Conformationally Rigid Glutamic Acid Analogues. Synth. Commun. 2004, 34, 3939-3947.

(198) Crosignani, S.; Jorand-Lebrun, C.; Page, P.; Campbell, G.; Colovray, V.; Missotten, M.; Humbert, Y.; Cleva, C.; Arrighi, J. F.; Gaudet, M.; et al. Optimization of the Central Core of Indolinone-acetic Acid-based CRTH2 (Dp2) Receptor Antagonists. ACS Med. Chem. Lett. 2011, 2, 644-649.

(199) Yamashita, H.; Demizu, Y.; Misawa, T.; Shoda, T.; Kurihara, M. Synthesis of a Bis-cationic $\alpha, \alpha$-Disubstituted Amino Acid (9-Aminobispidine-9-carboxylic Acid) and its Effects on the Conformational Properties of Peptides. Tetrahedron 2015, 71, 2241-2245.

(200) Handzlik, J.; Szymanska, E.; Chevalier, J.; Otrebska, E.; KiecKononowicz, K.; Pages, J. M.; Alibert, S. Amine-Alkyl Derivatives of Hydantoin: New Tool to Combat Resistant Bacteria. Eur. J. Med. Chem. 2011, 46, 5807-5816.

(201) Handzlik, J.; Szymanska, E.; Nedza, K.; Kubacka, M.; Siwek, A.; Mogilski, S.; Handzlik, J.; Filipek, B.; Kiec-Kononowicz, K. Pharmacophore Models Based Studies on the Affinity and Selectivity toward 5HT1A with Reference to Alpha1-Adrenergic Receptors among Arylpiperazine Derivatives of Phenytoin. Bioorg. Med. Chem. 2011, 19, $1349-1360$.

(202) Moribe, K.; Ogino, A.; Kumamoto, T.; Ishikawa, T.; Limwikrant, W.; Higashi, K.; Yamamoto, K. Mechanism of Nanoparticle Formation from Ternary Coground Phenytoin and Its Derivatives. J. Pharm. Sci. 2012, 101, 3413-3424.

(203) Bapna, M.; Parashar, B.; Sharma, V. K.; Chouhan, L. S. Microwave-Assisted Synthesis of Some Novel and Potent Antibacterial and Antifungal Compounds with Biological Screening. Med. Chem. Res. 2012, 21, 1098-1106.
(204) Yousefi, R.; Whitehead, D. C.; Mueller, J. M.; Staples, R. J.; Borhan, B. On the Chlorenium Source in the Asymmetric Chlorolactonization Reaction. Org. Lett. 2011, 13, 608-611.

(205) Lu, G.-J.; Nie, J.-Q.; Chen, Z.-X.; Yang, G.-C.; Lu, C.-F. Synthesis and Evaluation of a New Non-cross-linked Polystyrene Supported Hydantoin Chiral Auxiliary for Asymmetric Aldol Reactions. Tetrahedron: Asymmetry 2013, 24, 1331-1335.

(206) Whitehead, D. C.; Staples, R. J.; Borhan, B. A Simple and Expedient Method for the Preparation of N-Chlorohydantoins. Tetrahedron Lett. 2009, 50, 656-658.

(207) Kocer, H. B.; Worley, S. D.; Broughton, R. M.; Acevedo, O.; Huang, T. S. Effect of Phenyl Derivatization on the Stabilities of Antimicrobial N-Chlorohydantoin Derivatives. Ind. Eng. Chem. Res. 2010, 49, 11188-11194.

(208) McCann, B. W.; Song, H.; Kocer, H. B.; Cerkez, I.; Acevedo, O.; Worley, S. D. Inter- and Intramolecular Mechanisms for Chlorine Rearrangements in Trimethyl-substituted N-Chlorohydantoins. J. Phys. Chem. A 2012, 116, 7245-7252.

(209) Francavilla, C.; Turtle, E. D.; Kim, B.; O’Mahony, D. J. R.; Shiau, T. P.; Low, E.; Alvarez, N. J.; Celeri, C. E.; D’Lima, L.; Friedman, L. C.; et al. Novel N-Chloroheterocyclic Antimicrobials. Bioorg. Med. Chem. Lett. 2011, 21, 3029-3033.

(210) Padmanabhuni, R. V.; Luo, J.; Cao, Z.; Sun, Y. Preparation and Characterization of N-Halamine-based Antimicrobial Fillers. Ind. Eng. Chem. Res. 2012, 51, 5148-5156.

(211) Kocer, H. B.; Cerkez, I.; Worley, S. D.; Broughton, R. M.; Huang, T. S. Polymeric Antimicrobial N-Halamine Epoxides. ACS Appl. Mater. Interfaces 2011, 3, 2845-2850.

(212) Krolenko, K. Y.; Silin, O. V.; Vlasov, S. V.; Zhuravel, I. O.; Kovalenko, S. M. An Efficient Synthesis of 1,3,7-Triazaspiro[4.4] nonane-2,4-dione Derivatives and Antimicrobial Activity Thereof. Chem. Heterocycl. Compd. 2015, 51, 472-477.

(213) Rahma, H.; Asghari, S.; Logsetty, S.; Gu, X.; Liu, S. Preparation of Hollow N-Chloramine-functionalized Hemispherical Silica Particles with Enhanced Efficacy against Bacteria in the Presence of Organic Load: Synthesis, Characterization, and Antibacterial Activity. ACS Appl. Mater. Interfaces 2015, 7, 11536-11546.

(214) Liu, Y.; Li, J.; Li, L.; McFarland, S.; Ren, X.; Acevedo, O.; Huang, T. S. Characterization and Mechanism for the Protection of Photolytic Decomposition of N-Halamine Siloxane Coatings by Titanium Dioxide. ACS Appl. Mater. Interfaces 2016, 8, 3516-3523.

(215) Trost, B. M.; Stiles, D. T. Synthesis of Allenamides by CopperCatalyzed Coupling of Allenyl Halides with Amides, Carbamates, and Ureas. Org. Lett. 2005, 7, 2117-2120.

(216) Maligres, P. E.; Krska, S. W.; Dormer, P. G. A Soluble Copper(I) Source and Stable Salts of Volatile Ligands for Copper-catalyzed C-X Couplings. J. Org. Chem. 2012, 77, 7646-7651.

(217) Goossen, L. J.; Blanchot, M.; Brinkmann, C.; Goossen, K.; Karch, R.; Rivas-Nass, A. Ru-Catalyzed Stereoselective Addition of Imides to Alkynes. J. Org. Chem. 2006, 71, 9506-9509.

(218) Buba, A. E.; Arndt, M.; Goossen, L. J. Z-Selective Hydroamidation of Terminal Alkynes with Secondary Amides and Imides Catalyzed by a Ru/Yb-System. J. Organomet. Chem. 2011, 696, 170178 .

(219) Demmer, C. S.; Benoit, E.; Evano, G. Synthesis of Allenamides by Copper-catalyzed Coupling of Propargylic Bromides and Nitrogen Nucleophiles. Org. Lett. 2016, 18, 1438-1441.

(220) Aoki, Y.; Umezawa, N.; Asano, Y.; Hatano, K.; Yano, Y.; Kato, N.; Higuchi, T. A Versatile Strategy for the Synthesis of Crown EtherBearing Heterocycles: Discovery of Calcium-Selective Fluoroionophore. Bioorg. Med. Chem. 2007, 15, 7108-7115.

(221) Volonterio, A.; Ramirez de Arellano, C.; Zanda, M. Synthesis of 1,3,5-Trisubstituted Hydantoins by Regiospecific Domino Condensation/Aza-Michael/O $\rightarrow \mathrm{N}$ Acyl Migration of Carbodiimides with Activated $\alpha, \beta$-Unsaturated Carboxylic Acids. J. Org. Chem. 2005, 70, $2161-2170$

(222) Olimpieri, F.; Volonterio, A.; Zanda, M. Three-component, One-Pot Sequential Synthesis of 1,3-Disubstituted 5-Arylhydantoins. Synlett 2008, 19, 3016-3020. 
(223) Olimpieri, F.; Bellucci, M. C.; Marcelli, T.; Volonterio, A. Regioselective Multicomponent Sequential Synthesis of Hydantoins. Org. Biomol. Chem. 2012, 10, 9538-9555.

(224) Volonterio, A.; Zanda, M. One-Pot, Regioselective Synthesis of 1,3,5-Trisubstituted Hydantoins by Domino Condensation/AzaMichael/O $\rightarrow \mathrm{N}$ Acyl Migration of Unsymmetrical Carbodiimides with $\alpha, \beta$-Unsaturated Carboxylic Acids. Lett. Org. Chem. 2005, 2, 44-46.

(225) Bellucci, M. C.; Ghilardi, A.; Volonterio, A. Three-component, One-Pot Sequential Synthesis of Glyco-hydantoin Conjugates. Org. Biomol. Chem. 2011, 9, 8379-8392.

(226) Bellucci, M. C.; Sani, M.; Sganappa, A.; Volonterio, A. Diversity Oriented Combinatorial Synthesis of Multivalent Glycomimetics through a Multicomponent Domino Process. ACS Comb. Sci. 2014, 16, 711-720.

(227) Bellucci, M. C.; Sganappa, A.; Sani, M.; Volonterio, A. Multicomponent Diversity Oriented Synthesis of Multivalent Glycomimetics Containing Hexafluorovaline. Tetrahedron 2015, 71, 76307637.

(228) Bellucci, M. C.; Volonterio, A. Synthesis of N-Glycosyl Conjugates through a Multicomponent Domino Process. Eur. J. Org. Chem. 2014, 2014, 2386-2397.

(229) Bellucci, M. C.; Frigerio, M.; Marcelli, T.; Volonterio, A. Multicomponent Synthesis of N-Carbamoyl Hydantoin Derivatives. Synlett 2013, 24, 727-732.

(230) Zhang, D.; Ye, D.; Feng, E.; Wang, J.; Shi, J.; Jiang, H.; Liu, H. Highly $\alpha$-Selective Synthesis of Sialyl Spirohydantoins by Regiospecific Domino Condensation/O $\rightarrow \mathrm{N}$ Acyl Migration/N-Sialylation of Carbodiimides with Peracetylated Sialic Acid. J. Org. Chem. 2010, 75, 35523557.

(231) Talhi, O.; Fernandes, J. A.; Pinto, D. C. G. A.; Almeida Paz, F. A.; Silva, A. S. M. Diastereoselective Synthesis of Benzofuran-3(2H)-onehydantoin Dyads. Tetrahedron 2013, 69, 5413-5420.

(232) Talhi, O.; Lopes, G. R.; Santos, S. M.; Pinto, D. C. G. A.; Silva, A. M. S. Visible Light-induced Diastereoselective E/Z-Photoisomerization Equilibrium of the $\mathrm{C}=\mathrm{C}$ Benzofuran-3-one-hydantoin Dyad. J. Phys. Org. Chem. 2014, 27, 756-763.

(233) Fernandez-Nieto, F.; Rosello, J. M.; Lenoir, S.; Hardy, S.; Clayden, J. Palladium Catalyzed C-Arylation of Amino Acid Derived Hydantoins. Org. Lett. 2015, 17, 3838-3841.

(234) Castagna, D.; Duffy, E. L.; Semaan, D.; Young, L. C.; Pritchard, J. M.; Macdonald, S. J. F.; Budd, D. C.; Jamieson, C.; Watson, A. J. B. Identification of a Novel Class of Autotaxin Inhibitors through CrossScreening. MedChem Comm 2015, 6, 1149-1155.

(235) Kacem, Y.; Ben Hassine, B. Efficient Synthesis of New Imidazo[1,2-b][1,2] benzothiazine 4,4-Dioxide Derivatives Via Lateral Lithiation of N-Mesitylenesulfonyl Hydantoins. Tetrahedron Lett. 2012, $53,5608-5610$.

(236) Lee, B. S.; Mahajan, S.; Clapham, B.; Janda, K. D. Suspension Ring-Opening Metathesis Polymerization: The Preparation of Norbornene-based Resins for Application in Organic Synthesis. J. Org. Chem. 2004, 69, 3319-3329.

(237) Lesuisse, D.; Mauger, J.; Nemecek, C.; Maignan, S.; Boiziau, J.; Harlow, G.; Hittinger, A.; Ruf, S.; Strobel, H.; Nair, A.; et al. Discovery of the First Non-ATP Competitive IGF-1R Kinase Inhibitors: Advantages in Comparison with Competitive Inhibitors. Bioorg. Med. Chem. Lett. 2011, 21, 2224-2228.

(238) Severinsen, R.; Lau, J. F.; Bondensgaard, K.; Hansen, B. S.; Begtrup, M.; Ankersen, M. Parallel Solid-Phase Synthesis of Disubstituted (5-Biphenyltetrazolyl) Hydantoins and Thiohydantoins Targeting the Growth Hormone Secretagogue Receptor. Bioorg. Med. Chem. Lett. 2004, 14, 317-320.

(239) Zhang, W.; Nagashima, T.; Lu, Y.; Chen, C. H.-T. A Traceless Perfluorooctylsulfonyl Tag for Deoxygenation of Phenols under Microwave Irradiation. Tetrahedron Lett. 2004, 45, 4611-4613.

(240) Lu, Y.; Zhang, W. Fluorous Parallel Synthesis of a Hydantoin/ Thiohydantoin Library. Mol. Diversity 2005, 9, 91-98.

(241) Park, H.-S.; Choi, H.-J.; Shin, H.-S.; Lee, S. K.; Park, M.-S. Synthesis and Characterization of Novel Hydantoins as Potential COX-
2 Inhibitors: 1,5-Diarylhydantoins. Bull. Korean Chem. Soc. 2007, 28, $751-757$.

(242) Teno, N.; Gohda, K.; Wanaka, K.; Tsuda, Y.; Akagawa, M.; Akiduki, E.; Araki, M.; Masuda, A.; Otsubo, T.; Yamashita, Y. Novel Type of Plasmin Inhibitors: Providing Insight into P4Moiety and Alternative Scaffold to Pyrrolopyrimidine. Bioorg. Med. Chem. 2015, 23, 3696-3704.

(243) Nieto, M. J.; Philip, A. E.; Poupaert, J. H.; McCurdy, C. R. Solution-Phase Parallel Synthesis of Spirohydantoins. J. Comb. Chem. 2005, 7, 258-263.

(244) Lee, M.-J.; Sun, C.-M. Traceless Synthesis of Hydantoin by Focused Microwave Irradiation. Tetrahedron Lett. 2004, 45, 437-440.

(245) Arafa, R. K.; Nour, M. S.; El-Sayed, N. A. Novel HeterocyclicFused Pyrimidine Derivatives: Synthesis, Molecular Modeling and Pharmacological Screening. Eur. J. Med. Chem. 2013, 69, 498-507.

(246) Rmedi, H.; Baklouti, A. A New Approach for the Synthesis of NSulfonyl Hydantoins. Tetrahedron Lett. 2014, 55, 3585-3587.

(247) Attanasi, O. A.; Crescentini, L.; Favi, G.; Nicolini, S.; Perrulli, F. R. Santeusanio, S. 1,3,5-Trisubstituted and 5-Acyl-1,3-disubstituted Hydantoin Derivatives Via Novel Sequential Three-component Reaction. Org. Lett. 2011, 13, 353-355.

(248) Attanasi, O. A.; De Crescentini, L.; Filippone, P.; Giorgi, G.; Nicolini, S.; Perrulli, F. R.; Santeusanio, S. From Targeted Aza-Michael Addition to Linked Azaheterocyclic Scaffolds. Tetrahedron 2014, 70, $7336-7343$

(249) Aranha Potter, R.; Bowser, A. M.; Yang, Y.; Madalengoitia, J. S.; Ziller, J. W. Structure-Reactivity Relationships of Zwitterionic 1,3-DiazaClaisen Rearrangements. J. Org. Chem. 2013, 78, 11772-11782.

(250) Rigby, J. H.; Brouet, S. A. Metal-Mediated Reactions of Aryl Isocyanates with Dimethoxycarbene to Form Isatin Derivatives. Tetrahedron Lett. 2013, 54, 2542-2545.

(251) Nique, F.; Hebbe, S.; Peixoto, C.; Annoot, D.; Lefrancois, J.-M.; Duval, E.; Michoux, L.; Triballeau, N.; Lemoullec, J.-M.; Mollat, P.; et al. Discovery of Diarylhydantoins as New Selective Androgen Receptor Modulators. J. Med. Chem. 2012, 55, 8225-8235.

(252) Gao, M.; Yang, Y.; Wu, Y.-D.; Deng, C.; Shu, W.-M.; Zhang, D.X.; Cao, L.-P.; She, N.-F.; Wu, A.-X. An Efficient Synthesis of Hydantoins Via Sustainable Integration of Coupled Domino Processes. Org. Lett. 2010, 12, 4026-4029.

(253) Ventosa-Andres, P.; Gonzalez-Vera, J. A.; Garcia-Lopez, M. T.; Herranz, R. Chameleonic Reactivity of $\alpha$-Amino Nitrile-derived Ureas. Synthesis of Highly Functionalized Imidazolidin-2-one and Imidazolidine-2,4-dione Derivatives. Tetrahedron 2014, 70, 3407-3412.

(254) Latli, B.; Byrne, D.; Nummy, L.; Krishnamurthy, D.; Senanayake, C. H. Synthesis of Potent Lymphocyte Function-associated Antigen-1 Inhibitors Labeled with Carbon-14 and Deuterium, Part 1b. J. Labelled Compd. Radiopharm. 2011, 54, 763-768.

(255) van der Stelt, M.; Cals, J.; Broeders-Josten, S.; Cottney, J.; van der Doelen, A. A.; Hermkens, M.; de Kimpe, V.; King, A.; Klomp, J.; Oosterom, J.; et al. Discovery and Optimization of 1-(4-(Pyridin-2yl)benzyl)imidazolidine-2,4-dione Derivatives as a Novel Class of Selective Cannabinoid CB2 Receptor Agonists. J. Med. Chem. 2011, 54, $7350-7362$.

(256) Methot, J. L.; Dunstan, T. A.; Mampreian, D. M.; Adams, B.; Altman, M. D. An Unexpected Aminocyclopropane Reductive Rearrangement. Tetrahedron Lett. 2008, 49, 1155-1159.

(257) Teno, N.; Gohda, K.; Yamashita, Y.; Otsubo, T.; Yamaguchi, M.; Wanaka, K.; Tsuda, Y. Plasmin Inhibitors with Hydrophobic Amino Acid-based Linker between Hydantoin Moiety and Benzimidazole Scaffold Enhance Inhibitory Activity. Bioorg. Med. Chem. Lett. 2016, 26, 2259-2261.

(258) Jamieson, A. G.; Russell, D.; Hamilton, A. D. A 1,3-Phenyl-linked Hydantoin Oligomer Scaffold as a $\beta$-Strand Mimetic. Chem. Commun. 2012, 48, 3709-3711.

(259) Campestre, C.; Tortorella, P.; Agamennone, M.; Preziuso, S.; Biasone, A.; Nuti, E.; Rossello, A.; Gallina, C. Peptidyl 3-Substituted 1Hydroxyureas as Isosteric Analogues of Succinylhydroxamate MMP Inhibitors. Eur. J. Med. Chem. 2008, 43, 1008-1014. 
(260) Chernov, S. V.; Shul'ts, E. E.; Shakirov, M. M.; Gatilov, Y. V.; Tolstikov, G. A. Synthetic Transformations of Higher Terpenoids: XX. Synthesis and Transformations of Diterpene Ureido Esters. Russ. J. Org. Chem. 2010, 46, 1140-1150.

(261) Saloutina, L. V.; Zapevalov, A. Y.; Slepukhin, P. A.; Kodess, M. I.; Saloutin, V. I.; Chupakhin, O. N. Synthesis of Fluorine-containing Imidazolidin-2-ones, Glycolurils, and Hydantoins Based on Perfluorodiacetyl and Ureas. Chem. Heterocycl. Compd. 2014, 50, 958-966.

(262) Ignacio, J. M.; Macho, S.; Marcaccini, S.; Pepino, R.; Torroba, T. A Facile Synthesis of 1,3,5-Trisubstituted Hydantoins Via Ugi Fourcomponent Condensation. Synlett 2005, 20, 3051-3054.

(263) Sanudo, M.; Garcia-Valverde, M.; Marcaccini, S.; Torroba, T. A Diastereoselective Synthesis of Pseudopeptidic Hydantoins by an Ugi/ Cyclization/Ugi Sequence. Tetrahedron 2012, 68, 2621-2629.

(264) Medda, F.; Hulme, C. A Facile and Rapid Route for the Synthesis of Novel 1,5-Substituted Tetrazole Hydantoins and Thiohydantoins Via a $\mathrm{TMSN}_{3}$-Ugi/RNCX Cyclization. Tetrahedron Lett. 2012, 53, 55935596.

(265) Medda, F.; Martinez-Ariza, G.; Hulme, C. A Facile and Concise Route toward the Synthesis of Novel Imidazo-tetrazolodiazepinones Via Post-Condensation Modifications of the Ugi-azide Adduct. Tetrahedron Lett. 2015, 56, 5295-5298.

(266) Han, W.; Wu, J.; Dai, W.-M. Synthesis of Highly Functionalized Benzofuran-2-carboxamides by Ugi Four-component Reaction and Microwave-assisted Rap-Stoermer Reaction. Synlett 2014, 25, 20192024.

(267) Sehlinger, A.; Schneider, R.; Meier, M. A. R. Ugi Reactions with $\mathrm{CO}_{2}$ : Access to Functionalized Polyurethanes, Polycarbonates, Polyamides, and Polyhydantoins. Macromol. Rapid Commun. 2014, 35, $1866-1871$.

(268) Nikolaev, A. E.; Semenov, V. E.; Sharafutdinova, D. R.; Efremov, Y. Y.; Reznik, V. S. Macrocyclic 5-Bromouracil Derivatives: Synthesis and Transformation of a Uracil Ring. Tetrahedron Lett. 2008, 49, 59945997.

(269) Falcone, D.; Osimboni, E.; Guerin, D. J. N-Arylation of Carbamate-protected Glycine Derivatives Via Palladium Catalysis. Tetrahedron Lett. 2014, 55, 2646-2648.

(270) Kaschani, F.; Clerc, J.; Krahn, D.; Bier, D.; Hong, T. N.; Ottmann, C.; Niessen, S.; Colby, T.; van der Hoorn, R. A. L.; Kaiser, M. Identification of a Selective, Activity-based Probe for Glyceraldehyde 3Phosphate Dehydrogenases. Angew. Chem., Int. Ed. 2012, 51, 52305233.

(271) Fraile, J. M.; Lafuente, G.; Mayoral, J. A.; Pallares, A. Synthesis and Reactivity of 5-Methylenehydantoins. Tetrahedron 2011, 67, 86398647.

(272) Thenmozhiyal, J. C.; Wong, P. T.-H.; Chui, W.-K. Anticonvulsant Activity of Phenylmethylenehydantoins: A StructureActivity Relationship Study. J. Med. Chem. 2004, 47, 1527-1535.

(273) Luo, Y.; Ma, L.; Zheng, H.; Chen, L.; Li, R.; He, C.; Yang, S.; Ye, X.; Chen, Z.; Li, Z.; et al. Discovery of (Z)-5-(4-Methoxybenzylidene)thiazolidine-2,4-dione, a Readily Available and Orally Active Glitazone for the Treatment of Concanavalin A-Induced Acute Liver Injury of BALB/c Mice. J. Med. Chem. 2010, 53, 273-281.

(274) Evdokimov, N. M.; Magedov, I. V.; McBrayer, D.; Kornienko, A. Isatin Derivatives with Activity against Apoptosis-resistant Cancer Cells. Bioorg. Med. Chem. Lett. 2016, 26, 1558-1560.

(275) Majumdar, P.; Bathula, C.; Basu, S. M.; Das, S. K.; Agarwal, R.; Hati, S.; Singh, A.; Sen, S.; Das, B. B. Design, Synthesis and Evaluation of Thiohydantoin Derivatives as Potent Topoisomerase I (Top1) Inhibitors with Anticancer Activity. Eur. J. Med. Chem. 2015, 102, $540-551$.

(276) Lamiri, M.; Bougrin, K.; Daou, B.; Soufiaoui, M.; Nicolas, E.; Giralt, E. Microwave-assisted Solvent-free Regiospecific Synthesis of 5Alkylidene and 5-Arylidenehydantoins. Synth. Commun. 2006, 36, $1575-1584$

(277) Thirupathi Reddy, Y.; Narsimha Reddy, P.; Koduru, S.; Damodaran, C.; Crooks, P. A. Aplysinopsin Analogs: Synthesis and Anti-proliferative Activity of Substituted (Z)-5-(N-Benzylindol-3- ylmethylene)imidazolidine-2,4-diones. Bioorg. Med. Chem. 2010, 18, 3570-3574.

(278) Brun, E.; Safer, A.; Carreaux, F.; Bourahla, K.; L'Helgoua'ch, J.M.; Bazureau, J.-P.; Villalgordo, J. M. Microwave-Assisted Condensation Reactions of Acetophenone Derivatives and Activated Methylene Compounds with Aldehydes Catalyzed by Boric Acid under Solventfree Conditions. Molecules 2015, 20, 11617-11631.

(279) Alimardanov, A.; Nikitenko, A.; Connolly, T. J.; Feigelson, G.; Chan, A. W.; Ding, Z.; Ghosh, M.; Shi, X.; Ren, J.; Hansen, E.; et al. Practical Enantioselective Synthesis of a 3-Aryl-3-trifluoromethyl-2aminopropanol Derivative. Org. Process Res. Dev. 2009, 13, 1161-1168.

(280) Nishimura, T.; Kawamoto, T.; Sasaki, K.; Tsurumaki, E.; Hayashi, T. Rhodium-catalyzed Asymmetric Cyclodimerization of Oxaand Azabicyclic Alkenes. J. Am. Chem. Soc. 2007, 129, 1492-1493.

(281) Pardasani, R. T.; Pardasani, P.; Abraham, I. Synthesis and Semiempirical Studies of Quinodimethane Derivatives as Precursors for Indigoid Dyes. Indian J. Chem., Sect. B: Org. Chem. Incl. Med. Chem. 2010, 49B, 561-564.

(282) Arora, K.; Verma, S.; Joshi, R.; Pardasani, P.; Pardasani, R. T. Synthesis, Configurational Analysis and Antimicrobial Activity of Imidazolidinone, Thiazolidinone and Isoxazolone Derivatives of 9,10Phenanthrenequinone. Indian J. Chem., Sect. B: Org. Chem. Incl. Med. Chem. 2011, 50B, 83-88.

(283) Pardasani, R. T.; Pardasani, P.; Gupta, B.; Londhe, A. V.; Kohli, S. Synthesis and Semiempirical Calculations of Isatylidine, Thioisatylidine and Acenaphthylidine Derivatives of Imidazolidine, Thiazolidine, Oxazolidine and Pyrimidinetrione. Indian J. Chem., Sect. B: Org. Chem. Incl. Med. Chem. 2005, 44B, 1252-1256.

(284) Pardasani, R. T.; Prashant, A.; Sharma, K. Synthesis, Computational Study, Configurational Analysis and Biological Activity of Imidazolidinone, Thiazolidinone and Isoxazolone Derivatives of 1,2Naphthoquinone. Indian J. Chem., Sect. B: Org. Chem. Incl. Med. Chem. 2014, 53B, 619-624.

(285) Gwynne, E. A.; Holt, J. C.; Dwan, J. R.; Appoh, F. E.; Vogels, C. M.; Decken, A.; Westcott, S. A. Reaction of Hydantoin with Boronic Acids. Helv. Chim. Acta 2010, 93, 1093-1100.

(286) Bursavich, M. G.; Gilbert, A. M.; Lombardi, S.; Georgiadis, K. E.; Reifenberg, E.; Flannery, C. R.; Morris, E. A. Synthesis and Evaluation of Aryl Thioxothiazolidinone Inhibitors of ADAMTS-5 (Aggrecanase-2). Bioorg. Med. Chem. Lett. 2007, 17, 1185-1188.

(287) Xia, Z.; Knaak, C.; Ma, J.; Beharry, Z. M.; McInnes, C.; Wang, W.; Kraft, A. S.; Smith, C. D. Synthesis and Evaluation of Novel Inhibitors of PIM-1 and PIM-2 Protein Kinases. J. Med. Chem. 2009, 52, $74-86$.

(288) Feng, J.; Lu, Y.; Cai, Z. F.; Zhang, S. P.; Guo, Z. R. Design, Synthesis and in Vitro Evaluation of a Series Thiazolidinediones Analogs as PPAR Modulators. Chin. Chem. Lett. 2007, 18, 45-47.

(289) Balansa, W.; Islam, R.; Gilbert, D. F.; Fontaine, F.; Xiao, X.; Zhang, H.; Piggott, A. M.; Lynch, J. W.; Capon, R. J. Australian Marine Sponge Alkaloids as a New Class of Glycine-gated Chloride Channel Receptor Modulator. Bioorg. Med. Chem. 2013, 21, 4420-4425.

(290) Chezal, J. M.; Moreau, E.; Desbois, N.; Blache, Y.; Chavignon, O.; Teulade, J. C. Synthesis of Carbamoylpyridine and Imidazo[1,5a]pyridine-1,3-diones Via Ortho-Acetalhydantoin Intermediates. Tetrahedron Lett. 2004, 45, 553-556.

(291) Zask, A.; Birnberg, G.; Cheung, K.; Kaplan, J.; Niu, C.; Norton, E.; Yamashita, A.; Beyer, C.; Krishnamurthy, G.; Greenberger, L. M.; et al. D-Piece Modifications of the Hemiasterlin Analog HTI-286 Produce Potent Tubulin Inhibitors. Bioorg. Med. Chem. Lett. 2004, 14, 4353-4358.

(292) Handzlik, J.; Szymanska, E.; Alibert, S.; Chevalier, J.; Otrebska, E.; Pekala, E.; Pages, J.-M.; Kiec-Kononowicz, K. Search for New Tools to Combat Gram-Negative Resistant Bacteria among Amine Derivatives of 5-Arylidenehydantoin. Bioorg. Med. Chem. 2013, 21, 135-145.

(293) Akeng'a, T. O.; Read, R. W. Synthesis of Imidazo[1,5-a]indole1,3-diones from Imidazolidine-2,4-diones. S. Afr. J. Chem. 2007, 60, 1116. 
(294) Ulgheri, F.; Giunta, D.; Spanu, P. Short and Highly Stereoselective Total Synthesis of D-Ribo-configured Ureido Sugars. Tetrahedron 2008, 64, 11768-11775.

(295) Albers, H. M. H. G.; Hendrickx, L. J. D.; van Tol, R. J. P.; Hausmann, J.; Perrakis, A.; Ovaa, H. Structure-based Design of Novel Boronic Acid-based Inhibitors of Autotaxin. J. Med. Chem. 2011, 54, $4619-4626$.

(296) Aly, Y. L.; Wamberg, M.; Pedersen, E. B. Intercalating Nucleic Acids with Insertion of 5-[(Pyren-1-yl)methylidene]hydantoin-substituted Butane-1,2-diol. Helv. Chim. Acta 2005, 88, 3137-3144.

(297) El-Deeb, I. M.; Bayoumi, S. M.; El-Sherbeny, M. A.; Abdel-Aziz, A. A. M. Synthesis and Antitumor Evaluation of Novel Cyclic Arylsulfonylureas: ADME-T and Pharmacophore Prediction. Eur. J. Med. Chem. 2010, 45, 2516-2530.

(298) Jiang, S.; Tala, S. R.; Lu, H.; Zou, P.; Avan, I.; Ibrahim, T. S.; AboDya, N. E.; Abdelmajeid, A.; Debnath, A. K.; Katritzky, A. R. Design, Synthesis, and Biological Activity of a Novel Series of 2,5-Disubstituted Furans/Pyrroles as HIV-1 Fusion Inhibitors Targeting GP41. Bioorg. Med. Chem. Lett. 2011, 21, 6895-6898.

(299) Unlusoy, M. C.; Kazak, C.; Bayro, O.; Verspohl, E. J.; Ertan, R.; Dundar, O. B. Synthesis and Antidiabetic Activity of 2,4-Thiazolidindione, Imidazolidinedione and 2-Thioxo-imidazolidine-4-one Derivatives Bearing 6-Methyl Chromonyl Pharmacophore. J. Enzyme Inhib. Med. Chem. 2013, 28, 1205-1210.

(300) Harada, K.; Kubo, H.; Tanaka, A.; Nishioka, K. Identification of Oxazolidinediones and Thiazolidinediones as Potent $17 \beta$-Hydroxysteroid Dehydrogenase Type 3 Inhibitors. Bioorg. Med. Chem. Lett. 2012, 22, 504-507.

(301) Pekala, E.; Stadnicka, K.; Broda, A.; Zygmunt, M.; Filipek, B.; Kiec-Kononowicz, K. Synthesis, Structure-Activity Relationship of Some New Anti-arrhythmic 5-Arylideneimidazolidine-2,4-dione Derivatives. Eur. J. Med. Chem. 2005, 40, 259-269.

(302) Handzlik, J.; Szymanska, E.; Wojcik, R.; Dela, A.; JastrzebskaWiesek, M.; Karolak-Wojciechowska, J.; Fruzinski, A.; Siwek, A.; Filipek, B.; Kiec-Kononowicz, K. Synthesis and SAR-Study for Novel Arylpiperazine Derivatives of 5-Arylidenehydantoin with A1-Adrenoceptor Antagonistic Properties. Bioorg. Med. Chem. 2012, 20, 42454257.

(303) Kaminskyy, D.; Zimenkovsky, B.; Lesyk, R. Synthesis and in Vitro Anticancer Activity of 2,4-Azolidinedione-acetic Acids Derivatives. Eur. J. Med. Chem. 2009, 44, 3627-3636.

(304) Di Fabio, R.; Alvaro, G.; Bertani, B.; Donati, D.; Pizzi, D. M.; Gentile, G.; Pentassuglia, G.; Giacobbe, S.; Spada, S.; Ratti, E.; et al. Chiral Tetrahydroquinoline Derivatives as Potent Anti-hyperalgesic Agents in Animal Models of Sustained Inflammation and Chronic Neuropathic Pain. Bioorg. Med. Chem. Lett. 2007, 17, 1176-1180.

(305) Tinto, F.; Pagano, D.; Manzo, E. Synthesis of Parazoanthine B and Analogs. Tetrahedron 2015, 71, 4379-4384.

(306) Zhong, B.; Vatolin, S.; Idippily, N. D.; Lama, R.; Alhadad, L. A.; Reu, F. J.; Su, B. Structural Optimization of Non-nucleoside DNA Methyltransferase Inhibitor as Anti-cancer Agent. Bioorg. Med. Chem. Lett. 2016, 26, 1272-1275.

(307) Balavoine, F.; Malabre, P.; Alleaume, T.; Rey, A.; Cherfils, V.; Jeanneton, O.; Seigneurin-Venin, S.; Revah, F. Design and Synthesis of Novel Hydantoin-containing Melanin-concentrating Hormone Receptor Antagonists. Bioorg. Med. Chem. Lett. 2007, 17, 3754-3759.

(308) He, X.-Y.; Zou, P.; Qiu, J.; Hou, L.; Jiang, S.; Liu, S.; Xie, L. Design, Synthesis and Biological Evaluation of 3-Substituted 2,5Dimethyl-N-(3-(1H-tetrazol-5-yl)phenyl)pyrroles as Novel Potential HIV-1 GP41 Inhibitors. Bioorg. Med. Chem. 2011, 19, 6726-6734.

(309) Mulwad, V. V.; Langi, B. P.; Chaskar, A. C. Synthesis of Novel Biologicaliy Active Heterocyclic Compounds from 2-Oxo-2H-benzopyran-6-yl-imidazolidine. Acta Polym. Pharm. 2011, 68, 39-47.

(310) Hidayat, I.-W.; Bhadbhade, M.; Read, R. W. A Study of the Microwave-accelerated Condensation of Substituted Benzaldehydes with 3-Substituted Hydantoins and the Unexpected Interception of Alcohol Products. Procedia Chem. 2015, 17, 75-83.

(311) Ursic, U.; Groselj, U.; Meden, A.; Svete, J.; Stanovnik, B. [2 + 2] Cycloadditions of Electron-poor Acetylenes to (5Z)-5-
[(Dimethylamino)methylene]imidazolidine-2,4-diones. Helv. Chim. Acta 2009, 92, 481-490.

(312) Ursic, U.; Svete, J.; Stanovnik, B. Synthesis of 4-(2-Hydroxy-1methyl-5-oxo-1H-imidazol-4(5H)-ylidene)-5-oxo-1-aryl-4,5-dihydro1h-pyrrole-3-carboxylates, a New Triazafulvalene System. Tetrahedron 2010, 66, 4346-4356.

(313) Ivashkin, P. E.; Lukyanov, K. A.; Lukyanov, S.; Yampolsky, I. V. A Synthetic GFP-Like Chromophore Undergoes Base-catalyzed Autoxidation into Acylimine Red Form. J. Org. Chem. 2011, 76, 2782-2791.

(314) Khan, S.; Tyagi, V.; Mahar, R.; Bajpai, V.; Kumar, B.; Chauhan, P. M. S. Expedient Base-mediated Desulfitative Dimethylamination, Oxidation, or Etherification of 2-(Methylsulfanyl)-3,5-dihydro-4Himidazol-4-one Scaffolds. Synthesis 2013, 45, 2405-2412.

(315) Antipin, R. L.; Beloglazkina, E. K.; Magouga, A. G.; Chernysheva, A. N.; Zyk, N. V. A New Method for the Synthesis of 5Bromo(aryl)methylene-substituted Hydantoins. Chem. Heterocycl. Compd. 2008, 44, 1135-1137.

(316) Üngören, S. H.; Kani, I.; Gunay, A. A Facile Protocol for the Preparation of 5-Alkylidene and 5-Imino Substituted Hydantoins from N,N'-Disubstituted Parabanic Acids. Tetrahedron Lett. 2012, 53, 47584762.

(317) Wang, H.; Han, K.; Liu, J.; Yan, Z.; Hao, T.; Shen, D.; Liu, H.; Sheng, K.; Teng, Y.; Yu, P. Design, Synthesis and Biological Evaluation of Hydantoin Derivatives. J. Chem. Pharm. Res. 2014, 6, 424-427.

(318) Wang, M.-Y.; Jin, Y.-Y.; Wei, H.-Y.; Zhang, L.-S.; Sun, S.-X.; Chen, X.-B.; Dong, W.-L.; Xu, W.-R.; Cheng, X.-C.; Wang, R.-L. Synthesis, Biological Evaluation and 3D-QSAR Studies of Imidazolidine-2,4-dione Derivatives as Novel Protein Tyrosine Phosphatase 1B Inhibitors. Eur. J. Med. Chem. 2015, 103, 91-104.

(319) Zhou, S.; Ren, J.; Liu, M.; Ren, L.; Liu, Y.; Gong, P. Design, Synthesis and Pharmacological Evaluation of 6,7-Disubstituted-4phenoxyquinoline Derivatives as Potential Antitumor Agents. Bioorg. Chem. 2014, 57, 30-42.

(320) Martinez-Lopez, D.; Yu, M.-L.; Garcia-Iriepa, C.; Campos, P. J.; Frutos, L. M.; Golen, J. A.; Rasapalli, S.; Sampedro, D. Hydantoin-based Molecular Photoswitches. J. Org. Chem. 2015, 80, 3929-3939.

(321) Alizadeh, A.; Sheikhi, E. Stereospecific Synthesis of Functionalized C5-Unsaturated Hydantoin Derivatives Via a Three-component Reaction. Synthesis 2008, 39, 1061-1064.

(322) Mathur, P.; Joshi, R. K.; Rai, D. K.; Jha, B.; Mobin, S. M. One Pot Synthesis of Maleimide and Hydantoin by $\mathrm{Fe}(\mathrm{CO})_{5}$ Catalyzed $[2+2+$ 1] Co-Cyclization of Acetylene, Isocyanate and Co. Dalton Trans. 2012, $41,5045-5054$

(323) Kuninobu, Y.; Kikuchi, K.; Takai, K. Manganese-Catalyzed Synthesis of Hydantoin Derivatives from Terminal Alkynes and Isocyanates. Chem. Lett. 2008, 37, 740-741.

(324) Da Settimo, F.; Primofiore, G.; La Motta, C.; Salerno, S.; Novellino, E.; Greco, G.; Lavecchia, A.; Laneri, S.; Boldrini, E. Spirohydantoin Derivatives of Thiopyrano[2,3-b]pyridin-4(4H)-one as Potent in Vitro and in Vivo Aldose Reductase Inhibitors. Bioorg. Med. Chem. 2005, 13, 491-499.

(325) Iqbal, Z.; Hameed, S.; Ali, S.; Tehseen, Y.; Shahid, M.; Iqbal, J. Synthesis, Characterization, Hypoglycemic and Aldose Reductase Inhibition Activity of Arylsulfonylspiro[fluorene-9,5'-imidazolidine]2',4'-diones. Eur. J. Med. Chem. 2015, 98, 127-138.

(326) Prevet, H.; Flipo, M.; Roussel, P.; Deprez, B.; Willand, N. Microwave-assisted Synthesis of Functionalized Spirohydantoins as 3-D Privileged Fragments for Scouting the Chemical Space. Tetrahedron Lett. 2016, 57, 2888-2894.

(327) Aboul-Enein, M. N.; El-Azzouny, A. A.; Maklad, Y. A.; Ismail, M. A.; Ismail, N. S. M.; Hassan, R. M. Design and Synthesis of Certain Substituted Cycloalkanecarboxamides Structurally Related to Safinamide with Anticonvulsant Potential. Res. Chem. Intermed. 2015, 41, 3767-3791.

(328) Mahmoodi, N. O.; Khodaee, Z. One-Pot Diastereoselective Synthesis of New Racemic and Achiral Spirohydantoins. Mendeleev Commun. 2004, 14, 304-306. 
(329) Li, X.-G.; Rantapaju, M.; Kanerva, L. T. Candida Antarctica Lipase B in a Chemoenzymatic Route to Cyclic $\alpha$-Quaternary $\alpha$-Amino Acid Enantiomers. Eur. J. Org. Chem. 2011, 9, 1755-1762.

(330) Lee, W.; Miller, M. J. Concise Synthesis of 4-Acylamino Analogues of 2-Aminobicyclo[3.1.0]hexane-2,6-dicarboxylic Acids (LY354740) from an Acylnitroso Diels-Alder Cycloadduct. J. Org. Chem. 2004, 69, 4516-4519.

(331) Sakagami, K.; Kumagai, T.; Taguchi, T.; Nakazato, A. Scalable Synthesis of (+)-2-Amino-3-fluorobicyclo[3.1.0] hexane-2,6-dicarboxylic Acid as a Potent and Selective Group II Metabotropic Glutamate Receptor Agonist. Chem. Pharm. Bull. 2007, 55, 37-43.

(332) Oishi, S.; Kang, S.-U.; Liu, H.; Zhang, M.; Yang, D.; Deschamps, J. R.; Burke, T. R. Synthesis of $\alpha, \alpha$-Disubstituted 4-Phosphonophenylalanine Analogs as Conformationally-constrained Phosphotyrosyl Mimetics. Tetrahedron 2004, 60, 2971-2977.

(333) Martins, F. J. C.; van der Hoven, H.; Viljoen, A. M. Synthesis of Exo-3-amino-10-hydroxy-hexacyclo[ $\left[10 \cdot 2 \cdot 1 \cdot 0^{2,11} \cdot 0^{4,10} \cdot 0^{4,14} \cdot 0^{9,13}\right]$ pentadecane-5,7-diene-endo-3-carboxyclic Acid and Endo-3-amino-10hydroxy-hexacyclo $\left[10 \cdot 2 \cdot 1 \cdot 0^{2,11} \cdot 0^{4,10} \cdot 0^{4,14} \cdot 0^{9,13}\right]$ pentadecane-5,7-dieneexo-3-carboxylic Acid. Tetrahedron 2009, 65, 2921-2926.

(334) Pesquet, A.; Daich, A.; Coste, S.; Van Hijfte, L. An Unusual Polyheterocyclic Diversity by the П-Cyclisation of N-Carbamoyliminium Ion, with or without Tandem $\mathrm{N}, \mathrm{N}$-Acetal Cleavage, from Spiro(imidazolidinoquinazolinones). Synthesis 2008, 9, 1389-1396.

(335) Rowbottom, M. W.; Vickers, T. D.; Tamiya, J.; Zhang, M.; Dyck, B.; Grey, J.; Schwarz, D.; Heise, C. E.; Hedrick, M.; Wen, J.; et al. Synthesis and Structure-Activity Relationships of Spirohydantoinderived Small-molecule Antagonists of the Melanin-concentrating Hormone Receptor-1 (MCH-R1). Bioorg. Med. Chem. Lett. 2007, 17, 2171-2178.

(336) Bell, I. M.; Bednar, R. A.; Fay, J. F.; Gallicchio, S. N.; Hochman, J. H.; McMasters, D. R.; Miller-Stein, C.; Moore, E. L.; Mosser, S. D.; Pudvah, N. T.; et al. Identification of Novel, Orally Bioavailable Spirohydantoin CGRP Receptor Antagonists. Bioorg. Med. Chem. Lett. 2006, 16, 6165-6169.

(337) Stump, C. A.; Bell, I. M.; Bednar, R. A.; Fay, J. F.; Gallicchio, S. N.; Hershey, J. C.; Jelley, R.; Kreatsoulas, C.; Moore, E. L.; Mosser, S. D.; et al. Identification of Potent, Highly Constrained CCGRP Receptor Antagonists. Bioorg. Med. Chem. Lett. 2010, 20, 2572-2576.

(338) Wood, M. R.; Schirripa, K. M.; Kim, J. J.; Bednar, R. A.; Fay, J. F.; Bruno, J. G.; Moore, E. L.; Mosser, S. D.; Roller, S.; Salvatore, C. A.; et al. Novel CGRP Receptor Antagonists from Central Amide Replacements Causing a Reversal of Preferred Chirality. Bioorg. Med. Chem. Lett. 2010, 20, 6827-6830.

(339) Goebel, T.; Ulmer, D.; Projahn, H.; Kloeckner, J.; Heller, E.; Glaser, M.; Ponte-Sucre, A.; Specht, S.; Sarite, S. R.; Hoerauf, A.; et al. In Search of Novel Agents for Therapy of Tropical Diseases and Human Immunodeficiency Virus. J. Med. Chem. 2008, 51, 238-250.

(340) Meyers, M. J.; Anderson, E. J.; McNitt, S. A.; Krenning, T. M.; Singh, M.; Xu, J.; Zeng, W.; Qin, L.; Xu, W.; Zhao, S.; et al. Evaluation of Spiropiperidine Hydantoins as a Novel Class of Antimalarial Agents. Bioorg. Med. Chem. 2015, 23, 5144-5150.

(341) Blanco-Ania, D.; Hermkens, P. H. H.; Sliedregt, L. A. J. M.; Scheeren, H. W.; Rutjes, F. P. J. T. Synthesis of Hydantoins and Thiohydantoins Spiro-fused to Pyrrolidines: Druglike Molecules Based on the 2-Arylethyl Amine Scaffold. J. Comb. Chem. 2009, 11, 527-538.

(342) Li, J.; Lou, J.; Wang, Z.; Wang, T.; Xiao, Y.; Hu, X.; Liu, P.; Hong, $X$. Design, Synthesis and Pharmacological Evaluation of Novel N-(2(1,1-Dimethyl-5,7-Dioxo-4,6-diazaspiro[2.4]heptan-6-yl)ethyl) Sulfonamide Derivatives as Potential Anticonvulsant Agents. Eur. J. Med. Chem. 2015, 92, 370-376.

(343) Kuster, G. J. T.; van Berkom, L. W. A.; Kalmoua, M.; Van Loevezijn, A.; Sliedregt, L. A. J. M.; Van Steen, B. J.; Kruse, C. G.; Rutjes, F. P. J. T.; Scheeren, H. W. Synthesis of Spirohydantoins and Spiro-2,5diketopiperazines Via Resin-Bound Cyclic $\alpha, \alpha$-Disubstituted $\alpha$-Amino Esters. J. Comb. Chem. 2006, 8, 85-94.

(344) Vaddypally, S.; Xu, C.; Zhao, S.; Fan, Y.; Schafmeister, C. E.; Zdilla, M. J. Architectural Spiroligomers Designed for Binuclear Metal Complex Templating. Inorg. Chem. 2013, 52, 6457-6463.
(345) Kheirabadi, M.; Celebi-Olcum, N.; Parker, M. F. L.; Zhao, Q.; Kiss, G.; Houk, K. N.; Schafmeister, C. E. Spiroligozymes for Transesterifications: Design and Relationship of Structure to Activity. J. Am. Chem. Soc. 2012, 134, 18345-18353.

(346) Mehrotra, M. M.; Heath, J. A.; Smyth, M. S.; Pandey, A.; Rose, J. W.; Seroogy, J. M.; Volkots, D. L.; Nannizzi-Alaimo, L.; Park, G. L.; Lambing, J. L.; et al. Discovery of Novel 2,8-Diazaspiro[4.5]decanes as Orally Active Glycoprotein IIb-IIIa Antagonists. J. Med. Chem. 2004, 47, 2037-2061.

(347) Zhu, Q.; Pan, Y.; Xu, Z.; Li, R.; Qiu, G.; Xu, W.; Ke, X.; Wu, L.; $\mathrm{Hu}, \mathrm{X}$. Synthesis and Potential Anticonvulsant Activity of New N-3Substituted 5,5-Cyclopropanespirohydantoins. Eur. J. Med. Chem. 2009, 44, 296-302.

(348) Patel, H. J.; Sarra, J.; Caruso, F.; Rossi, M.; Doshi, U.; Stephani, R. A. Synthesis and Anticonvulsant Activity of New N-1, $1^{\prime}-3^{\prime}-$ Disubstituted-2' $\mathrm{H}, 3 \mathrm{H}, 5^{\prime} \mathrm{H}$-spiro-(2-benzofuran-1,4'-imidazolidine)2',3,5'-triones. Bioorg. Med. Chem. Lett. 2006, 16, 4644-4647.

(349) Lopez-Rodriguez, M. L.; Ayala, D.; Viso, A.; Benhamu, B.; Fernandez de la Pradilla, R.; Zarza, F.; Ramos, J. A. Synthesis and Structure-Activity Relationships of a New Model of Arylpiperazines. Part 7: Study of the Influence of Lipophilic Factors at the Terminal Amide Fragment on 5-HT1A Affinity/Selectivity. Bioorg. Med. Chem. 2004, 12, 1551-1557.

(350) Sun, C.; Robl, J. A.; Wang, T. C.; Huang, Y.; Kuhns, J. E.; Lupisella, J. A.; Beehler, B. C.; Golla, R.; Sleph, P. G.; Seethala, R.; et al. Discovery of Potent, Orally-active, and Muscle-selective Androgen Receptor Modulators Based on an N-Aryl-hydroxybicyclohydantoin Scaffold. J. Med. Chem. 2006, 49, 7596-7599.

(351) Hamann, L. G.; Manfredi, M. C.; Sun, C.; Krystek, S. R.; Huang Y.; Bi, Y.; Augeri, D. J.; Wang, T.; Zou, Y.; Betebenner, D. A.; et al. Tandem Optimization of Target Activity and Elimination of Mutagenic Potential in a Potent Series of N-Aryl Bicyclic Hydantoin-based Selective Androgen Receptor Modulators. Bioorg. Med. Chem. Lett. 2007, 17, 1860-1864.

(352) Marco, I.; Valhondo, M.; Martin-Fontecha, M.; Vazquez-Villa, H.; Del Rio, J.; Planas, A.; Sagredo, O.; Ramos, J. A.; Torrecillas, I. R.; Pardo, L.; et al. New Serotonin 5-HT1A Receptor Agonists with Neuroprotective Effect against Ischemic Cell Damage. J. Med. Chem. 2011, 54, 7986-7999.

(353) Foley, D. J.; Doveston, R. G.; Churcher, I.; Nelson, A.; Marsden, S. P. A Systematic Approach to Diverse, Lead-like Scaffolds from $\alpha, \alpha$ Disubstituted Amino Acids. Chem. Commun. 2015, 51, 11174-11177.

(354) Delgado, G. E.; Contreras, J. E. Synthesis and Structural Characterization of $(S)$-Tetrahydropyrrolo[1,2,c]imidazole-1,3-dione. Int. J. Mater. Chem. 2012, 2, 141-144.

(355) Kolyasnikova, K. N.; Vichuzhanin, M. V.; Konstantinopol'skii, M. A.; Trofimov, S. S.; Gudasheva, T. A. Synthesis and Pharmacological Activity of Analogs of the Endogenous Neuropeptide Cycloprolylglycine. Pharm. Chem. J. 2012, 46, 96-102.

(356) Ambrozak, A.; Guetschow, M. Transformation of a Spirobarbituric Acid Via Aminobarbituric Acid-hydantoin Rearrangement. J. Heterocycl. Chem. 2006, 43, 807-811.

(357) Alagille, D.; Pfeiffer, B.; Scalbert, E.; Ferry, G.; Boutin, J. A.; Renard, P.; Viaud-Massuard, M. C. Design and Synthesis of Indole and Tetrahydroisoquinoline Hydantoin Derivatives as Human Chymase Inhibitors. J. Enzyme Inhib. Med. Chem. 2004, 19, 137-143.

(358) Caubert, V.; Viaud-Massuard, M.-C. Synthesis of 7-Phenylethoxy-1,2,3,4-tetrahydroisoquinoline Derivatives. Heterocycl. Commun. 2004, 10, 175-180.

(359) Chaulet, C.; Croix, C.; Alagille, D.; Normand, S.; Delwail, A.; Favot, L.; Lecron, J. C.; Viaud-Massuard, M. C. Design, Synthesis and Biological Evaluation of New Thalidomide Analogues as TNF-Alpha and IL-6 Production Inhibitors. Bioorg. Med. Chem. Lett. 2011, 21, $1019-1022$

(360) Jansa, P.; Wsol, V.; Bertolasi, V.; Machacek, V. Hydantoins and Thiohydantoins Derived from 1,2,3,4-Tetrahydroisoquinoline-3-carboxylic Acid. Heterocycles 2006, 68, 2527-2547.

(361) Blanco-Ania, D.; Hermkens, P. H. H.; Sliedregt, L. A. J. M.; Scheeren, H. W.; Rutjes, F. P. J. T. Solution-phase Parallel Annulation of 
(Thio)hydantoins to Tetrahydroisoquinolines and Tetrahydro- $\beta$-carbolines Containing the 2-Arylethyl Amine Scaffold. J. Comb. Chem. 2009, 11, 547-555.

(362) Charton, J.; Gassiot, A. C.; Melnyk, P.; Girault-Mizzi, S.; Sergheraert, C. Optimized Synthesis of Tetrahydroisoquinolinehydantoins. Tetrahedron Lett. 2004, 45, 7081-7085.

(363) Toussaint, M.; Mousset, D.; Foulon, C.; Jacquemard, U.; Vaccher, C.; Melnyk, P. Sigma-1 Ligands: Tic-hydantoin as a Key Pharmacophore. Eur. J. Med. Chem. 2010, 45, 256-263.

(364) Xiao, S.; Shi, X.-X. The First Highly Stereoselective Approach to the Mitotic Kinesin EG5 Inhibitor HR22C16 and Its Analogues. Tetrahedron: Asymmetry 2010, 21, 226-231.

(365) Sunder-Plassmann, N.; Sarli, V.; Gartner, M.; Utz, M.; Seiler, J.; Huemmer, S.; Mayer, T. U.; Surrey, T.; Giannis, A. Synthesis and Biological Evaluation of New Tetrahydro- $\beta$-carbolines as Inhibitors of the Mitotic Kinesin EG5. Bioorg. Med. Chem. 2005, 13, 6094-6111.

(366) Walton, J. G. A.; Patterson, S.; Liu, G.; Haraldsen, J. D.; Hollick, J. J.; Slawin, A. M. Z.; Ward, G. E.; Westwood, N. J. Synthesis and Biological Evaluation of Functionalised Tetrahydro- $\beta$-carboline Analogues as Inhibitors of Toxoplasma Gondii Invasion. Org. Biomol. Chem. 2009, 7, 3049-3060.

(367) Shankaraiah, N.; Nekkanti, S.; Chudasama, K. J.; Senwar, K. R.; Sharma, P.; Jeengar, M. K.; Naidu, V. G. M.; Srinivasulu, V.; Srinivasulu, G.; Kamal, A. Design, Synthesis and Anticancer Evaluation of Tetrahydro- $\beta$-carboline-hydantoin Hybrids. Bioorg. Med. Chem. Lett. 2014, 24, 5413-5417.

(368) Kuo, F.-M.; Tseng, M.-C.; Yen, Y.-H.; Chu, Y.-H. Microwave Accelerated Pictet-Spengler Reactions of Tryptophan with Ketones Directed toward the Preparation of 1,1-Disubstituted Indole Alkaloids. Tetrahedron 2004, 60, 12075-12084.

(369) Lin, M.-J.; Zhang, W.; Sun, C.-M. Fluorous and Traceless Synthesis of Substituted Indole Alkaloids. J. Comb. Chem. 2007, 9, 951958.

(370) Yeh, W.-P.; Chang, W.-J.; Sun, M.-L.; Sun, C.-M. Microwaveassisted Traceless Synthesis of Hydantoin-Fused $\beta$-carboline Scaffold. Tetrahedron 2007, 63, 11809-11816.

(371) Chen, C.-H.; Chang, C.-M.; Chen, H.-Y.; Lai, J.-J.; Sun, C.-M. Scaffold-directed Traceless Synthesis of Tetrahydro- $\beta$-carbolinehydantoins. J. Comb. Chem. 2007, 9, 618-626.

(372) Maiti, B.; Chanda, K.; Sun, C.-M. Traceless Synthesis of Hydantoin Fused Tetrahydro- $\beta$-carboline on Ionic Liquid Support in Green Media. Org. Lett. 2009, 11, 4826-4829.

(373) Shirakawa, S.; Liu, K.; Ito, H.; Le, T. N.; Maruoka, K. Phasetransfer-catalyzed Asymmetric Synthesis of 1,1-Disubstituted Tetrahydroisoquinolines. Adv. Synth. Catal. 2011, 353, 2614-2618.

(374) Shirakawa, S.; Liu, K.; Ito, H.; Maruoka, K. Catalytic Asymmetric Synthesis of 1,1-Disubstituted Tetrahydro- $\beta$-carbolines by PhaseTransfer Catalyzed Alkylations. Chem. Commun. 2011, 47, 1515-1517.

(375) Manku, S.; Curran, D. P. Fluorous Mixture Synthesis of Fusedtricyclic Hydantoins. Use of a Redundant Tagging Strategy on Fluorinated Substrates. J. Org. Chem. 2005, 70, 4470-4473.

(376) Firth, J. D.; Zhang, R.; Morgentin, R.; Guilleux, R.; Kalliokoski, T.; Warriner, S.; Foster, R.; Marsden, S. P.; Nelson, A. Exploitation of the Ugi-Joullie Reaction in the Synthesis of Libraries of Drug-like Bicyclic Hydantoins. Synthesis 2015, 47, 2391-2406.

(377) Pei, W.; Tao, J.; Sun, L.; Sun, M. Merrifield Resin Supported Solid Phase Synthesis of 1-Amino-2,4-imidazolidinedione. Chin. J. Org. Chem. 2009, 29, 265-268.

(378) Liu, W.; Zhao, C.; Zhang, Y.; Lu, S.; Liu, J.; Xi, R. Preparation of Polyclonal Antibodies to a Derivative of 1-Aminohydantoin (AHD) and Development of an Indirect Competitive Elisa for the Detection of Nitrofurantoin Residue in Water. J. Agric. Food Chem. 2007, 55, 68296834.

(379) Ali, A.; Fisara, P.; Freemont, J. A.; Kyi, S.; Meyer, A. G.; Riches, A. G.; Sargent, R. M.; Sawutz, D. G.; Turner, K. A.; Winzenberg, K. N.; et al. Discovery of Ectoparasiticidal Hydrazonotrifluoromethanesulfonanilides. Bioorg. Med. Chem. Lett. 2010, 20, 649-652.

(380) Chumanee, S.; Sutthivaiyakit, S.; Sutthivaiyakit, P. New Reagent for Trace Determination of Protein-bound Metabolites of Nitrofurans in
Shrimp Using Liquid Chromatography with Diode Array Detector. J. Agric. Food Chem. 2009, 57, 1752-1759.

(381) Haj Mohammad Ebrahim Tehrani, K.; Hashemi, M.; Hassan, M.; Kobarfard, F.; Mohebbi, S. Synthesis and Antibacterial Activity of Schiff Bases of 5-Substituted Isatins. Chin. Chem. Lett. 2016, 27, 221225 .

(382) Leban, J.; Blisse, M.; Krauss, B.; Rath, S.; Baumgartner, R.; Seifert, M. H. J. Proteasome Inhibition by Peptide-semicarbazones. Bioorg. Med. Chem. 2008, 16, 4579-4588.

(383) Murasawa, S.; Iuchi, K.; Sato, S.; Noguchi-Yachide, T.; Sodeoka, M.; Yokomatsu, T.; Dodo, K.; Hashimoto, Y.; Aoyama, H. Smallmolecular Inhibitors of $\mathrm{Ca}^{2+}$-Induced Mitochondrial Permeability Transition (MPT) Derived from Muscle Relaxant Dantrolene. Bioorg. Med. Chem. 2012, 20, 6384-6393.

(384) Hosoya, T.; Inoue, A.; Hiramatsu, T.; Aoyama, H.; Ikemoto, T.; Suzuki, M. Facile Synthesis of Diazido-functionalized Biaryl Compounds as Radioisotope-free Photoaffinity Probes by Suzuki-Miyaura Coupling. Bioorg. Med. Chem. 2009, 17, 2490-2496.

(385) Liu, Z.; Wang, B.; Ma, Z.; Zhou, Y.; Du, L.; Li, M. Fluorogenic Probe for the Human Ether-a-Go-Go-Related Gene Potassium Channel Imaging. Anal. Chem. 2015, 87, 2550-2554.

(386) Kumata, K.; Ogawa, M.; Takei, M.; Fujinaga, M.; Yoshida, Y.; Nengaki, N.; Fukumura, T.; Suzuki, K.; Zhang, M.-R. Radiosynthesis of $\left[{ }^{13} \mathrm{~N}\right]$ Dantrolene, a Positron Emission Tomography Probe for Breast Cancer Resistant Protein, Using No-carrier-added $\left[{ }^{13} \mathrm{~N}\right]$ Ammonia. Bioorg. Med. Chem. 2012, 20, 305-310.

(387) Wang, Q.; Liu, Y.-C.; Chen, Y.-J.; Jiang, W.; Shi, J.-L.; Xiao, Y.; Zhang, M. Development of a Direct Competitive Chemiluminescent Elisa for the Detection of Nitrofurantoin Metabolite 1-Aminohydantoin in Fish and Honey. Anal. Methods 2014, 6, 4414-4420.

(388) Park, Y. S.; Seo, S.; Kim, E.-H.; Paek, K. Encapsulation of Anionic Guests in a New Hydantoinylamido Molecular Capsule. Org. Lett. 2011, 13, 5904-5907.

(389) Guo, X.; Shen, Z.; Yu, P.; Chu, H.; Tang, Y.; You, Q. Discovery of Benzamide Derivatives as Potent Kv1.5 Inhibitors. J. Chin. Pharm. Sci. 2012, 21, 553-560.

(390) Schlogl, K.; Derkosch, J.; Wawersich, E. $\alpha$-Amino-N-carboxylic Acid Dihydrazides and Their Derivatives. Monatsh. Chem. 1954, 85, 607-626.

(391) Lalezari, I. One-step Synthesis of 3-Amino-2,4-imidazolinediones (3-Aminohydantoins) from $\alpha$-Amino Acids. J. Heterocycl. Chem. 1985, 22, 741-743.

(392) Yoon, J.; Cho, C.-W.; Han, H.; Janda, K. D. Solution and Soluble Polymer Syntheses of 3-Aminoimidazoline-2,4-diones. Chem. Commun. 1998, 24, 2703-2704.

(393) Vincent-Rocan, J.-F.; Clavette, C.; Leckett, K.; Beauchemin, A. M. A Cascade Synthesis of Aminohydantoins Using in Situ-generated NSubstituted Isocyanates. Chem. - Eur. J. 2015, 21, 3886-3890.

(394) Abdul Nasser, A. J.; Idhayadhulla, A.; Kumar, R. S.; Selvin, J. Synthesis and Biological Activities of New Series of Imidazolidine-2,4dione Derivatives. Asian J. Chem. 2010, 22, 5853-5858.

(395) Kumar, R. S.; Idhayadhulla, A.; Abdul Nasser, A. J.; Selvin, J. Synthesis and Characterization of New Series of Imidazolidin-2,4-dione Derivatives and Its Antimicrobial Activity. Orient. J. Chem. 2010, 26, $1425-1430$.

(396) Amin, K. M.; Kamel, M. M.; Anwar, M. M.; Khedr, M.; Syam, Y. M. Synthesis, Biological Evaluation and Molecular Docking of Novel Series of Spiro[ $(2 \mathrm{H}, 3 \mathrm{H})$ quinazoline-2,1'-cyclohexan]-4(1H)-one Derivatives as Anti-inflammatory and Analgesic Agents. Eur. J. Med. Chem. 2010, 45, 2117-2131.

(397) Novak, A.; Bezensek, J.; Groselj, U.; Golobic, A.; Stanovnik, B.; Svete, J. Serendipity at Work: Unexpected Ring Transformations of 4Aminopyrazolidin-3-ones into N-Aminohydantoins. ARKIVOC 2011, $18-28$.

(398) Gibbons, J. B.; Salvant, J. M.; Vaden, R. M.; Kwon, K.-H.; Welm, B. E.; Looper, R. E. Synthesis of Naamidine A and Selective Access to N2-Acyl-2-Aminoimidazole Analogues. J. Org. Chem. 2015, 80, 1007610085 . 
(399) Aberle, N. S.; Lessene, G.; Watson, K. G. A Concise Total Synthesis of Naamidine A. Org. Lett. 2006, 8, 419-421.

(400) Aberle, N.; Catimel, J.; Nice, E. C.; Watson, K. G. Synthesis and Biological Evaluation of Analogs of the Anti-tumor Alkaloid Naamidine A. Bioorg. Med. Chem. Lett. 2007, 17, 3741-3744.

(401) Koswatta, P. B.; Lovely, C. J. Expedient Total Syntheses of Preclathridine A and Clathridine A. Tetrahedron Lett. 2009, 50, 49985000.

(402) Koswatta, P. B.; Lovely, C. J. Total Syntheses of Naamidine G and 14-Methoxynaamidine G. Tetrahedron Lett. 2010, 51, 164-166.

(403) Koswatta, P. B.; Lovely, C. J. Concise Total Synthesis of Naamine G and Naamidine H. Chem. Commun. 2010, 46, 2148-2150. (404) Lima, H. M.; Garcia-Barboza, B. J.; Khatibi, N. N.; Lovely, C. J. Total Syntheses of Isonaamine C and Isonaamidine E. Tetrahedron Lett. 2011, 52, 5725-5727.

(405) Witchard, H. M.; Watson, K. G. Synthesis of 5-Amino-3Methylimidazolidine-2,4-dione and 1,3,5-Triazine Derivatives as Analogues of the Alkaloids Naamidine A and G. Synthesis 2010, 24, 4312-4316.

(406) Bakalova, A.; Buyukliev, R.; Momekov, G.; Ivanov, D.; Todorov, D.; Konstantinov, S.; Karaivanova, M. Synthesis, Physicochemical and in Vitro Pharmacological Investigation of New Platinum(II) Complexes with Some Cycloalkanespiro-5' -hydantoins. Eur. J. Med. Chem. 2005, 40, 590-596.

(407) Bakalova, A.; Buyukliev, R.; Momekov, G. Synthesis, DFT Calculations and Cytotoxic Investigation of Platinum Complexes with 3Thiolanespiro-5'-hydantoin and 4-Thio-1H-tetrahydropyranespiro-5'hydantoin. J. Mol. Struct. 2015, 1091, 118-124.

(408) Bakalova, A.; Buyukliev, R.; Varbanov, H.; Momekov, G. Design, Synthesis and Comparative Cytotoxic Investigation of Platinum(II) Complexes with Some Derivatives of 5-Methyl-5-(4-pyridyl)hydantoin. Inorg. Chim. Acta 2014, 423, 46-51.

(409) Bakalova, A.; Varbanov, H.; Buyukliev, R.; Momekov, G.; Ferdinandov, D.; Konstantinov, S.; Ivanov, D. Synthesis, Characterization and Biological Activity of $\mathrm{Pt}(\mathrm{II})$ and $\mathrm{Pt}(\mathrm{IV})$ Complexes with 5Methyl-5(4-pyridyl)-2,4-imidazolidenedione. Eur. J. Med. Chem. 2008, 43, 958-965.

(410) Bakalova, A.; Varbanov, H.; Buyukliev, R.; Momekov, G.; Ivanov, D. Palladium(II) Complexes with 5-Methyl-5-(4-pyridyl)-2,4-imidazolidenedione. Synthesis, Thermogravimetric and Cytotoxic Investigation. J. Therm. Anal. Calorim. 2009, 95, 241-246.

(411) Sabounchei, S. J.; Shahriary, P.; Gholiee, Y.; Salehzadeh, S.; Khavasi, H. R.; Chehregani, A. Platinum and Palladium Complexes with 5-Methyl-5-(2-pyridyl)-2,4-imidazolidenedione: Synthesis, Crystal and Molecular Structure, Theoretical Study, and Pharmacological Investigation. Inorg. Chim. Acta 2014, 409, 265-275.

(412) Sabounchei, S. J.; Shahriary, P.; Salehzadeh, S.; Gholiee, Y.; Nematollahi, D.; Chehregani, A.; Amani, A.; Afsartala, Z. Pd(II) and Pd(IV) Complexes with 5-Methyl-5-(4-pyridyl)hydantoin: Synthesis, Physicochemical, Theoretical, and Pharmacological Investigation. Spectrochim. Acta, Part A 2015, 135, 1019-1031.

(413) Sabounchei, S. J.; Shahriary, P.; Salehzadeh, S.; Gholiee, Y.; Chehregani, A. Spectroscopic, Theoretical, and Antibacterial Approach in the Characterization of 5-Methyl-5-(3-pyridyl)-2,4-imidazolidenedione Ligand and of Its Platinum and Palladium Complexes. C. R. Chim. 2015, 18, 564-572.

(414) Sabounchei, S. J.; Shahriary, P.; Salehzadeh, S.; Gholiee, Y.; Nematollahi, D.; Chehregani, A.; Amani, A. Gold(III) Complexes of 5Methyl-5-(pyridyl)-2,4-imidazolidenedione: Synthesis, Physicochemical, Theoretical, Antibacterial, and Cytotoxicity Investigation. New J. Chem. 2014, 38, 1199-1210.

(415) Sabounchei, S. J.; Shahriary, P.; Salehzadeh, S.; Gholiee, Y.; Khavasi, H. R. Mercury(II) Complexes with 5-Methyl-5-(4-pyridyl)-2,4imidazolidinedione: Synthesis, Structural Characterization, and Theoretical Studies. J. Mol. Struct. 2013, 1051, 15-22.

(416) Sabounchei, S. J.; Shahriary, P.; Rudbari, H. A.; Chehregani, A. Synthesis and Characterization of Monomeric and Polymeric $\mathrm{Hg}$ (II) Complexes with 5-Methyl-5-(3-pyridyl)-2,4-imidazolidenedione Show- ing a Wide Spectrum of Effective Antibacterial Activities. J. Inorg. Organomet. Polym. Mater. 2015, 25, 1032-1039.

(417) Puszynska-Tuszkanow, M.; Grabowski, T.; Daszkiewicz, M.; Wietrzyk, J.; Filip, B.; Maciejewska, G.; Cieslak-Golonka, M. Silver(I) Complexes with Hydantoins and Allantoin: Synthesis, Crystal and Molecular Structure, Cytotoxicity and Pharmacokinetics. J. Inorg. Biochem. 2011, 105, 17-22.

(418) Puszynska-Tuszkanow, M.; Daszkiewicz, M.; Maciejewska, G.; Staszak, Z.; Wietrzyk, J.; Filip, B.; Cieslak-Golonka, M. Hsab Principle and Nickel(II) Ion Reactivity Towards 1-Methylhydantoin. Polyhedron 2011, 30, 2016-2025.

(419) Hu, X.; Xu, X.; Wang, D.; Zhang, Y. Bis(5,5-diphenylhydantoinato-Kn3) (ethylenediamine)Zinc(II). Acta Crystallogr., Sect. E: Struct. Rep. Online 2009, 65, m1426.

(420) Payen, O.; Top, S.; Vessieres, A.; Brule, E.; Plamont, M.-A.; McGlinchey, M. J.; Mueller-Bunz, H.; Jaouen, G. Synthesis and Structure-Activity Relationships of the First Ferrocenyl-aryl-hydantoin Derivatives of the Nonsteroidal Antiandrogen Nilutamide. J. Med. Chem. 2008, 51, 1791-1799.

(421) Metallinos, C.; John, J.; Zaifman, J.; Emberson, K. Diastereoselective Synthesis of N-Substituted Planar Chiral Ferrocenes Using a Proline Hydantoin-derived Auxiliary. Adv. Synth. Catal. 2012, 354, 602606.

(422) Ahmedova, A.; Marinova, P.; Marinov, M.; Stoyanov, N. An Integrated Experimental and Quantum Chemical Study on the Complexation Properties of (9'-Fluorene)-spiro-5-hydantoin and Its Thioanalogue. J. Mol. Struct. 2016, 1108, 602-610.

(423) Knizhnikov, V. O.; Voitenko, Z. V.; Golovko, V. B.; Gorichko, M. V. Diastereospecific Ring Cleavage of Bornane-2,3-dione in the Bucherer-Bergs Reaction. Tetrahedron: Asymmetry 2012, 23, 10801083.

(424) Mashiko, T.; Kumagai, N.; Shibasaki, M. Managing Highly Coordinative Substrates in Asymmetric Catalysis: A Catalytic Asymmetric Amination with a Lanthanum-based Ternary Catalyst. J. Am. Chem. Soc. 2009, 131, 14990-14999.

(425) Girijavallabhan, V. M.; Chen, L.; Dai, C.; Feltz, R. J.; Firmansjah, L.; Li, D.; Kim, S. H.; Kozlowski, J. A.; Lavey, B. J.; Kosinski, A.; et al. Novel TNF-A Converting Enzyme (TACE) Inhibitors as Potential Treatment for Inflammatory Diseases. Bioorg. Med. Chem. Lett. 2010, 20, $7283-7287$.

(426) Barnwell, N.; Watts, A.; Purdie, L.; Gill, D. M. Stereoselective Synthesis of a Dialkylhydantoin Featuring an Asymmetric Strecker Reaction on an Acyclic Dialkyl Ketone. Tetrahedron Lett. 2012, 53, 1951-1953.

(427) Saravanan, S.; Khan, N.-u. H.; Kureshy, R. I.; Abdi, S. H. R.; Bajaj, H. C. Small Molecule as a Chiral Organocatalyst for Asymmetric Strecker Reaction. ACS Catal. 2013, 3, 2873-2880.

(428) Fang, Y.-Q.; Tadross, P. M.; Jacobsen, E. N. Highly Enantioselective, Intermolecular Hydroamination of Allenyl Esters Catalyzed by Bifunctional Phosphinothioureas. J. Am. Chem. Soc. 2014, 136, 17966-17968.

(429) Mehra, V.; Kumar, V. Facile Diastereoselective Synthesis of Functionally Enriched Hydantoins Via Base-promoted Intramolecular Amidolysis of C-3 Functionalized Azetidin-2-ones. Tetrahedron Lett. 2013, 54, 6041-6044.

(430) Miao, C.-B.; Dong, C.-P.; Zhang, M.; Ren, W.-L.; Meng, Q.; Sun, X.-Q.; Yang, H.-T. Highly Stereoselective, One-Pot Synthesis of Azetidines and 2,4-Dioxo-1,3-diazabicyclo[3.2.0] Compounds Mediated by $\mathrm{I}_{2}$. J. Org. Chem. 2013, 78, 4329-4340.

(431) Alizadeh, A.; Bijanzadeh, H. R. Reaction between Dialkyl Acetylenedicarboxylates and Arylsulfonyl Isocyanates in the Presence of Trialkyl Phosphites: A Simple and Efficient Synthesis of Tetrasubstituted Hydantoins. Synthesis 2004, 18, 3023-3028.

(432) Alizadeh, A.; Masrouri, H. New, Diastereoselective One-Pot Synthesis of Tetrasubstituted Hydantoins. Helv. Chim. Acta 2006, 89, $1187-1193$.

(433) Gololobov, Y. G.; Golding, I. R.; Galkina, M. A.; Lokshin, B. V.; Garbuzova, I. A.; Petrovskii, P. V.; Starikova, Z. A.; Averkiev, B. B. 
Reactions of Distabilized $\beta$-Dicarbonyl Sulfonium and Iodonium Ylides with Isocyanates. Russ. Chem. Bull. 2006, 55, 883-891.

(434) Boultwood, T.; Bull, J. A. Stereospecific Functionalization of Iodoaziridines Via Unstabilized Aziridinyllithiums Generated by IodineLithium Exchange. Org. Lett. 2014, 16, 2740-2743.

(435) Miura, T.; Mikano, Y.; Murakami, M. Nickel-catalyzed Synthesis of 1,3,5-Trisubstituted Hydantoins from Acrylates and Isocyanates. Org. Lett. 2011, 13, 3560-3563.

(436) Hill, M. S.; Liptrot, D. J.; Mahon, M. F. A Magnesium-mediated Cascade Assembly for the Atom-economical Synthesis of Bis(imidazolidine-2,4-dione)S. Angew. Chem., Int. Ed. 2013, 52, 53645367.

(437) Seebach, D.; Sting, A. R.; Hoffmann, M. Self-Regeneration of Stereocenters (SRS) - Applications, Limitations, and Abandonment of a Synthetic Principle. Angew. Chem., Int. Ed. Engl. 1996, 35, 2708-2748.

(438) Chowdari, N. S.; Barbas, C. F., III Total Synthesis of LFA-1 Antagonist BIRT-377 Via Organocatalytic Asymmetric Construction of a Quaternary Stereocenter. Org. Lett. 2005, 7, 867-870.

(439) Patwardhan, A. P.; Pulgam, V. R.; Zhang, Y.; Wulff, W. D. Highly Diastereoselective Alkylation of Aziridine-2-Carboxylate Esters: Enantioselective Synthesis of LFA-1 Antagonist BIRT-377. Angew. Chem., Int. Ed. 2005, 44, 6169-6172.

(440) Han, Z.; Yamaguchi, Y.; Kitamura, M.; Maruoka, K. Convenient Preparation of Highly Active Phase-transfer Catalyst for Catalytic Asymmetric Synthesis of $\alpha$-Alkyl- and $\alpha, \alpha$-Dialkyl- $\alpha$-Amino Acids: Application to the Short Asymmetric Synthesis of BIRT-377. Tetrahedron Lett. 2005, 46, 8555-8558.

(441) Vassiliou, S.; Magriotis, P. A. Improved Schoellkopf Construction of Quaternary $\alpha$-Amino Acids: Efficient Enantioselective Synthesis of Integrin LFA-1 Antagonist BIRT-377. Tetrahedron: Asymmetry 2006, 17, 1754-1757.

(442) Kanemitsu, T.; Furukoshi, S.; Miyazaki, M.; Nagata, K.; Itoh, T. Application of Asymmetric Alkylation of Malonic Diester with Phasetransfer Catalysis: Synthesis of LFA-1 Antagonist BIRT-377. Tetrahedron: Asymmetry 2015, 26, 214-218.

(443) Sugiyama, S.; Arai, S.; Ishii, K. Non-Enzymatic Diastereoselective Asymmetric Desymmetrization of 2-Benzylserinols Giving Optically Active 4-Benzyl-4-hydroxymethyl-2-oxazolidinones: Asymmetric Syntheses of $\alpha$-(Hydroxymethyl)phenylalanine, N-Boc- $\alpha$ methylphenylalanine, Cericlamine and BIRT-377. Tetrahedron 2012, 68, 8033-8045.

(444) Atkinson, R. C.; Leonard, D. J.; Maury, J.; Castagnolo, D.; Volz, N.; Clayden, J. Intramolecular Arylation of Amino Acid Enolates. Chem. Commun. 2013, 49, 9734-9736.

(445) Atkinson, R. C.; Fernandez-Nieto, F.; Mas Rosello, J.; Clayden, J. Pseudoephedrine-Directed Asymmetric $\alpha$-Arylation of a-Amino Acid Derivatives. Angew. Chem., Int. Ed. 2015, 54, 8961-8965.

(446) Tomohara, K.; Yoshimura, T.; Hyakutake, R.; Yang, P.; Kawabata, T. Asymmetric A-Arylation of Amino Acid Derivatives by Clayden Rearrangement of Ester Enolates Via Memory of Chirality. J. Am. Chem. Soc. 2013, 135, 13294-13297.

(447) Gore, S.; Chinthapally, K.; Baskaran, S.; Koenig, B. Synthesis of Substituted Hydantoins in Low Melting Mixtures. Chem. Commun. 2013, 49, 5052-5054.

(448) Lumbroso, A.; Catak, S.; Sulzer-Mosse, S.; De Mesmaeker, A. Efficient Access to Functionalized Cyclobutanone Derivatives Using Cyclobuteniminium Salts as Highly Reactive Michael Acceptors. Tetrahedron Lett. 2015, 56, 2397-2401.

(449) Kato, N.; Suzuki, M.; Kanai, M.; Shibasaki, M. General and Practical Catalytic Enantioselective Strecker Reaction of Keto-imines: Significant Improvement through Catalyst Tuning by Protic Additives. Tetrahedron Lett. 2004, 45, 3147-3151.

(450) Liu, Y.-L.; Zhou, J. Organocatalytic Asymmetric Cyanation of Isatin Derived N-Boc ketoimines. Chem. Commun. 2013, 49, 44214423.

(451) Sacchetti, A.; Silvani, A.; Gatti, F. G.; Lesma, G.; Pilati, T.; Trucchi, B. Addition of TMSCN to Chiral Ketimines Derived from Isatin. Synthesis of an Oxindole-based Peptidomimetic and a Bioactive Spirohydantoin. Org. Biomol. Chem. 2011, 9, 5515-5522.
(452) Bleriot, Y.; Simone, M. I.; Wormald, M. R.; Dwek, R. A.; Watkin, D. J.; Fleet, G. W. J. Sugar Amino Acids at the Anomeric Position of Carbohydrates: Synthesis of Spirocyclic Amino Acids of 6-Deoxy-Llyxofuranose. Tetrahedron: Asymmetry 2006, 17, 2276-2286.

(453) Fujiwara, Y.; Fu, G. C. Application of a New Chiral Phosphepine to the Catalytic Asymmetric Synthesis of Highly Functionalized Cyclopentenes That Bear an Array of Heteroatom-substituted Quaternary Stereocenters. J. Am. Chem. Soc. 2011, 133, 12293-12297.

(454) Foti, F.; Grassi, G.; Risitano, F.; Rotondo, E.; Zona, D. Reaction of Bromo Dipoles with ( $Z$ )-4-(Arylmethylene)azol-5-ones. Substratecontrolled Synthesis of New Bromo-substituted Heterocyclic Spirans and Unusual N-Benzoyl $\alpha$-Amino Acids. Synlett 2004, 9, 1577-1578.

(455) Shih, H.-W.; Cheng, W.-C. Solution-phase Parallel Synthesis of Highly Diverse Spiroisoxazolinohydantoins. Tetrahedron Lett. 2008, 49, $1008-1011$

(456) Said, A. M.; Savage, G. P. Atropisomerism-induced Facial Selectivity in Nitrile Oxide Cycloadditions with 5-Methylenehydantoins. J. Org. Chem. 2011, 76, 6946-6950.

(457) Harding, S. L.; Marcuccio, S. M.; Savage, G. P. Aryl Nitrile Oxide Cycloaddition Reactions in the Presence of Pinacol Boronic Acid Ester. Beilstein J. Org. Chem. 2012, 8, 606-612 10.3762/bjoc.8.67.

(458) Bahy, A.; Kacem, Y.; Hassine, B. B. 1,3-Dipolar Cycloaddition of Nitrones with 5-Methylenehydantoins: Synthesis and Transformation of New Spirohydantoin Derivatives. Synth. Commun. 2010, 40, 13771390.

(459) Bellucci, M. C.; Marcelli, T.; Scaglioni, L.; Volonterio, A. Synthesis of Diverse Spiroisoxazolidinohydantoins by Totally Regioand Diastereoselective 1,3-Dipolar Cycloadditions. RSC Adv. 2011, 1, $1250-1264$

(460) Tran, S. B.; Maxwell, B. D.; Chen, S.-Y.; Bonacorsi, S. J.; Leith, L.; Ogan, M.; Rinehart, J. K.; Balasubramanian, B. Synthesis of Lead LFA-1 Antagonist $\left[{ }^{14} \mathrm{C}\right]$ Spyrocyclic Hydantoin. J. Labelled Compd. Radiopharm. 2009, 52, 236-242.

(461) DelMonte, A. J.; Waltermire, R. E.; Fan, Y.; McLeod, D. D.; Gao, Z.; Gesenberg, K. D.; Girard, K. P.; Rosingana, M.; Wang, X.; KuehneWillmore, J.; et al. Kilogram Synthesis of a LFA-1/ICAM Inhibitor. Org. Process Res. Dev. 2010, 14, 553-561.

(462) Dransfield, P. J.; Wang, S.; Dilley, A.; Romo, D. Highly Regioselective Diels-Alder Reactions toward Oroidin Alkaloids: Use of a Tosylvinyl Moiety as a Nitrogen Masking Group with Adjustable Electronics. Org. Lett. 2005, 7, 1679-1682.

(463) Wang, S.; Dilley, A. S.; Poullennec, K. G.; Romo, D. Planned and Unplanned Halogenations in Route to Selected Oroidin Alkaloids. Tetrahedron 2006, 62, 7155-7161.

(464) Tan, X.; Chen, C. Regiocontrol in MnIII-Mediated Oxidative Heterobicyclizations: Access to the Core Skeletons of Oroidin Dimers. Angew. Chem., Int. Ed. 2006, 45, 4345-4348.

(465) Cernak, T. A.; Gleason, J. L. Density Functional Theory Guided Design of Exo-Selective Dehydroalanine Dienophiles for Application toward the Synthesis of Palau'amine. J. Org. Chem. 2008, 73, 102-110.

(466) Smit, B. M.; Pavlovic, R. Z. Three-step Synthetic Pathway to Fused Bicyclic Hydantoins Involving a Selenocyclization Step. Tetrahedron 2015, 71, 1101-1108.

(467) Rajarathinam, B.; Vasuki, G. Diastereoselective Multicomponent Reaction in Water: Synthesis of 2-Azapyrrolizidine Alkaloid Analogues. Org. Lett. 2012, 14, 5204-5206.

(468) Zancanella, M. A.; Romo, D. Facile Synthesis of the Trans-fused Azabicyclo[3.3.0]octane Core of the Palau'amines and the Tricyclic Core of the Axinellamines from a Common Intermediate. Org. Lett. 2008, 10, 3685-3688.

(469) Cheung, L. L. W.; He, Z.; Decker, S. M.; Yudin, A. K. Skeletal Fusion of Small Heterocycles with Amphoteric Molecules. Angew. Chem., Int. Ed. 2011, 50, 11798-11802.

(470) Crouillebois, L.; Pantaine, L.; Marrot, J.; Coeffard, V.; Moreau, X.; Greck, C. Solvent- and Catalyst-free Synthesis of Nitrogencontaining Bicycles through Hemiaminal Formation/Diastereoselective Hetero-Diels-Alder Reaction with Diazenes. J. Org. Chem. 2015, 80, 595-601. 
(471) Umstead, W. J.; Mukhina, O. A.; Kutateladze, A. G. Conformationally Constrained Penta(hetero)cyclic Molecular Architectures by Photoassisted Diversity-oriented Synthesis. Eur. J. Org. Chem. 2015, 2015, 2205-2213.

(472) Casabona, D.; Cativiela, C. Efficient Synthesis of a New Pipecolic Acid Analog with a Bicyclic Structure. Tetrahedron 2006, 62, 10000-10004.

(473) Krysiak, J.; Midura, W. H.; Wieczorek, W.; Sieron, L.; Mikolajczyk, M. Constrained Cycloalkyl Analogues of Glutamic Acid: Stereocontrolled Synthesis of (+)-2-Aminobicyclo[3.1.0]hexane-2,6dicarboxylic Acid (LY354740) and Its 6-Phosphonic Acid Analogue. Tetrahedron: Asymmetry 2010, 21, 1486-1493.

(474) Maury, J.; Clayden, J. $\alpha$-Quaternary Proline Derivatives by Intramolecular Diastereo-Selective Arylation of N-Carboxamido Proline Ester Enolates. J. Org. Chem. 2015, 80, 10757-10768.

(475) Monn, J. A.; Prieto, L.; Taboada, L.; Pedregal, C.; Hao, J.; Reinhard, M. R.; Henry, S. S.; Goldsmith, P. J.; Beadle, C. D.; Walton, L.; et al. Synthesis and Pharmacological Characterization of C4Disubstituted Analogs of 1S,2S,5R,6S-2-Aminobicyclo[3.1.0] hexane2,6-dicarboxylate: Identification of a Potent, Selective Metabotropic Glutamate Receptor Agonist and Determination of Agonist-bound Human mGlu2 and mGlu3 Amino Terminal Domain Structures. J. Med. Chem. 2015, 58, 1776-1794.

(476) Sakagami, K.; Yasuhara, A.; Chaki, S.; Yoshikawa, R.; Kawakita, Y.; Saito, A.; Taguchi, T.; Nakazato, A. Synthesis, in Vitro Pharmacology, and Pharmacokinetic Profiles of 2-[1-Amino-1carboxy-2-(9H-xanthen-9-yl)-ethyl]-1-fluorocyclopropanecarboxylic Acid and Its 6-Heptyl Ester, a Potent mGlur2 Antagonist. Bioorg. Med. Chem. 2008, 16, 4359-4366.

(477) Chen, X.; Choo, H.; Huang, X.-P.; Yang, X.; Stone, O.; Roth, B. L.; Jin, J. The First Structure-Activity Relationship Studies for Designer Receptors Exclusively Activated by Designer Drugs. ACS Chem. Neurosci. 2015, 6, 476-484.

(478) Chu, Y.; Lynch, V.; Iverson, B. L. Synthesis and DNA Binding Studies of Bis-intercalators with a Novel Spiro-cyclic Linker. Tetrahedron 2006, 62, 5536-5548.

(479) Hayashi, S.; Nakata, E.; Morita, A.; Mizuno, K.; Yamamura, K.; Kato, A.; Ohashi, K. Discovery of $\{1-[4-(2-\{$ Hexahydropyrrolo[3,4c]pyrrol-2(1H)-yl\}-1H-benzimidazol-1-yl)piperidin-1-yl] cyclooctyl $\}$ methanol, Systemically Potent Novel Non-Peptide Agonist of Nociceptin/Orphanin FQ Receptor as Analgesic for the Treatment of Neuropathic Pain: Design, Synthesis, and Structure-Activity Relationships. Bioorg. Med. Chem. 2010, 18, 7675-7699.

(480) Weatherhead, R. A.; Carducci, M. D.; Mash, E. A. Synthesis of Conformationally Constrained Diaminodicarboxylic Acid Derivatives. J. Org. Chem. 2009, 74, 8773-8778.

(481) Kabalka, G. W.; Wu, Z. Z.; Yao, M. L.; Natarajan, N. The Syntheses and in Vivo Biodistribution of Novel Boronated Unnatural Amino Acids. Appl. Radiat. Isot. 2004, 61, 1111-1115.

(482) Wallace, G. A.; Gordon, T. D.; Hayes, M. E.; Konopacki, D. B.; Fix-Stenzel, S. R.; Zhang, X.; Grongsaard, P.; Cusack, K. P.; Schaffter, L. M.; Henry, R. F.; et al. Scalable Synthesis and Isolation of the Four Stereoisomers of Methyl 1-Amino-3-(4-bromophenyl)cyclopentanecarboxylate, Useful Intermediates for the Synthesis of S1P1 Receptor Agonists. J. Org. Chem. 2009, 74, 4886-4889.

(483) Yu, W.; Williams, L.; Camp, V. M.; Olson, J. J.; Goodman, M. M. Synthesis and Biological Evaluation of Anti-1-Amino-2-[ $\left.{ }^{18} \mathrm{~F}\right]$ fluorocyclobutyl-1-carboxylic Acid (Anti-2- $\left[{ }^{18} \mathrm{~F}\right] \mathrm{FACBC}$ ) in Rat 9L Gliosarcoma. Bioorg. Med. Chem. Lett. 2010, 20, 2140-2143.

(484) Yu, W.; Williams, L.; Malveaux, E.; Camp, V. M.; Olson, J. J.; Goodman, M. M. Synthesis and Evaluation of $\left[{ }^{123} \mathrm{I}\right]$ Labeled Iodovinyl Amino Acids Syn-, Anti-1-Amino-3-[2-iodoethenyl]-cyclobutane-1carboxylic Acid, and 1-Amino-3-iodomethylene-cyclobutane-1-carboxylic Acid as Potential Spect Brain Tumor Imaging Agents. Bioorg. Med. Chem. Lett. 2008, 18, 1264-1268.

(485) Zaidlewicz, M.; Cytarska, J.; Dzielendziak, A.; Ziegler-Borowska, M. Synthesis of Boronated Phenylalanine Analogs with a Quaternary Center for Boron Neutron Capture Therapy. ARKIVOC 2004, 11-21.
(486) Zhao, J.; Zhang, J.; Xu, B.; Wang, Z.; Cheng, J.; Zhu, G. Design, Synthesis, and Analysis of the Quantitative Structure-Activity Relationships of 4-Phenyl-acyl-substituted 3-(2,5-Dimethylphenyl)-4-hydroxy1-azaspiro[4.5] dec-3-ene-2,8-dione Derivatives. J. Agric. Food Chem. 2012, 60, 4779-4787.

(487) Chu, X.-J.; Bartkovitz, D.; Danho, W.; Swistok, J.; Cheung, A. W.-H.; Kurylko, G.; Rowan, K.; Yeon, M.; Franco, L.; Qi, L.; et al. Discovery of 1-Amino-4-phenylcyclohexane-1-carboxylic Acid and Its Influence on Agonist Selectivity between Human Melanocortin-4 and -1 Receptors in Linear Pentapeptides. Bioorg. Med. Chem. Lett. 2005, $15,4910-4914$

(488) Costanzo, M. J.; Almond, H. R., Jr.; Hecker, L. R.; Schott, M. R.; Yabut, S. C.; Zhang, H.-C.; Andrade-Gordon, P.; Corcoran, T. W.; Giardino, E. C.; Kauffman, J. A.; et al. In-Depth Study of Tripeptidebased $\alpha$-Ketoheterocycles as Inhibitors of Thrombin. Effective Utilization of the $\mathrm{S1}^{\prime}$ Subsite and Its Implications to Structure-Based Drug Design. J. Med. Chem. 2005, 48, 1984-2008.

(489) Makatini, M.; Chetty, T.; Onajole, O. K.; Govender, T.; Govender, P.; Maguire, G. E. M.; Kruger, H. G. Synthesis and NMR Elucidation of Novel Tetrapeptides. J. Pept. Sci. 2012, 18, 114-121.

(490) Oishi, S.; Kang, S.-U.; Karki, R. G.; Worthy, K. M.; Bindu, L.; Chertov, O.; Esposito, D.; Frank, P.; Gillette, W. K.; Nicklaus, M. C.; et al. Synthesis and Application of Novel Phosphotyrosyl Mimetics to GRB2 SH2 Domain-Binding Inhibitors. Pept. Sci. 2005, 41, 397-400.

(491) Kamon, T.; Irifune, Y.; Tanaka, T.; Yoshimitsu, T. Total Synthesis of ( \pm -Kainic Acid: A Photochemical C-H Carbamoylation Approach. Org. Lett. 2011, 13, 2674-2677.

(492) Aboul-Enein, M. N.; El-Azzouny, A. A. S.; Saleh, O. A.; Amin, K. M.; Maklad, Y. A.; Hassan, R. M. Synthesis and Anticonvulsant Activity of Substituted-1,3-diazaspiro[4.5]decan-4-ones. Arch. Pharm. 2015, $348,575-588$.

(493) Morales, O.; Seide, W.; Watson, S. Synthesis of 7,6-Fused Bicyclic Lactams for Use as Beta-turn Mimics. Synth. Commun. 2006, 36, 965-973.

(494) Levins, C. G.; Brown, Z. Z.; Schafmeister, C. E. Maximizing the Stereochemical Diversity of Spiro-ladder Oligomers. Org. Lett. 2006, 8, 2807-2810.

(495) Rivero, I. A.; Reynoso-Soto, E. A.; Ochoa-Teran, A. MicrowaveAssisted Synthesis of Cycloalkanespirohydantoins and Piperidinespirohydantoins as Precursors of Restricted $\alpha$-Amino Acids. ARKIVOC 2011, 260-271.

(496) de Meijere, A.; Khlebnikov, A. F.; Suennemann, H. W.; Frank, D.; Rauch, K.; Yufit, D. S. Convenient Access to Various 1Cyclopropylcyclopropane Derivatives. Eur. J. Org. Chem. 2010, 17, 3295-3301.

(497) Oba, M.; Ishikawa, N.; Demizu, Y.; Kurihara, M.; Suemune, H.; Tanaka, M. Helical Oligomers with a Changeable Chiral Acetal Moiety. Eur. J. Org. Chem. 2013, 2013, 7679-7682.

(498) Rajca, A.; Kathirvelu, V.; Roy, S. K.; Pink, M.; Rajca, S.; Sarkar, S.; Eaton, S. S.; Eaton, G. R. A Spirocyclohexyl Nitroxide Amino Acid Spin Label for Pulsed EPR Spectroscopy Distance Measurements. Chem. Eur. J. 2010, 16, 5778-5782.

(499) Hirata, T.; Ueda, A.; Oba, M.; Doi, M.; Demizu, Y.; Kurihara, M.; Nagano, M.; Suemune, H.; Tanaka, M. Amino Equatorial Effect of a SixMembered Ring Amino Acid on Its Peptide 310- and $\alpha$-Helices. Tetrahedron 2015, 71, 2409-2420.

(500) Wrobleski, M. L.; Reichard, G. A.; Paliwal, S.; Shah, S.; Tsui, H.C.; Duffy, R. A.; Lachowicz, J. E.; Morgan, C. A.; Varty, G. B.; Shih, N.-Y. Cyclobutane Derivatives as Potent NK1 Selective Antagonists. Bioorg. Med. Chem. Lett. 2006, 16, 3859-3863.

(501) Kabalka, G. W.; Wu, Z.; Yao, M.-L. Synthesis of a Series of Boronated Unnatural Cyclic Amino Acids as Potential Boron Neutron Capture Therapy Agents. Appl. Organomet. Chem. 2008, 22, 516-522.

(502) Kabalka, G. W.; Yao, M.-L. Synthesis of 1-Amino-3[(dihydroxyboryl)methyl]cyclobutanecarboxylic Acid as a Potential Therapy Agent. J. Org. Chem. 2004, 69, 8280-8286.

(503) Kabalka, G. W.; Yao, M.-L.; Navarane, A. Synthesis of a Boronated Amino Acid as a Potential Neutron Therapy Agent: 1- 
Amino-3-[(dihydroxyboryl)ethyl]cyclobutanecarboxylic Acid. Tetrahedron Lett. 2005, 46, 4915-4917.

(504) Linetsky, M. D.; Shipova, E. V. Convenient Synthesis of GOLD and MOLD and Identification of Their Oxidation Products in Vitro and in Vivo. Amino Acids 2007, 32, 285-289.

(505) Sergent, D.; Wang, Q.; Sasaki, N. A.; Ouazzani, J. Synthesis of Hydantoin Analogues of $(2 S, 3 R, 4 S)$-4-Hydroxyisoleucine with Insulinotropic Properties. Bioorg. Med. Chem. Lett. 2008, 18, 4332-4335.

(506) Smit, B.; Rodic, M.; Pavlovic, R. Z. Synthesis of Angularly Fused (Homo)triquinane-Type Hydantoins as Precursors of Bicyclic Prolines. Synthesis 2016, 48, 387-393.

(507) Saito, T.; Obitsu, T.; Kohno, H.; Sugimoto, I.; Matsushita, T.; Nishiyama, T.; Hirota, T.; Takeda, H.; Matsumura, N.; Ueno, S.; et al. Pyrrolo[1,2-b]pyridazines, Pyrrolo[2,1-f]triazin-4(3H)-ones, and Related Compounds as Novel Corticotropin-releasing Factor 1 (CRF1) Receptor Antagonists. Bioorg. Med. Chem. 2012, 20, 1122-1138.

(508) Waser, M.; Moher, E. D.; Borders, S. S. K.; Hansen, M. M.; Hoard, D. W.; Laurila, M. E.; LeTourneau, M. E.; Miller, R. D.; Phillips, M. L.; Sullivan, K. A.; et al. Process Development for a Key Synthetic Intermediate of LY2140023, a Clinical Candidate for the Treatment of Schizophrenia. Org. Process Res. Dev. 2011, 15, 1266-1274.

(509) Ulgheri, F.; Orru, G.; Crisma, M.; Spanu, P. Diastereoselective Synthesis of 5-(Alditol-1-c-yl)-hydantoins and Their Use as Precursors of Polyhydroxylated- $\alpha$-amino Acids. Tetrahedron Lett. 2004, 45, 10471050.

(510) Jarkas, N.; Voll, R. J.; Williams, L.; Camp, V. M.; Goodman, M. M. (R,S)-Anti-1-Amino-2- $\left[{ }^{18} \mathrm{~F}\right]$ fluorocyclopentyl-1-carboxylic Acid: Synthesis from Racemic 2-Benzyloxycyclopentanone and Biological Evaluation for Brain Tumor Imaging with Positron Emission Tomography. J. Med. Chem. 2010, 53, 6603-6607.

(511) Schann, S.; Menet, C.; Arvault, P.; Mercier, G.; Frauli, M.; Mayer, S.; Hubert, N.; Triballeau, N.; Bertrand, H.-O.; Acher, F.; et al. Design and Synthesis of APTCs (Aminopyrrolidinetricarboxylic Acids): Identification of a New Group III Metabotropic Glutamate Receptor Selective Agonist. Bioorg. Med. Chem. Lett. 2006, 16, 4856-4860.

(512) Oba, M.; Shimabukuro, A.; Ono, M.; Doi, M.; Tanaka, M. Synthesis of Both Enantiomers of Cyclic Methionine Analogue: $(R)$ and $(S)$-3-Aminotetrahydrothiophene-3-carboxylic Acids. Tetrahedron: Asymmetry 2013, 24, 464-467.

(513) Koura, M.; Sumida, H.; Yamazaki, Y.; Shibuya, K. A Practical Synthesis for (S)-5-(4-(1-Methylethoxy)phenyl)-5-methylimidazolidine-2,4-dione and Its Application in the Synthesis of a Novel Liver X Receptor $\beta$-Selective Agonist. Tetrahedron: Asymmetry 2016, 27, 63-68.

(514) Washburn, W. N.; Sun, C. Q.; Bisacchi, G.; Wu, G.; Cheng, P. T.; Sher, P. M.; Ryono, D.; Gavai, A. V.; Poss, K.; Girotra, R. N.; et al. BMS201620: A Selective Beta 3 Agonist. Bioorg. Med. Chem. Lett. 2004, 14, 3525-3529.

(515) Regla, I.; Luna, H.; Perez, H. I.; Demare, P.; Bustos-Jaimes, I.; Zaldivar, V.; Calcagno, M. L. Enzymatic Resolution of N-Acetylhomophenylalanine with Mammalian Kidney Acetone Powders. Tetrahedron: Asymmetry 2004, 15, 1285-1288.

(516) Ogawa, J.; Horinouchi, N.; Shimizu, S. Hydrolysis and Formation of Hydantoins. Enzyme Catalysis in Organic Synthesis; Wiley-VCH Verlag GmbH \& Co.: Berlin, 2012; Chapter 16, pp 651674.

(517) Nandanwar, H. S.; Hoondal, G. S.; Vohra, R. M. Enzymatic Production of D-Amino Acids. Methods Biotechnol 2005, 17, 91-103.

(518) Aranaz, I.; Acosta, N.; Heras, A. Synthesis of $p$-Hydroxyphenylglycine by Cell Extract from Agrobaterium Radiobacter Encapsulated in Alginate Capsules. Enzyme Microb. Technol. 2006, 39, 215-221.

(519) Arcuri, M. B.; Antunes, O. A. C.; Machado, S. P.; Almeida, C. H. F.; Oestreicher, E. G. Stability of Immobilized D-Hydantoinase from Vigna Angularis and Repeated Cycles of Highly Enantioenriched Production of N-Carbamoyl-D-phenylglycines. Amino Acids 2004, 27, 69-74.

(520) Wu, S.; Yang, L.; Liu, Y.; Zhao, G.; Wang, J.; Sun, W. Enzymatic Production of D-p-Hydroxyphenylglycine from DL-5-p-Hydroxyphenylhydantoin by Sinorhizobium Morelense S-5. Enzyme Microb. Technol. 2005, 36, 520-526.
(521) Yu, H.; Yang, S.; Jiang, W.; Yang, Y. Efficient Biocatalytic Production of D-4-Hydroxyphenylglycine by Whole Cells of Recombinant Ralstonia Pickettii. Folia Microbiol. 2009, 54, 509-515.

(522) Zhang, J.; Cai, Z. Efficient and Cost-Effective Production of D-pHydroxyphenylglycine by Whole-cell Bioconversion. Biotechnol. Bioprocess Eng. 2014, 19, 76-82.

(523) Chiang, C.-J.; Lin, L.-J.; Wang, Z. W.; Lee, T.-T.; Chao, Y.-P. Design of a Noncovalently Linked Bifunctional Enzyme for Whole-cell Biotransformation. Process Biochem. 2014, 49, 1122-1128.

(524) Latacz, G.; Pekala, E.; Ciopinska, A.; Kiec-Kononowicz, K. Unnatural D-Amino Acids as Building Blocks of New Peptidomimetics. Acta Polym. Pharm. 2006, 63, 430-433.

(525) Nozaki, H.; Takenaka, Y.; Kira, I.; Watanabe, K.; Yokozeki, K. DAmino Acid Production by E. Coli Co-expressed Three Genes Encoding Hydantoin Racemase, D-Hydantoinase and N-Carbamoyl-D-Amino Acid Amidohydrolase. J. Mol. Catal. B: Enzym. 2005, 32, 213-218.

(526) Lo, C.-K.; Kao, C.-H.; Wang, W.-C.; Wu, H.-M.; Hsu, W.-H.; Lin, L.-L.; Hu, H.-Y. Engineering of the Critical Residues at the Stereochemistry-gate Loops of Brevibacillus Agri Dihydropyrimidinase for the Production of L-Homophenylalanine. Process Biochem. 2009, 44, 309-315.

(527) Jiang, M.; Shang, L.; Wei, P.; Yu, R.; Shen, N.; Ouyang, P.; Chang, H. N. Pilot-Scale Production of D-p-Hydroxyphenylglycine from DL-5-p-Hydroxyphenylhydantoin by Burkholderia Cepacia JS-02. Enzyme Microb. Technol. 2007, 41, 407-412.

(528) Konnert, L.; Gonnet, L.; Halasz, I.; Suppo, J. S.; de Figueiredo, R. M.; Campagne, J. M.; Lamaty, F.; Martinez, J.; Colacino, E. Mechanochemical Preparation of 3,5-Disubstituted Hydantoins from Dipeptides and Unsymmetrical Ureas of Amino Acid Derivatives. J. Org. Chem. 2016, 81, 9802-9809.

\section{NOTE ADDED AFTER ASAP PUBLICATION}

This paper was published to the Web on June 23, 2017, with an incomplete list of authors. This was fixed in the version published to the Web on December 4, 2017. 